2. To: (Recolving Organtzation)
Techntcal Operations
5. Pro/Prog./Dopt/DW.:
SNE Profect

8. Orbinclor Romarks:

For release

11. Recolver Remarks:

3. From: (Originating Organtzation)
CSB Project
6. Deagn Authorty/Dedign Agent/Cog. Engr.:
G.D. Bazinet/L.H. Goldmann

G.D. Bazinet/L.H. Goldmann
1

4. Rolatiod EDT No.:

$N / A$

7. Purchase Ordor No.:

$N / A$

9. Equp./Componont No.

MCO

10. Syetom/ledafracily:

CSB

12. Mafor Aam, Ding. No.:

N/A

13. Permil/Permil Appilication No.:

N/A

14. Requlined Recponen Dalis:

$\mathbf{N} / \mathbf{A}$

\begin{tabular}{|c|c|c|c|c|}
\hline & \multicolumn{3}{|c|}{ DATA TRANSMITTED } \\
\hline (A) & (B) Document/Druwing No. & (C) Sheot & (D) Rev. & (E) Tttle or Description of Data Tranemittad \\
\hline 1 & SNE-5204 & a.11 & 0 & Analysis for Eccentric \\
\hline & $(\mathrm{CsB}-\mathrm{S}-0073)$ & & & Multi-Canister Overpack \\
\hline & & & & Drops at the Canister \\
\hline & $\because$ & & & storage Building \\
\hline & $\therefore$ & . & & \\
\hline & . & & & . \\
\hline & & & & \\
\hline
\end{tabular}

KEY (c)
(F)

\begin{tabular}{|c|c|c|c|}
\hline (F) & (c) & $(H)$ & (I) \\
\hline $\begin{array}{l}\text { Anproval } \\
\text { nator }\end{array}$ & $\begin{array}{l}\text { Reveon } \\
\text { or tipen }\end{array}$ & Orpot & 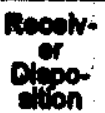 \\
\hline 5 & $i$ & 1 & 1 \\
\hline & & & \\
\hline & & & \\
\hline & & & \\
\hline & & & \\
\hline & & & \\
\hline & & & \\
\hline
\end{tabular}

16.

\begin{tabular}{|c|c|}
\hline Approval Bocinater (F) & \\
\hline 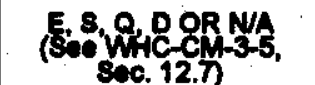 & $\begin{array}{l}\text { 1. Approval } \\
\text { 3. Richerea }\end{array}$ \\
\hline
\end{tabular}

17.

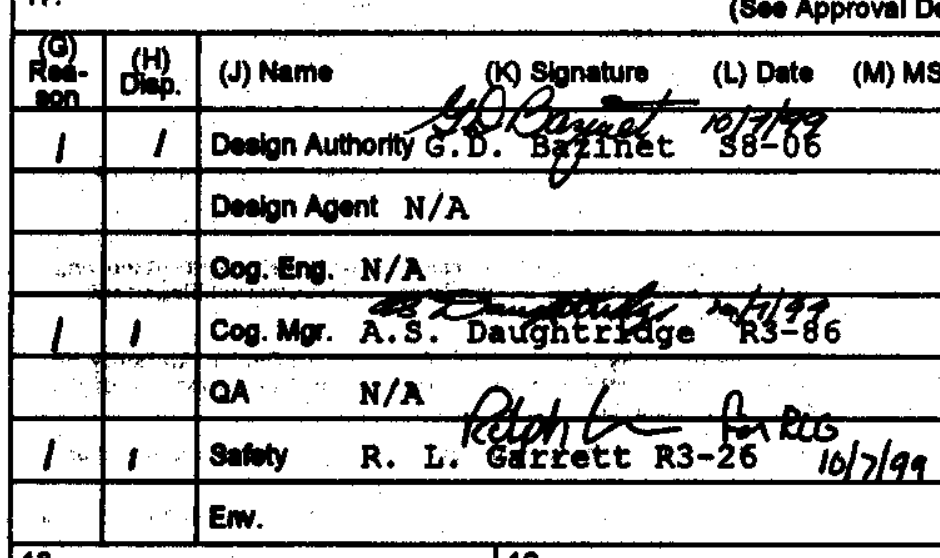

18.

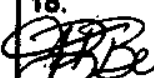

T.B. Bestgman

Sirnture of EDT crovines
Reacon for Tranemiltal (G)

4. Roviow

6. Dient. (Recelpt Acknow. Required)
Dispoetition (H) \& (I)

1. Approved

2. Approved w/comment

3. Diepproved w/oommint

4. Revlawedrioloomment 5. Revm Holomment o. Recelpt acknowidged

SIGNATUREJOISTRIBUTION
(Ses Approval Dealgnator for required eignatures)

(See Approval Deelonator for required elignatures)
(J) Name (K) stonature (L) Date (M) MSN

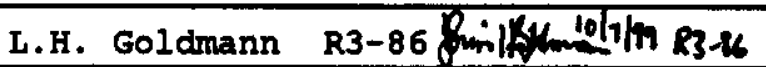




\title{
ANALYSIS FOR ECCENTRIC MULTI-CANISTER OVERPACK DROPS AT THE CANISTER STORAGE BUILDING (CSB-S-0073)
}

\author{
X.C. Tu/R.G. Hollenbeak \\ Fluor Daniel Northwest \\ Richland, WA 99352 \\ U.S. Department of Energy Contract DE-AC06-96RL13200 \\ EDT/ECN: 627587 \\ Org Code: 2G200 \\ BeR Code: EW7040000 \\ UC: 510 \\ Change Code: $105626 / \mathrm{B} 000$ \\ Total Pages: 142
}

Key Words: Drop Analysis, CSB, MCO, SNF

Abstract: Multi-Canister overpacks (MCOs) containing spent nuclear fuel (SNF) will be routinely handled at the Canister storage Building (CSB) during fuel movement operations in the SNF Project. This analysis was performed to investigate the potential for damage from an eccentric accidental drop onto the standard storage tube, overpack tube, service station, or sample/weld station. Appendix D was added to the FDNW document to include the peer Review Comment Record \& transmittal record.

TRADEMARK DISCLAIMER. Reference hereln to any apeclific commercial product, proceses, or eervice by trade name, trademark, manufecturer, or othenwbe, does not nocesearlly conctitute or imply ke endoreement, recommendation, or favoring by the United states Covernment or any agency thereof or lts contrectors or aubcontractors.

Printed in the United States of America. To obtain copies of this document, contact: Document Control Senvices, P.O. Box 850, Malietop He-06, Richland WA 99352, Phone (509) 372-2420; Fax (500) 376-4989.
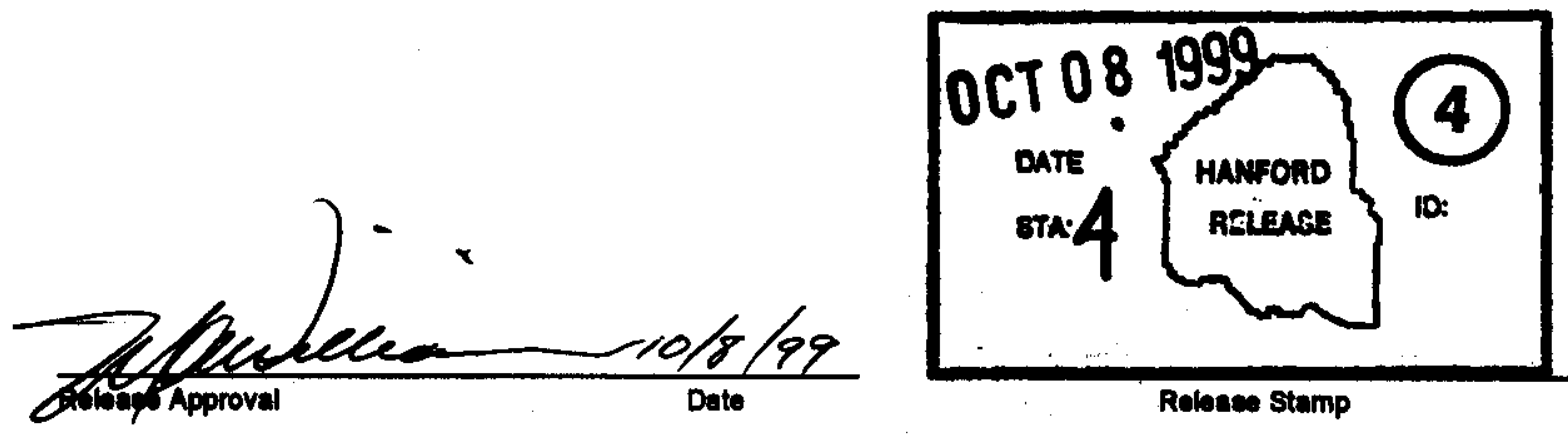

Rolosece Stamp

\section{Approved For Public Release}




\title{
ENGINEERING REPORT
}

\author{
ANALYSIS FOR
}

ECCENTRIC MULTI-CANISTER OVERPACK DROPS

AT THE CANISTER STORAGE.BUILDING

FLUOR DANIEL HANFORD, INC.

RICHLAND, WA

SPENT NUCLEAR FUEL PROJECT

CONTRACT 804602101800

September 1999

K. C. Tu

R. G. Hollenbeck

Fluor Daniel Northwest, Inc. 


\section{EXECUTIVE SUMMARY}

The Spent Nuclear Fuel (SNF) Canister Storage Building (CSB) is the interim storage facility for the K-Basin SNF at the U.S. Department of Energy (DOE) Hanford Site. The SNF is packaged in multi-canister overpacks (MCOs). The MCOs are placed inside transport casks, then delivered to the service station inside the CSB. At the service station, the MCO handling machine (MHM) moves the MCO from the cask to a storage tube or one of two sample/weld stations. There are $\mathbf{2 2 0}$ standard storage tubes and six overpack storage tubes contained in a below grade reinforced concrete vault. Each storage tube can hold two MCOs.

The purpose of this report is to investigate the potential for damage to the MCO during impact from an eccentric accidental drop onto the standard storage tube, overpack tube, service station or sampling/weld station.

The MCO impacts a $45^{\circ}$ inclined surface on the lower flange at both the standard storage tube and the overpack storage tube. The standard storage tubes have a smaller gap between the tube and the embedment than the overpack tubes. This limits the tube lateral displacements to a lower value, which means that during a drop more force would be transferred to the MCO causing more potential for damage. Therefore, the standard storage tube was selected to represent the drop for both locations.

The shielding rings at the service and sampling/weld station are fixed in place and do not move during impact. The inclinations of the impact surfaces of the shielding rings have been reduced from $45^{\circ}$ to $15^{\circ}$ from vertical to reduce the impact damage to the MCO. The temporary shielding at the sampling/weld station is less massive than the shield hatch ring at the service station and will cause less damage to the MCO from an accidental drop. Therefore, the receiving service station pit has been chosen to represent the drop for both locations.

The maximum equivalent plastic strain is $\mathbf{4 0}$ to $45 \%$ and occurs on the MCO bottom near the point of impact and is compressive (negative trlaxiality factor). Some gouging may occur but since the compressive failure strain for the base metal is above $80 \%$, it is not likely that through the wall cracking will occur, however removal of local surface metal may occur.

The maximum predicted equivalent plastic strain at the MCO lower weld is about $2 \%$, during the drop onto the standard storage tube. This is well below the weld metal failure strain of $10 \%$ with a triaxiality factor of greater than 2 . The maximum tensile principal strain is in a radial direction, therefore, any failure would be by spalling or flaking rather than through-wall cracking.

The deceleration of the MCO baskets are shown to be about $20 \mathrm{~g}$ or less, well within the design allowable of $35 \mathrm{~g}$.

The deformations of the $\mathrm{MCO}$ and standard storage tube are less than the tube clearance, therefore, no wedging of the MCO in the tube is expected. 


\section{Table of Contents}

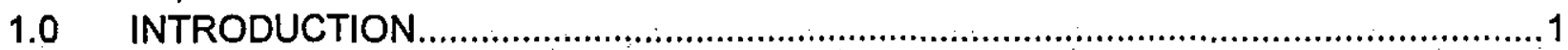

2.0 OBJECTIVE

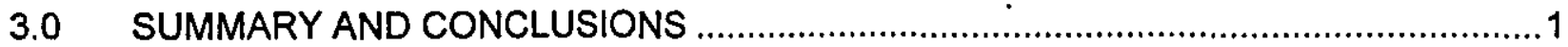

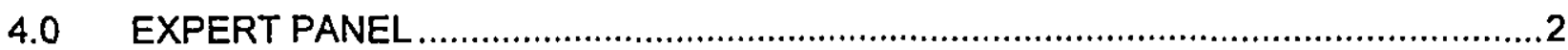

5.0 DESCRIPTION

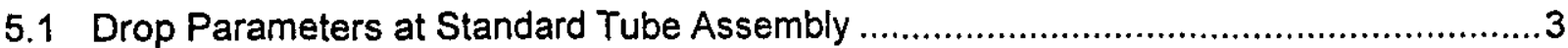

5.2 Drop Parameters at Service Station ............................................................................

5.3 MCO Physical Properties .........................................................................................

5.4 Standard Storage Tube Physical Properties ................................................................4

5.5 Service Station Physical Properties .............................................................................

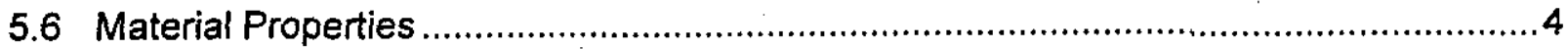

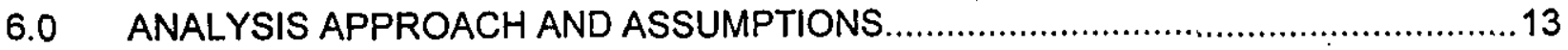

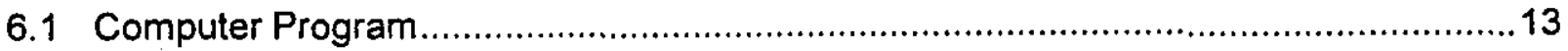

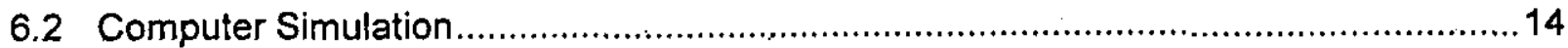

6.3 Computer Modeling of MCO Drops onto Storage Tube Assembly ..............................14

6.4 Computer Modeling of MCO Drops onto Service Station ..............................................15

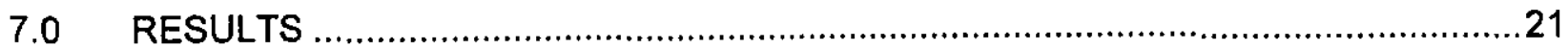

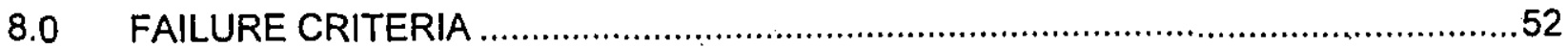

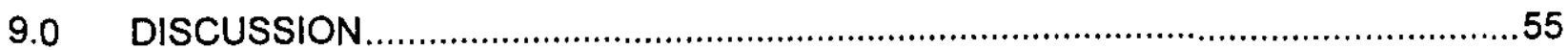

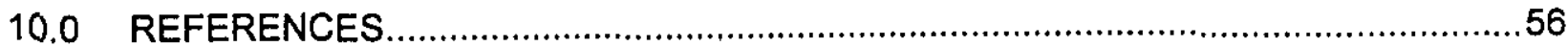

\section{Attachment \\ Expert Panel Report}




\section{Appendices}
A Material Properties for ABAQUS/Explicit Input
B Stress-Strain Triaxiality Factor Calculations
C Computer Input Files
C-1 ABAQUS input File Section One, MCO Drop on Standard Storage Tube
C-2 ABAQUS Input File Section Two, MCO Drop on Service Station

\section{List of Table}

7.1 Calculated Failure Strain and Predicted Strain 


\section{List of Figures}

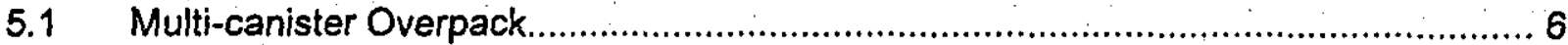

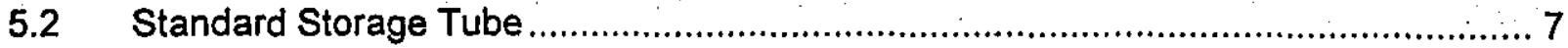

5.3 MCO, MHM and Storage Tube At Time Of Impact ............................................. 8

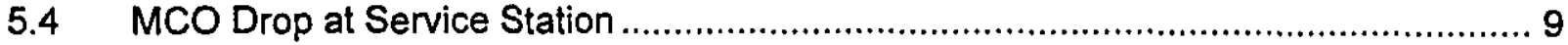

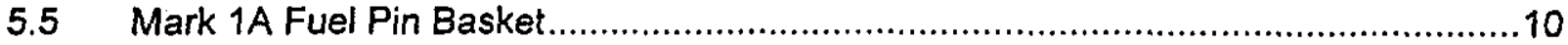

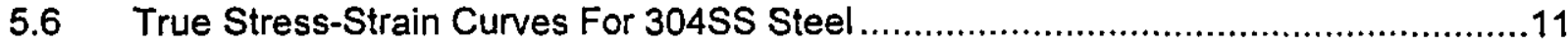

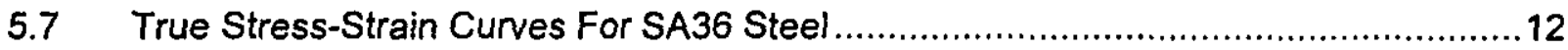

6.1 Computer Model of MCO Drop Onto Storage Tube ................................................17

6.2 Close-up of Computer Model of MCO Drop Onto Standard Storage Tube ..................18

6.3 Computer Model of MCO Drop Onto Service Station Shield Hatch Ring ...................19

6.4 Close-up Computer Model of MCO Drop Onto Service Station Shield Hatch Ring ....20

7.1 Close-up View at 0.03 Second After Impact Onto Storage Tube Assembly ...............23

7.2 Equivalent Plastic Strain at MCO Bottom at 0.03 Second After Impact at Storage Tube Assembly

7.3 Equivalent Plastic Strain at MCO Lower Weld at $0.03 \mathrm{Sec}$ After Impact on Storage Tube Assembly

7.4 Equivalent Plastic Strain at 0.028 Second at High Strain Rate for MCO Drop Onto Storage Tube Assembly.

7.5 Equivalent Plastic Strain at MCO Bottom 0.04 Second After Impact Onto Service Station Shield Hatch Ring

7.6 Equivalent Plastic Strain Near Lower Weld At 0.04 Second After Impact Onto Service Station Shield Hatch Ring ..... .28

7.7 Basket Velocity vs. Time of MCO Impact Onto Storage Tube Assembly ...................29

7.8 Basket Velocity vs. Time of MCO Impact Onto Service Station Shield Hatch Ring ....30

7.9 Node Locations for Velocity Plot of MCO Drop onto Service Station .........................31

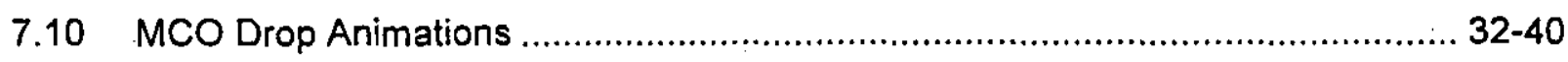

7.11 Mises Equivalent Stress Time History Plot of Element 70307 near Outside Weld .....41

7.12 Mises Equivalent Stress Time History Plot of Element 70019 at MCO bottom Near Impact Location

7.13 Stress in Radial Direction (direction 1) at Time 0.03 Second ...................................43

7.14 Stress in Meridian Direction (direction 2) at Time 0.03 Second ................................44 
7.15 Stress in Hoop Direction (direction 3) at Time 0.03 Second.................................... $\overline{45}$

7.16 Plastic Strain in Radial in Direction (direction 1) at Time 0.03 Second......................46

7.17 Plastic Strain in Meridian Direction (direction 2) at Time 0.03 Second .......................47

7.18 Plastic Strain in Hoop Direction (direction 3) at Time 0.03 Second ............................48

7.19 Total Kinetic Energy Time History of the MCO Drops onto the Standard Storage

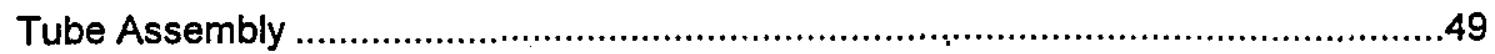

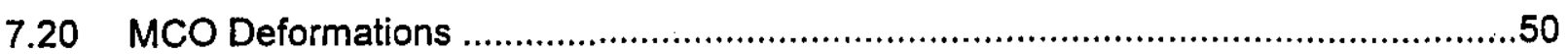

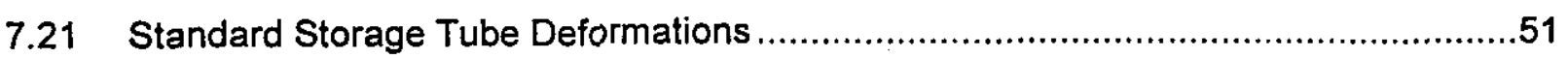

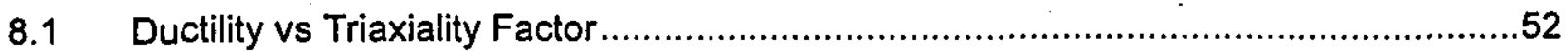




\section{ACRONYM LISTING}

$\begin{array}{ll}\text { CSB } & \text { Canister Storage Building } \\ \text { DESH } & \text { Duke Engineering \& Services Hanford, Inc. } \\ \text { DOE } & \text { U.S. Department of Energy } \\ \text { FDNW } & \text { Fluor Daniel Northwest } \\ \text { MCO } & \text { Multi-canister overpack } \\ \text { MHM } & \text { MCO handling machine } \\ \text { QA } & \text { Quality Assurance } \\ \text { SNF } & \text { Spent Nuclear Fuel }\end{array}$




\title{
ENGINEERING REPORT
}

\author{
ANALYSIS FOR \\ ECCENTRIC MULTI-CANISTER OVERPACK DROPS \\ AT THE CANISTER STORAGE BUILDING
}

\subsection{INTRODUCTION}

The Spent Nuclear Fuel (SNF) Canister Storage Building (CSB) is the interim storage facility for the K-Basin SNF at the U.S. Department of Energy (DOE) Hanford Site. The SNF is packaged in multi-canister overpacks (MCOs). The MCOs are placed inside transport casks, then delivered to the service station inside the CSB. At the service station, the MCO handling machine (MHM) moves the MCO from the cask to a storage tube or one of two sample/weld stations. There are 220 standard storage tubes and six overpack storage tubes in a below grade reinforced concrete vault. Each storage tube can hold two MCOs.

\subsection{OBJECTIVE}

The purpose of this report is to investigate the potential for damage to the MCO during impact from an eccentric accidental drop onto the standard storage tube, overpack storage tube, service station or sampling/weld station. Damage to the storage tube and sample/weld station is beyond the scope of this report. The results of this analysis are required to show the following;

- If a breach resulting in unacceptable release of contamination could occur in the MCO.

- If the dropped MCO could become stuck in the storage tube after the drop.

- Maximum deceleration of the spent nuclear fuel baskets.

\subsection{SUMMARY AND CONCLUSIONS}

The maximum equivalent MCO strain is 40 to $45 \%$ and occurs on the MCO bottom near the point of impact and is compressive (negative triaxiality factor). Some gouging may occur but since the compressive failure strain is above $80 \%$ for the base metal, it is not likely that through the wall cracking will occur but removal of local surface metal may occur.

The maximum predicted equivalent plastic strain at the MCO lower weld is about $2 \%$, during the drop into the standard storage tube. This is well below a $42 \%$ failure strain for a negative triaxiality factor. The maximum tensile principal 
strain is in a radial direction, therefore, any failure would be by spalling or flaking rather than through-wall cracking.

The maximum deceleration of the MCO baskets is about $20 \mathrm{~g}$ or less, well within the design allowable of $35 \mathrm{~g}$.

The deformations of the MCO and target assembly are less than the tube clearance, therefore, wedging of the MCO in the tube ls not expected.

The analyses of the standard and overpack storage tube assemblies have been studied in References 1 and 2. However, the strains found in this report are in agreement with previous analyses and no rupture or through wall cracking is anticipated.

\subsection{EXPERT PANEL}

An expert panel was assembled to oversee this report to verify that appropriate inputs, methods, and assumptions were used and to ensure the findings of this report would be available in a timely manner. The panel was made up of the following members.
- L. D. Blackburn
- R. D. Crow
- L. H. Goldmann
- R. P. Kennedy
- L. K. Severud

Metallurgy

Safety Analysis

MCO Design Authority

Structural Analysis

Engineering Management \& Structural

Analysis

The expert panel report is included as an attachment to this report.

\subsection{DESCRIPTION}

Four eccentric MCO drops from the MHM in the CSB are studied in this report. The drops occur at the following locations:

- Standard storage tube assembly

- Overpack storage tube assembly

- Service station

- Sampling/weld station

The MCO is constructed of stalnless steel and measures approximately 24 inches in diameter by about 13 feet in length as shown in Figure 5.1 as the shell assembly. The MCOs are maneuvered inside the CSB by the MCO handling machine (MHM). The MCO impacts a $45^{\circ}$ inclined surface on the lower flange at both the standard storage tube and the overpack storage tube. The damage to the tube assembly has been studied in References 1 and 2 . The standard 
storage tubes have a smaller gap (1/2") between the tube and the embedment than the overpack tubes ( 1 "). This limits the tube lateral displacements to a lower value, which means that during a drop more force would be transferred to the MCO causing more potential for damage. Therefore, the standard storage tube was chosen to represent the drop for both locations. The standard storage tube is 28 inches in diameter and approximately 40 feet long and is shown in Figure 5.2. A sketch of the drop onto the standard storage tube is shown in Figure 5.3.

The shielding rings at the service and sampling/weld station are fixed in place and do not move during impact. The inclinations of the impact surfaces of the shielding rings have been reduced from $45^{\circ}$ to $15^{\circ}$ from vertical to reduce the impact damage to the MCO. The temporary shielding ring at the sampling/weld station is supported on steel posts from the base of the pit. The service station shield hatch ring is more rigidly supported directly on the floor embedment and is more massive than the sampling/weld station shielding ring. A drop on this more rigid and massive ring would cause more damage to the MCO from an accidental drop. Therefore, the service station was chosen to represent the drop for both locations. A sketch of the drop onto the service station is shown on Figure 5.4.

Each MCO has the capacity to contain six Mark 1A baskets (see Figure 5.5) or five Mark IV baskets loaded with fuel pins. The baskets are stacked one on top of the other. At the bottom of the MCO are 6 basket support plates (ribs) in a radial arrangement. These 6 ribs support the entire basket stack. The loaded baskets make up about $70 \%$ of the total $M C O$ weight.

\subsection{Drop Parameters at Standard Tube Assembly}

Loaded MCO weight, without cap

Drop height

Drop velocity

Kinetic energy at impact

Point of impact

Impact distance from inside face

of standard tube assembly

MHM off center dimension

Drop angle

\subsection{Drop Parameters at Service Station}

Loaded MCO weight, without cap

Drop height

Drop velocity
$20,000 \mathrm{lbf}$

90 inches

$263.7 \mathrm{in} / \mathrm{sec}$

$1,800,000$ in-lbf

$45^{\circ}$ inclined surface of lower flange

2.75 inches

1 inch

$2^{\circ} 21^{\prime}$

$20,000 \mathrm{lbf}$

90 inches

$263.7 \mathrm{in} / \mathrm{sec}$ 
Kinetic energy at impact

Point of impact

ring

Impact distance from top inside

face of opening

MHM off center dimension

Drop angle
$1,800,000$ in-lbf

$15^{\circ}$ inclined surface of shield hatch

1.58 inches

3.63 inches

$1{ }^{\circ} 40^{\prime}$

\subsection{MCO Physical Properties}

Wall thickness

Bottom thickness

Outside diameter

Outside diameter at head
0.5 inches

2.01 inches

24.0 inches

25.3 inches

\subsection{Standard Storage Tube Physical Properties}

Lower flange thickness

Slope of lower flange sealing surface

Tube inner diameter

Wall thickness
3.5 inches

$45^{\circ}$ from vertical

27 inches

0.5 inches

\subsection{Service Station Physical Propertles}

Shield hatch ring thickness

10 inches .

Slope of shield hatch ring

$15^{\circ}$ from vertical

\subsection{Material Properties}

The MCO is constructed from $304 \mathrm{~L}$ stainless steel while the storage tubes are constructed from ASTM A36 steel. The stress-strain curves for these steels are dependent on the applied strain rate. Stress-strain data for a strain rate of 60 inch/inch per second (maximum strain rate observed in an earlier computer run) was calculated (Appendix A) and is plotted on Figures 5.6 and 5.7 along with the normal stress-strain curve for $304 \mathrm{~L}$ and A36 steel, respectively.

The material properties for the MCO and storage tubes are as follows: 
SNF-5204, Rev. 0/CSB-S-0073

MCO MATERIAL

(Ref. Drawing no. H-2-828043)

Elastic modulus

Poisson ratio

STANDARD TUBE ASSEMBLY MATERIAL

Elastic modulus

Poisson ratio
304L stainless steel

$28,000,000$ psi

0.27

ASTM A36

29,500,000 psi

0.27 
SNF-5204, Rev. 0/CSB-S-0073

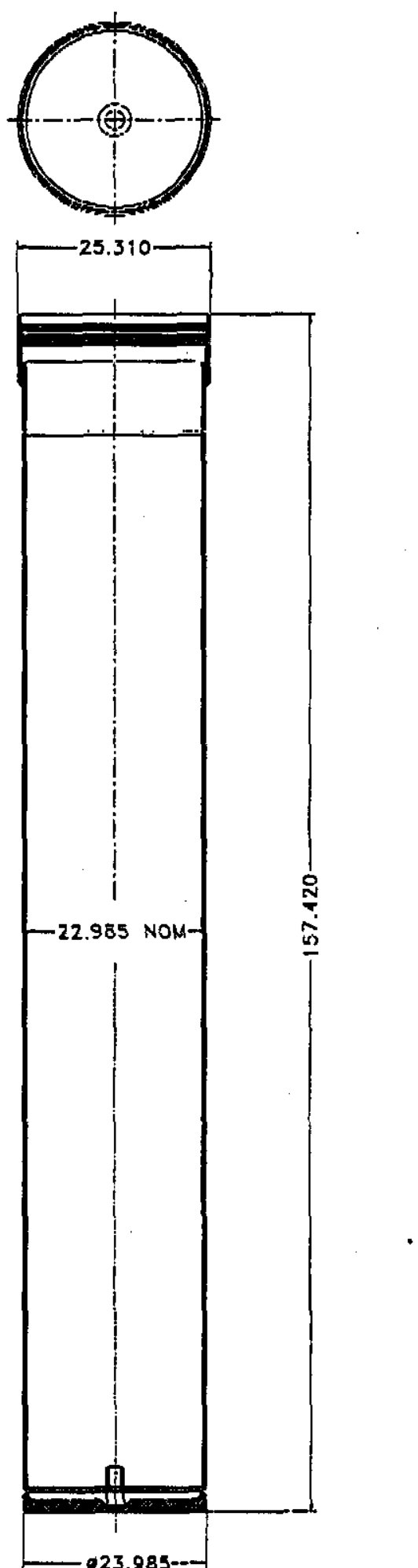

Figure 5.1. Multi-canister Overpack Shell Assembly 

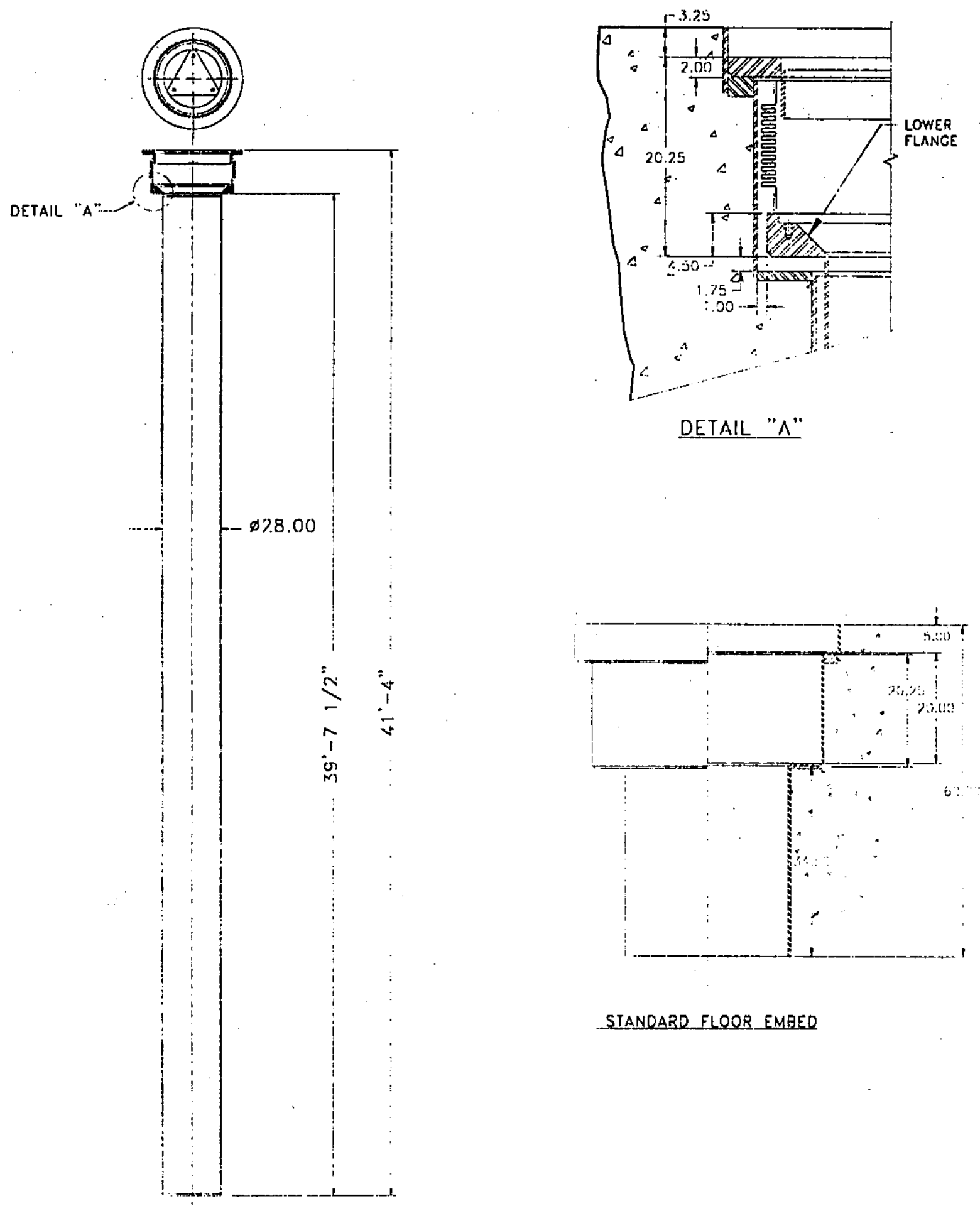

SIANOARO FLOOR EMAED

Figure 5.2. Standard Storage Tube. 


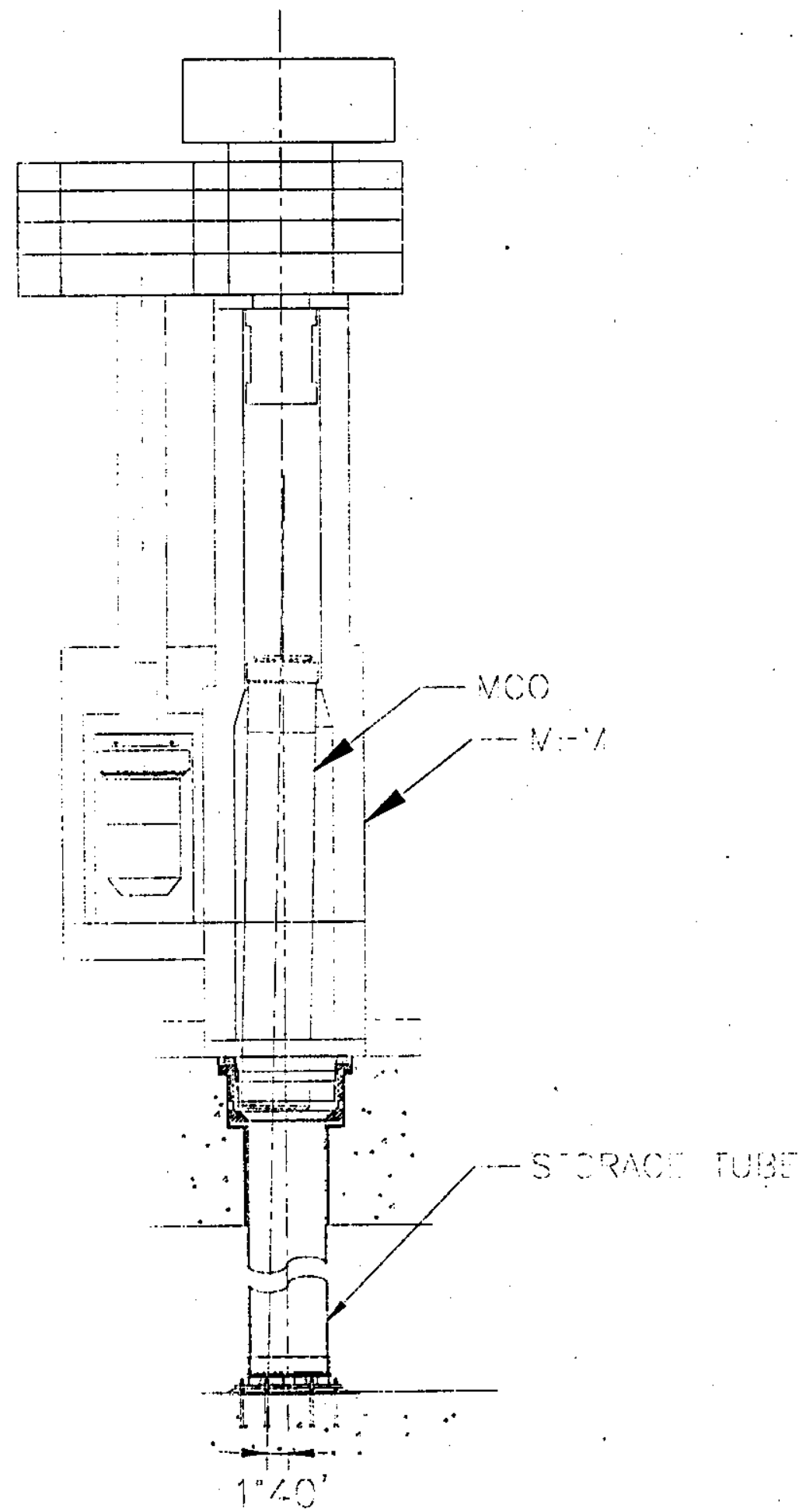

Figure 5.3. MCO, MHM and Storage Tube at Time of Impact. 


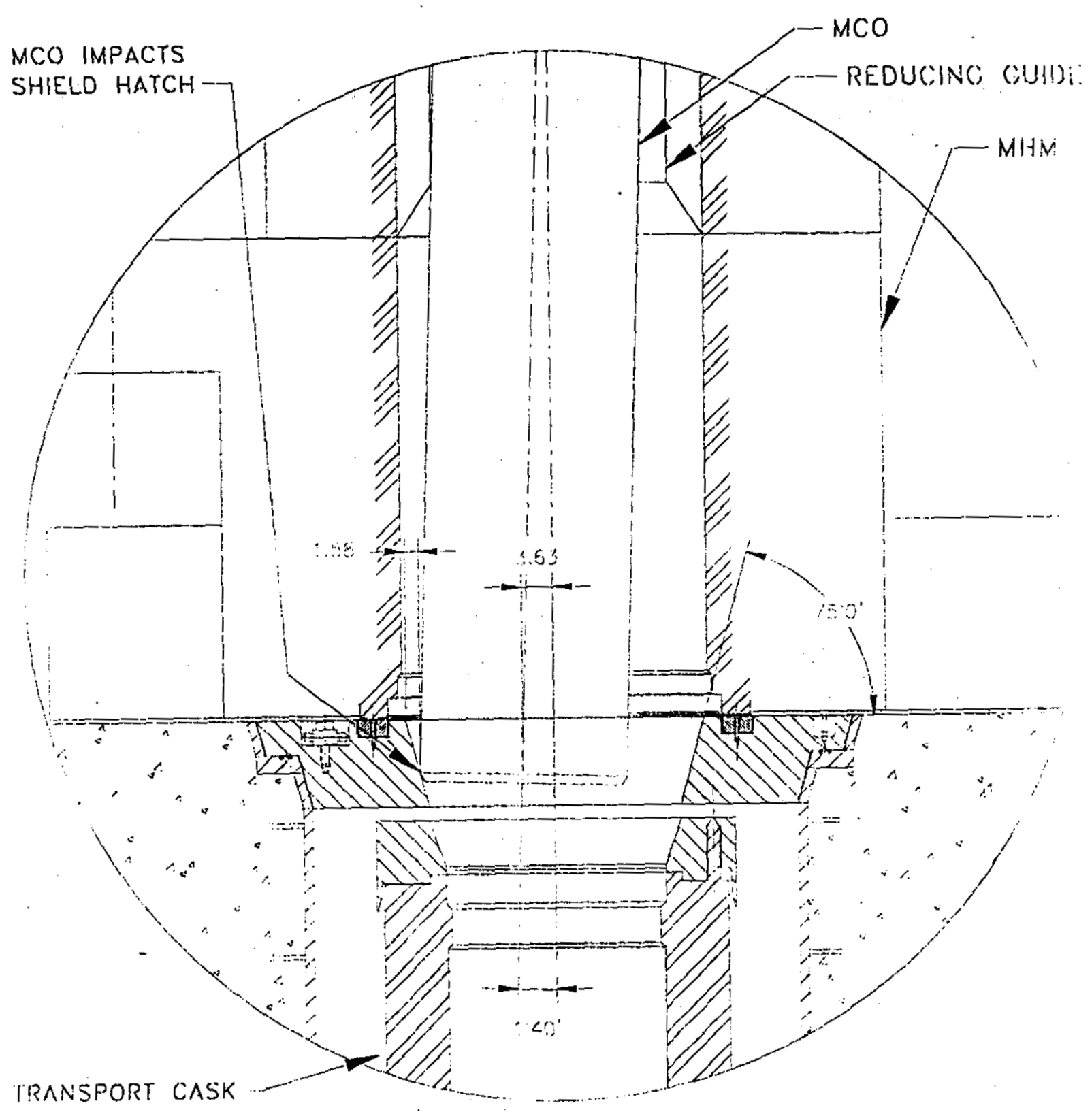

Figure 5.4. MCO Drop at Service Station. 


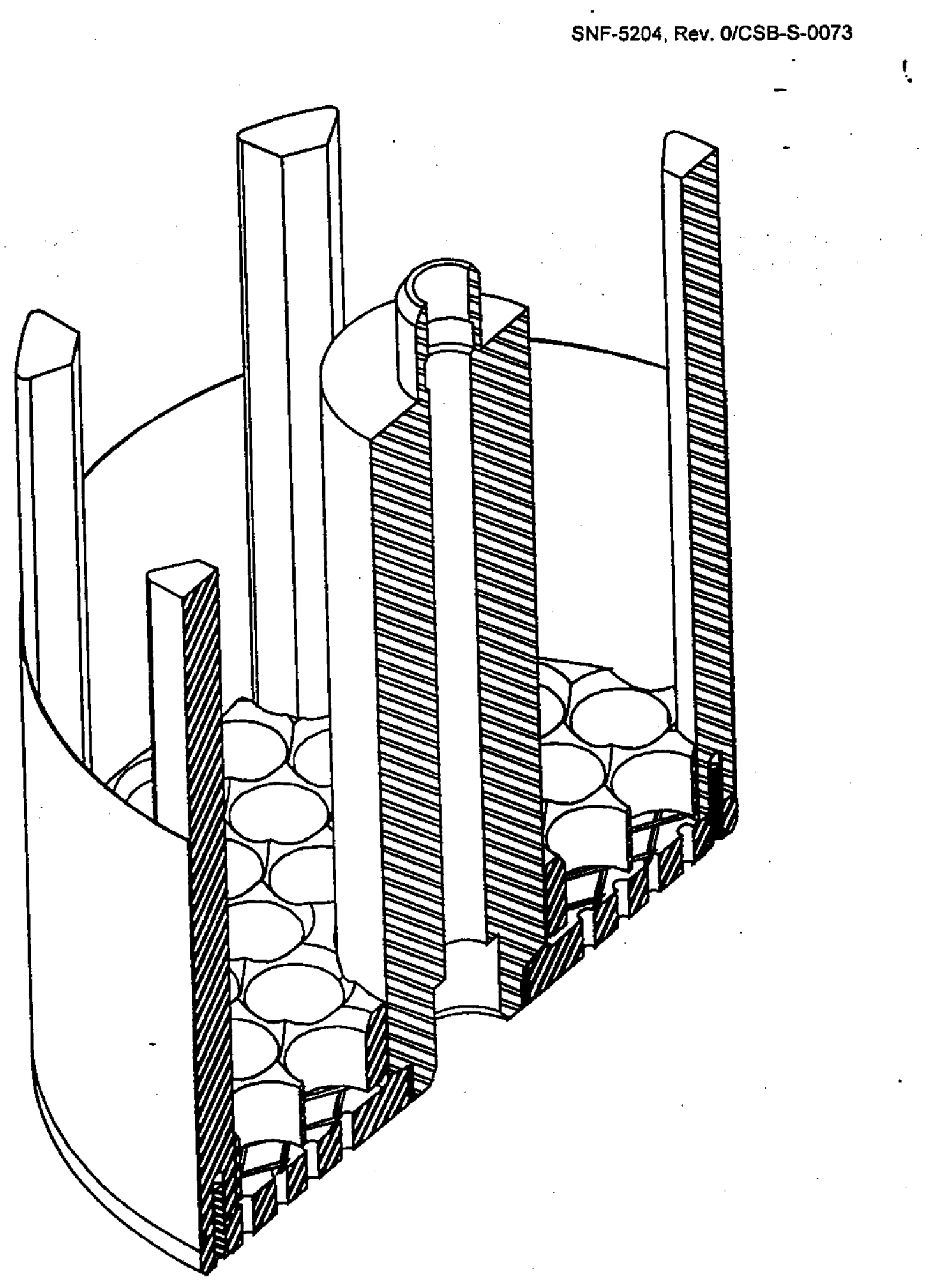

Figure 5.5. Mark 1A Fuel Pin Basket. 


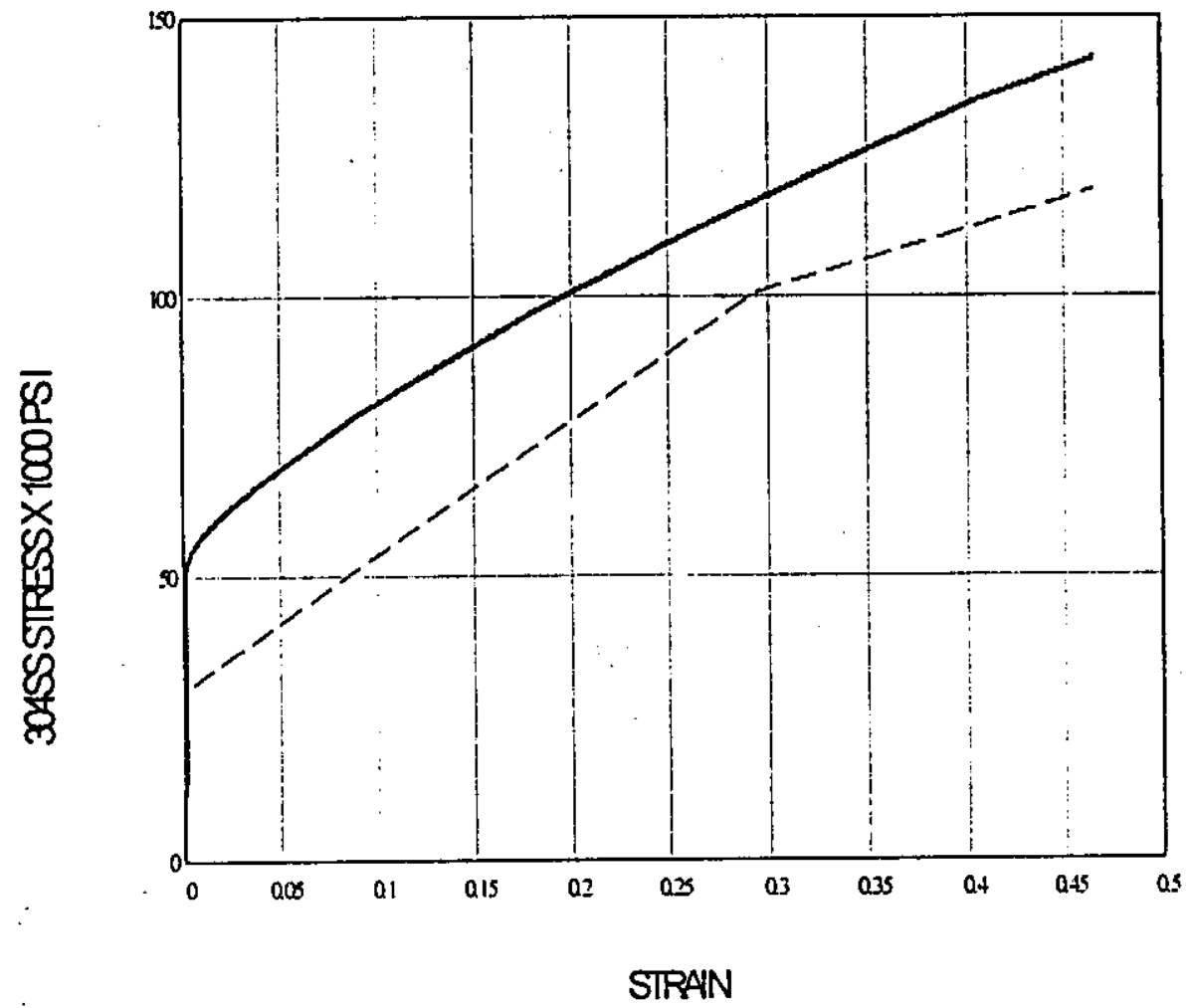

- STRANRATEGFINAN FERECOND

- - NOMNALSTRAINRATE

Figure 5.6. True Stress-Strain Curves for 304SS Steel. 


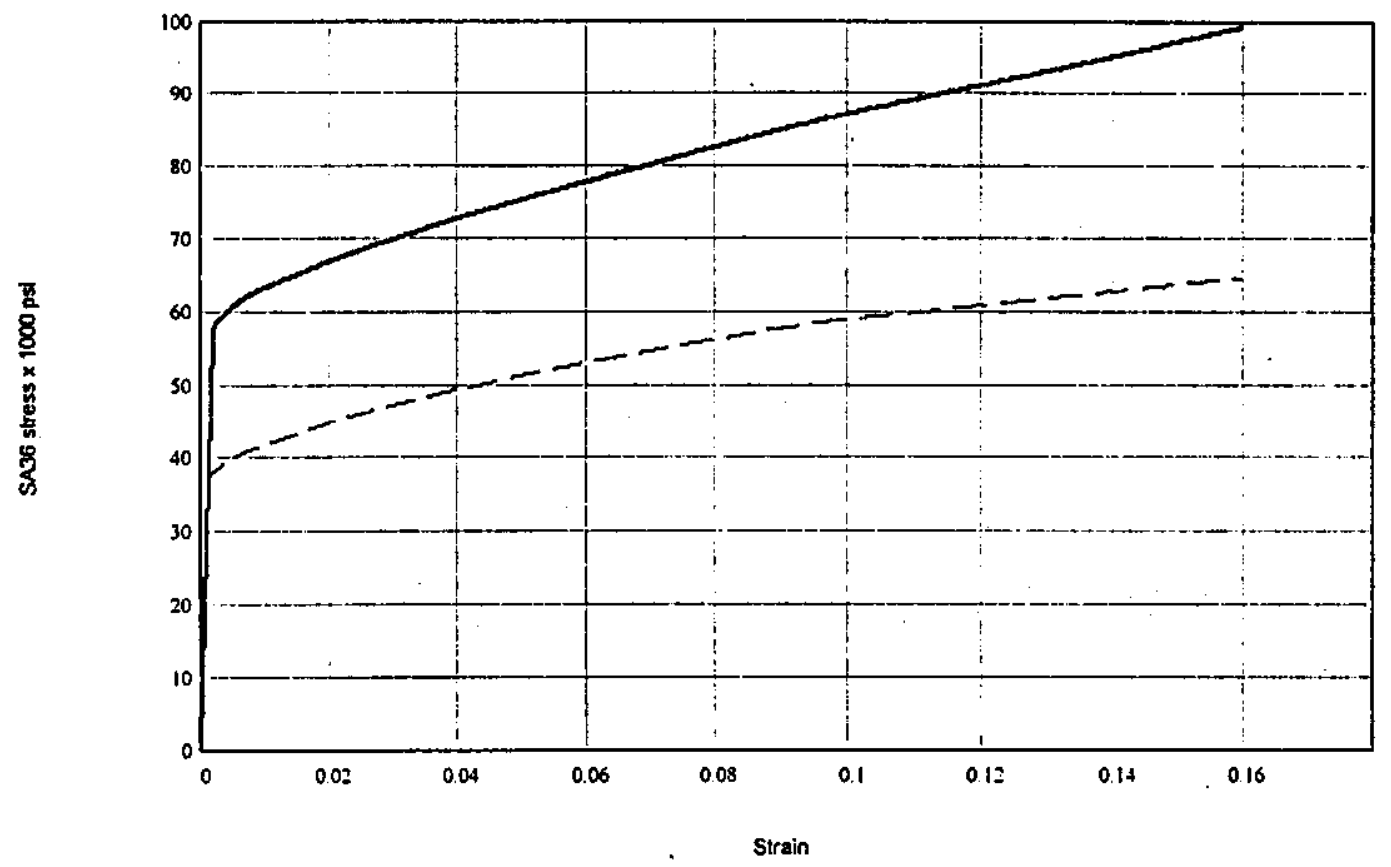

Strain rate of $60 \mathrm{in} . / \mathrm{in} / \mathrm{per}$ second Nominal strain rate

Figure 5.7. True Stress-Strain Curves for SA36 Steel. 


\subsection{ANALYSIS APPROACH AND ASSUMPTIONS}

A finite element computer model is utilized to simulate the MCO impact analysis. The MCO, the standard storage tube assembly and the shielding ring are explicitly modeled so that elastic and plastic strains for both assemblies can be computed to characterize the reactive forces and energy absorption during impact.

The high strain rate material property was used to study the damage at the bottom of the MCO. The strain rate capability of the ABAQUS/Explicit program was not used because it would significantly increase the computer run time.

\subsection{Computer Program}

Industry-accepted, quality assurance (QA) approved and efficient computer analysis codes are required to perform sophisticated nonlinear dynamic finiteelement analyses. The ABAQUS/Explicit computer program was selected for this analysis. ABAQUS/Explicit is a well-documented and proven finite-element program. It is a general-purpose finite-element analysis program, which has been used in the nuclear industry for decades. The program has an extensive element library. Nonlinear geometry (contact surfaces, sliding surfaces and large deflections), nonlinear material properties (plasticity and strain hardening), and explicit time integration are specific options that make the program ideal for evaluation of nonlinear dynamic impact evaluations. Contact surfaces allow free movement of two adjacent nontouching surfaces but preclude penetration of one contact surface into another. Sliding surfaces allow free movement of two adjacent nontouching surfaces but resist movement if the two surfaces are in contact. Friction forces that are determined by normal forces and prescribed friction coefficients model the resistance. The program comes with a welldocumented theoretical manual and verification manual. The program has an error reporting system available through the Internet. ABAQUS/Explicit has extensive preprocessing, and graphics capabilities.

ABAQUS/Explicit has previously been used to simulate the puncture-drop tests and drop tests on SNF canisters. Actual test drops were set up and performed to determine how well the simulated drop results and the actual drop results matched. Evaluations of the drop simulations and actual drops are found in References 13 and 14. There was a good match in deformations of the actual dropped canister to those calculated in the model, with the model generally overpredicting the deformations. The model was very good in simulating the actual dropped canister response.

ABAQUS/Explicit has been verified and validated through the FDNW QA program. ABAQUS/Explicit is currently maintained in accordance with these requirements. Use of the program at FDNW is restricted to authorized users administered by the FDNW software administrator. ABAQUS/Explicit version $5.8-10$ is used in this analysis 


\subsection{Computer Simulation}

Two computer runs using the comprehensive finite-element model were used to determine the effect of an MCO drop onto a standard storage tube assembly for the material properties (nominal and maximum strain rate stress-strain curves) and geometry parameters listed in Section 5.0. Another computer run was performed for the MCO drop at the service station using the nominal strain rate stress-strain curves (without considering the high strain rate effect).

Coefficients of friction for various materials are given in Reference 3 . Sliding coefficients for mild steel on medium steel varied from 0.53 to 0.18 for sliding speeds of $0.0001 \mathrm{in} / \mathrm{sec}$ to $100 \mathrm{in} / \mathrm{sec}$. A coefficient of sliding friction of 0.3 is used throughout this analysis.

\subsection{Computer Modeling of MCO Drops onto Storage Tube Assembly}

The interface surfaces of the MCO and the MHM (MCO handling machine) are modeled with contact surfaces to control the lateral displacement of the falling MCO. The interface surfaces of the standard storage tube assembly lower flange and the concrete deck embedment are modeled with contact surfaces to control the lateral displacement of the deflecting standard tube assembly lower flange resulting from the glancing blow of the MCO onto the inclined surface of the lower flange. The MHM and the concrete deck embedment are modeled with rigid elements.

The interface surfaces of the MCO and the inclined surface of the standard tube assembly lower flange are modeled with contact surfaces to characterize the deformation and sliding at the point of impact. The elements depicting the contact surfaces of the MCO and the standard storage tube assembly are modeled with solid elements having elasto-plastic material properties. Figures 6.1 and 6.2 show the computer model for the drop at the standard storage tube assembly.

Two previous MCO drop analyses were performed to determine the effects of an accidental drop. One analysis (Reference 1) studied the potential damage to the standard storage tubes and the other (Reference 2) studied potential damage to the overpack storage tube. The computer models of these reports are not suitable to study the damage to the MCO.

The improvements in this analysis include better modeling of the MCO internals, accounting for the strain rate effects on the material stress-strain properties, refinement of the finite element model in areas of high strains, and inclusion of appropriate predictions of the failure strain levels. Specifically, the MCO model . has been improved in the following ways: 


\section{- Mesh Size}

A finer mesh was used in the high stress/strain area around the impact location. The finer mesh yields lower results, but requires a longer run time.

- Shell vs. solid elements

In previous analyses the MCO bottom was made up of solid elements up to the area of the weld between the bottom and the wall. From that point up shell elements were used. The transition from solid to shell elements at the weld could cause undesirable effects on the results. For this analysis the area of solid elements was extended above the high stress area.

- Four elements vs. seven elements through the wall

A model with 7 elements across the thickness of the wall has been developed to compare the results with a 4-element model. The maximum equivalent plastic strain of the 7 -element model is about $20 \%$ less than the results of the 4-element model. Each element in the 7-element model is about 0.07 inches thick. The time required for each iteration of the ABAQUS/Explicit program is controlled by the element size. The 7-element model requires about 60 hours of computer time to run. The final analysis of the drop on the storage tube assembly uses the 7-element model.

- Basket mass

The mass of the basket and its contents was accounted for in previous analyses by placing mass elements in the MCO bottom. This method of modeling did not accurately represent the movement of the baskets that occurs during an impact. For this analysis the basket is modeled with solid elements and beam elements in the proper locations. Contact surfaces are modeled between the baskets and the MCO interior surface. The basket is free to bounce inside the MCO during impact, which more accurately simulates the actual condition. The density of the basket material in this model was increased to include the mass of the fuel pins. This process, known as smearing, provides conservative results.

For the MCO drop on the storage tube assembly, the vertical and horizontal gaps between the tube assembly and the concrete deck are included in the preimpact model configuration to accurately characterize the influence of the impact of the MCO on the inclined surface of the tube assembly lower flange. As the impact occurs the lower flange moves down and away from the point of impact. At the same time the MCO slides down the inclined surface of the lower flange.

\subsection{Computer Modeling of MCO Drops onto Service Station}

The interface surfaces of the MCO and the inclined surface of service station shield hatch ring are modeled with contact surfaces to characterize the deformation and sliding at the point of impact. The elements depicting the contact surfaces of the MCO and shipping cask are modeled with solid elements 
having elasto-plastic material properties. Figure 6.3 and 6.4 show the computer model for the drop at the service station.

Basically, the MCO model for the drop onto the service station is similar to the MCO model for the drop onto the storage tube assembly except as follows.

- The number of elements through the wall thickness was reduced from seven to four. The reduction in elements reduces computer run time and gives conservative results.

- $\quad$ A finer vertical mesh was used through the full length of the MCO. A finer horizontal mesh was used near the impact location (as in Standard storage tube assembly drop) and on the opposite side of the impact location.

The finer mesh on the opposite side of the impact location was necessary to yield reasonable results because the basket bounces and impacts the MCO wall at that location. 


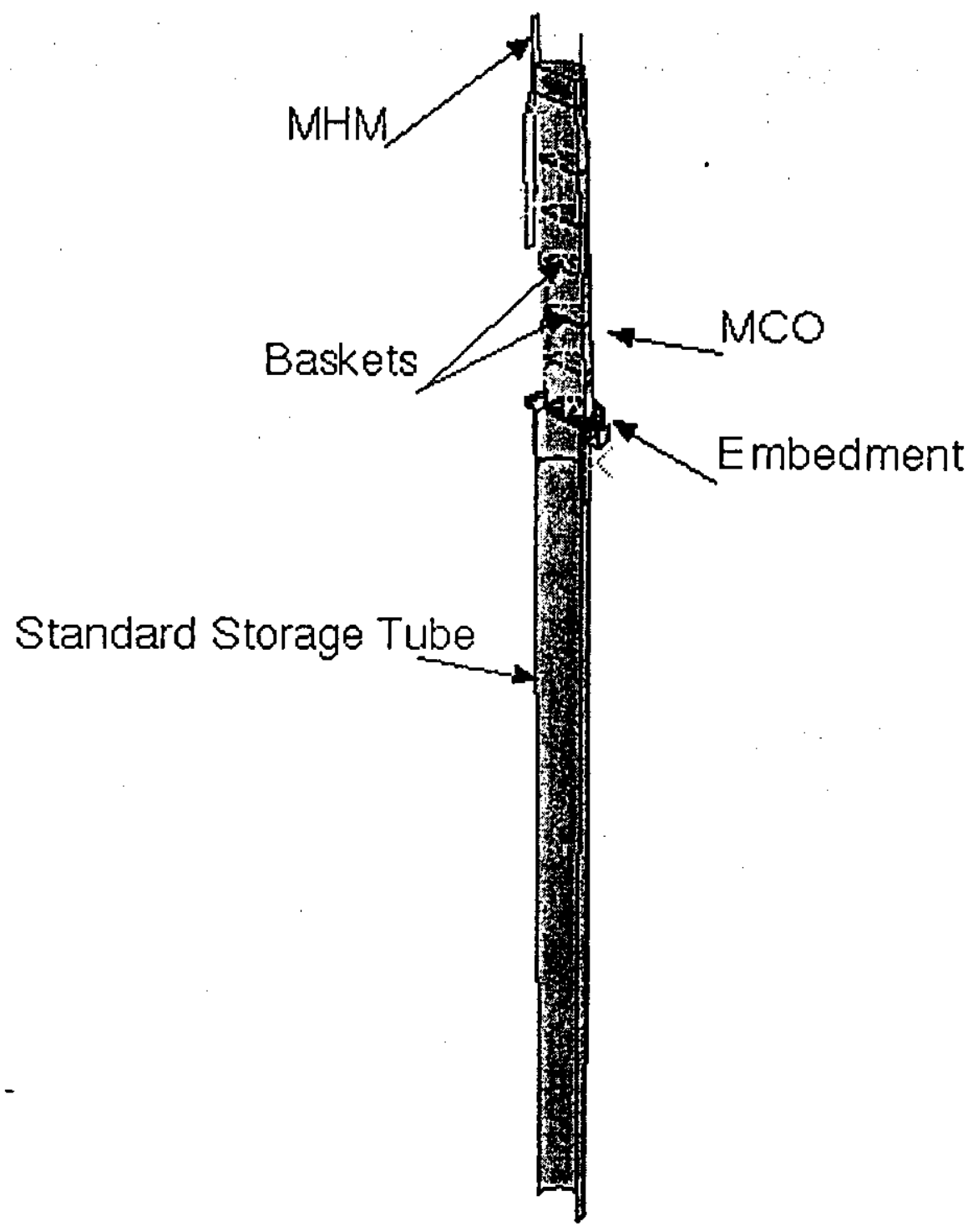

Figure 6.1. Computer Model of MCO Drop onto Storage Tube. 
SNF-5204, Rev. 0/CSB-S-0073

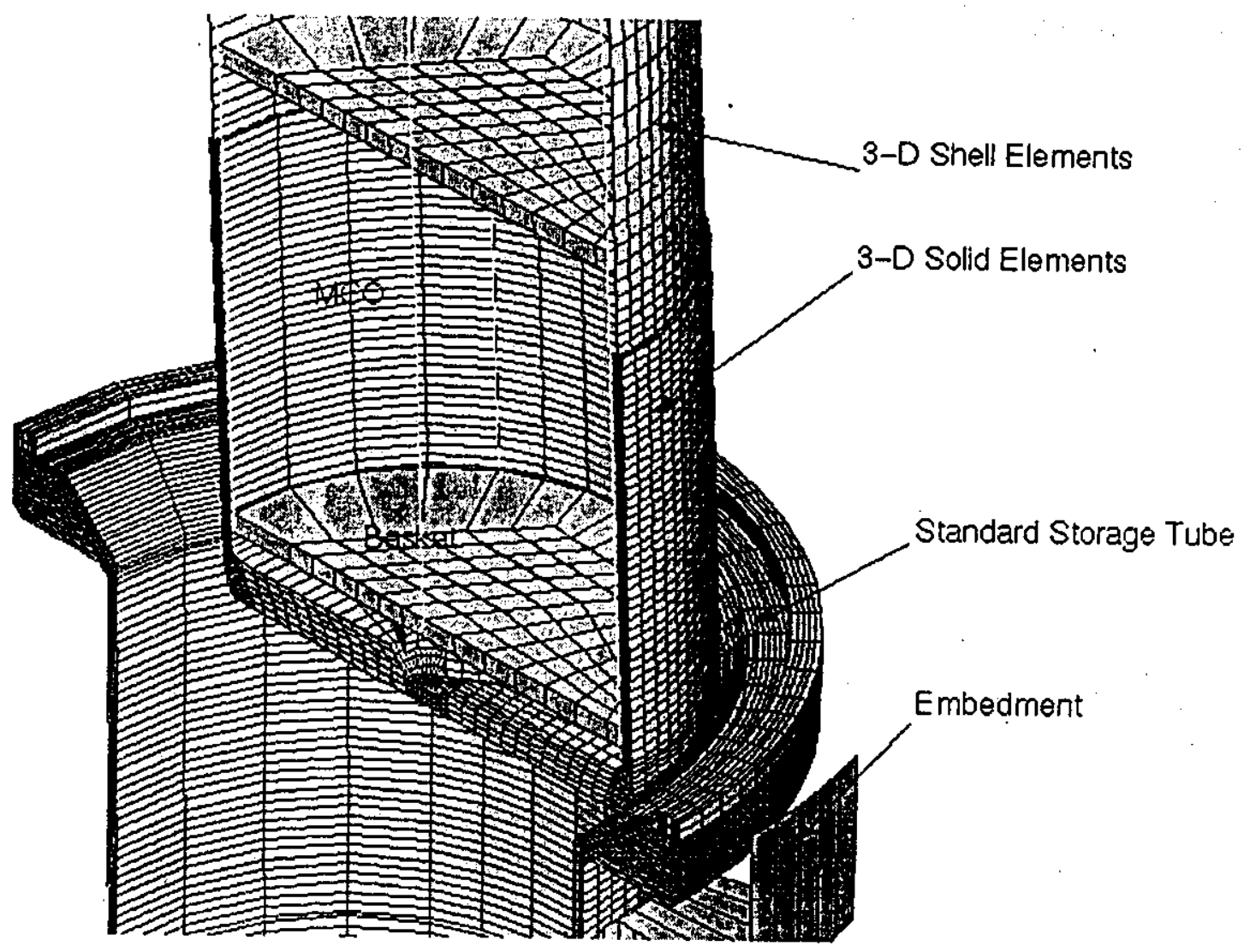

Figure 6.2. Close-up of Computer Model of MCO Drop onto Standard Storage Tube. 


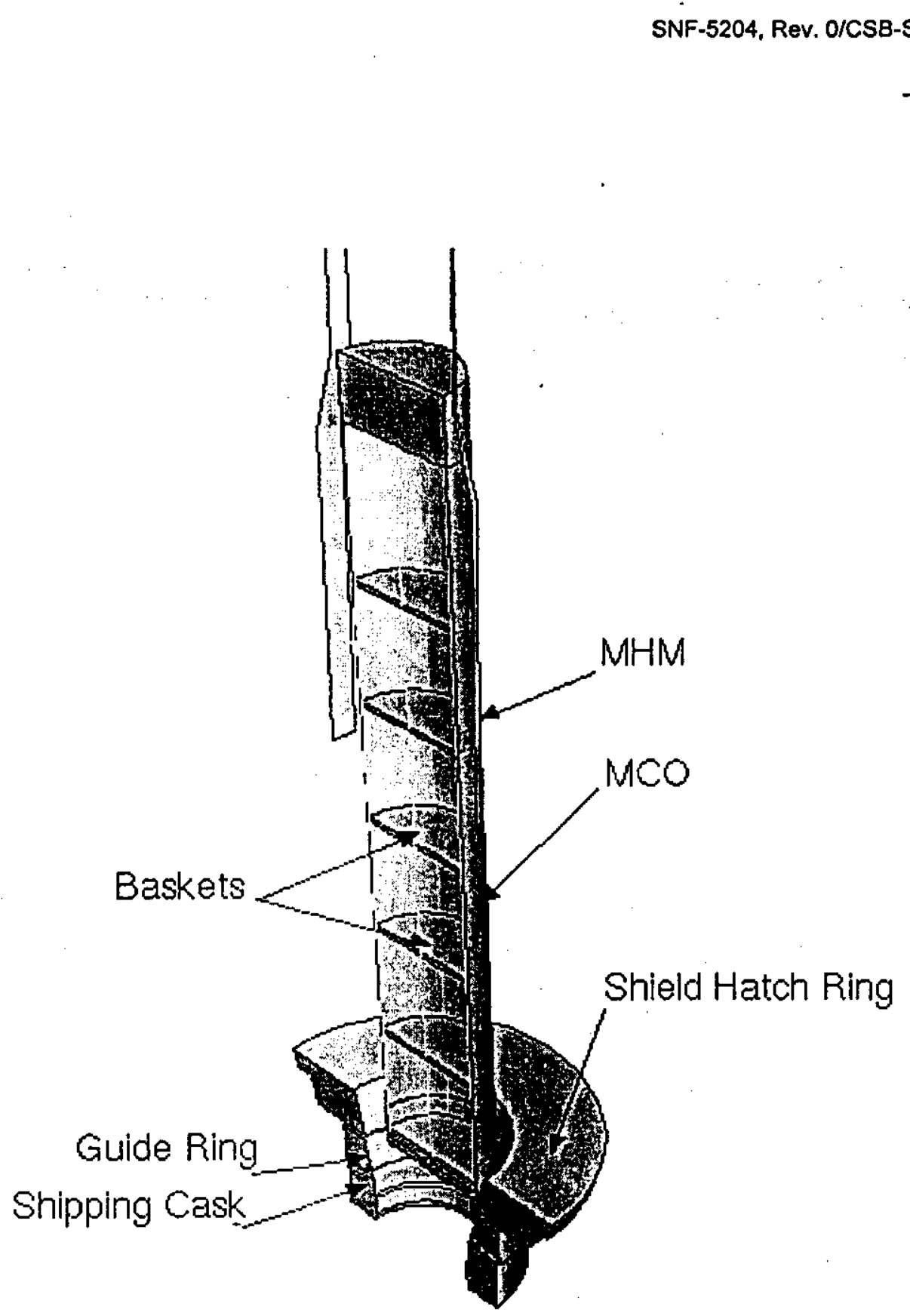

Figure 6.3. Computer Model of MCO Drop onto Service Station Shield Hatch Ring. 

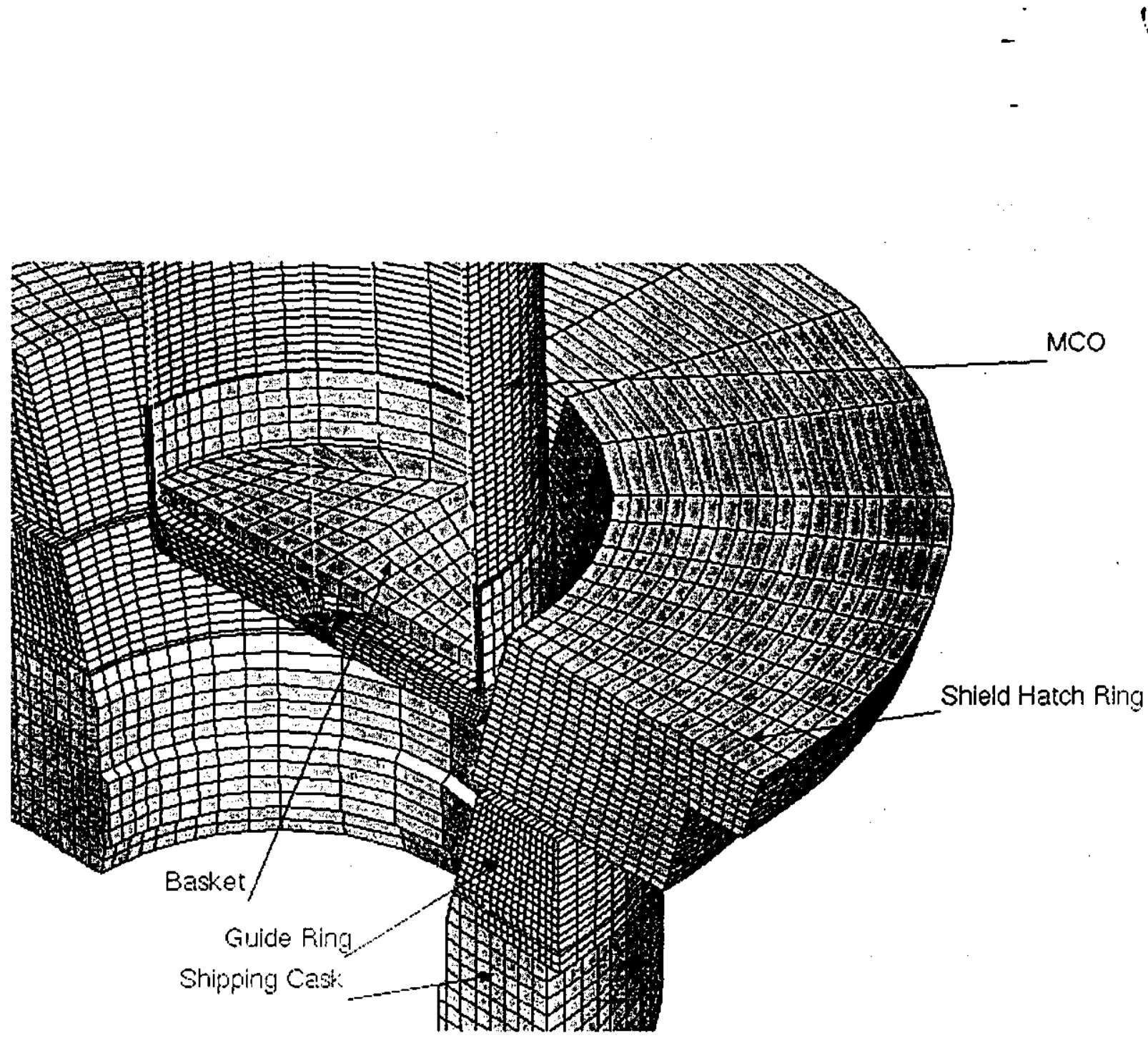

Figure 6.4. Close-up Computer Model of MCO Drop onto Service Station Shield Hatch Ring. 


\subsection{RESULTS}

The equivalent plastic strain (peeq) is calculated from three principal plastic strain, and the value is greater than the maximum absolute value of the three direction strains. It is convenient to measure the magnitude of permanent damage/deformation by using peeq value that is represented by the plastic strain in all directions. The Mises equivalent stress, triaxiality factors, and peeq's for each component are found in Appendix B. The triaxiality factors and strains at critical location and critical time are summarized in Table 7.1.

Table 7.1. Calculated Failure Strain and Predicted Strain

\begin{tabular}{|c|c|c|c|c|c|}
\hline Location & $\begin{array}{c}\text { Node } \\
\text { number }\end{array}$ & $\begin{array}{c}\text { Time } \\
\text { (second) }\end{array}$ & $\begin{array}{c}\text { Triaxiality } \\
\text { factor }\end{array}$ & $\begin{array}{c}\text { Effective } \\
\text { failure strain }\end{array}$ & $\begin{array}{c}\text { Equivalent } \\
\text { plastic strain }\end{array}$ \\
\hline Lower weld & 72179 & 0.021 & -0.115 & 0.428 & 0.0175 \\
\hline Lower weld & 72179 & 0.02175 & 0.656 & 0.018 & 0.0018 \\
\hline MCO bottom & 70019 & 0.0052501 & -2.679 & 0.80 & 0.3966 \\
\hline
\end{tabular}

Figure 7.1 shows the deformed shape of the MCO and standard storage tube 0.03 seconds after impact. Figures 7.2 through 7.6 show the deformed shapes and strains of the MCO and storage tube after impact. Deformation strains along with failure strains at the bottom and lower weld on the MCO from the ABAQUS analysis are calculated and documented in Appendix B. These locations represent the areas of highest MCO strain.

The Mises time history plots of the stress near the outer weld surface and the impact location are shown on Figure 7.11 and 7.12, respectively.

The basket velocity during impact with the standard storage tube is plotted in Figure 7.7. The slope of the velocity curve gives the basket deceleration. The steeper the velocity curve, the greater the deceleration. The steepest portion of the curve is between 260 and 230 inches per second. The time interval between the two points is 0.0045 seconds. The change in speed divided by the time interval is $30 / 0.0045$ or $6667 \mathrm{in} / \mathrm{sec} / \mathrm{sec}$. Since the acceleration from gravity is 386.4 inches per second, the $g$ force that the basket experiences is $6667 / 386.4=17 \mathrm{~g}$ (say less than $20 \mathrm{~g}$ ).

The basket velocity during impact with the service station is plotted in Figure 7.8. Using the method noted above, the basket $\mathrm{g}$ force is about $4 \mathrm{~g}$. The basket nodes used for the $\mathrm{g}$ force calculations are shown in Figure 7.9.

The computer-generated views on Figures 7.10.a through 7.10.i show a timed sequence of the MCO drop onto the standard storage tube.

The ABAQUS/Explicit computer simulation uses global coordinates to describe the stresses and strains in the model. The ABAQUS direction 1 corresponds to stress/strain in the radial direction at the point of impact and $180^{\circ}$ from the point 
of impact. At other locations around the MCO circumference, the direction 1 stress/strain represents some combination of radial and hoop stress/strain.- The hoop stress and strain at the point of impact is shown on Figures 7.15 and 7.18, respectively. The radial stress and strain at the point of impact is shown on Figures 7.13 and 7.16, respectively. The ABAQUS/Explicit direction 2 corresponds to the stress/strain in the meridian (vertical) direction. The ABAQUS direction 3 corresponds to the hoop stress/strain at the point of impact and $180^{\circ}$ from the point of impact. At other locations around the MCO circumference the direction 3 stress represents some combination of hoop and radial stress/strain. The meridian stress and strain at the point of impact is shown on Figures 7.14 and 7.17 , respectively.

The deformations near the point of impact for the MCO and standard storage tube are shown in Figures 7.20 and 7.21, respectively. The clearances between the MCO and standard storage tube after the drop are calculated below.

Cold tube O. D.

$28.00^{n}$

tolerance

$\frac{.07^{\prime \prime}}{27.93^{n}}$

Tube Wall Thickness

$-.588^{\prime \prime}$

Cold Tube I. D.

"MCO top at $220^{\circ} \mathrm{F}$

$-\frac{.588^{\prime \prime}}{26.754^{\prime \prime}}$

Reduction in tube $\mathrm{O}$. D

Net Clearance

$-25.31^{n}$

$\frac{-1.0^{\prime \prime}}{.444^{\prime \prime}}$

- The top of the MCO is 25.31 inches in diameter while the maximum deformed barrel diameter is about 24.1 inches, the larger of the two values is used.

The maximum kinetic energy during the drop is about $1,800,000$ in-lbf. The time history of the kinetic energy for half of the MCO during the drop is plotted in Figure 7.19. 
PEEQ

Multiple section points

(Ave. Crit.: 100\%)

$+4.489 \mathrm{e}-01$

$+1.000 e-01$

$+9.0000-02$

$+8.000 e-02$

$+7.000 \mathrm{e}-02$

$+6.000 \mathrm{e}-02$

$+5.000 \mathrm{e}-02$

$+4.000 \mathrm{e}-02$

$+3.000 e-02$

$+2.000 \mathrm{e}-02$

$+1.000 \mathrm{e}-02$

$+0.000 e+00$

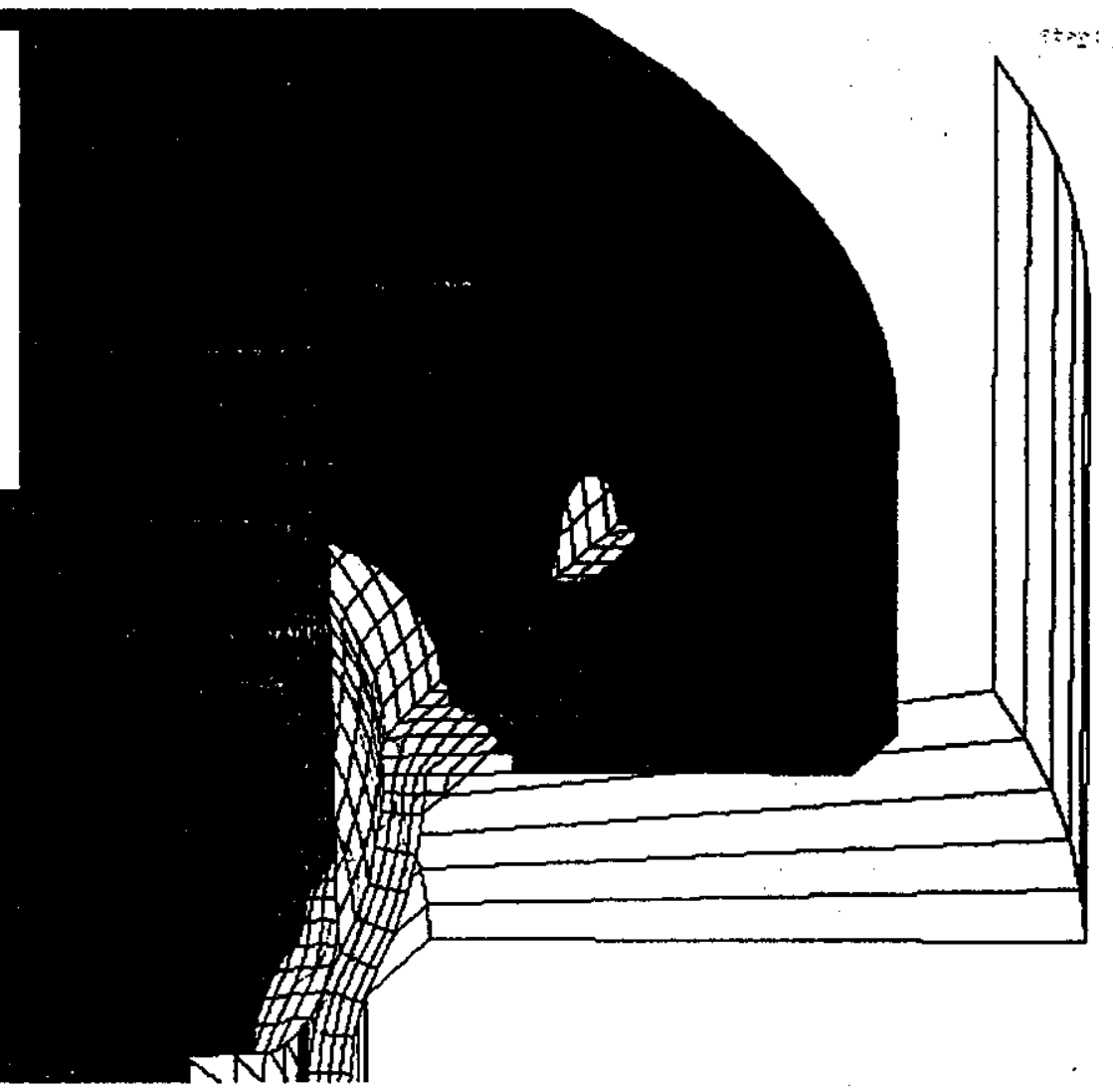

Figure 7.1. Close-up View at 0.03 Seconds After Impact Onto Storage Tube Assembly. 


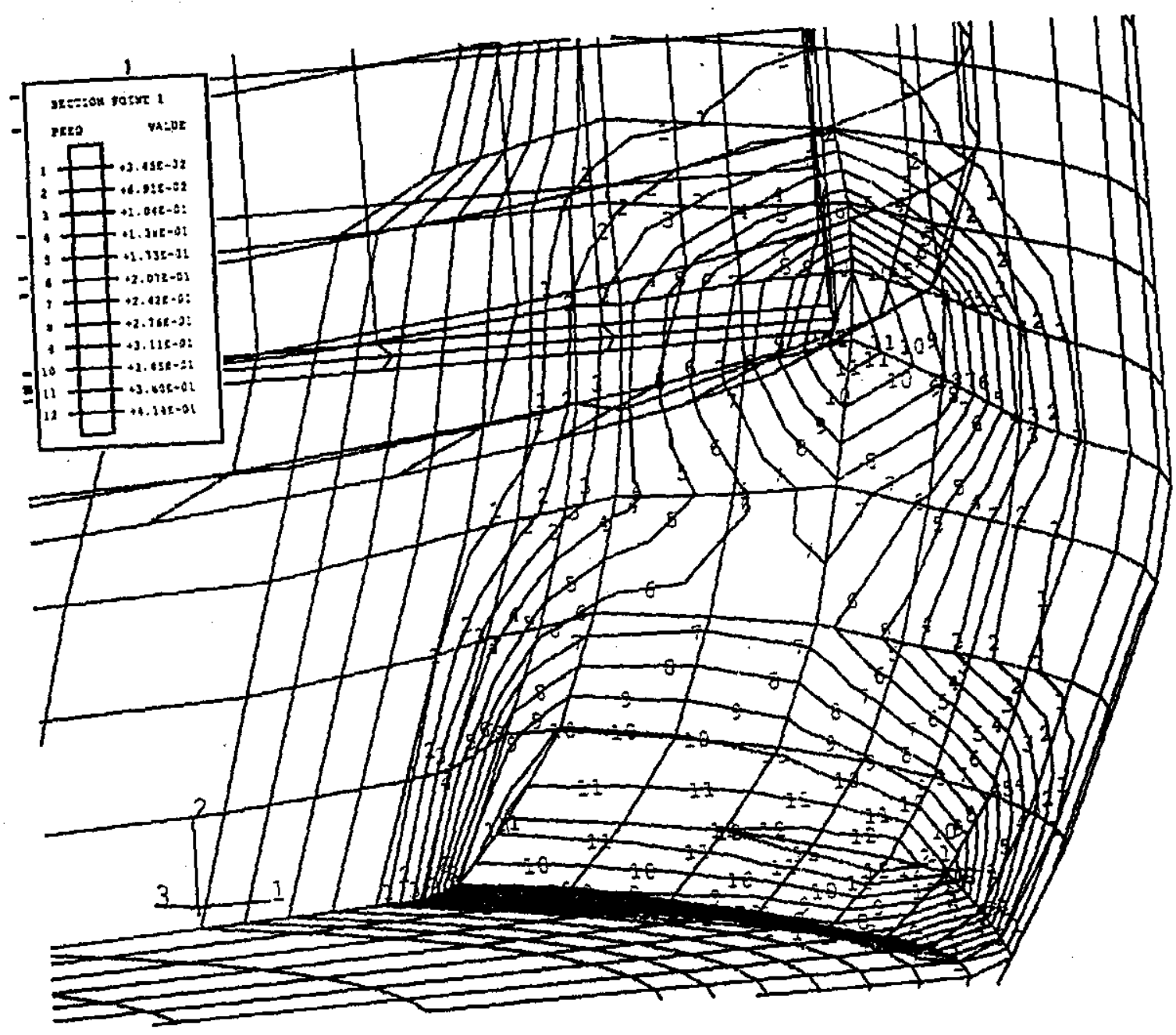

Figure 7.2. Equivalent Plastic Strain at MCO Bottom at 0.03 Second After impact at Storage Tube Assembly. 


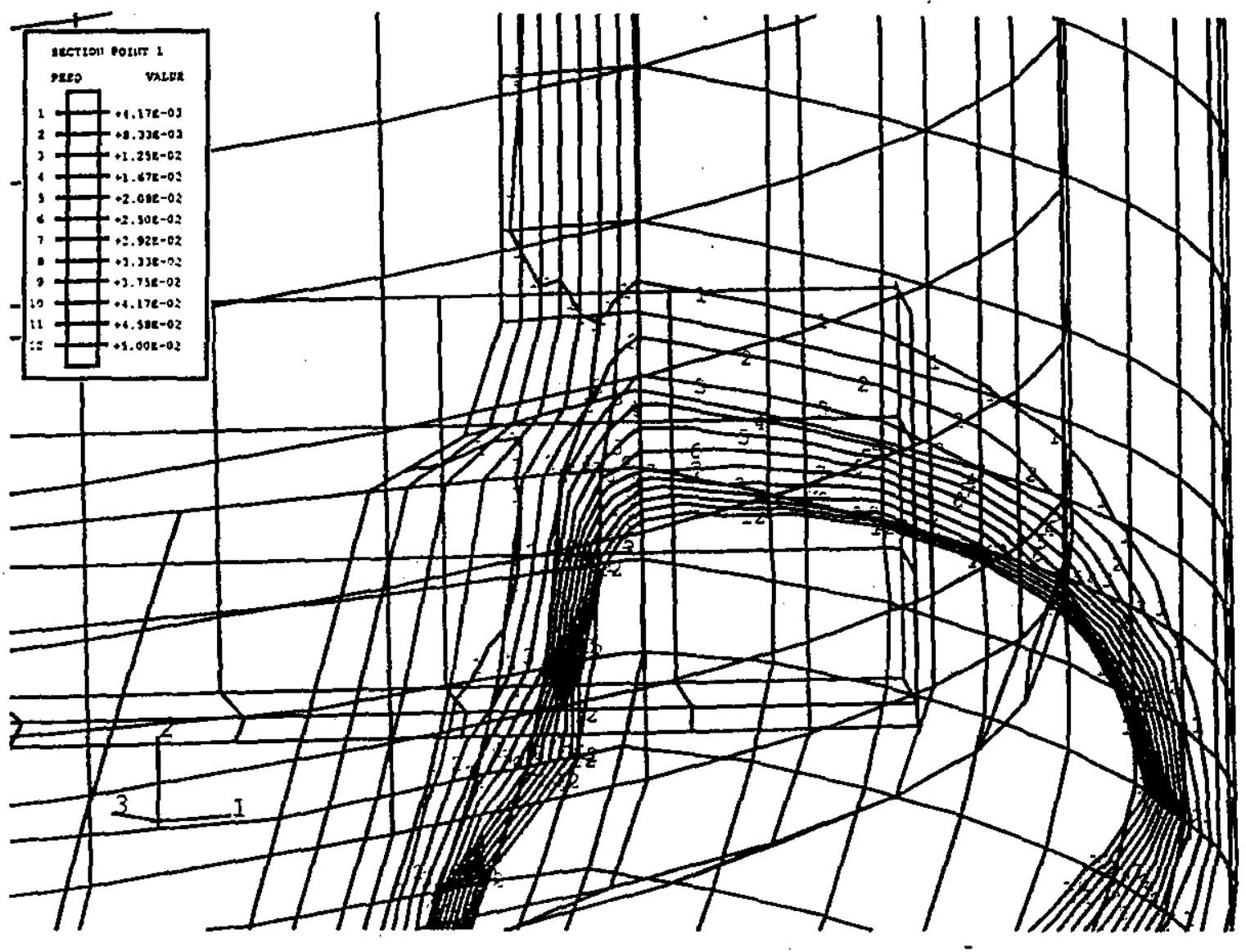

Figure 7.3. Equivalent Plastic Strain at MCO Lower Weld at $0.03 \mathrm{Sec}$ After Impact on Storage Tube Assembly. 


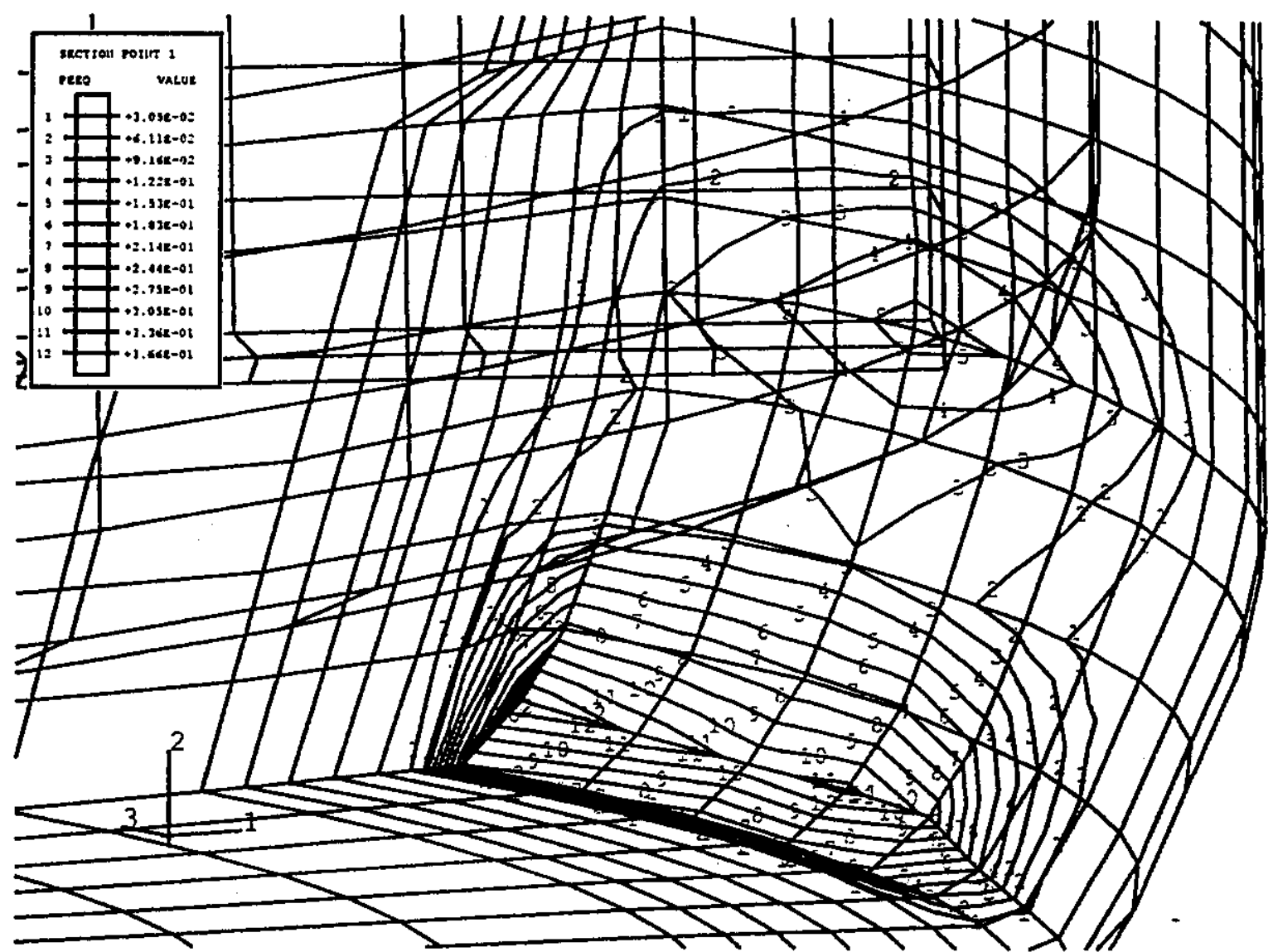

Figure 7.4. Equivalent Plastic Strain at 0.028 Second at High Strain Rate for MCO Drop Onto Storage Tube Assembly. 


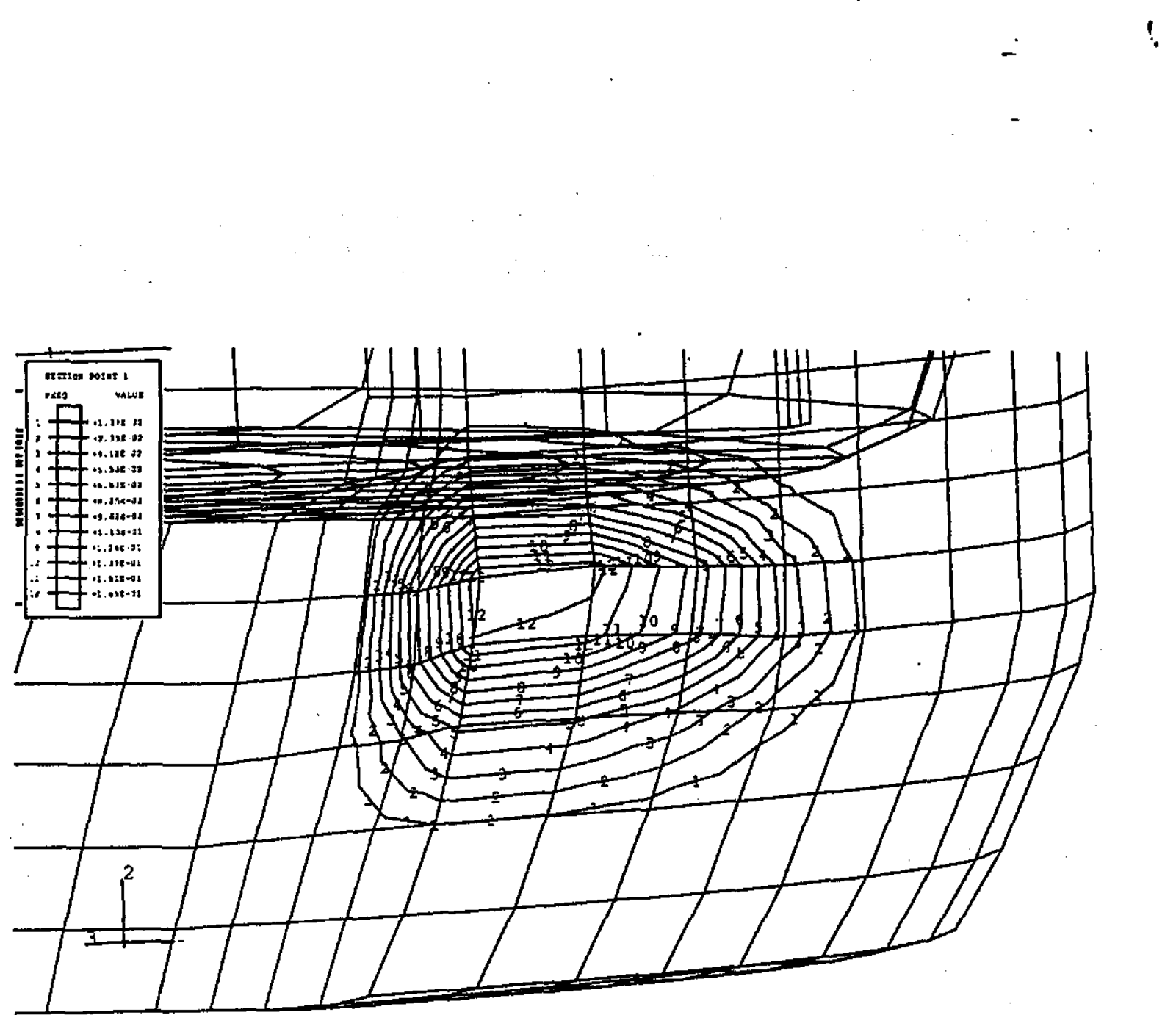

Figure 7.5. Equivalent Plastic Strain at MCO Bottom 0.04 Second After Impact Onto Service Station Shield Hatch Ring. 


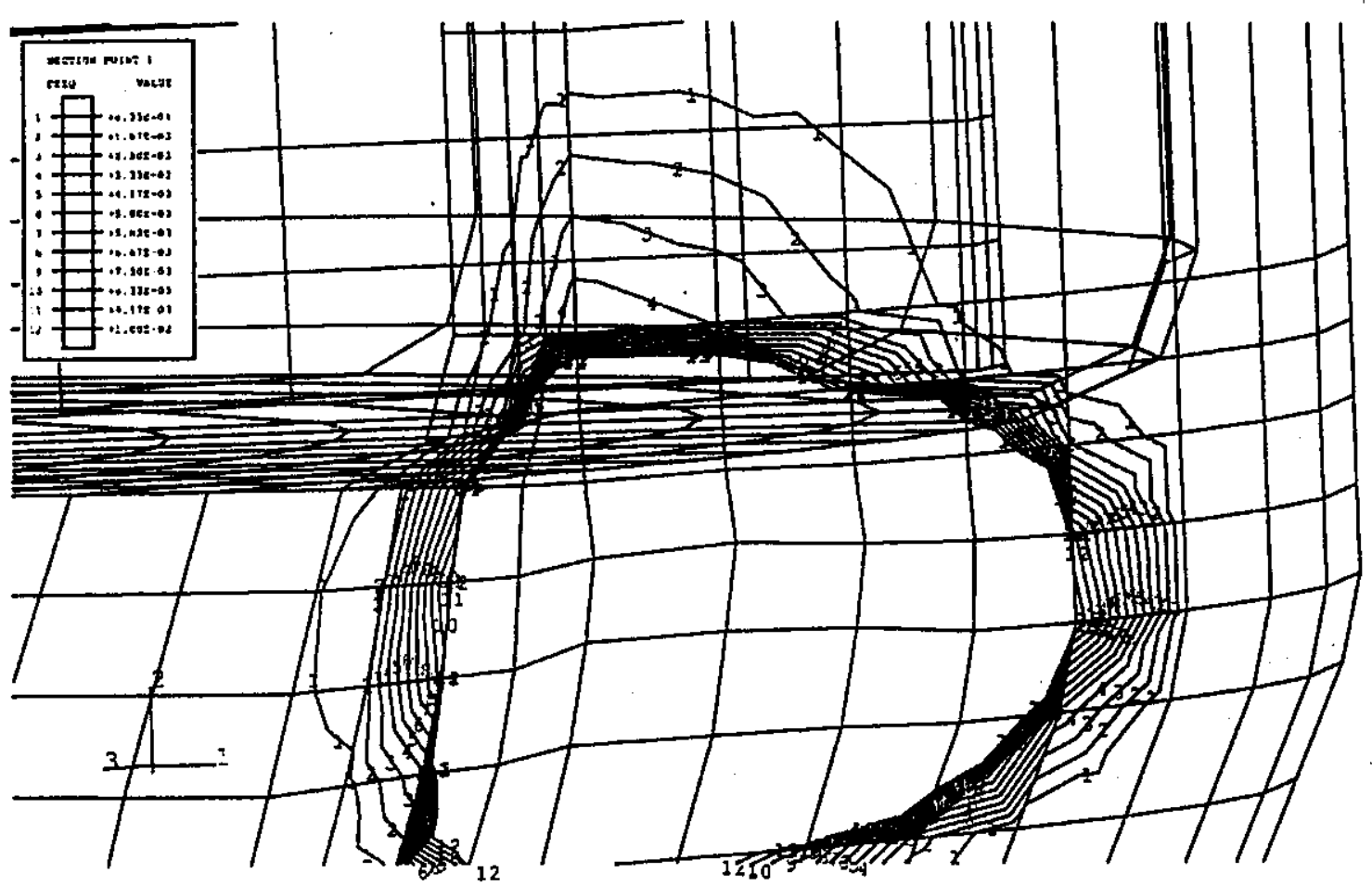

Figure 7.6. Equivalent Plastic Strain Near Lower Weld At 0.04 Second After Impact Onto Service Station Shield Hatch Ring. 


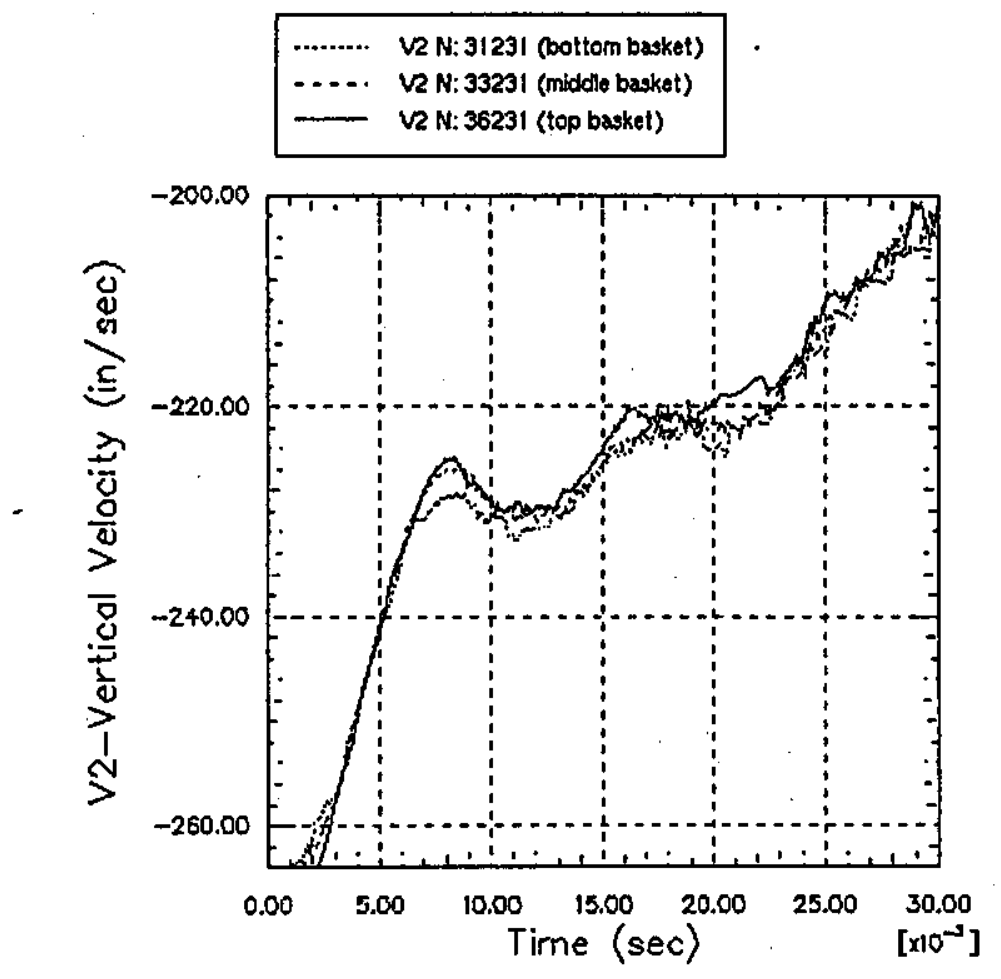

Deceleration of Baskets:

$$
\begin{aligned}
& (260-230) /(.007-.0025) \\
& =6667 \mathrm{in} / \mathrm{sec} / \mathrm{sec} \\
& =17 \mathrm{~g} \\
& \text { say. less than } 20 \mathrm{~g}
\end{aligned}
$$

Figure 7.7. Basket Velocity vs Time of MCO Impact onto Storage Tube Assembly. 
........ v2 x: 21031 (bottom basket)

-.... V2 Hi 33031 (m1ddle basket)

v2 ki 36031 (top baskat)

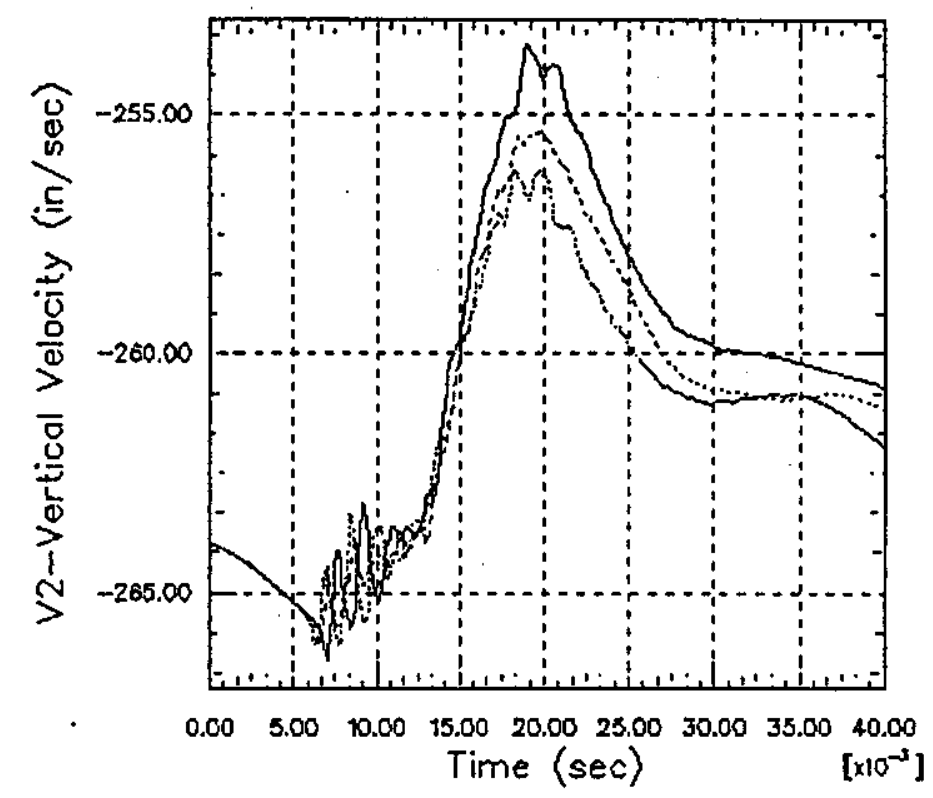

Deceleration of Baskets:

(264-253.5) / (.019-.012)

$=1500 \mathrm{in} / \mathrm{sec} / \mathrm{sec}$

$=3.9 \mathrm{~g}$

say less than $4 \mathrm{~g}$

Figure 7.8. Basket Velocity vs Time of MCO Impact onto Service Station Shield Hatch Ring. 


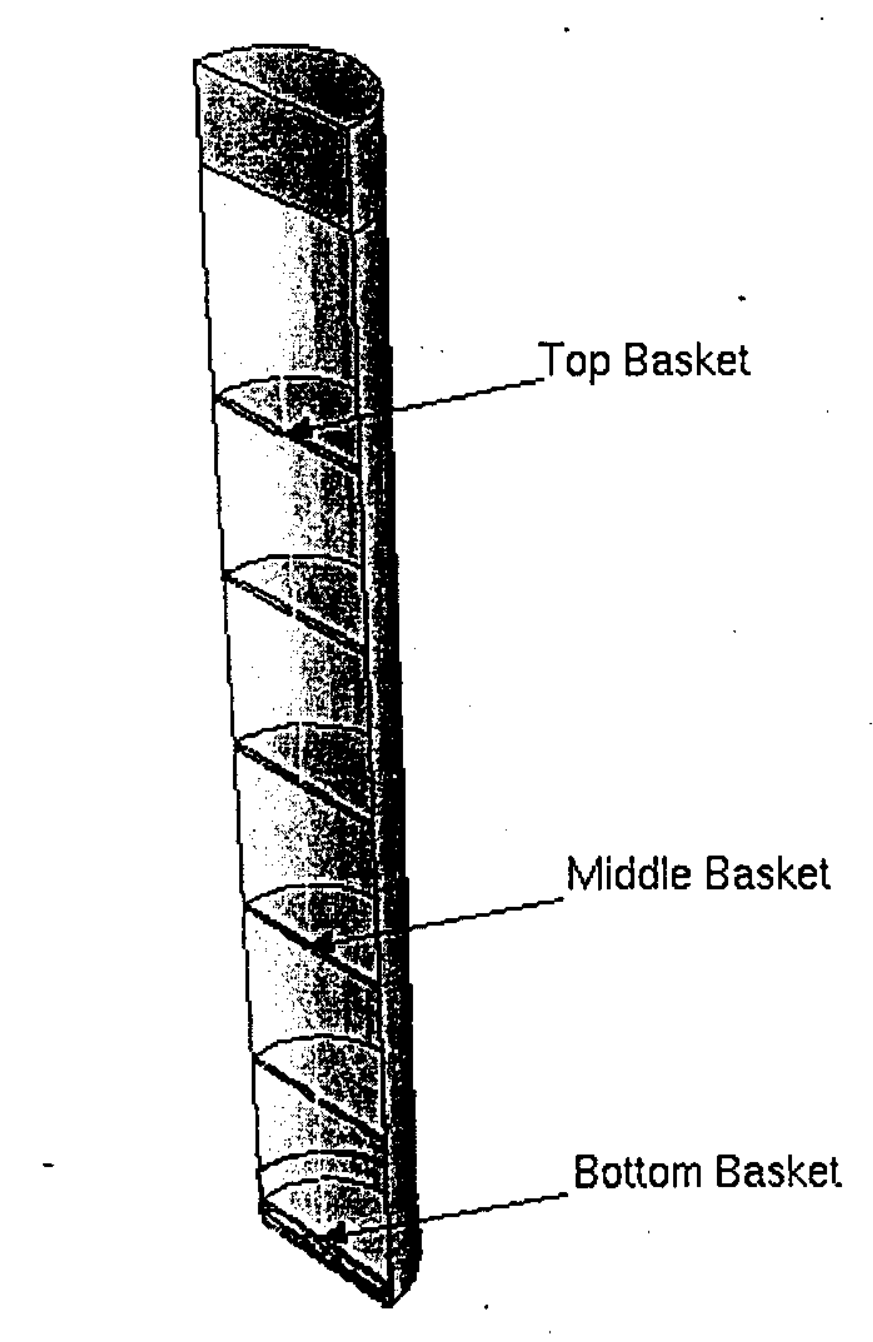

Figure 7.9. Node Locations for Velocity Plot of MCO Drop onto Service Station. 


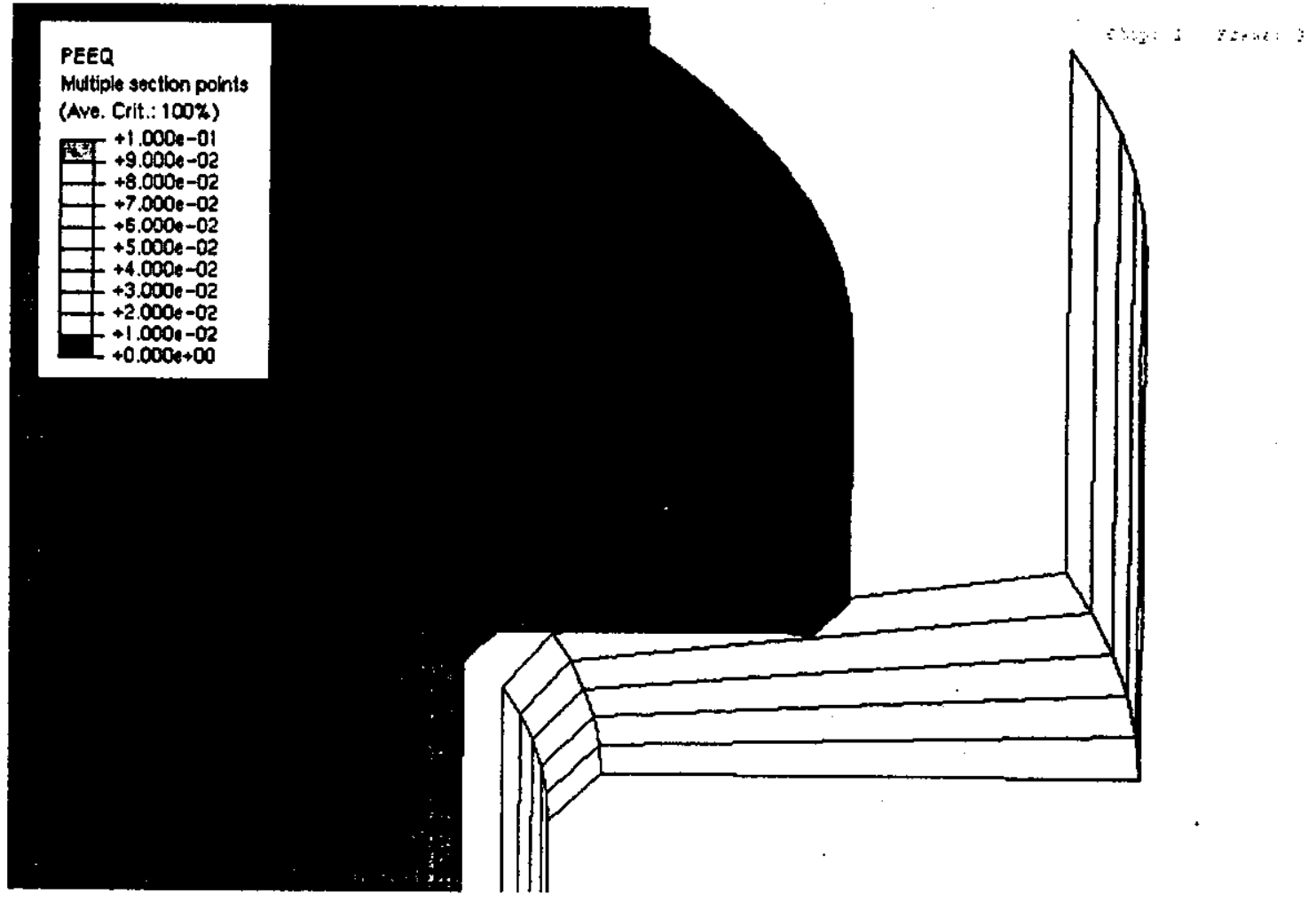

Figure 7.10.a. MCO Drop Animation (Time $=0$ second). 


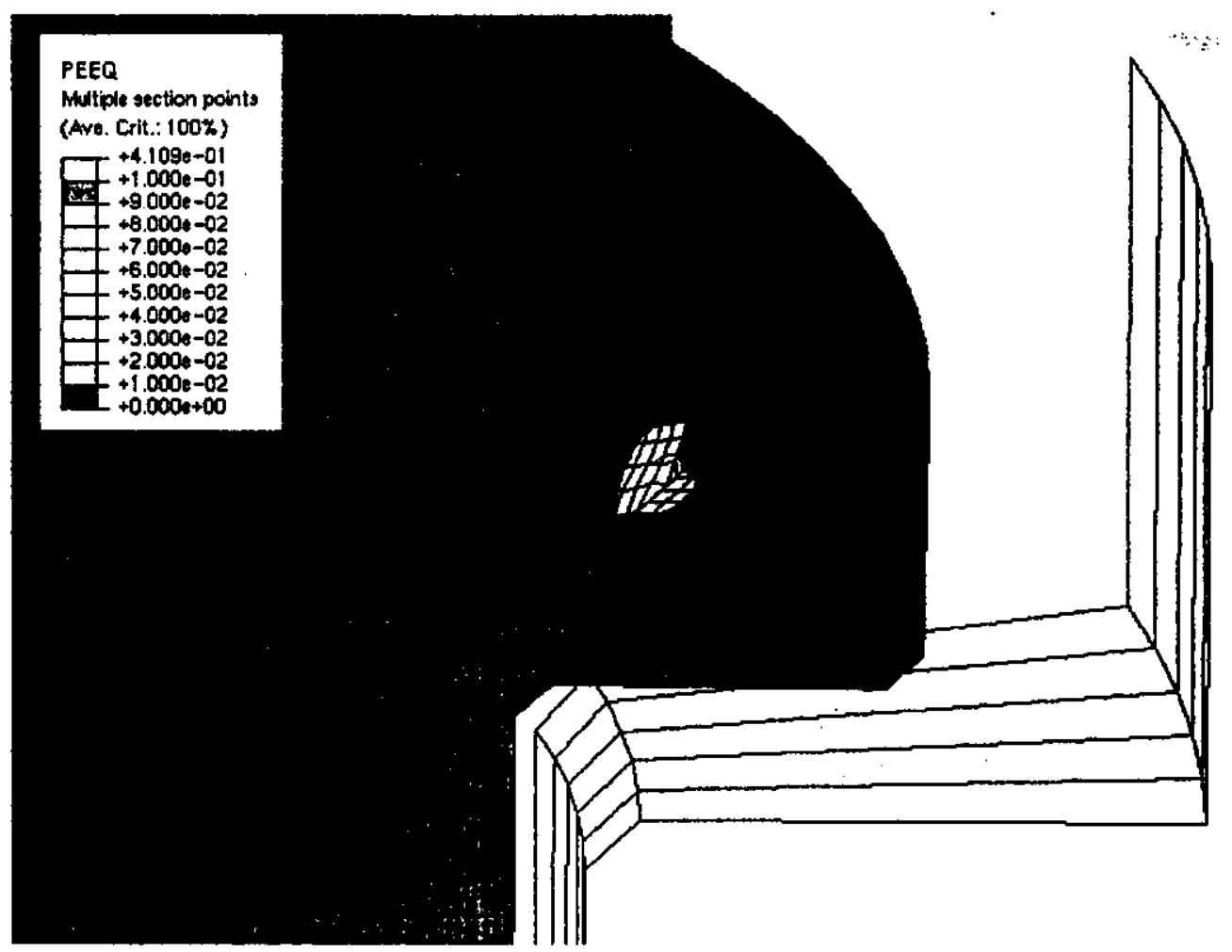

Figure 7.10.b. MCO Drop Animation (Time $=\mathbf{. 0 0 3 7 5}$ second). 


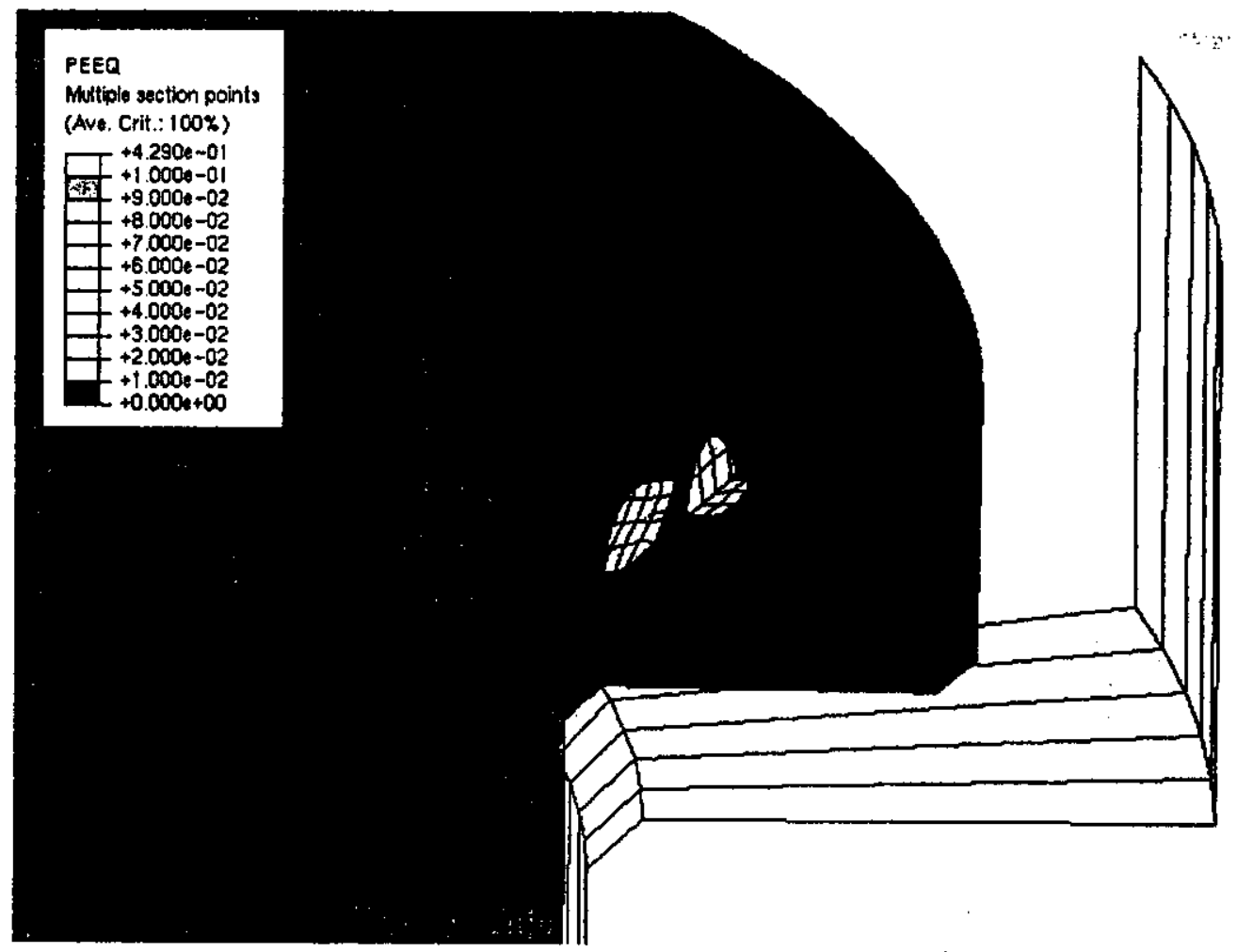

Figure 7.10.c. MCO Drop Animation (Time $=.0075$ second). 


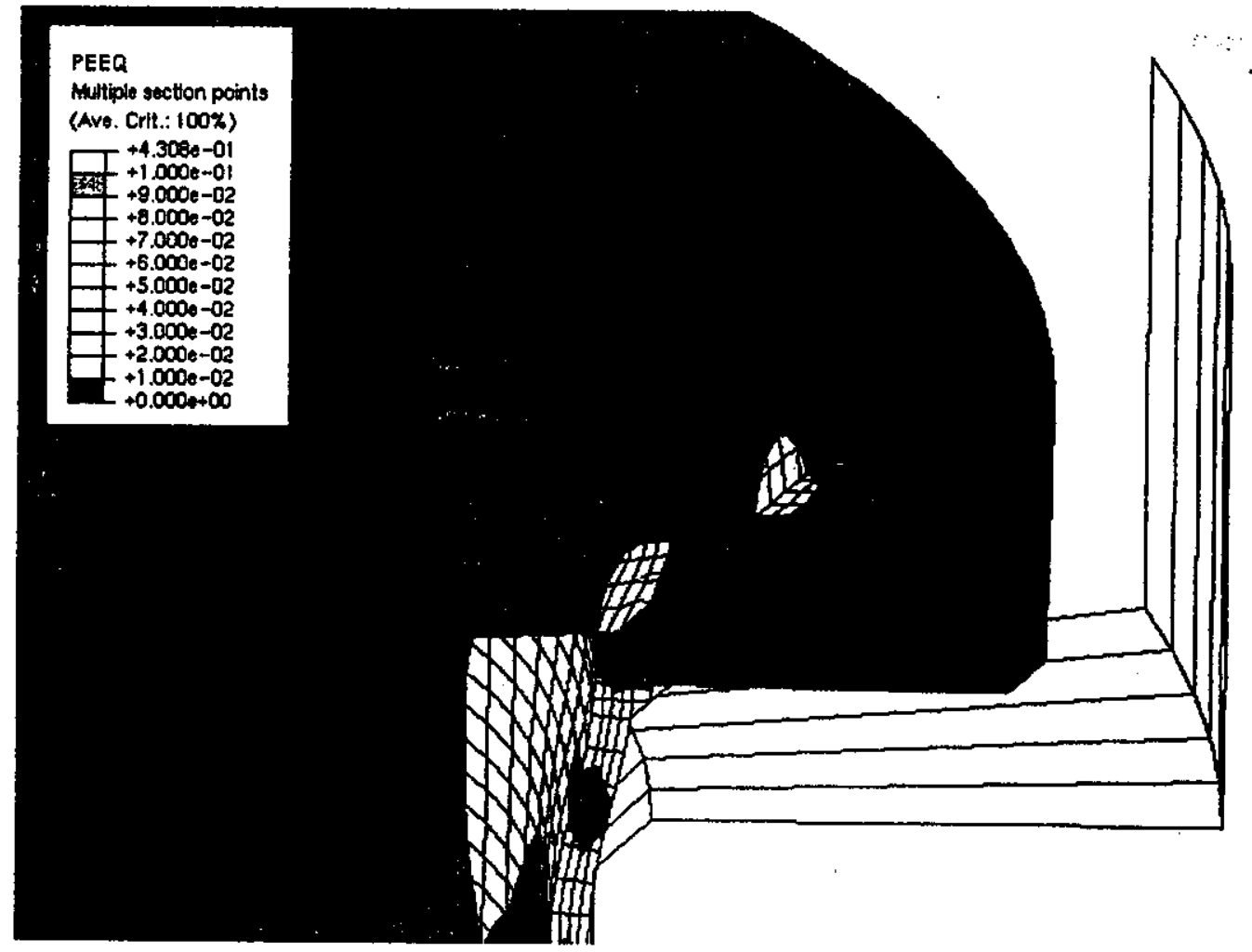

Figure 7.10.d. MCO Drop Animation (Time $=.01125$ second). 


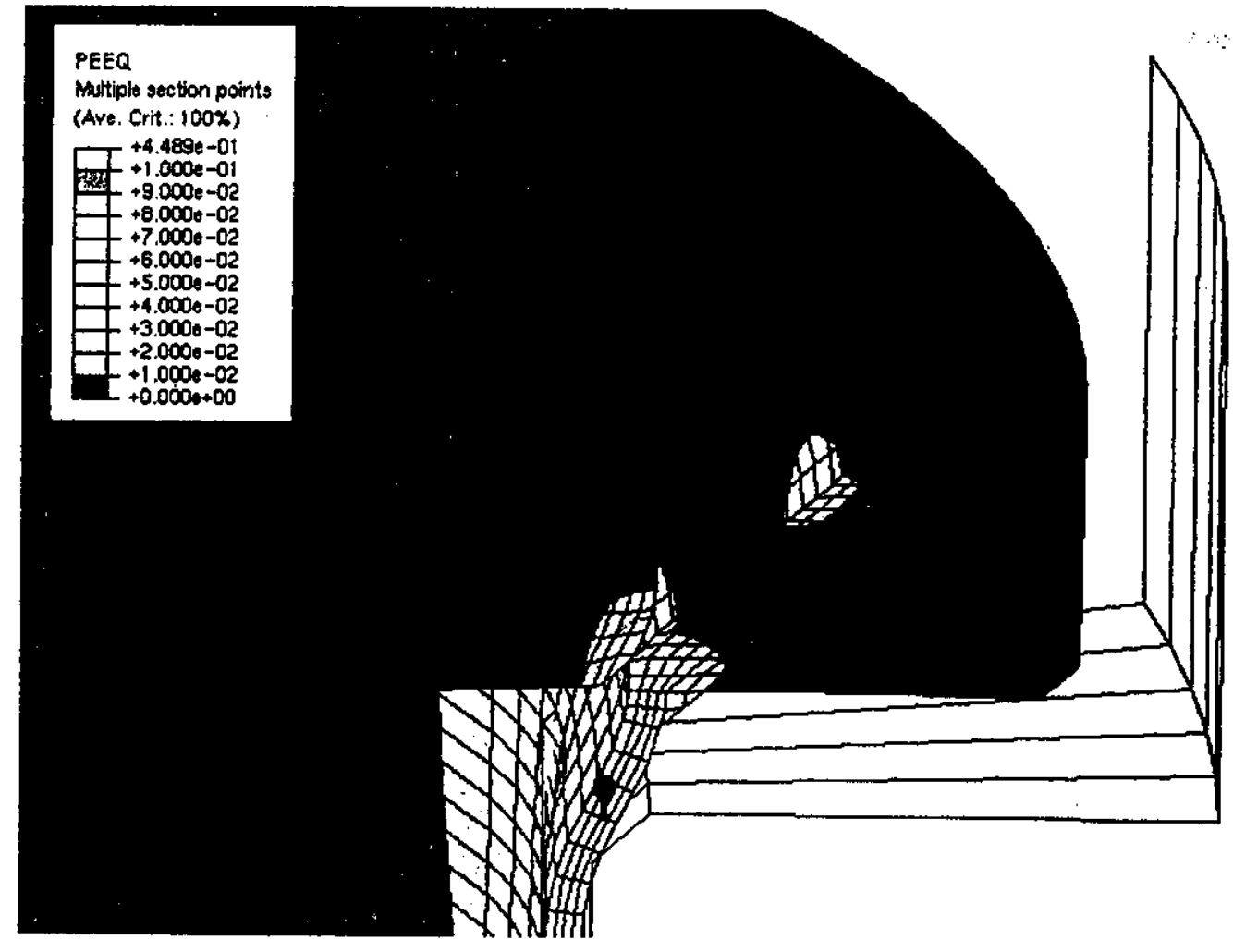

Figure 7.10.e. MCO Drop Animation (Time $=.015$ second). 


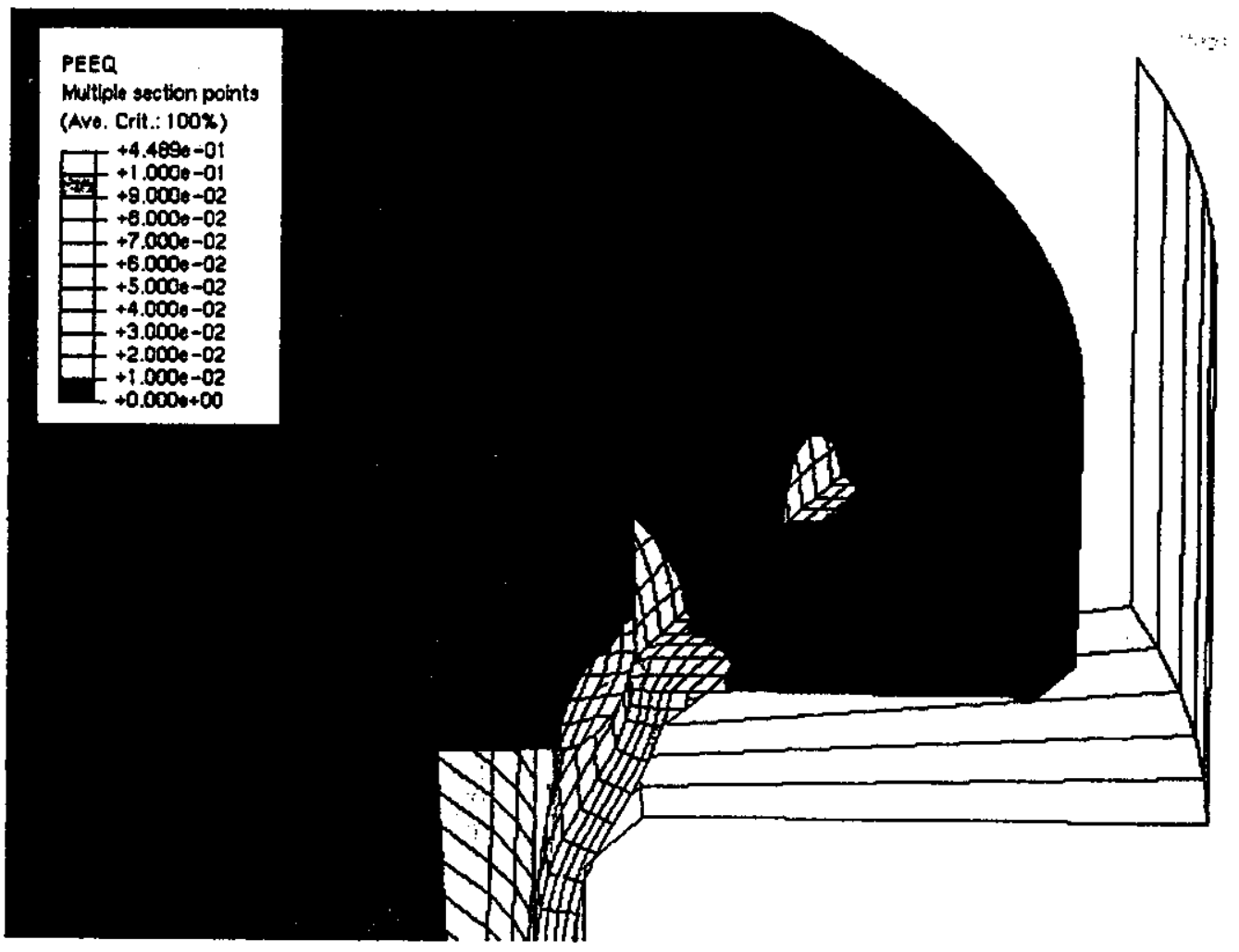

Figure 7.10.f. MCO Drop Animation (Time $=.01875$ second). 


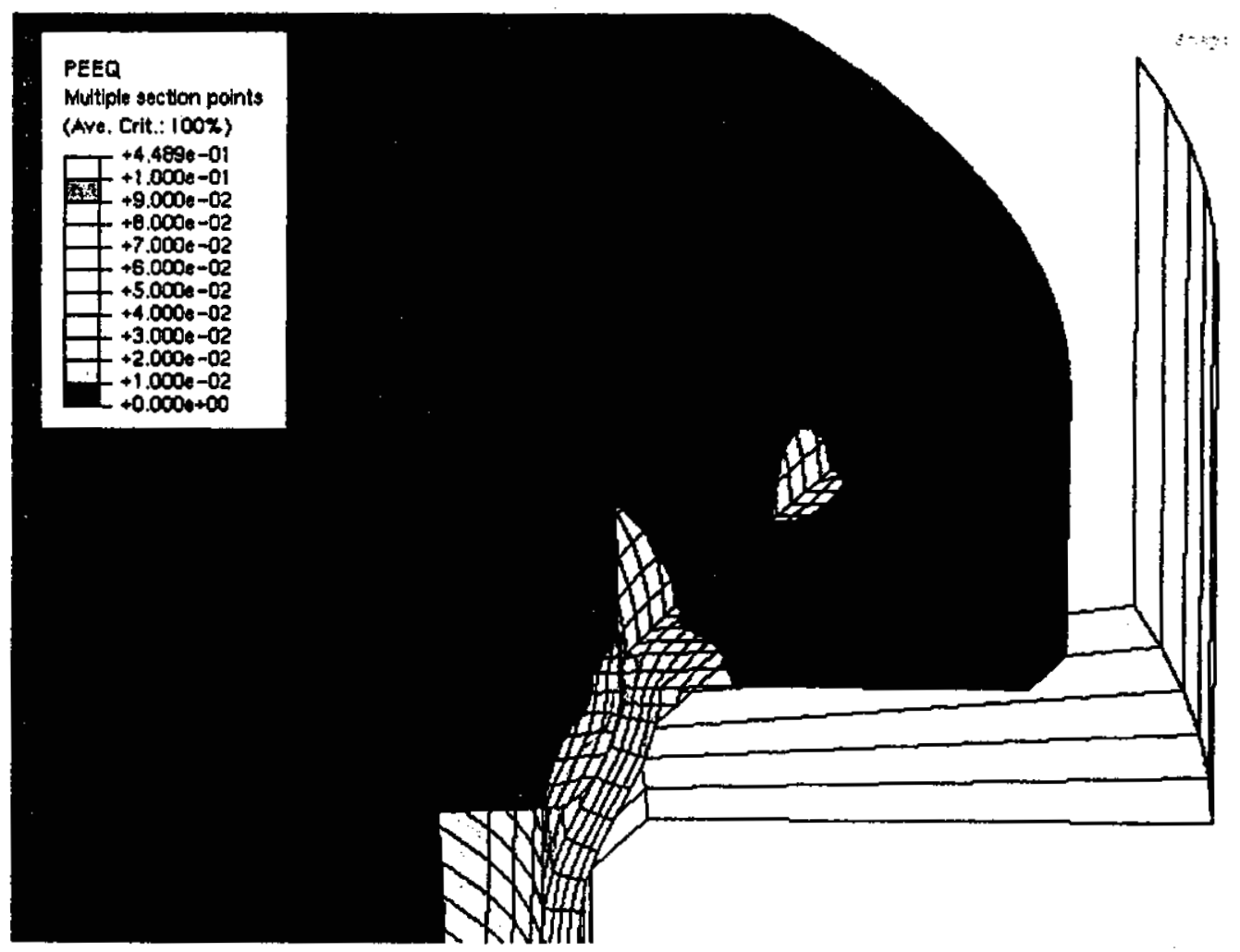

Figure 7.10.g. MCO Drop Animation (Time $=.0225$ second). 


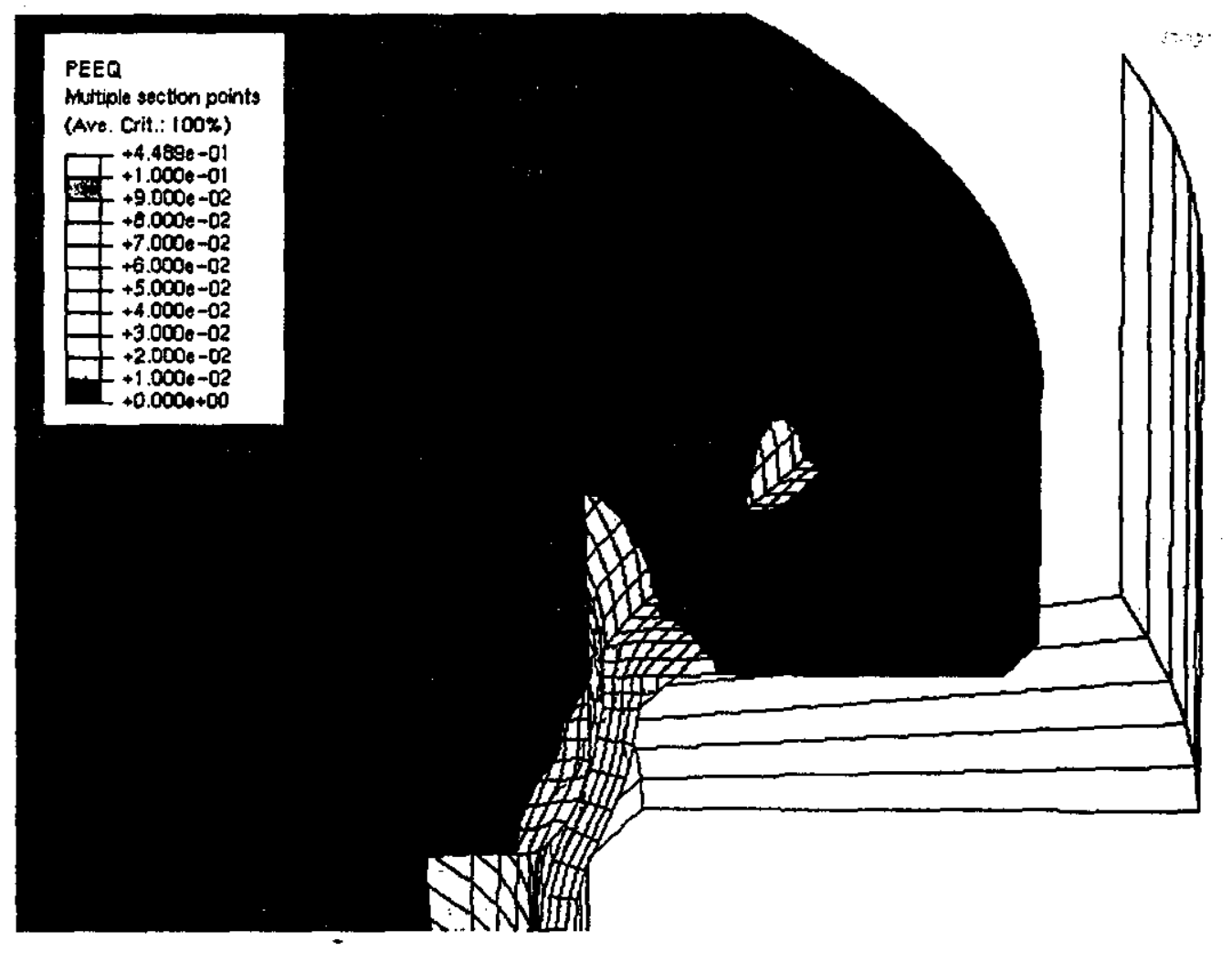

Figure 7.10.h. MCO Drop Animation (Time $=\mathbf{0 2 6 2 5}$ second). 


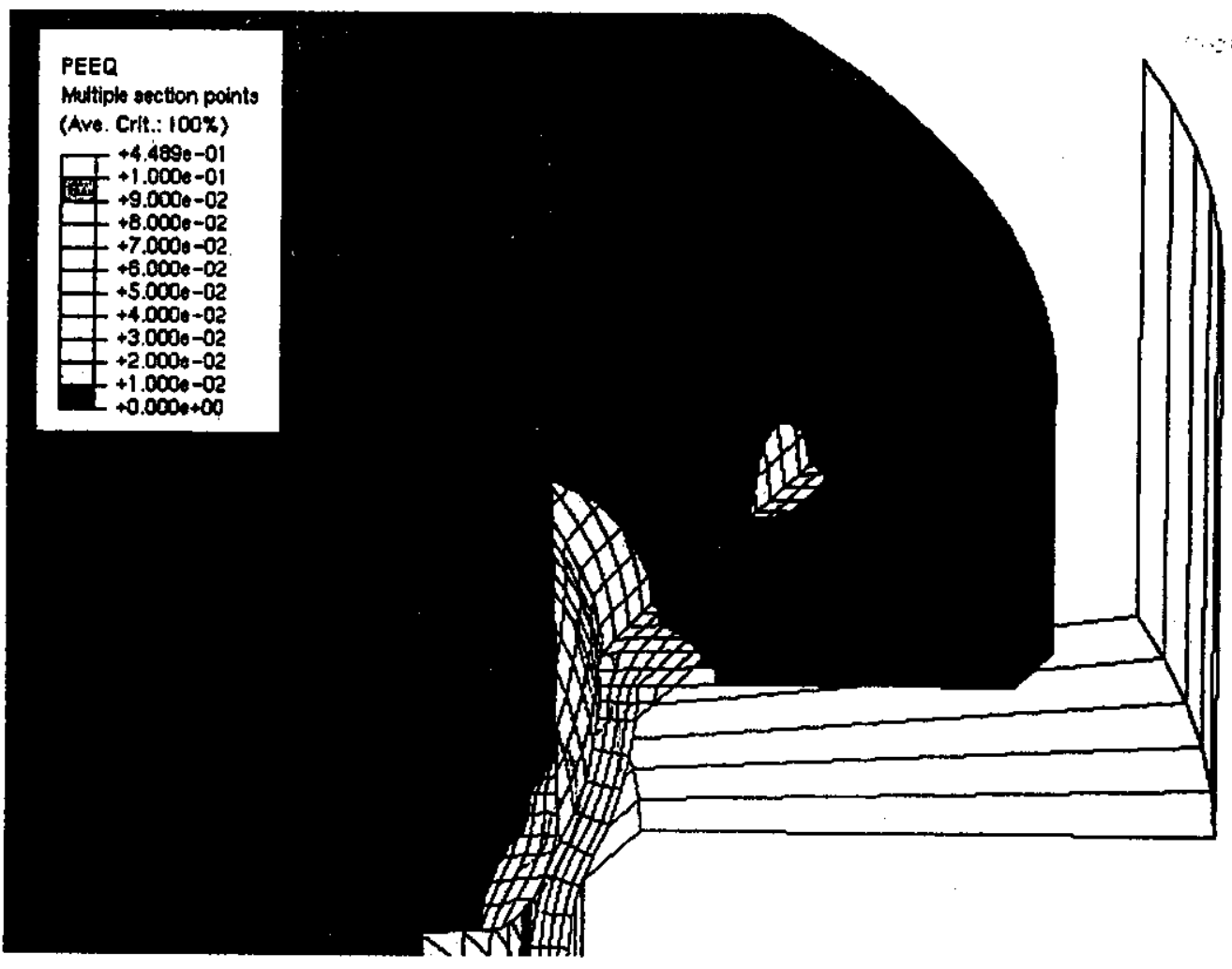

Figure 7.10.j. MCO Drop Animation (Time $=.03$ second). 


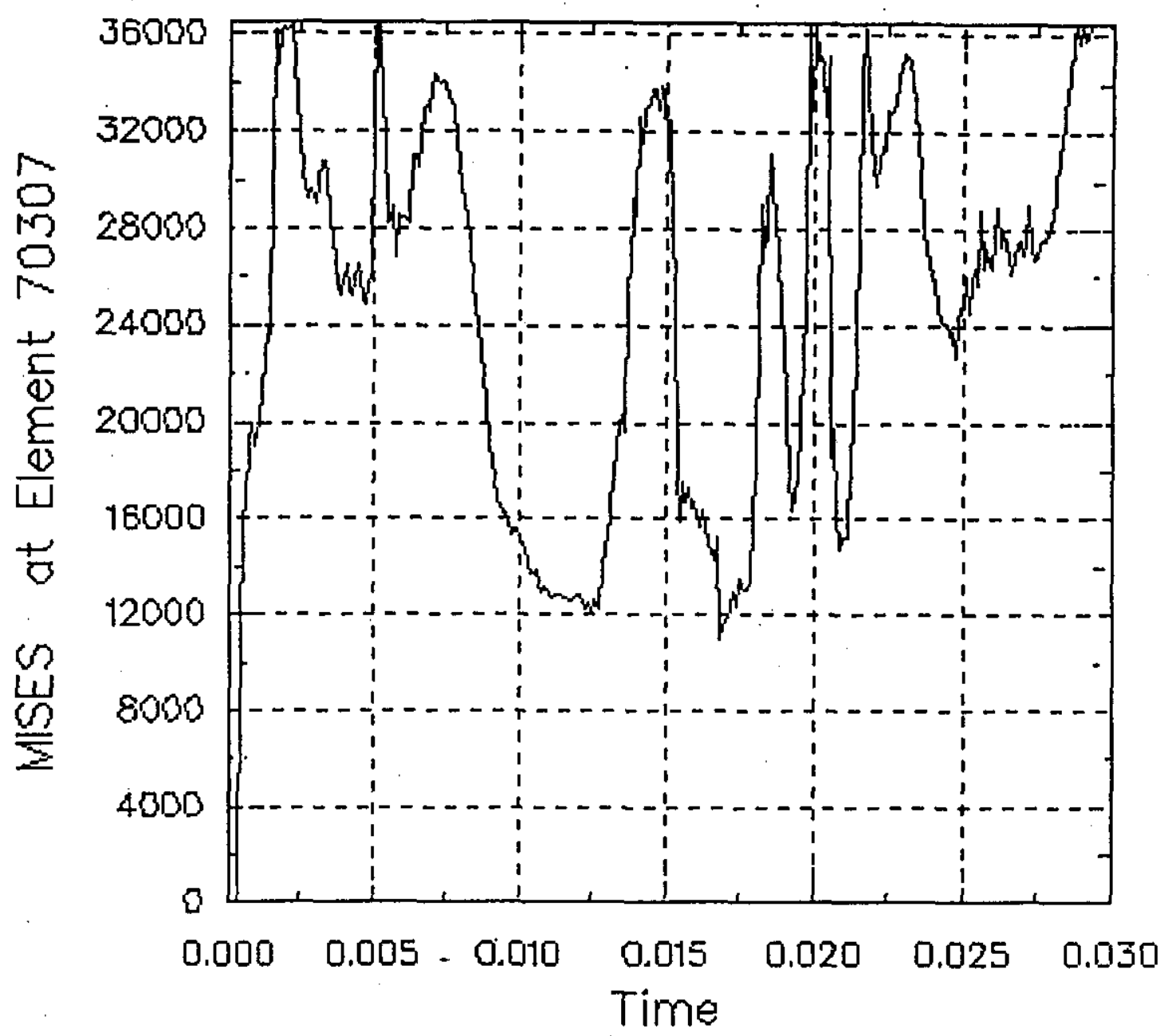

Figure 7.11. Mises Equivalent Stress Time History Plot of Element 70307 near Outside weld. 


\section{MISES S: 70019 IP: 1 BLSET 2007}

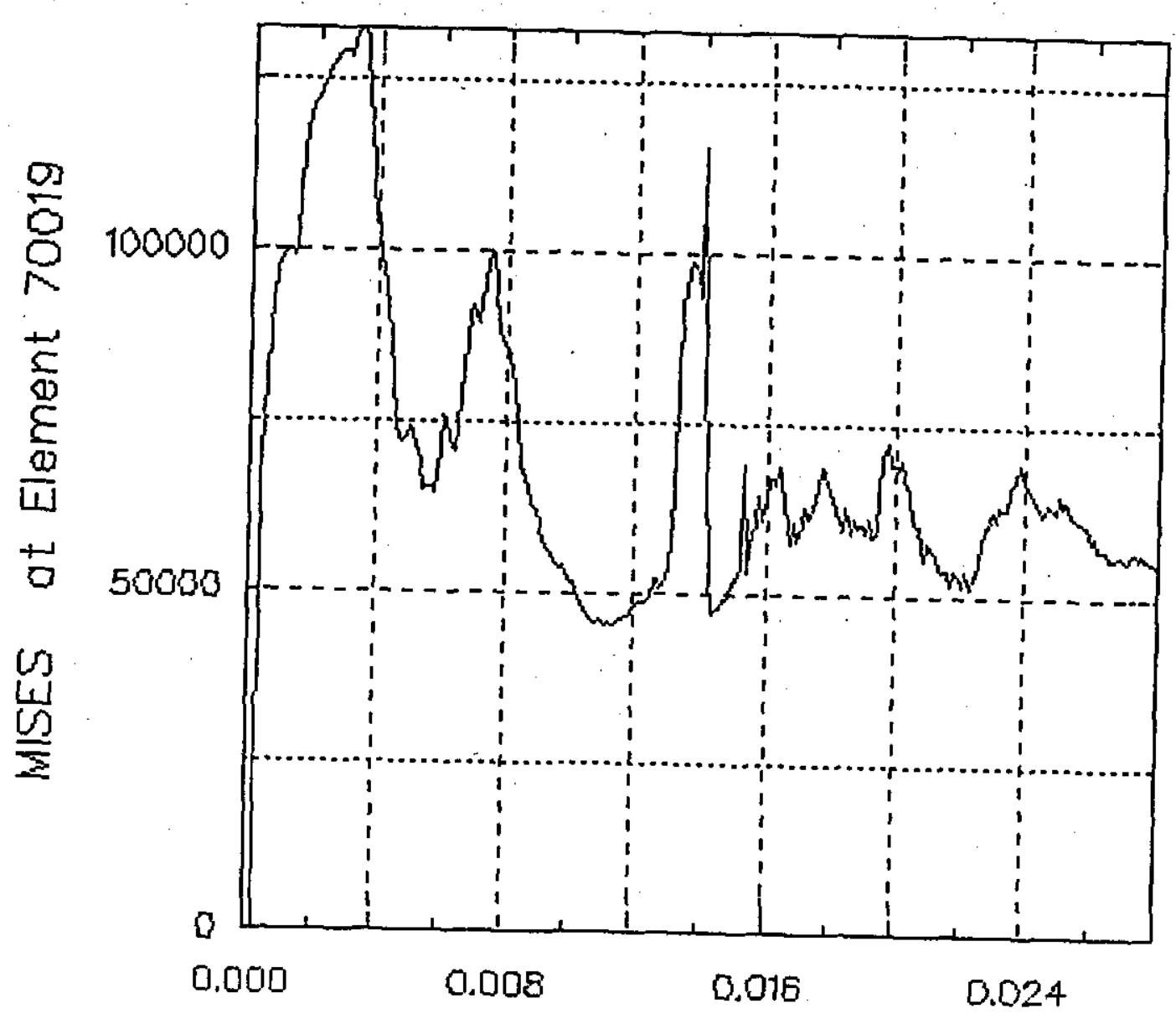

Time

Figure 7.12. Mises Equivalent Stress Time History Plot of Element 70019 at MCO bottom near Impact location. 


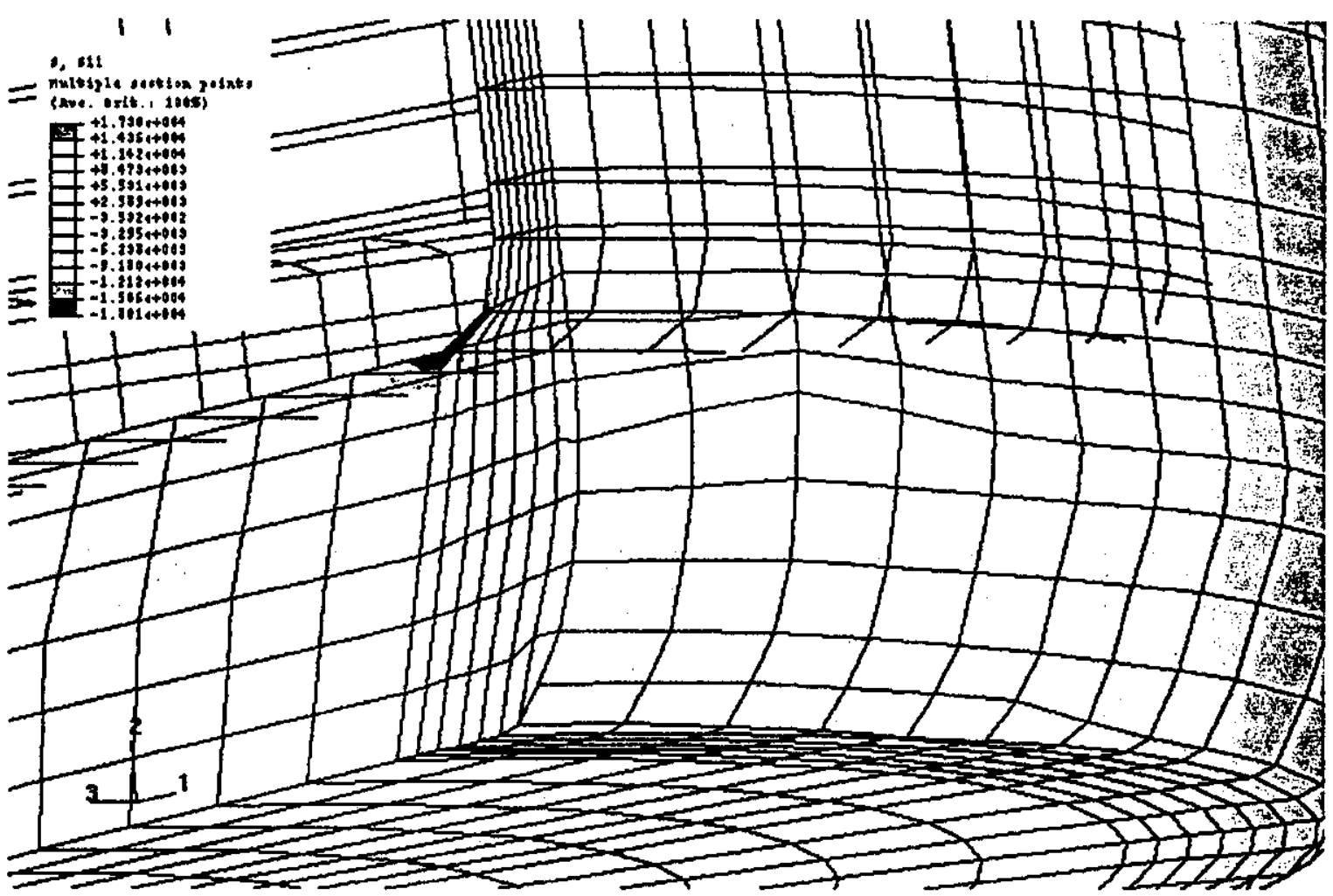

Figure 7.13. Stress in Radial Direction (direction 1) at Time 0.03 Second. 


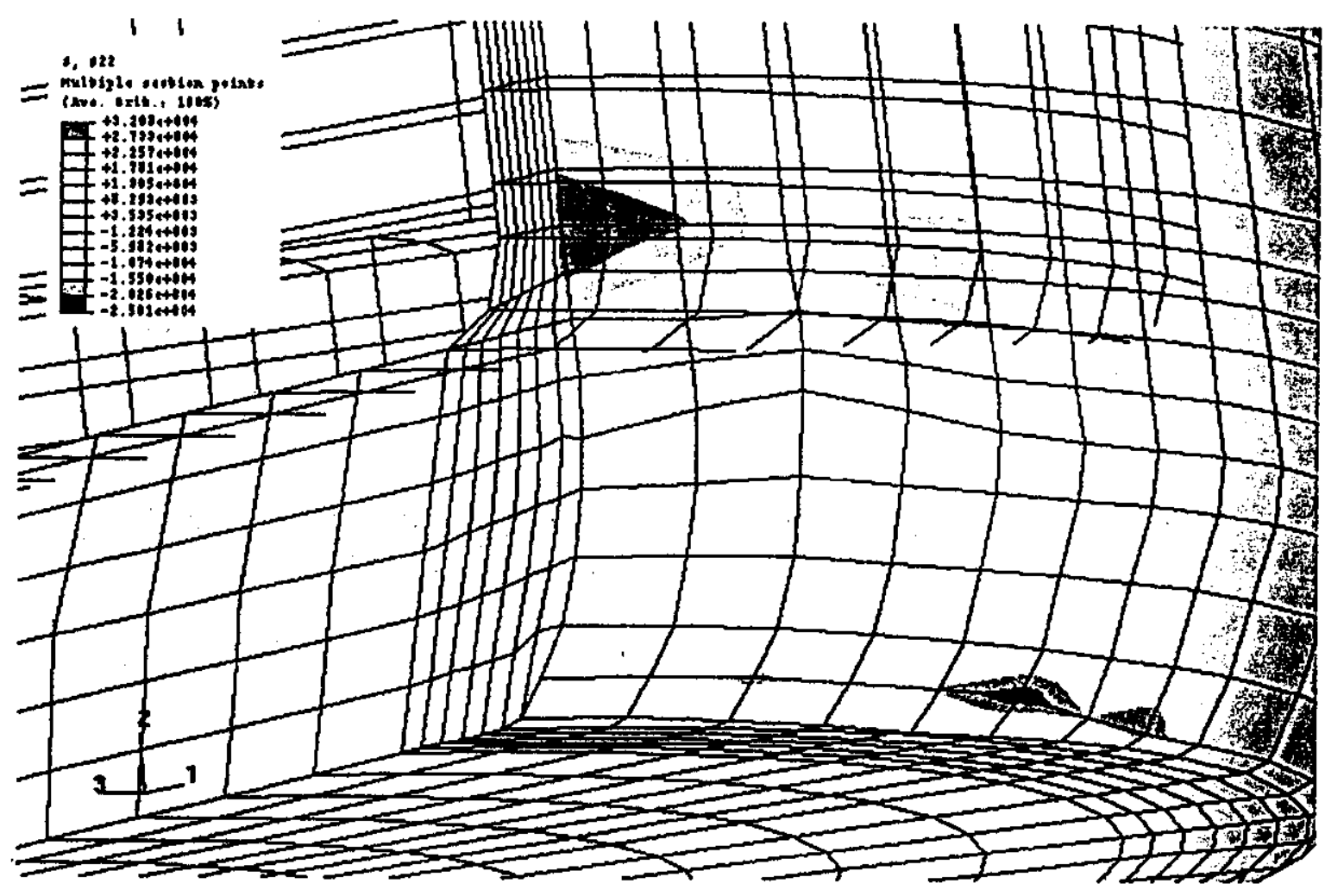

Figure 7.14. Stress in Meridian Direction (direction 2) at Time 0.03 Second. 


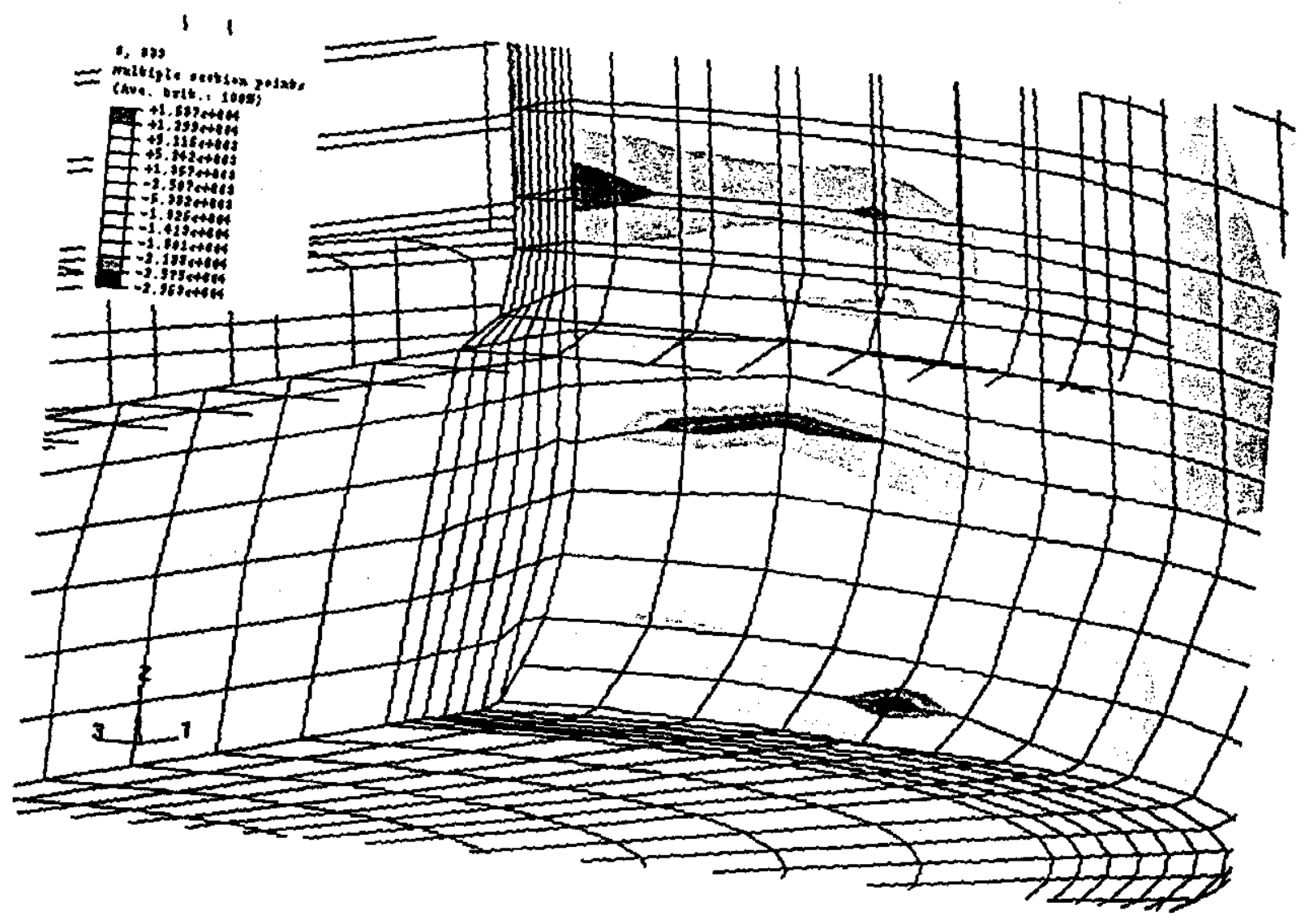

Figure 7.15. Stress in Hoop Direction (direction 3) at Time 0.03 Second. 


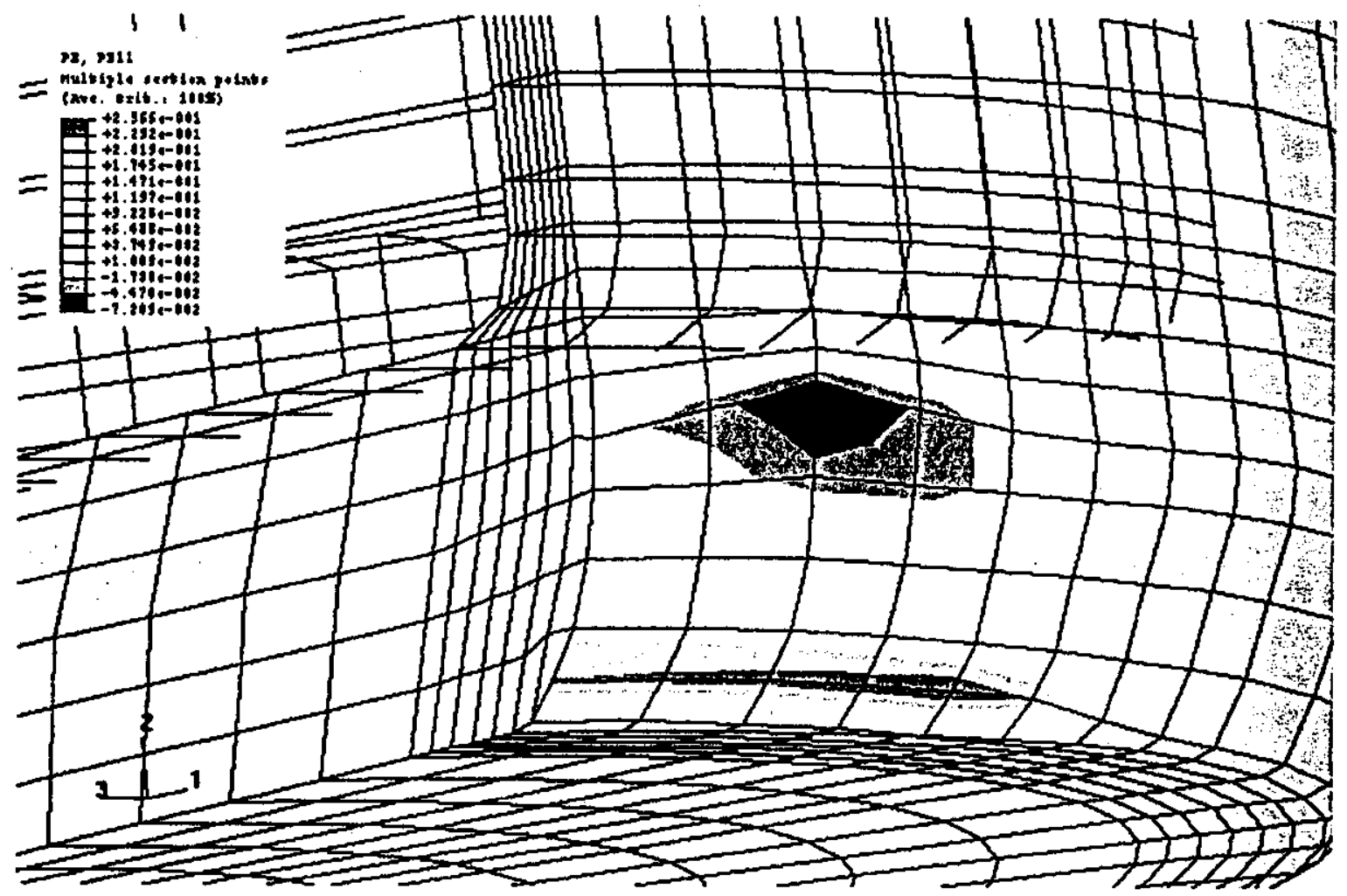

Figure 7.16. Plastic Strain in Radial in Direction (direction 1) at Time 0.03 Second. 


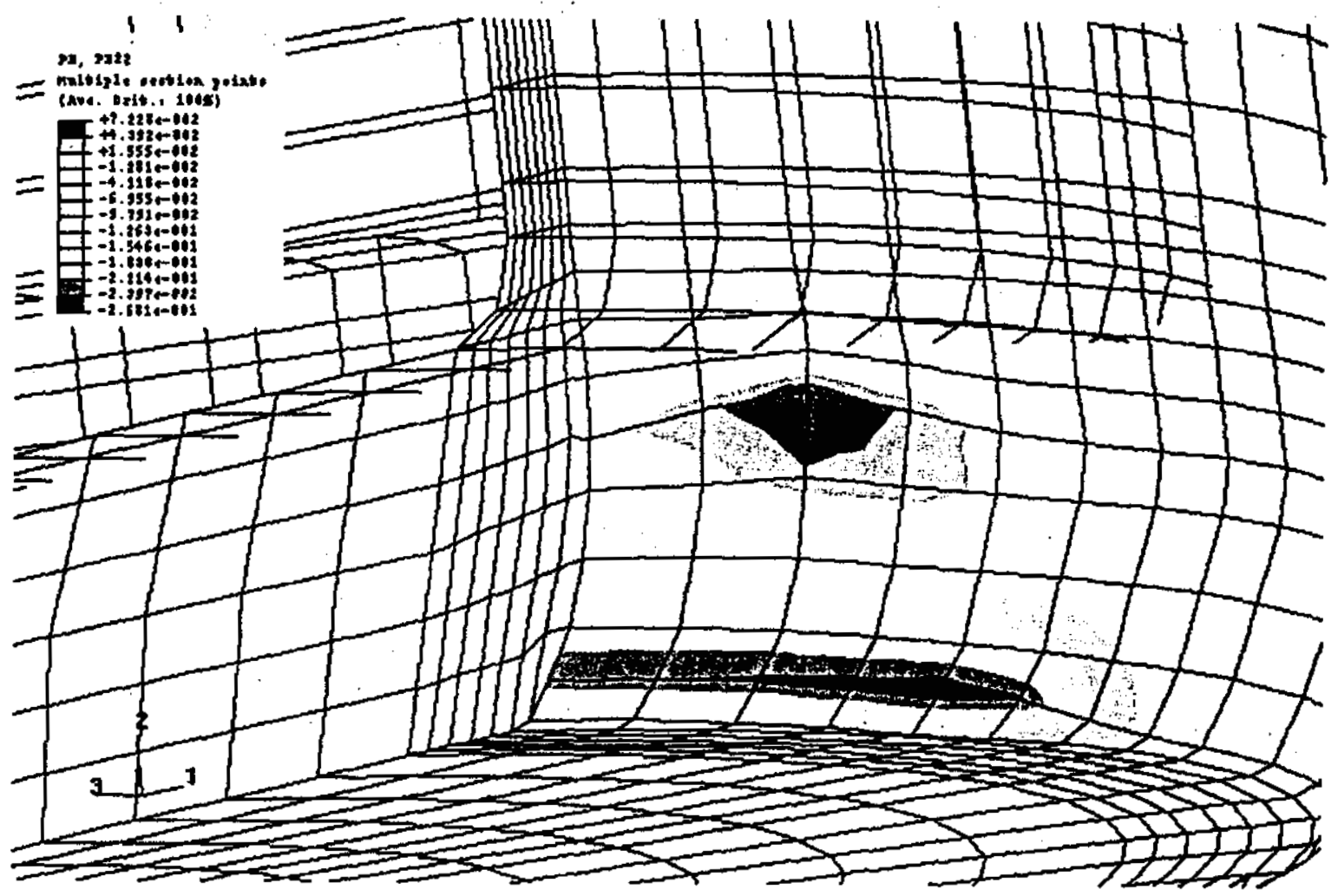

Figure 7.17. Plastic Strain in Meridian Direction (direction 2) at Time 0.03 Second. 


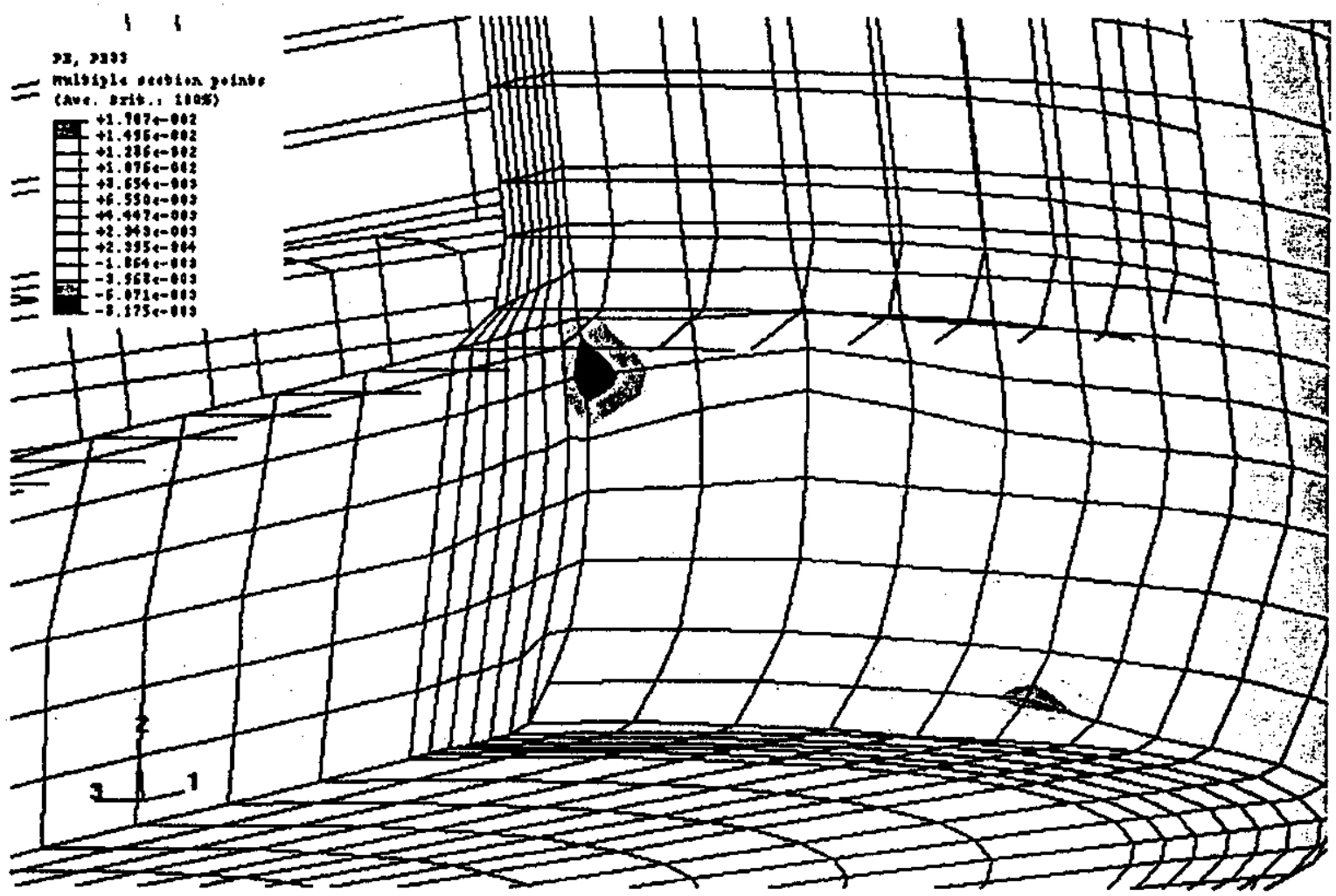

Figure 7.18. Plastic Strain in Hoop Direction (direction 3) at Time 0.03 Second. 


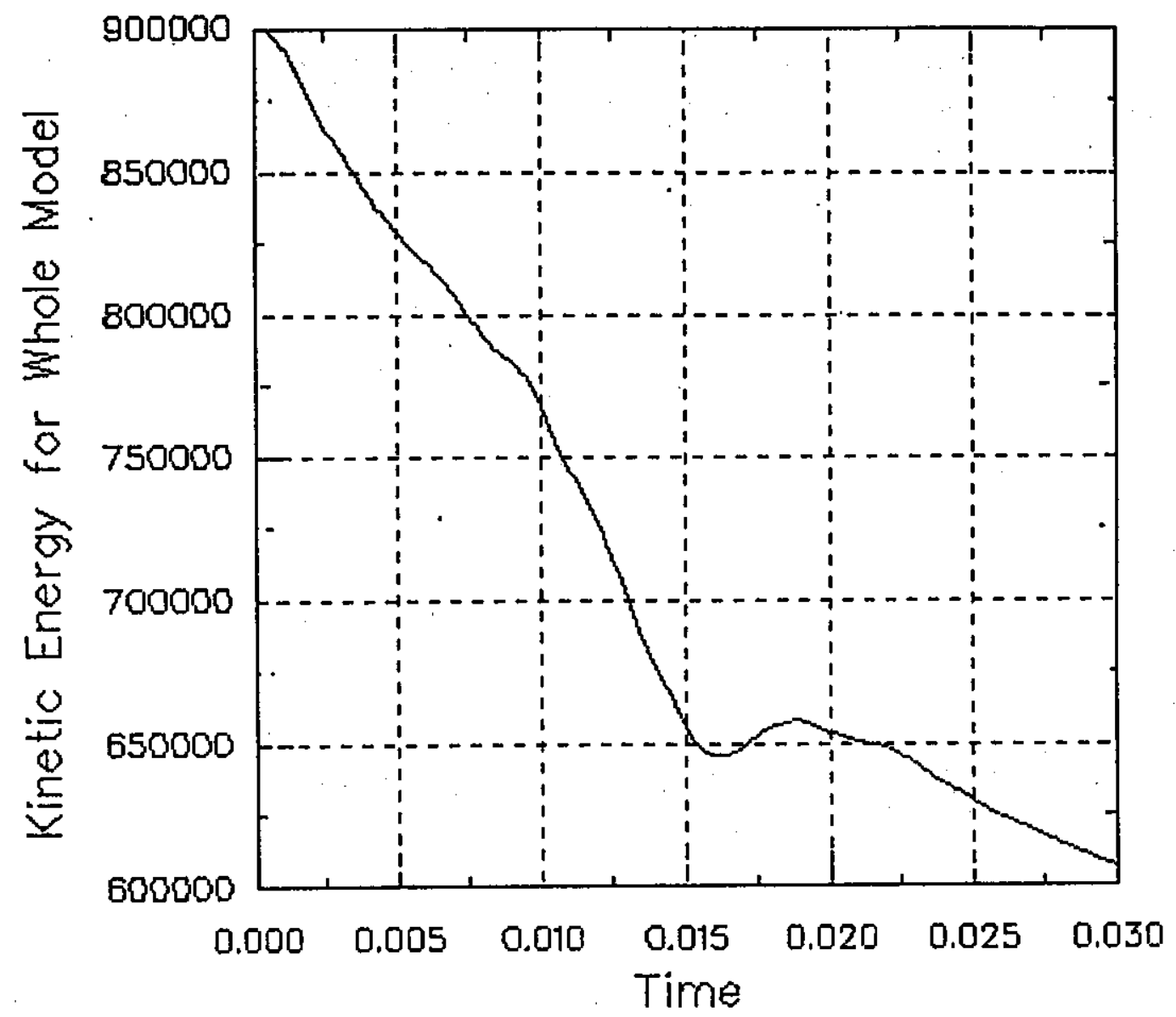

Figure 7.19. Total Kinetic Energy Time History of the MCO Drops onto the Standard Storage Tube Assembly 


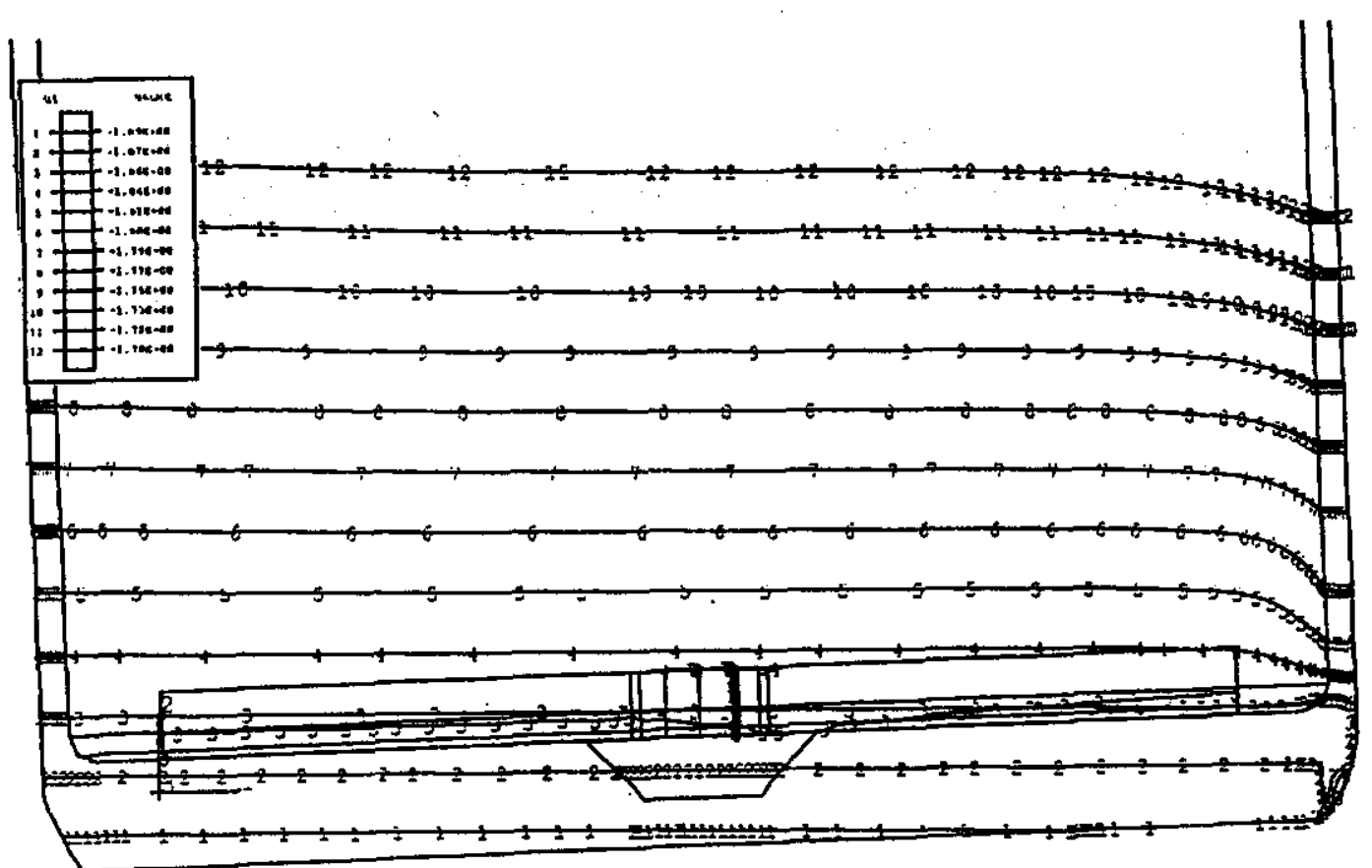

Figure 7.20. MCO Deformations. 


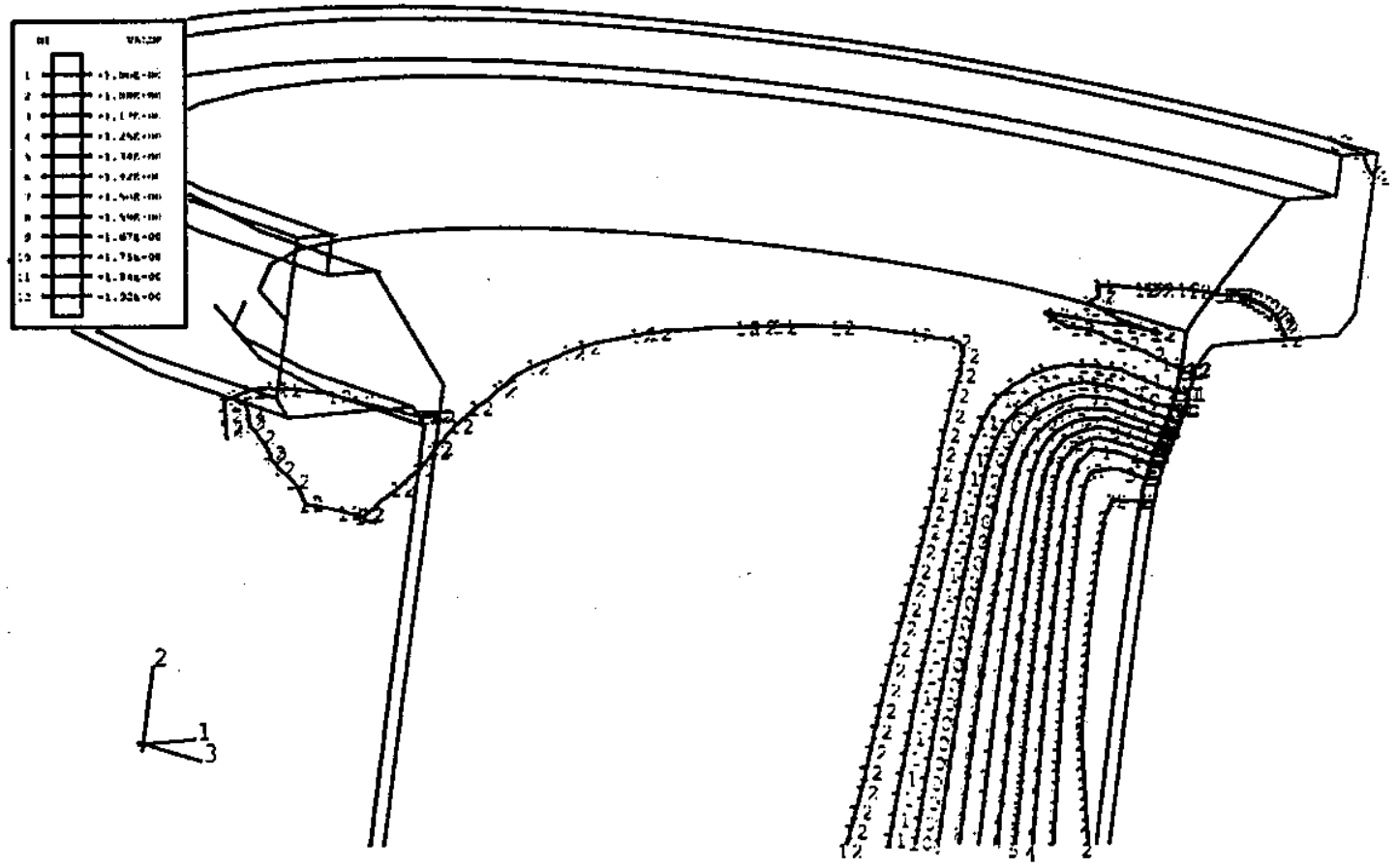

Figure 7.21. Standard Storage Tube Deformations. 


\subsection{FAILURE CRITERIA}

(Discussion and criteria provided by Larry Blackburn, Metallurgy Consultant to DESH/FDH.)

Failure of the MCO will not occur if the maximum principal strain resulting from the drop is below a value that could initiate local cracking. The multi-axial loading and deformation associated with the drop need to be considered in evaluating limits on maximum principal strain. Manjoine (4) has proposed that the tensile elongation measured in a tension test can be adjusted to predict multi-axial failure strain by the relation.

$$
\begin{aligned}
& \frac{\bar{\epsilon}}{e_{1}}=2^{(1-T H)} \text { for } T F \geq 0, \text { and } \\
& \frac{\bar{\epsilon}}{e_{\iota}}=2 \text { for } T F \leq 0
\end{aligned}
$$

where $\bar{\epsilon}$ is the effective (Mises) strain at failure,

$e_{t}$ is the tensile elongation from tension test, and

TF is the stress state triaxiality factor.

The ratio of the Mises strain at failure divided by the uniaxial tensile elongation is a measure of relative ductility between multi-axial and uniaxial stress states. Ductility given by Equation (1) increases as the Triaxiality factor decreases from one and decreases as the triaxiality factor increases from one as shown in Figure 8.1 below.

The effective strain and triaxiality factor is defined by the relations

$\bar{\epsilon}=\frac{\sqrt{2}}{3}\left[\left(\epsilon_{1}-\epsilon_{2}\right)^{2}+\left(\epsilon_{2}-\epsilon_{3}\right)^{2}+\left(\epsilon_{3}-\epsilon_{1}\right)^{2}\right]^{1 / 2}$

where $\epsilon_{1}, \epsilon_{2}$ and $\epsilon_{3}$ are the principal strains, and

$T F=\frac{\sqrt{2}\left(\sigma_{1}+\sigma_{2}+\sigma_{3}\right)}{\left[\left(\sigma_{1}-\sigma_{2}\right)^{2}+\left(\sigma_{2}-\sigma_{3}\right)^{2}+\left(\sigma_{3}-\sigma_{1}\right)^{2}\right]^{\frac{1}{2}}}$

where $\sigma_{1}, \sigma_{2}$, and $\sigma_{3}$ are the principal stresses. 


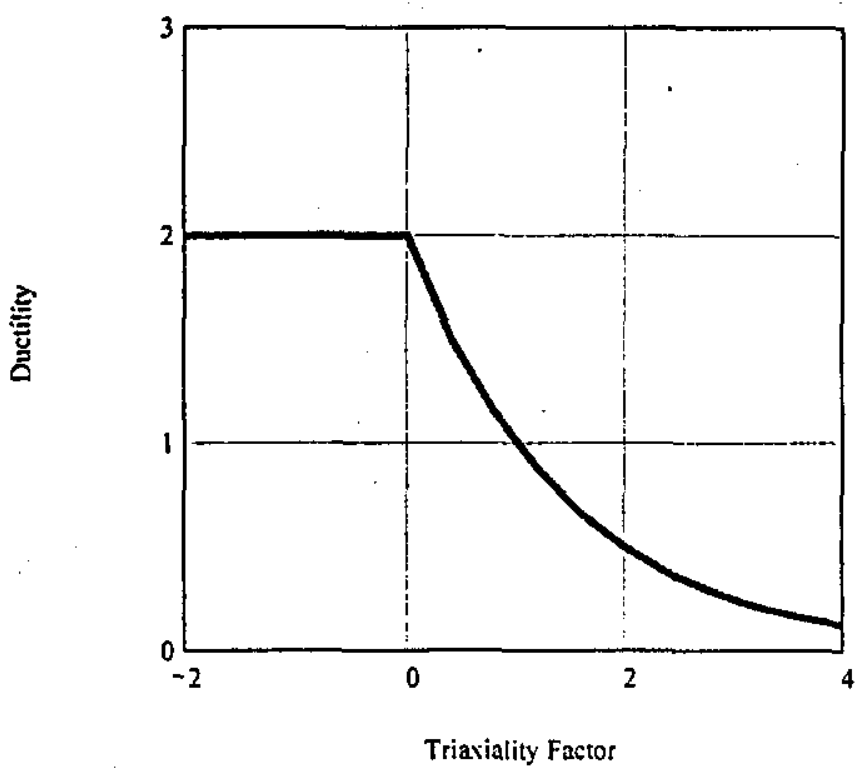

Figure 8.1 Ductility vs Triaxiality Factor.

Manjoine indicates support for the correlation from several alioys, but does not cite the specific references for the test data. A pressure vessel burst test program sponsored by the Pressure Vessel Research Committee (PVRC) provides support for the Manjoine correlation. Boyer and Rolfe (5) report that $\epsilon$ measured after bursting by internal pressure of a smooth pressure vessel made of carbon steel was 0.236 , while $e_{t}$ was 0.33 . These results are in good agreement with Equation (1a). A test on a second pressure vessel containing an intentional notch reduced $\epsilon$ to 0.125 . Goller et al (6) report failure strains in pressurized discs (both smooth and reinforced) of alloy steel that are twice as large as the tensile elongation. These multi-axial failure strains in discs are much higher than would be predicted by the Manjoine correlation. Several researchers (Blejwas [7], Clauss [8], and Horschel [9]) report results for bursting of sub-scale models of nuclear reactor containment structures of carbon steel. In a simple $1 / 32$-scale model, failure strains were about 0.21 for a smooth geometry, and about 0.16 for geometry containing penetrations (Reference 7 ). The tensile elongation for the steel was not reported, but the multi-axial failure strains are similar to those cited above for the PVRC vessels. Containment models that were $1 / 8$ and $1 / 6$ scale (References $8 \& 9$ ) were geometrically more complex and contained various penetrations, hatches, and stiffening rings. Localized failure strains were not measured directly, but indicated strain gage readings for the $1 / 8$ scale test would suggest local failure strain exceeded 0.08 . 
In these models, failures initiated at a formed stiffener adjacent to the reinforcement at an equipment hatch penetration ( $1 / 8$ scale model), and at a thickened region around a penetration ( $1 / 6$ scale model). Both models were loaded beyond general yielding, and the free-field strains (i.e.; away from geometric discontinuities) were in the range 0.013 to 0.031 when ultimate failure occurred.

The MCO being analyzed in the present evaluation exhibits a smooth geometry without any discontinuities or notches that would reduce failure strains below those predicted from the Manjoine correlation.

For assessment of the weld region, the tensile elongation should be based on tests of weld metal. Results from thirteen different welds (References 10 \& 11) tested at room temperature were used to determine tensile elongation. These welds were produced using various welding procedures and represent $308,16-$ $8-2$, and 316 stainless steel weld metal compositions. For a total of 27 tension tests on as-deposited welds, the mean value of $e_{i}$ is 0.37 with a standard deviation of 0.078 . Defining the minimum value of $e_{1}$ as the mean value minus twice the standard deviation, $e_{\ell}$ (min.) is 0.214 .

For assessment of base metal regions, the specification minimum value for $e_{1}$ of $304 \mathrm{~L}$ stainless steel base metal is $40 \%$ based on uniaxial tensile test at "low" (nominal) strain rate. The maximum acceptable value of $e_{t}$ for $304 \mathrm{~L}$ stainless steel base metal is therefore about twice that for the weld metal. 


\subsection{DISCUSSION}

Results of the inelastic analysis calculations include the following significant findings.

- Failure Criteria.

Conservative failure strain levels were predicted for both welds and parent 304L stainless steel material, accounting for scatter in properties and multiaxial stresses and strains, using the methods in Section 8 . For a triaxiality factor of 1.0 (uniaxial tension), the above values are $21 \%$ for the weld metal and $40 \%$ for the base metal. For a triaxiality factor of 2.0 (maximum value for biaxial tension at surface) the above values are $10 \%$ and $20 \%$, respectively. For negative values of triaxiality factor (significant compressive stress) that are characteristic of the major portion of the strain accumulation in the drop, the failure strain values are $42 \%$ and $80 \%$, for weld metal and base metal respectively.

- Drop onto Storage Tube.

Improving the model for the MCO internals and impact locations, using the refined finite element model of the wall ( 7 solid elements through the wall), and maximizing the strain rate effects gives the highest weld region effective strain of less than $0.6 \%$. If the low strain rate effects are used, the value is increased but is still less than $3 \%$ with a triaxiality factor less than 2.0 . Comparing these to the bounding $10 \%$ failure strain predicted above (or $5 \%$ when including strain rate effect reduction factor) indicated to the Expert Panel that no cracking would occur. Moreover, the maximum tensile principal strain is in a radial direction, maximum at the outer surface and any failure would be by spalling or flaking rather than crack formation and propagation through the wall.

With the improved models of above, the results indicate the MCO bottom plate area-of-impact sustains a high triaxial compressive stress state (triaxiality factor is negative) with a maximum effective strain of about $45 \%$ and $40 \%$ for the cases using low (nominal) and high strain rate effects. Since the predicted failure strain is $80 \%$, no cracking is expected to occur. If the strain rate reduction factor is included the failure strain is reduced to $40 \%$, indication a potential failure. However, the maximum tensile principal strain is perpendicular to the base surface and is a Poisson's ratio effect, therefore any failure would be through spalling or flaking.

The above results also show that the areas of $M C O$ not discussed above are structurally acceptable since the strains are much lower (mostly in the elastic range). No structural instabilities are indicated, and the vertical deceleration of the MCO baskets is less than $\mathbf{2 0} \mathrm{g}$ 's, well within a conservative allowable of $35 \mathrm{~g}$ 's from the MCO design criteria. 
The deformation of the support tube where the flange attaches to the tube cylinder is much less than that of the MCO-to-tube clearance, thus, no adverse wedging of the MCO in the tube is expected.

- Drop onto Service Station Guide Ring.

The finite element model gives the highest weld region effective strain of about $1 \%$. Comparing this strain to the bounding $10 \%$ failure strain predicted above (or $5 \%$ when including strain rate effect reduction factor) indicated to the Expert Panel that no cracking would occur. Moreover, the maximum tensile principal strain is in a radial direction, maximum at the outer surface and any failure would be by spalling or flaking rather than crack formation and propagation through the wall.

The results indicate the MCO bottom plate area-of-impact sustains a triaxial compressive stress state (triaxiality factor is negative) with a maximum effective strain of about $18 \%$, which is less than the storage tube case. Since the predicted failure strain is $80 \%$ (or $40 \%$ when including strain rate effect reduction factor), no cracking is expected to occur. Moreover, the maximum tensile principal strain is again perpendicular to the base surface and is a Poisson's ratio effect, therefore, any failure would be through spalling or flaking.

The above results also show that the areas of $\mathrm{MCO}$ not discussed above are structurally acceptable as the strains are much lower (mostly in the elastic range). No structural instabilities are indicated, and the vertical deceleration of the MCO baskets are about $4 \mathrm{~g}$ 's, well within a conservative allowable of $35 \mathrm{~g}$ 's from the MCO design criteria.

\subsection{REFERENCES}

1. Tu, K. C. MCO Drop Impacts on the Standard Storage Tubes, Calculation Number CSB-S-0067, January 15, 1999.

2. Tu, K. C. MCO Drop Impacts on the Overpack Storage Tube, Calculation Number CSB-S-0068, April 1999.

3. Avallone, E. A. and T. Baumeister, III. Marks' Standard Handbook for Mechanical Engineers, New York, McGraw-Hill Book Company, 1987.

4. Manjoine, M. J. Creep-Rupture Behavior of Weldments, Research Supplement, February 1982.

5. Boyer, C. P. and S. T. Rolfe, Effect of Strain-Hardening Exponent and Strain Concentrations on the Bursting Behavior of Pressure Vessels, ASME Paper No. 74MAT-1, 1974.

6. Goller, B., R. Krieg, and G. Messemer. Failure of Reinforced Sections of Spherical Steel Containments Under Excessive Internal Pressure, Transactions of $8^{\text {th }}$ 
International. Conference On Structural Mechanics in Reactor Technology, North Holland Physics Publishing, 1985, Paper J3/6.

7. Blejwas, T. E. Ibid, Paper J2/3.

8. Clauss, D. B. Nuclear Engineering and Design, 90 (1985), pp. 241-260.

9. Horschel, D. S. Containment Model-Test Program and Results, SAND88-1747C, May 1989.

10. Ward, A. L. and L. D. Blackburn, Journal of Engineering Materials and Technology, 98, p. $213,1976$.

11. Blackburn, L. D. and D. L. Greenslade, Mechanical Properties of Type 316 Stainless Steel Materials after Irradiation at $515^{\circ} \mathrm{C}$ and $585^{\circ} \mathrm{C}$, HEDL-TME 81-4, Hanford Engineering Development Laboratory, Richland, Washington, April 1981.

12. Drawing No. H-2-828043.

13. Snow, S. D. Analytical Evaluation of Preliminary Puncture-Drop Tests Performed to Develop a Robust and Drop Resistant Design Concept for the Standardized DOE Spent Nuclear Fuel Canister, EDF No. AMG-06-98, June 15, 1999.

14. Snow, S. D. Analytical Evaluation of Preliminary Drop Tests Performed to Develop a Robust and Drop Resistant Design Concept for the Standardized DOE Spent Nuclear Fuel Canister, EDF No. AMG-01-99, September. 1998. 


\section{ATTACHMENT}

\section{EXPERT PANEL REPORT}

ATT-1 


\section{Conclusions of Expert Panel on Analysis for Eccentric MCO Drops at CSB September 15, 1999 Richland. WA}

Earlier analysis of a postulated eccentric drop at a CSB tube indicated that significant inelastic deformation in the MCO may occur and a breach of the MCO could not be ruled out. In addition, criticality configuration contingency control for the spent nuclear fuel could not be assured. The radiological dose consequences from such a breach had not been shown to meet evaluation guidelines. Accordingly, a plan of action to resolve this issue was undertaken. This plan included the assembly of an expert panel to provide guidance for further work including modeling activities, preliminary calculations, refining the resolution strategy, and implementing the resolution. The drop of the $\mathrm{MCO}$ was assessed for the drop on storage tube and for the drop on the service station guide ring. The Expert Panel has met a number of times and the current conclusions reported herein are the results and findings of the new modeling and calculations,

The Expert Panel members were:

LD Blackburn - Metallurgy

RD Crowe - Safety Analysis

LH Goldmann - MCO Design Authority

RP Kennedy - Structural Analysis

LK Severud - Engineering Management \& Structural Analysis

The Expert Panel, after review of the earlier analysis, made recommendations for improving the modeling and reducing the conservatism in the earlier model and calculations. These included better modeling of the MCO internals and impact locations, accounting for the strain rate effects on the material stress-strain properties, refinement of the finite element model in the areas of the high strains, and inclusion of appropriate predictions of the failure strain levels. Results of the inelastic analysis calculations with these changes include the following significant findings:

Failure Criteria. Conservative failure strain levels were predicted for both welds and parent 304L stainless steel material, accounting for scatter in properties and multi-axial stresses and strains, and using the methods in Attachment 1. For a triaxiality factor of 1.0 (uniaxial tension), the above values are $21 \%$ for weld metal and $40 \%$ base metal. For a triaxiality factor of 2.0 (maximum value for biaxial tension at surface) the above values are $10 \%$ and $20 \%$. For negative values of triaxiality factor (significant compressive stress) that are characteristic of the major portion of the strain accumulation in the drop, the values are $42 \%$ and $80 \%$, again for weld metal and base metal respectively.

Drop onto Storage Tube.

1. Improving the model for the $\mathrm{MCO}$ internals and impact locations, using the refined finite element model of the wall ( 7 solid elements through the wall), and maximizing the strain rate effects gives the highest weld region effective strain of less than $0.6 \%$. If the minimum strain rate effects are used, the value is increased but is still less than $3 \%$ with a triaxiality factor less than 2.0. Comparing these to the bounding $10 \%$ failure strain predicted above indicates to the Expert Panel that no cracking will occur. Moreover, the maximum tensile principal strain is in a 
radial direction, maximum at the outer surface and any failure would be by spalling or flaking rather than crack formation and propagation through the wall.

2. With the improved models of above, the calculations indicate the $\mathrm{MCO}$ bottom plate arc-ofimpact sustains a high triaxial compressive stress state (triaxiality factor is negative) with a maximum effective strain of about $45 \%$ and $40 \%$ for the cases using maximum and minimum strain rate effects. Since the predicted failure strain is $80 \%$, no cracking is expected to occur. Moreover, the maximum tensile principal strain is perpendicular to the base surface and is a Poisson's ratio effect, so that any failure would be through spalling or flaking.

3. The above calculations also show that the areas of $\mathrm{MCO}$ not discussed above are structurally acceptable as the strains are much lower, mostly in the elastic range, no structural instabilities are indicated, and the vertical deceleration of the MCO baskets is about 20G's, well within a conservative allowable of 35G's from the MCO design criteria.

4. The deformation of the support tube where the flange attaches to the tube cylinder is much less than that of the MCO-to-tube clearance and so, no adverse sticking of the MCO is expected.

\section{Drop onto Service Station Guide Ring.}

1. The finite element model gives the highest shell weld region effective strain, located at the outer surface, of less than $1 \%$. Comparing this strain to the bounding $10 \%$ failure strain predicted above indicates to the Expert Panel that no cracking will occur. Moreover, the maximum tensile principal strain is in a radial direction, maximum at the outer surface and any failure would be by spalling or flaking rather than crack formation and propagation through the wall.

2. The calculations indicate the MCO bottom plate arc-of-impact sustains a triaxial cempressive stress state (triaxiality factor is negative) with a maximum effective strain of about $18 \%$, which is less than that for the storage tube case. Since the predicted failure strain is $80 \%$, no cracking is expected to occur. Moreover, the maximum tensile principal strain is again perpendicular to the base surface and is a Poisson's ratio effect, so that any failure would be through spalling or flaking.

3. The above calculations also show that the areas of $\mathrm{MCO}$ not discussed above are structurally acceptable as the strains are much lower, mostly in the elastic range, no structural instabilities are indicated, and the maxinum vertical deceleration of the MCO baskets is about 4G's, well within a conservative allowable of 35G's from the MCO design criteria. 
Although the drop analysis report is yet to be drafted, checked and reviewed, the Expert Panel judges that the ongoing work and final report will show that the MCO is not breached in the event of a postulated drops on either the support tube or service station guide ring. The results of the drop on the service station guide ring are also applicable to the drop of the $\mathrm{MCO}$ at the sample/weld station.
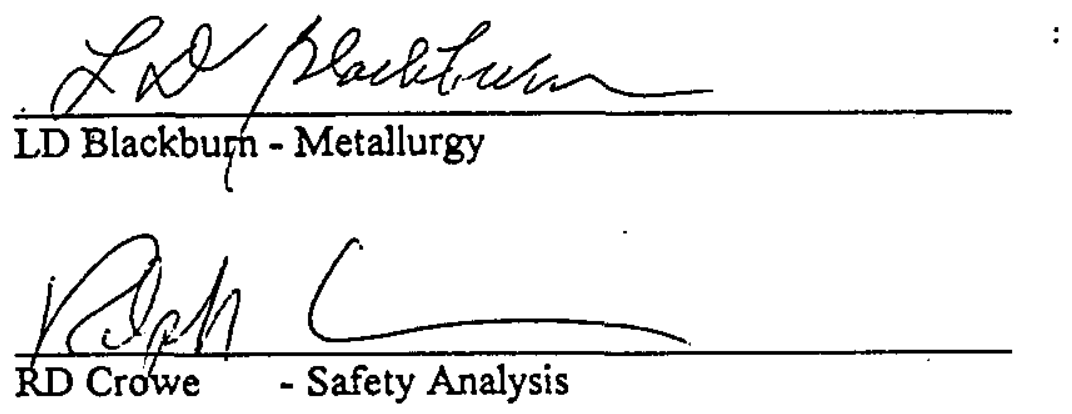

Gubs HAtworm

LH Goldmann - MCO Design Authority
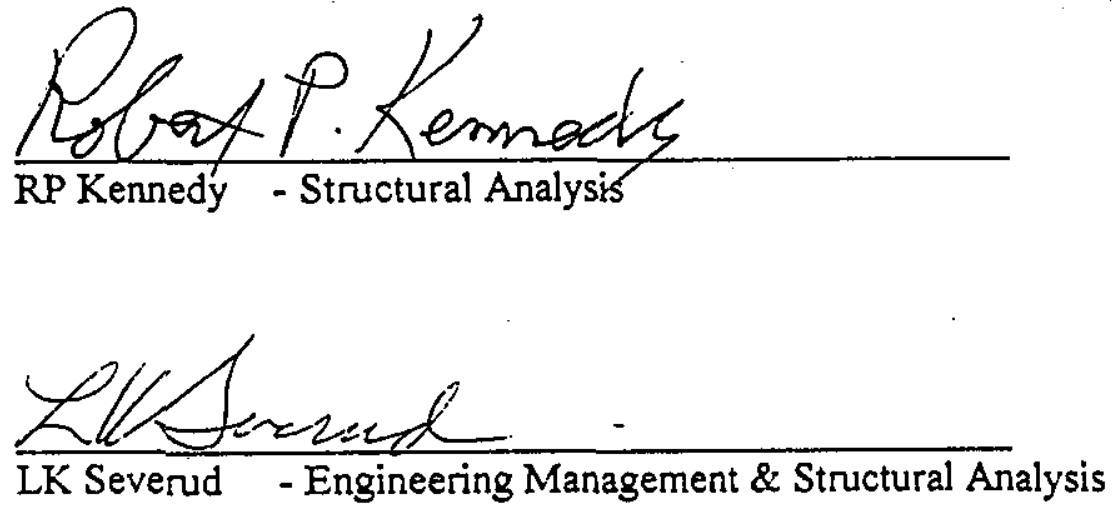


\section{PREDICTION OF FAILURE STRAIN}

Failure of the MCO will not occur if the maximum principal strain resulting from the drop is below a value that could initiate local cracking. The multi-axial loading and deformation associated with the drop need to be considered in evaluating limits on maximum principal strain. Manjoine (1) has proposed that the tensile elongation measured in a tension test can be adjusted to predict multi-axial failure strain by the relation.

$$
\begin{aligned}
& \frac{\bar{\epsilon}}{e_{1}}=2^{(1-l)} \text { for } T F \geq 0, \text { and } \\
& \frac{\bar{E}}{e_{1}}=2 \text { for } T F \leq 0
\end{aligned}
$$

Where $\bar{\epsilon}$ is the effective (Mises) strain at failure

$e_{t}$ is the tensile elongation from tension test, and

TF is the triaxiality facto:

The effective strain and triaxiality factor are defined by the relations.

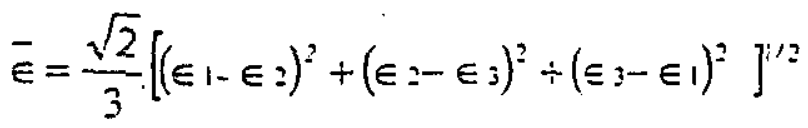

where $\varsigma_{1}, \Xi_{2}$, and $\varsigma_{3}$ are the principal strains, and

$$
T F=\frac{\sqrt{2}\left(\sigma_{1}+\sigma_{2}+\sigma_{3}\right)}{\left[\left(\sigma_{1}-\sigma_{2}\right)^{2}+\left(\sigma_{2}-\sigma_{3}\right)^{2}+\left(\sigma_{3}-\sigma_{1}\right)^{2}\right]^{\frac{1}{2}}}
$$

where $\sigma_{1}, \sigma_{2}$, and $\sigma_{3}$ are the principal stresses.

Manjoine indicates support for the correlation from several alloys, but does not cite the specific references for the test data. A pressure vessel burst test program sponsored by the Pressure Vessel Research Committee (PVRC) provides support for the Manjoine correlation. Boyer and Rolfe (2) report that $\bar{\epsilon}$ measured after bursting by internal pressure of a smooth pressure vessel made of carbon steel was 0.236 , while $e_{\text {: }}$ was 0.33 . These results are in good agreement with equation $1 \mathrm{a}$. A test on a second pressure vessel containing an intentional notch reduced $\bar{E}$ to 0.125 . Goller et al (3) report failure strains in pressurized discs (both smooth and reinforced) of alloy steel that are twice as large as the tensile elongation. These multi-axial failures strains in discs are much higher than would be predicted by the Manjoine correlation. Several 
researchers (Blejwas [4], Clauss [5], and Horschel [6]) report results for bursting of subscale models of nuclear reactor containment structures of carbon steel. In a simple 1/32 scale model, failure strains were about 0.21 for a smooth geometry, and about 0.16 for a geometry containing penetrations (Ref. 4). The tensile elongation for the steel was not reported, but the multi-axial failure strains are similar to those cited above for the PVRC vessels. Containment models that were $1 / 8$ and $1 / 6$ scale (Ref. 5,6 ) were geometrically more complex and contained various penetrations, hatches, and stiffening rings. Localized failure strains were not measured directly, but indicated strain gage readings for the $1 / 8$ scale test would suggest local failure strain exceeded 0.08 . In these models, failures initiated at a formed stiffener adjacent to the reinforcement at an equipment hatch penetration (1/8 scale model), and at a thickened region around a penetration (1/6 scale model). Both models were loaded beyond general yielding, and the free-field strains (i.e.; away from geometric discontinuities) were in the range 0.013 to 0.031 when uitimate failure occurred.

The MCO being analyzed in the present evaluation exhibits a smooth geometry without any discontinuities or notches that would reduce failure strains below those predicted from the Manjoine correlation.

For assessment of the weld region, the tensile elongation should be based on tests of weld metal. Results from thirteen different welds $(7,8)$ tested at room temperature were used to determine tensile elongation. These welds were produces using various welding procedures and represent $308,16-8-2$, and 316 stainless steel weld metal compositions. For a total of 27 tension tests on as-deposited welds; the mean value of $\epsilon_{1}$ is 0.37 with a standard deviation of 0.078 . Defining the minimum value of $e_{1}$ as the mean value minus twice the standard deviation, $\epsilon_{;}$(min.) is 0.214 .

For assessment of base metal regions, the specification minimum value for e: of $304 \mathrm{~L}$ stain!ess steel base metal is 0.40 . The maximum acceptable value of $e:$ for $304 \mathrm{~L}$ stainless steel is therefore about twice that for weld metal.

\section{REFERENCES}

1. M. J. Manjoine, Weldina J., Research Supplement, February 1982.

2. C. P. Boyer and S. T. Rolfe, "Effect of Strain - Hardening Exponent and Strain Concentrations on the Bursting Behavior of Pressure Vessels", ASME Paper No. 74-MAT-1.

3. B. Goller, R. Krieg, and G. Messemer, Transactions of $8^{\text {th }}$ intl. Conf. On Strucutral Mechanics in Reactor Technology, North Holland Physics Publishing. 1985, Paper J3/6.

4. T. E. Blejwas, ibid, Paper J2/3.

5. D. B.Clauss, Nucl. Eno. and Design, 90 (1985) 241-260.

6. D. S. Horschel, "Containment Model-Test Program and Results", SAND88 1747C, May 1989.

7. A. L. Ward and L. D. Blackburn, Journal of Engineering Materials and Technology, 98, p. 213, 1976.

8. L. D. Blackburn and D. L. Greenslade, Mechanical Properties of Type 316 Stainless Steel Materials After Irradiation at $515^{\circ} \mathrm{C}$ and $585^{\circ} \mathrm{C}, \mathrm{HEDL}-T M E 81-4$, Hanford Engineering Development Laboratory, Richland, Washington, April 1981. 


\section{APPENDIX - A \\ MATERIAL PROPERTIES \\ FOR ABAQUS/EXPLICIT INPUT}

Originator:M.B. LAsorA Date: $9 / 27 / 99$ 


\section{MATERIAL PROPERTIES FOR ABAQUS/EXPLICIT INPUT Engineering stress-strain curve for $316 \mathrm{SS}$ heat $\mathrm{T}$. \\ On the basis of data provided in table A-3 contained in Blackbum 1981, engineering stress-strain curve can be construcled by linear interpolation. Stress values in the table are given in mega Pascals. Further the values are converted to psi.}

\begin{tabular}{|c|c|c|c|c|c|}
\hline$i:=0$ & & & 0.000000 & & 36114 \\
\hline$\varepsilon_{1}:=$ & $f\left(23_{i}:=\right.$ & & 0.001000 & & 37405 \\
\hline .002 & 249 & & 0.002000 & & 38261 \\
\hline .003 & 257.9 & $S_{\text {t23 }}:=f_{\mathrm{t}} 23^{\prime} \cdot \mathrm{Pa} \cdot 1000000$ & $0.0,03000$ & & 38972 \\
\hline .004 & 263.8 & & 0.004000 & & 39610 \\
\hline .005 & 268.7 & $\varepsilon_{p l}:=\varepsilon-0.002$ & 0.005000 & $s+23=$ & 40146 \\
\hline .006 & 273.1 & & 0.006000 & & 40640 \\
\hline $\begin{array}{l}.007 \\
.008\end{array}$ & 276.8 & & 0.007000 & & 41046 \\
\hline .009 & 283 & & 0.005000 & & 41379 \\
\hline .01 & 285.3 & & 0.018000 & & 44498 \\
\hline .02 & 306.8 & & 0.028000 & & 46949 \\
\hline .03 & 323.7 & & 0.035000 & & 49052 \\
\hline .04 & $\frac{338.2}{35.5}$ & & 0.045000 & & 50981 \\
\hline \begin{tabular}{|l|}
.05 \\
.06 \\
\end{tabular} & $\frac{351.5}{363.4}$ & & 0.058000 & & 52707 \\
\hline .07 & 374.8 & & 0.068000 & & 54360 \\
\hline .05 & 335.9 & & 0.078000 & & 55970 \\
\hline .09 & 396.2 & & 0.088000 & & 57464 \\
\hline .1 & 405.7 & & 0.098000 & & 58842 \\
\hline .2 & $\frac{471.2}{5003}$ & & 0.199000 & & 68342 \\
\hline$\frac{.3}{.4}$ & 509.3 & & 0.298000 & & 73868 \\
\hline .5 & 548 & & 0.398000 & & 77204 \\
\hline .6 & 548 & & 0.498000 & & $794 \$ 1$ \\
\hline & & & 0.595000 & & 79481 \\
\hline
\end{tabular}

Using the term "Engineering stress-strain" it is implied that cross section of the specimen during uniaxial tension test remains unchanged.

$$
v \varepsilon_{p l}:=\overrightarrow{\varepsilon_{p l}} \quad \text { vs } t 23:=\vec{s}_{23} \quad \text { vs } t 23(\varepsilon):=\text { linterp v } \varepsilon_{p l}, \text { vs } t 23, \varepsilon
$$

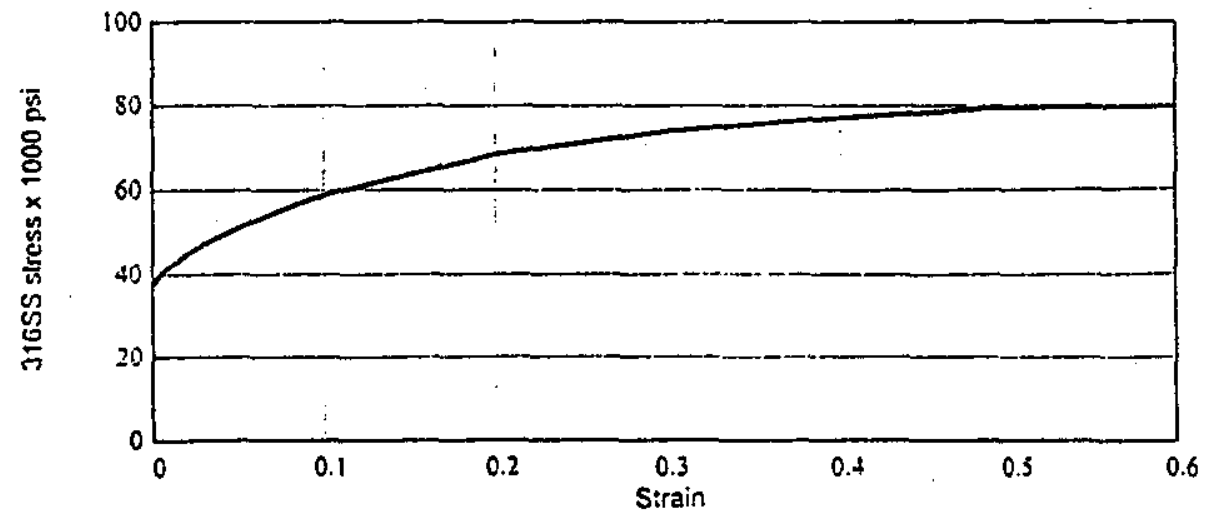

ENGINEERING STRESS-STRAIN CURVE FOR 316 SS STEEL

INELASTIC RANGE 


\section{MATERIAL PROPERTIES FOR ABAQUS/EXPLICIT INPUT}

\section{True stress-strain curve for 316 SS heat T.}

Most materials that exhibit duclile behavior ((large inelastic strains) yield al stress levels that are ordērs of magnitude less than the elastic modulus of material, which implies that the relevant stress and strain measures are "true" stress (Cauchy stress) and logaritmic strain. Material data for all of these models should, therefore, be given in these measures. The engineering (nominal) stress-strain data from uniaxlal test for isotropic material can be simply converted to true stress and logarithmic plastic strain by use of the following formulas:

$\sigma_{\text {true }}=\sigma_{\text {eng }}(1+\varepsilon$ eng $) \quad$ and $\quad \varepsilon$ pl $=\ln (1+\varepsilon$ eng $)-\frac{\sigma \text { true }}{E}$

Thus for 316 SS heat T steel true stress strain relation can be expressed as follows:

$$
\begin{aligned}
& E_{\text {ss316 }}:=28000000 \cdot p s i \quad \varepsilon_{\text {eng }}:=\frac{s t_{i}}{E_{s s 316}}+\varepsilon_{p_{i}} \quad s_{t_{i}}:=1+\varepsilon_{\text {eng }_{i}} s_{t 23_{i}} \\
& \varepsilon_{t_{i}}:=\ln \left(1+\varepsilon \text { eng }_{i} j-\frac{s t_{i}}{\varepsilon_{s s} 316}\right. \\
& v_{t r}:=\overrightarrow{\varepsilon_{t r}} \quad \text { vs } t r: \overrightarrow{s t r} \\
& \text { vs } t_{t r} \varepsilon_{t r}::=\text { linterp } v \varepsilon_{t r}, v_{t r}, \varepsilon_{t r}
\end{aligned}
$$

\begin{tabular}{|c|c|c|c|c|c|}
\hline & 0.0012901 & & 36161 & & {$[-0.000]$} \\
\hline & 0.002336 & & 37493 & & 0.001 \\
\hline & 0.003366 & & 38390 & & 0.002 \\
\hline & 0.004392 & & 39143 & & 0.003 \\
\hline & 0.005415 & & 39524 & & 0.004 \\
\hline$\varepsilon_{\text {eng }}=$ & 0.006434 & $s_{t r}=$ & $40 \div 05$ & $\varepsilon_{t r}=$ & 0.005 \\
\hline & 0.007451 & & $409+2$ & & 0.006 \\
\hline & 0.008466 & & 41393 & & 0.007 \\
\hline & 0.009478 & & $417 \pi$ & & 0.008 \\
\hline & 0.019589 & & 45369 & & 0.018 \\
\hline & 0.029677 & & $4 S: \div 2$ & & 0.028 \\
\hline & 0.039752 & & 51002 & & 0.037 \\
\hline & 0.049821 & & 53521 & & 0.047 \\
\hline & 0.059882 & & $55 \$ 63$ & & 0.056 \\
\hline & 0.069941 & & $5 \$ 162$ & & 0.066 \\
\hline & 0.079999 & & $60 \div 48$ & & 0.075 \\
\hline & 0.090052 & & 62639 & & 0.084 \\
\hline & 0.100101 & & 64732 & & 0.093 \\
\hline & 0.200441 & & $\$ 2040$ & & 0.180 \\
\hline & $0.30063 \mathrm{~S}$ & & 96075 & & 0.259 \\
\hline & 0.400757 & & 108143 & & 0.333 \\
\hline & 0.500839 & & 119288 & & 0.402 \\
\hline & $0.600 \$ 39$ & & 127236 & & 0.466 \\
\hline
\end{tabular}




\section{MATERIAL PROPERTIES FOR ABAQUS/EXPLICIT INPUT}

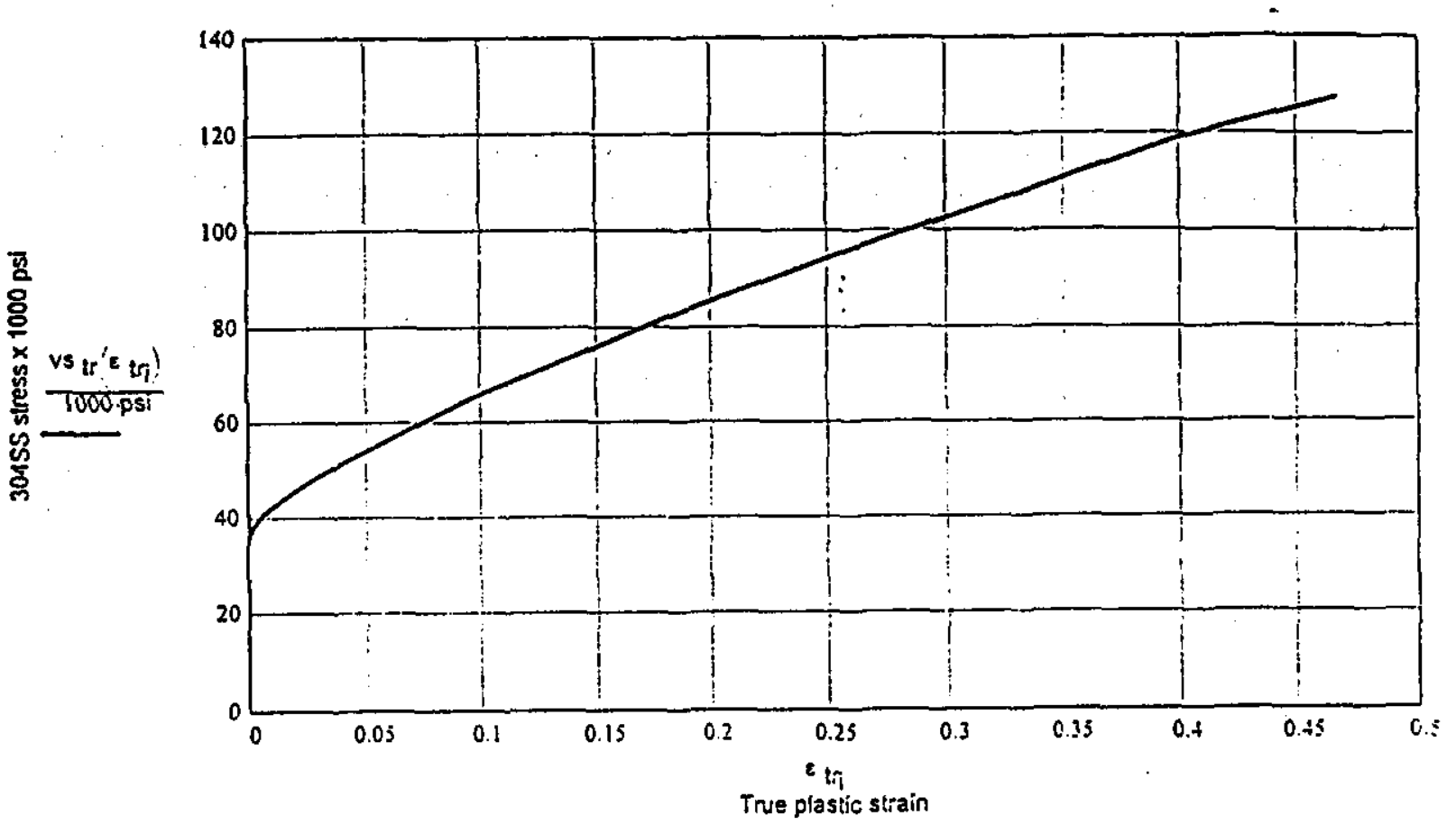

TRUE STRESS-STRAIN CURVE FOR 316 SS STEEL

True stress-strain curve for 304 SS @ specific strain rate.

From $A B A Q U S$ output an estimated strain rate can be computed as follows:

Dependent upon how fast the the strain is applied to the material, the material exhibits varying value of $2 \%$ yie! $d$ stress. This behavior of Type 304 Stainiess Stesl is captured in Steinken, 1971. Using actual strain rate from ABAQUCSIEXPLICIT run the mateirial properties are adjusted accordingly.

Time interval for which plastic strain can be approximated as straight line is:

$\Delta t:=\frac{11.3}{19} \cdot 5 \cdot 10^{-3} \cdot \sec -\frac{4}{19} \cdot 5 \cdot 10^{-3} \cdot \sec$

$\Delta t=0.0019 \cdot \sec$

Corresponding plastic strain increase is:

$\Delta \varepsilon_{\rho l}:=0.1633-0.0475 \quad \Delta \varepsilon p l=0.1158$

$\frac{\Delta \varepsilon p l}{\Delta t}=60.28 \cdot \sec ^{-1}$

The effect of the strain rate on the value of "0.2\% Yield Stress" (Steicken, 1971, Figure 2.) for 304 SS.

s yss304:= 51820.psi

$\frac{4}{22} \cdot 10+50 ; \cdot 1000=51818$ 


\section{MATERIAL PROPERTIES FOR ABAQUS/EXPLICIT INPUT}

The stress-strain curves for 316 SS steel and 304 SS steel are similar. Due to similarity the final plastic strain curve can be estimated by adjusting the 316 SS curve by a difference in the value of the yield stress for 316 SS and 304SS@ formerly computed strain rate.

$$
\begin{aligned}
& \Delta s_{y}:=s_{y s s 304}-s_{t_{0}} \quad \Delta s_{y}=15659.02 \cdot p s i \quad s:=s_{123_{0}} \quad s=36114.4 \cdot p s i
\end{aligned}
$$

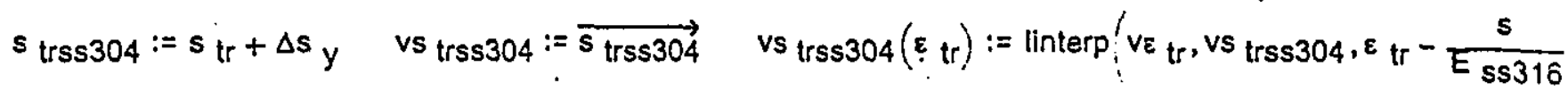

$$
\begin{aligned}
& \varepsilon_{\text {elss304 }}:=\frac{s}{E s s 316} \\
& \varepsilon^{\prime}{ }_{t r}:=0,0.0001 \ldots .0
\end{aligned}
$$

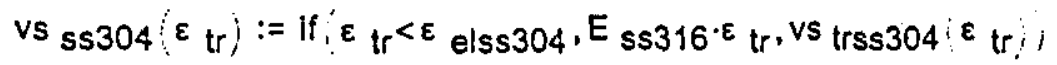

\begin{tabular}{|c|c|c|}
\hline 0.00001 & 30032 & $s_{\text {tin }}:=f_{\text {tin }} \cdot p s i$ \\
\hline 0.293 & 100701. & \\
\hline 0.3 & Tि1451. & $\varepsilon$ plin $:=\varepsilon$ \\
\hline 0.307 & 102201. & plin in in \\
\hline
\end{tabular}

$$
\begin{aligned}
& E_{s s 316 \cdot \varepsilon} \text { elss304 }=36114.4 \cdot p s i \\
& \text { vs } \operatorname{trss} 304(.00127)=51796.8 \mathrm{~S} \cdot \mathrm{psi} \\
& \mathrm{j}:=0 . .3 \\
& \varepsilon_{\text {in }_{j}}:=\quad f_{\text {tin }_{j}}:=
\end{aligned}
$$

$s_{\operatorname{tin}}=\left[\begin{array}{c}30032^{-} \\ 100701 \\ 101451 \\ 102201\end{array}\right] \cdot p s i \quad \varepsilon$ plin $=\left[\begin{array}{l}0.000010 \\ 0.293000 \\ 0.300000 \\ 0.307000\end{array}\right]$

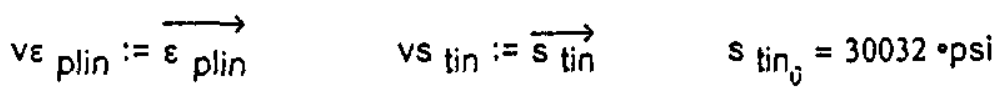

$\varepsilon^{\prime}$ elss304 $:=\frac{s \operatorname{tin}_{0}}{E s s 316} \quad \varepsilon^{\prime}$ els $304^{\prime}=0.001073$

$v s_{\text {tin }} \varepsilon_{\text {plin }}:=$ linterp ve plin, $v s_{\text {tin }}, \varepsilon$ plin:

vs tel $\varepsilon_{\text {plin }}:=E_{s s 316^{-\varepsilon} \text { plin }}$ vs tin $(.3)=101451 \cdot p s i$ 


$$
\begin{aligned}
& \text { vs orig }\left(\varepsilon_{\text {plin }}\right):=\text { if }\left(\varepsilon_{\text {plin }}<\varepsilon^{\prime} \text { elss304, vs tel }\left(\varepsilon_{\text {plin }}\right) \text {, vs tin }(\varepsilon \text { plin })\right) \\
& \varepsilon_{\text {plin }}:=0,0.0001 .0 .466
\end{aligned}
$$

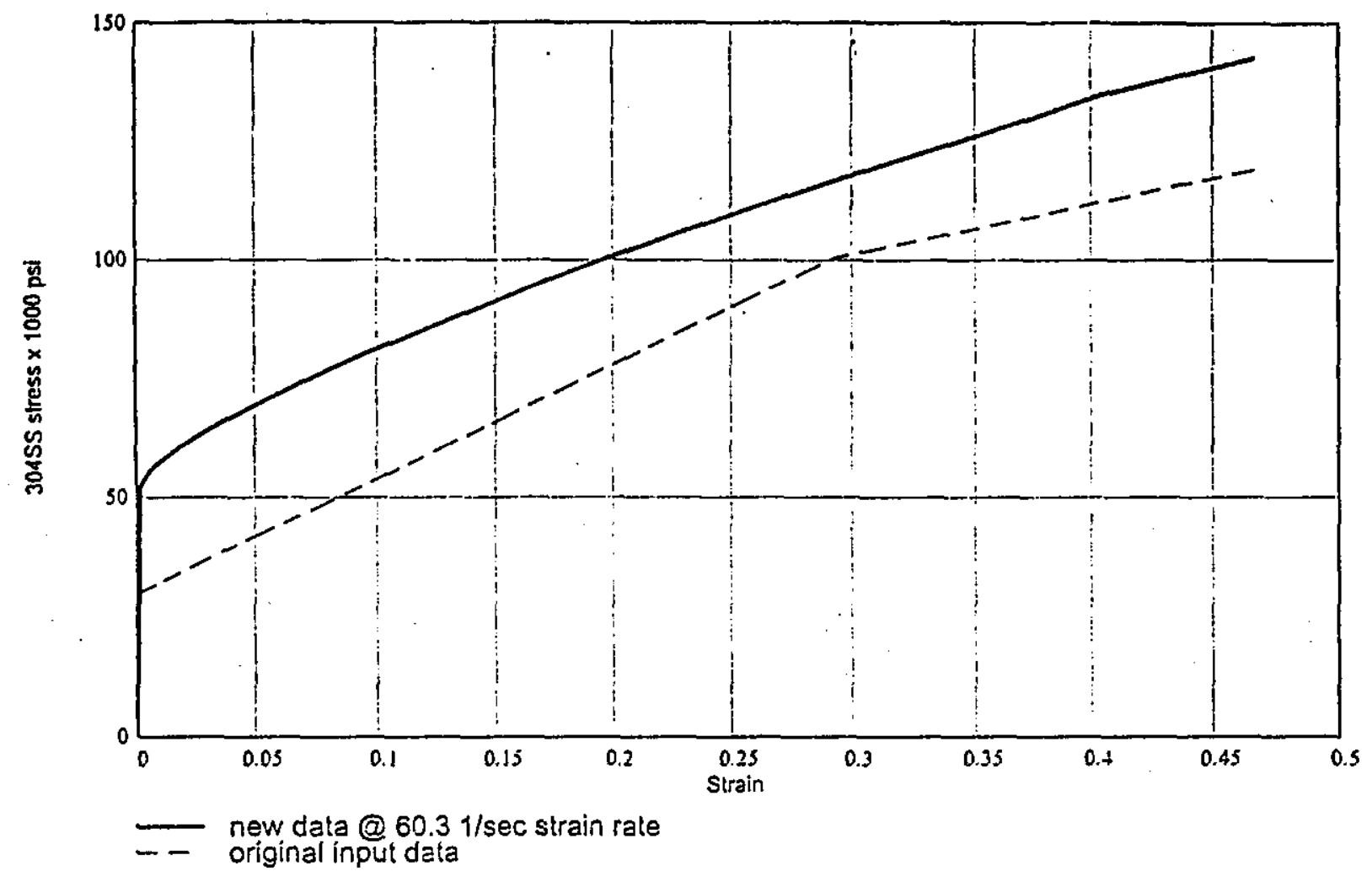

Figure 2sr-0a. TRUE STRESS-STRAIN CURVES FOR 304SS STEEL

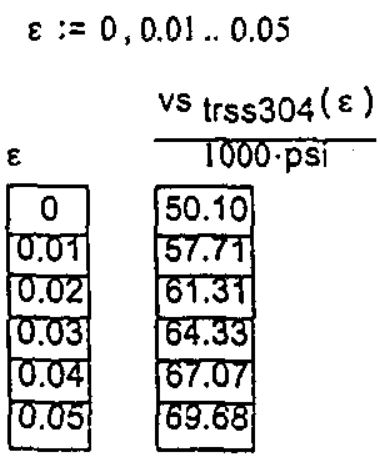

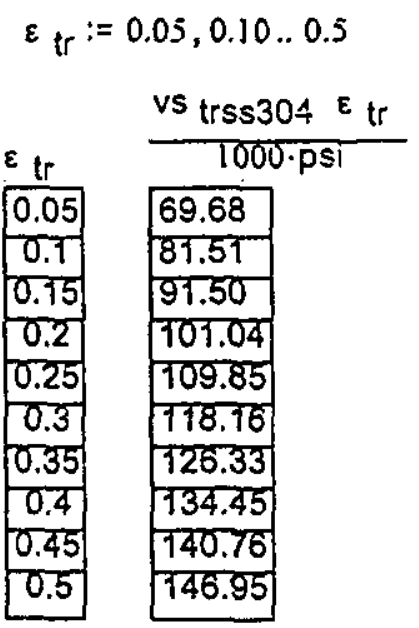




\section{MATERIAL PROPERTIES FOR ABAQUS/EXPLICIT INPUT :}

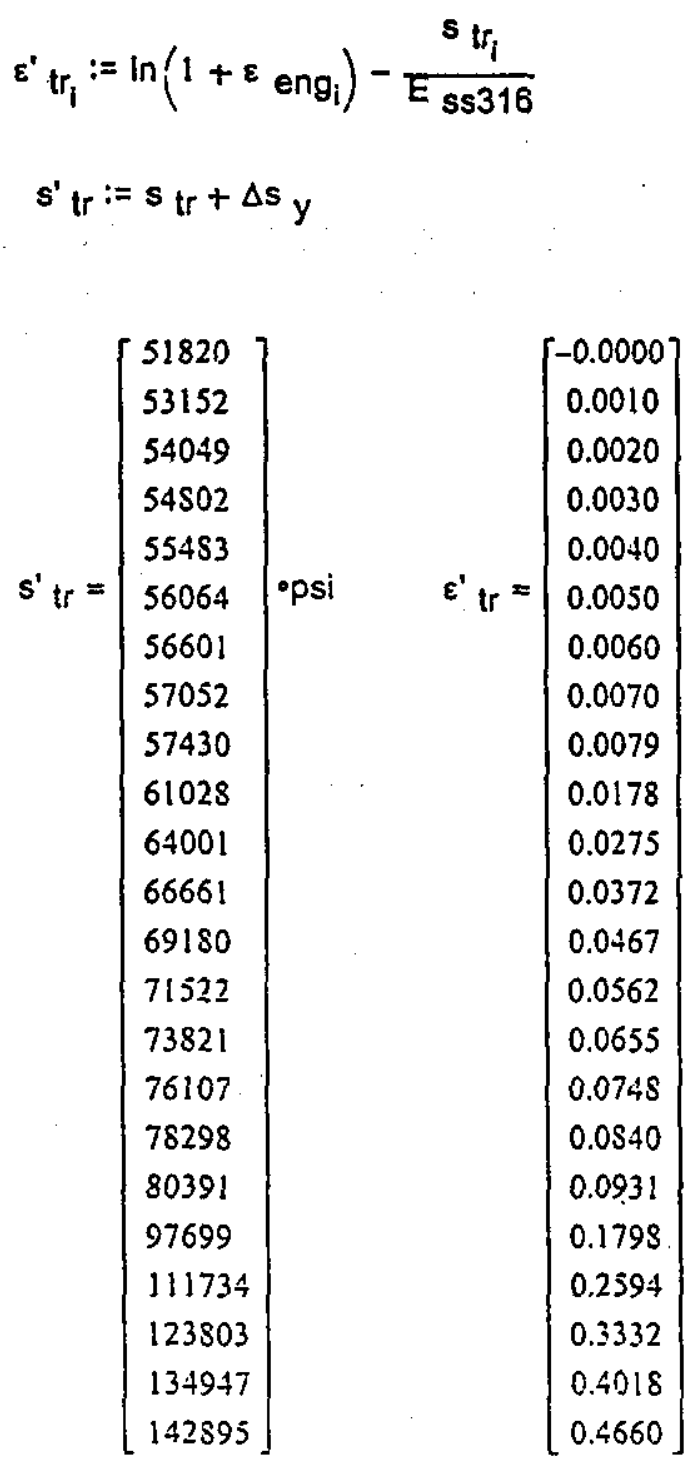




\section{MATERIAL PROPERTIES FOR ABAQUS/EXPLICIT INPUT}

Engineering stress-strain curve for SA36.

$$
\begin{aligned}
& j:=0 . .3 \\
& \varepsilon_{c s_{j}}:=\quad f_{c s t 23_{j}}:= \\
& \begin{array}{|l|l|}
\hline .00 \\
\hline .02 \\
\hline .095 \\
\hline 167 \\
\hline
\end{array} \\
& \text { s } \operatorname{cst} 23:=f \operatorname{cst} 23 \cdot p s i \\
& \varepsilon_{\text {cspl }}:=\varepsilon \text { cs } \\
& E_{\operatorname{cs} 36}:=29500000 \cdot p s i \\
& \varepsilon_{\mathrm{cspl}}=\left[\begin{array}{l}
0.000000 \\
0.020000 \\
0.095000 \\
0.161000
\end{array}\right] \\
& s_{c s t 23}=\left[\begin{array}{l}
36044 \\
37786 \\
55085 \\
64728
\end{array}\right] \cdot p s i \\
& \varepsilon \quad e_{\text {elcs } 36}:=\frac{s \operatorname{cs} 23_{0}}{E \operatorname{cs} 36} \\
& \varepsilon_{\text {elcs } 36}=0.00122183
\end{aligned}
$$

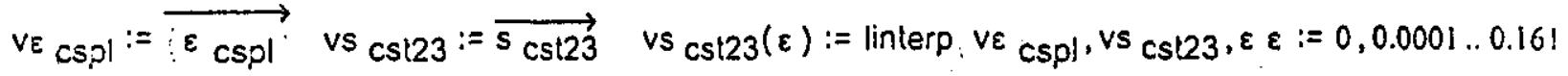

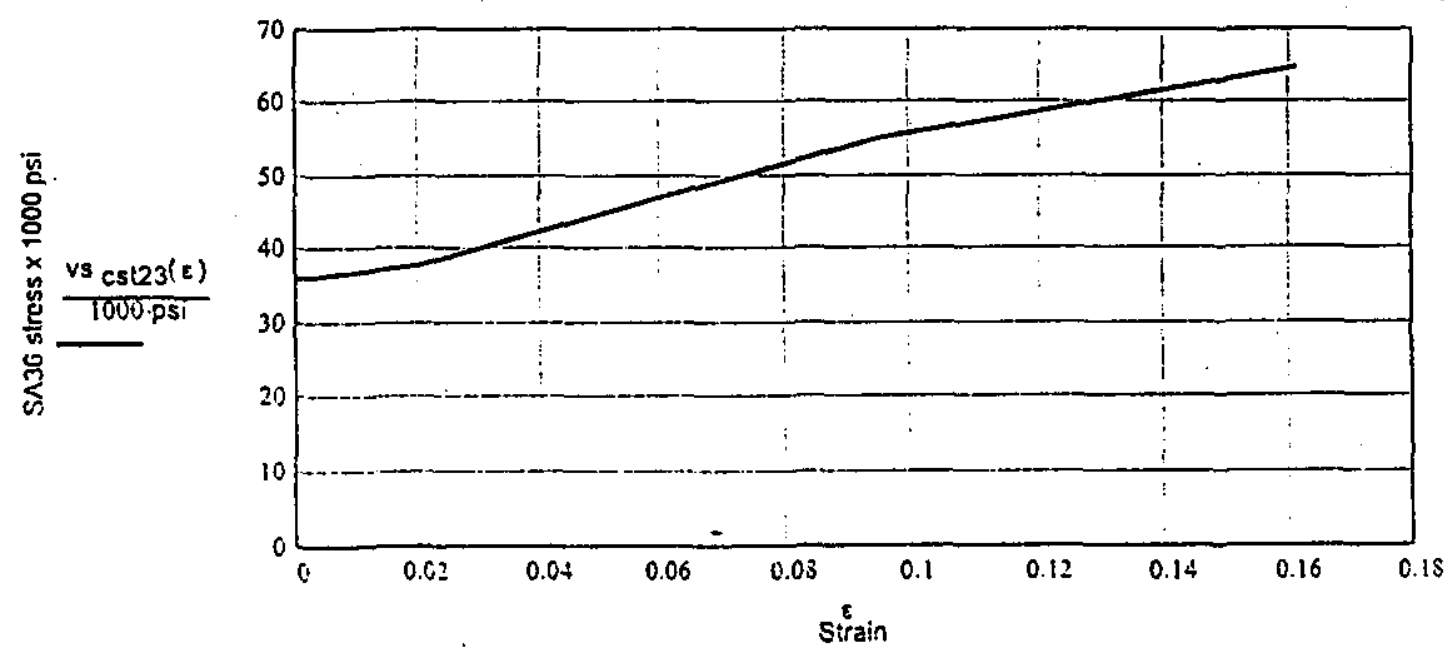

ENGINEERING STRESS-STRAIN CURVE FOR SA36 CS STEEL 


\section{MATERIAL PROPERTIES FOR ABAQUS/EXPLICIT INPUT}

True stress-strain curve for SA36 CS.

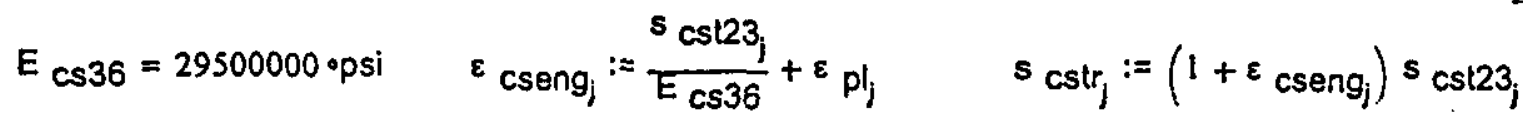

$\varepsilon_{\text {cstr }_{j}}:=\ln (1+\varepsilon \operatorname{cseng})-\frac{s \operatorname{cstr}_{1}}{E \cdot \operatorname{cs} 36} \quad \frac{s \operatorname{cstr}}{E \operatorname{cs} 36} \cdot 10^{-3}=0.000001$

$v \varepsilon_{\text {cstr }}:=\overrightarrow{\left.\varepsilon_{\text {cstr }}\right)} \quad$ vs cstr $:=\overrightarrow{\text { sestr }}^{\longrightarrow}$

vs $\operatorname{cstr}(\varepsilon):=\operatorname{linterp}\left(v \varepsilon_{\text {cstr }}\right.$, vs $\operatorname{cstr}, \varepsilon$

$\varepsilon_{\text {cseng }}=\left[\begin{array}{l}0.001222 \\ 0.002281 \\ 0.003867 \\ 0.005194\end{array}\right]$

$s_{\text {cstr }}=\left[\begin{array}{l}36088 \\ 37872 \\ 5529 \mathrm{~S} \\ 65064\end{array}\right] \cdot p s i \quad \varepsilon_{\text {cstr }}=\left[\begin{array}{c}-0.000002 \\ 0.000994 \\ 0.001985 \\ 0.002975\end{array}\right]$

$\varepsilon:=0,0.0001 . .0 .161$

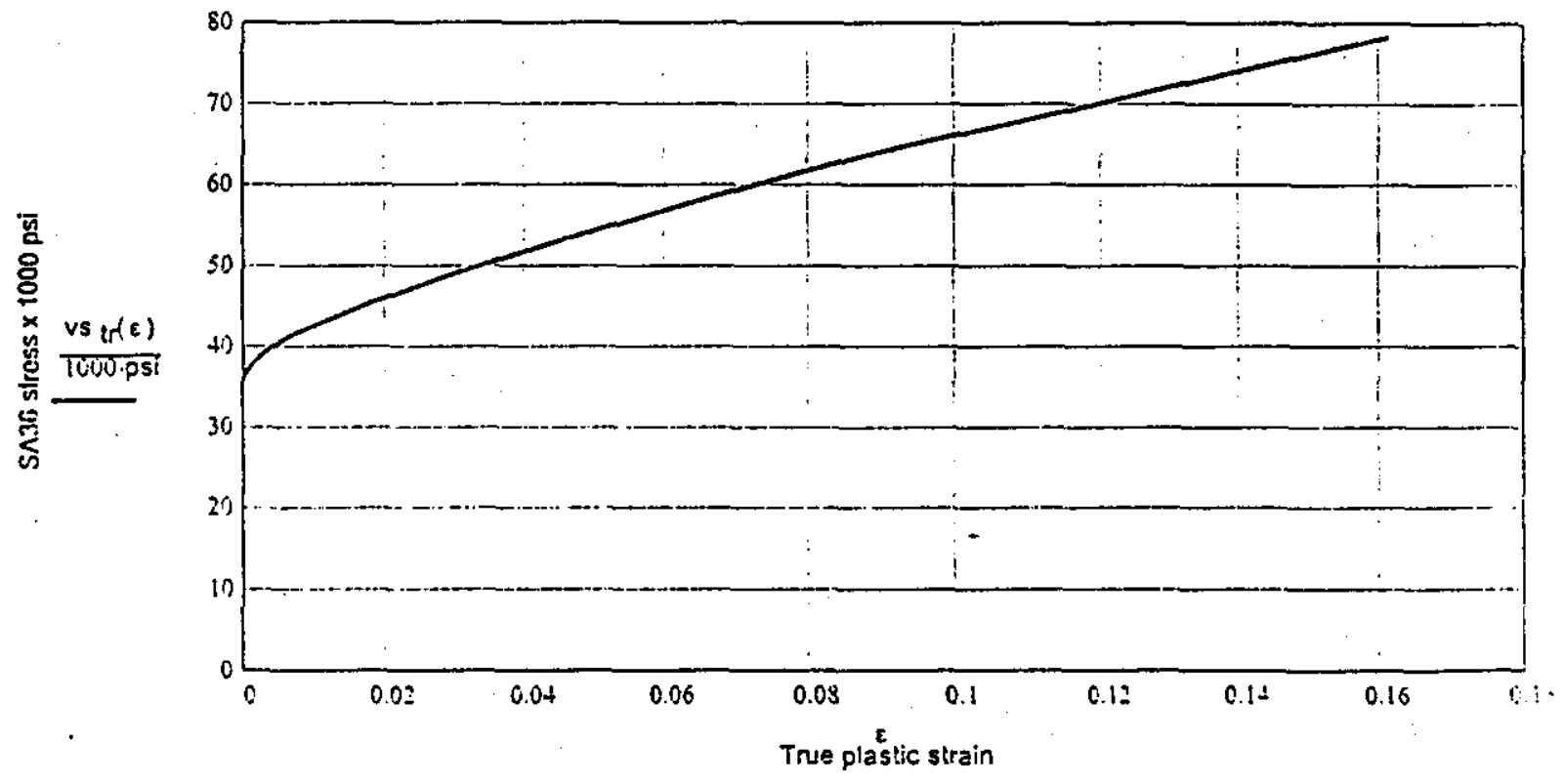

TRUE STRESS-STRAIN CURVE FOR SA36 CS STEEL. 


\section{MATERIAL PROPERTIES FOR ABAQUS/EXPLICIT INPUT}

\section{True stress-strain curve for SA36 @ specific strain rate.}

From ABAQUS output an estimated strain rate can be computed as follows:

Time interval for which plastic strain can be approximated as straight line is:

$\Delta t:=\frac{11.3}{19} \cdot 5 \cdot 10^{-3} \cdot \sec -\frac{4}{19} \cdot 5 \cdot 10^{-3} \cdot \sec \quad \quad \vdots \quad \Delta t=0.0019 \cdot \mathrm{sec}$

Corresponding plastic strain increase is:

$$
\begin{aligned}
& \Delta \varepsilon_{\mathrm{pl}}:=0.1633-0.0475 \quad \Delta \varepsilon_{\mathrm{pl}}=0.115 \mathrm{~S} \\
& \frac{\Delta \varepsilon_{\mathrm{pl}}}{\Delta \mathrm{l}}=60.28 \cdot \mathrm{sec}^{-1}
\end{aligned}
$$

The effect of the strain rate on the value of $0.2 \%$ Yield Stress (Figure 2. ref......) for SA36.

$$
s_{\text {ysa36 }}:=57820 \cdot \text { psi } \quad\left(\frac{17.2}{22} \cdot 10+50 \cdot 1000=57818\right.
$$

The stress-strain curves for SA36 steel and 304 SS steel are similar. Due to similarity the final plastic strain curve can be estimated by adjusting the $316 \mathrm{SS}$ curve by a difierence in the value of the yield stress for $316 \mathrm{SS}$ and 304SS@ formerly computed strain rate.

$$
\begin{aligned}
& \Delta s_{y}:=s_{y s a 36}-s_{t_{0}} \quad \Delta s_{y}=21659.02 \cdot p s i
\end{aligned}
$$

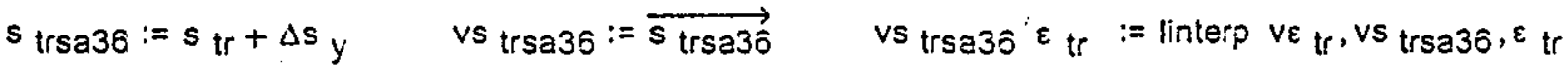

$$
\begin{aligned}
& \Delta s_{y}=21659.02 \cdot p s i \quad s:=s t 23_{0} \quad s=3611 \div .4 \cdot 0 s i
\end{aligned}
$$

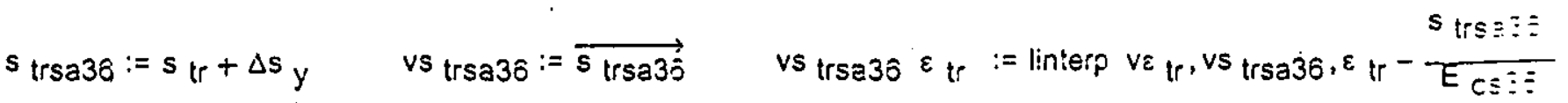

$$
\begin{aligned}
& \varepsilon_{\text {elcs36 }}:=\frac{\operatorname{sirsa36}_{0}}{E_{\operatorname{cs} 36}} \\
& \varepsilon_{\mathrm{tr}}:=0,0.0001 . .0 .5
\end{aligned}
$$

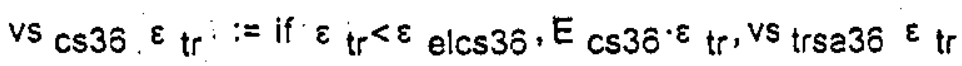

$$
\begin{aligned}
& E_{\operatorname{cs} 36{ }^{\cdot} \varepsilon_{\text {elcs } 36}=57 \$ 20 \cdot p s i} \varepsilon_{\text {elcs } 36}=0.00196 \\
& \text { vs } \operatorname{cs} 36(0.00122183)=36043.99 \cdot p s i \\
& \text { vs } \operatorname{cs36}(0.0016)=47200 \text { คpsi } \quad \varepsilon_{\text {elcs } 36}=0.00196
\end{aligned}
$$




\section{MATERIAL PROPERTIES FOR ABAQUS/EXPLICIT INPUT}

$$
\begin{aligned}
& \varepsilon^{\prime} \text { elcs36 }:=\frac{s t 23_{0}}{E \operatorname{cs} 36} \quad \varepsilon^{\prime} \text { elcs36 }=0.00122422 \\
& v^{\prime} t_{23}(\varepsilon):=\text { if }\left(\varepsilon<\varepsilon^{\prime} \text { elcs } 36, E \operatorname{cs} 36^{-} \varepsilon, \text { vs } t 23(\varepsilon)\right) \\
& \varepsilon_{\text {plin }}:=0,0.00001 . .0 .16
\end{aligned}
$$

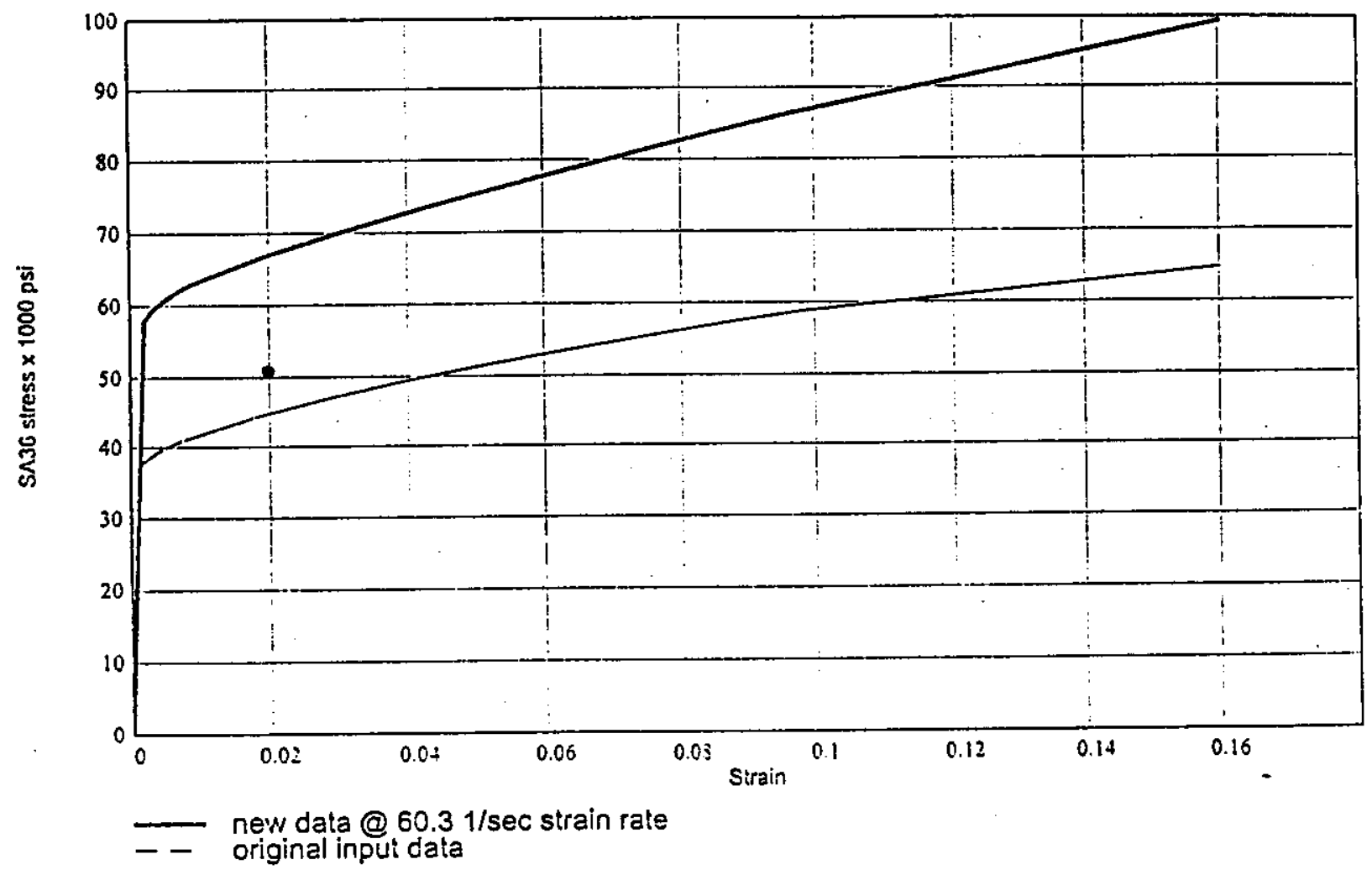

Figure 2sr-0b. TRUE STRESS-STRAIN CURVES FOR SA36 STEEL 


\section{MATERIAL PROPERTIES FOR ABAQUS/EXPLICIT INPUT}

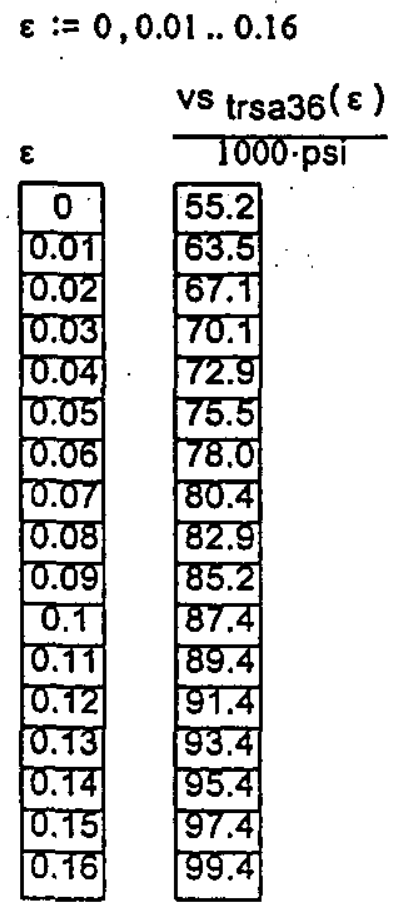

$$
\begin{aligned}
& \varepsilon^{\prime} t_{j}:=\ln \left(1+\varepsilon e_{\text {eng }}\right)-\frac{s_{\text {tr }}}{E_{\operatorname{css} 36}} \quad s^{\prime} t_{t r}:=s_{t r}+\Delta s_{y} \\
& s^{\prime} t r=\left[\begin{array}{l}
57820 \\
59152 \\
60049 \\
60802 \\
61483 \\
62064 \\
62601 \\
63052 \\
63430 \\
67028 \\
70001 \\
72661 \\
75180 \\
77522 \\
79821 \\
82107 \\
84298 \\
86391 \\
103699 \\
117734 \\
129803 \\
140947 \\
145895
\end{array}\right] \cdot p s i \quad \varepsilon^{\prime} \mathrm{tr}=\left[\begin{array}{l}
0.0001 \\
0.0011 \\
0.0021 \\
0.0031 \\
0.0040 \\
0.0050 \\
0.0060 \\
0.0070 \\
0.0079 \\
0.0178 \\
0.0275 \\
0.0372 \\
0.0467 \\
0.0562 \\
0.0655 \\
0.0748 \\
0.0840 \\
0.0931 \\
0.1798 \\
0.2594 \\
0.3332 \\
0.4018 \\
0.4660
\end{array}\right]
\end{aligned}
$$

\section{REFERENCES:}

Blackburn, L.D., Gransiade, D.L. Mechanical Properties of Type 316 Stainless Steel Materials After Irradiation at $515^{\circ} \mathrm{C}$ and $585^{\circ} \mathrm{C}$. HEDL-TME 81-4, April 1981. Hanford Engineering Development Laboratory, Richland, WA.

Steicken, J.M. High Strain Rate Mechanical Properties of Type 304 Stainless Steel and Nickel 200 (RM-14). HEDL-TME 71-145, September 1971. Hanford Engineering Development Laboratory, Richland, WA.

$$
\text { A-12 }
$$




\section{APPENDIX B}

\section{STRESS-STRAIN}

\section{TRIAXIALITY FACTOR CALCULATION}

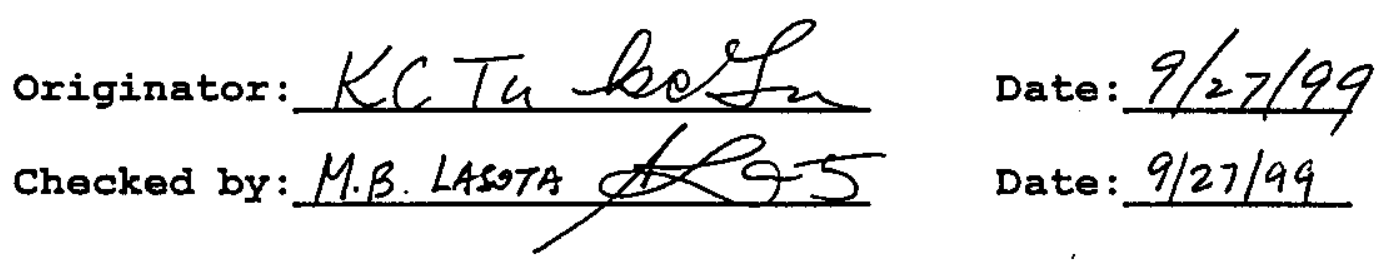




\section{B.1 CHECK CRITICAL AREA IN WELD REGION}

ELEMENT 70301 (element located at welding area near inside surface)

\begin{tabular}{|c|c|c|c|c|c|c|c|c|c|}
\hline $\begin{array}{c}\text { time } \\
\text { (second) }\end{array}$ & $\begin{array}{l}\text { minimum } \\
\text { principal } \\
\text { stress } \\
\text { (psi) }\end{array}$ & $\begin{array}{c}\text { Intermed. } \\
\text { principal } \\
\text { stress } \\
\text { (psi) }\end{array}$ & $\begin{array}{c}\text { maximum } \\
\text { principal } \\
\text { stress } \\
\text { (psi) }\end{array}$ & $\begin{array}{l}\text { minimum } \\
\text { principal } \\
\text { plastic } \\
\text { strain }\end{array}$ & $\begin{array}{c}\text { intermed. } \\
\text { principal } \\
\text { plastic } \\
\text { strain }\end{array}$ & $\begin{array}{c}\text { maximum } \\
\text { principal } \\
\text { plastic } \\
\text { strain }\end{array}$ & $\begin{array}{c}\text { triaxiality } \\
\text { factor } \\
\text { (TF) }\end{array}$ & $\begin{array}{c}\text { Mises } \\
\text { stress } \\
\text { (psi) }\end{array}$ & $\begin{array}{l}\text { plastic } \\
\text { strain }\end{array}$ \\
\hline 008 & 9924 & -5782 & -1989 & -0.00031 & 0.00013 & 0.00019 & -1.3180 & 36188 & $\overline{0.0003}$ \\
\hline 0.0015 & -43395 & -13645 & -2953 & -0.00155 & 0.00052 & 0.00102 & -1.6528 & 6297 & 0016 \\
\hline 0.0023 & -42909 & -16688 & -2967 & -0.00668 & 0.00162 & 0.00506 & -1.7799 & 5151 & .0070 \\
\hline 0.0030 & -29056 & -15954 & -1376 & -0.00668 & 0.00162 & .00506 & -1.9341 & 23983 & 0070 \\
\hline 038 & -15477 & -9839 & -1150 & -0.00668 & 0.00162 & 0.00506 & -2.1171 & 12501 & $\overline{0070}$ \\
\hline 0.0045 & -14843 & -2179 & 6607 & -0.00668 & 0.00162 & 0.00506 & .0 .5576 & 18677 & 0070 \\
\hline 0.0053 & -8849 & -7531 & 28411 & -0.00613 & 128 & 485 & 0.3285 & 19 & 065 \\
\hline 0.0060 & -11998 & -9144 & 10543 & -0.00582 & 0.00112 & 4471 & -0.4986 & 21258 & 062 \\
\hline 068 & -16102 & -13519 & -3429 & -0.00582 & 0.00112 & 0.00471 & -2.8493 & 11599 & 062 \\
\hline 0.0075 & -23759 & -18898 & -5655 & -0.00582 & 0.00112 & 0.00471 & -2.9769 & 16229 & 062 \\
\hline 0.0083 & -17337 & -15182 & -5220 & -0.00582 & 0.00112 & 471 & 707 & 96 & $\overline{062}$ \\
\hline 0.0090 & -14405 & -7115 & 1586 & -0.00582 & 0.00112 & 471 & -1.4376 & 13867 & 062 \\
\hline 98 & -15306 & -6741 & 4506 & -0.00582 & 0.00112 & 471 & -1.0192 & 17210 & 062 \\
\hline 105 & -15936 & -6283 & 4399 & -0.00582 & 0.00112 & 471 & -1.0115 & 7618 & 062 \\
\hline 0.0113 & -17049 & -6614 & 737 & -0.00582 & 112 & 471 & 810 & 80 & 62 \\
\hline 120 & 016 & -6536 & -3240 & 82 & 112 & 471 & 687 & 3435 & 62 \\
\hline & 344 & 11635 & -6069 & -0.0 & 132 & 471 & -3.3861 & 10646 & 62 \\
\hline 35 & -22769 & 5744 & -6533 & -0.00582 & 112 & 471 & & 14103 & 062 \\
\hline & -35357 & 3943 & .7171 & -0.00582 & 112 & 471 & -2.2159 & 25484 & 62 \\
\hline 0.0150 & -37669 & -13260 & -7139 & -0.00 & 112 & 471 & -2.0756 & 27976 & \\
\hline 158 & -13776 & -6544 & -2704 & -0.0 & 12 & 471 & -2.3645 & 9737 & 62 \\
\hline & -10715 & -6214 & -2996 & -0.00 & & 471 & -2.9670 & 6716 & 62 \\
\hline & -12206 & -5991 & -1672 & -0.00582 & 12 & 471 & -2.1663 & 9172 & 62 \\
\hline 180 & -17384 & -15982 & -6819 & -0.0 & 112 & 471 & -4.0434 & 9938 & \\
\hline 0.0188 & -18902 & -11656 & -1148 & -0.0 & 12 & 471 & 506 & 5462 & \\
\hline & -30888 & 2322 & -5421 & -0.0 & 12 & 71 & 22 & 22445 & 62 \\
\hline 203 & -23525 & -16428 & -5741 & -0.00582 & 112 & 471 & -2.9469 & 15506 & 062 \\
\hline 210 & -29179 & -5845 & -2128 & -0.00582 & 112 & 471 & -1.4628 & 25397 & $\overline{062}$ \\
\hline 0.0218 & -32429 & -15516 & -4848 & -0.00 & 12 & 471 & -2.1916 & 89 & 62 \\
\hline 0.0225 & -34793 & -23161 & -5170 & -0.00 & 12 & 471 & -2.4419 & 25851 & \\
\hline & -36657 & -24853 & -5525 & -0.00582 & 112 & 471 & -2.4625 & 27222 & 062 \\
\hline 0.0240 & -27363 & -11578 & -5707 & -0.00582 & 12 & 471 & -2.3016 & 19399 & 062 \\
\hline 0.0248 & -27891 & -14712 & -5179 & -0.00 & 12 & 471 & -2.4189 & 19753 & 62 \\
\hline & -27132 & -13810 & -5406 & -0.00 & 12 & 471 & -2.4425 & 18975 & \\
\hline & -28649 & -14014 & -5532 & -0.00582 & 0.00112 & 0.00471 & -2.3794 & 20255 & 062 \\
\hline 0.0270 & -28097 & -14318 & -4522 & -0.00582 & 0.00112 & 0.00471 & -2.2881 & 20513 & 062 \\
\hline 0.0278 & -26474 & -12245 & -4936 & -0.00582 & 0.00112 & 0.00471 & -2.3012 & 18971 & 062 \\
\hline & -25230 & -10376 & -4122 & -0.00582 & 0.00112 & 0.00471 & -2.1156 & 18779 & 062 \\
\hline 0.0293 & -29796 & -16385 & -4335 & -0.00582 & 0.00112 & 0.00471 & -2.2899 & 22060 & 0.0062 \\
\hline 0.0300 & -30207 & -14414 & -4467 & -0.00582 & 0.00112 & 0.00471 & -2.1834 & 22482 & 0.0062 \\
\hline Max. & & -2179 & 28411 & & 0.00162 & & & 36619 & \\
\hline Min. & -43395 & -24853 & -7171 & -0.00668 & 0.00013 & 0.00019 & -4.0434 & 6716 & 0.0003 \\
\hline
\end{tabular}


ELEMENT 72307 (element located at welding area near outside surface)

\begin{tabular}{|c|c|c|c|c|c|c|c|c|c|}
\hline $\begin{array}{c}\text { time } \\
\text { (second) }\end{array}$ & $\begin{array}{c}\text { minimum } \\
\text { principal } \\
\text { stress } \\
\text { (psi) }\end{array}$ & $\begin{array}{l}\text { intermed. } \\
\text { principal } \\
\text { stress } \\
\text { (psi) }\end{array}$ & $\begin{array}{c}\text { maximum } \\
\text { principal } \\
\text { stress } \\
\text { (psi) }\end{array}$ & $\begin{array}{c}\text { minimum } \\
\text { principal } \\
\text { plastic } \\
\text { strain }\end{array}$ & $\begin{array}{c}\text { intermed. } \\
\text { principal } \\
\text { plastic } \\
\text { strain }\end{array}$ & $\begin{array}{c}\text { maximum } \\
\text { principal } \\
\text { plastic } \\
\text { strain }\end{array}$ & $\begin{array}{c}\text { triaxiality } \\
\text { factor } \\
\text { (TF) }\end{array}$ & $\begin{array}{c}\text { Mises } \\
\text { stress } \\
\text { (psi) }\end{array}$ & $\begin{array}{c}\text { equivalent } \\
\text { plastic } \\
\text { strain }\end{array}$ \\
\hline 0.0008 & -20419 & -4986 & 974 & 0.00000 & 0.00000 & 0.00000 & -1.2776 & 19123 & .0000 \\
\hline 0.0015 & -26572 & -8035 & 293 & 0.00000 & 0.00000 & 0.00000 & -1.4406 & 23819 & 0000 \\
\hline 0.0023 & -37094 & -3577 & -1147 & -0.00108 & .00013 & 0.00095 & -1.2018 & 34796 & 0012 \\
\hline 0.0030 & -30850 & -4588 & 935 & -0.00108 & 0013 & 095 & -1.1730 & 29415 & 012 \\
\hline 0.0038 & -27803 & -6760 & 3780 & -0.00108 & 013 & 095 & -1.1053 & 27851 & 0012 \\
\hline 0.0045 & -25385 & -9064 & 5432 & 108 & 13 & 995 & 866 & & 012 \\
\hline & 303 & 13248 & 2912 & 125 & 23 & 102 & 522 & & 013 \\
\hline 60 & 264 & 51 & 3037 & 135 & 229 & 106 & 2611 & & 014 \\
\hline 668 & -38785 & 745 & 634 & -0.00135 & 029 & 106 & -1.4659 & & 0014 \\
\hline & 398 & & 424 & -0. & 032 & & -1.5071 & & \\
\hline & & & 503 & & 32 & 11 & -1.5790 & & \\
\hline & 442 & & 904 & 43 & 32 & 11 & 012 & & 015 \\
\hline 98 & 316 & -9580 & 798 & -0. & 32 & 111 & 019 & & 015 \\
\hline & & -8000 & 737 & & & & & & \\
\hline & & & 566 & & & & 088 & & \\
\hline & 12 & 57 & 549 & & 32 & & 54 & & \\
\hline & & -8448 & 414 & & 32 & & 686 & & \\
\hline & & & -2125 & & 32 & & & & \\
\hline & & 76 & 4304 & & & & 009 & & \\
\hline 50 & 25 & -1410 & 283 & 43 & 32 & & 999 & & 015 \\
\hline 158 & 694 & -1459 & 10768 & 143 & & & 0.4164 & & 015 \\
\hline & 71 & 3024 & & & & & & & \\
\hline & 81 & 17 & 18 & & & & & & \\
\hline 80 & 302 & -4562 & 694 & 143 & 32 & & & & 015 \\
\hline 188 & 367 & 383 & 22937 & & & & & & \\
\hline & & 43 & & & & & & & 016 \\
\hline 03 & 90 & 10 & 87 & & & & 626 & & \\
\hline 210 & 778 & 49 & & & & & & & \\
\hline 0.0218 & 347 & 17 & 34009 & 169 & & & 999 & & 016 \\
\hline & 79 & & 65 & & & & & & \\
\hline 33 & 34 & 80 & 90 & & & & & & \\
\hline 0.0240 & -4428 & 432 & 32283 & & & & & & 18 \\
\hline 0.0248 & -7804 & 392 & 28695 & 169 & & & 510 & & \\
\hline & 59 & & & & & & 072 & & \\
\hline 0.0263 & 128 & & 29668 & 69 & & & 1.7082 & & 018 \\
\hline 0.0270 & -3835 & 715 & 28162 & 2169 & 035 & & 1.2629 & & 018 \\
\hline 0.0278 & -906 & 178 & 28248 & & 335 & & 1.5626 & 92 & 018 \\
\hline 285 & 29 & & & & & & & & 018 \\
\hline 0.0293 & 15392 & & 33257 & & & & & & 018 \\
\hline 0.0300 & 211 & 80 & 33409 & -0.00169 & 035 & 0.00134 & 4.5340 & 15483 & 0.0018 \\
\hline Max. & & 80 & & & 035 & & 4.5340 & 36298 & 0.0018 \\
\hline $\operatorname{Min}$ & -40398 & -14052 & -2125 & -0.00169 & 0.00000 & 0.00000 & -2.1461 & 10135 & $0.000 \mathrm{C}$ \\
\hline
\end{tabular}




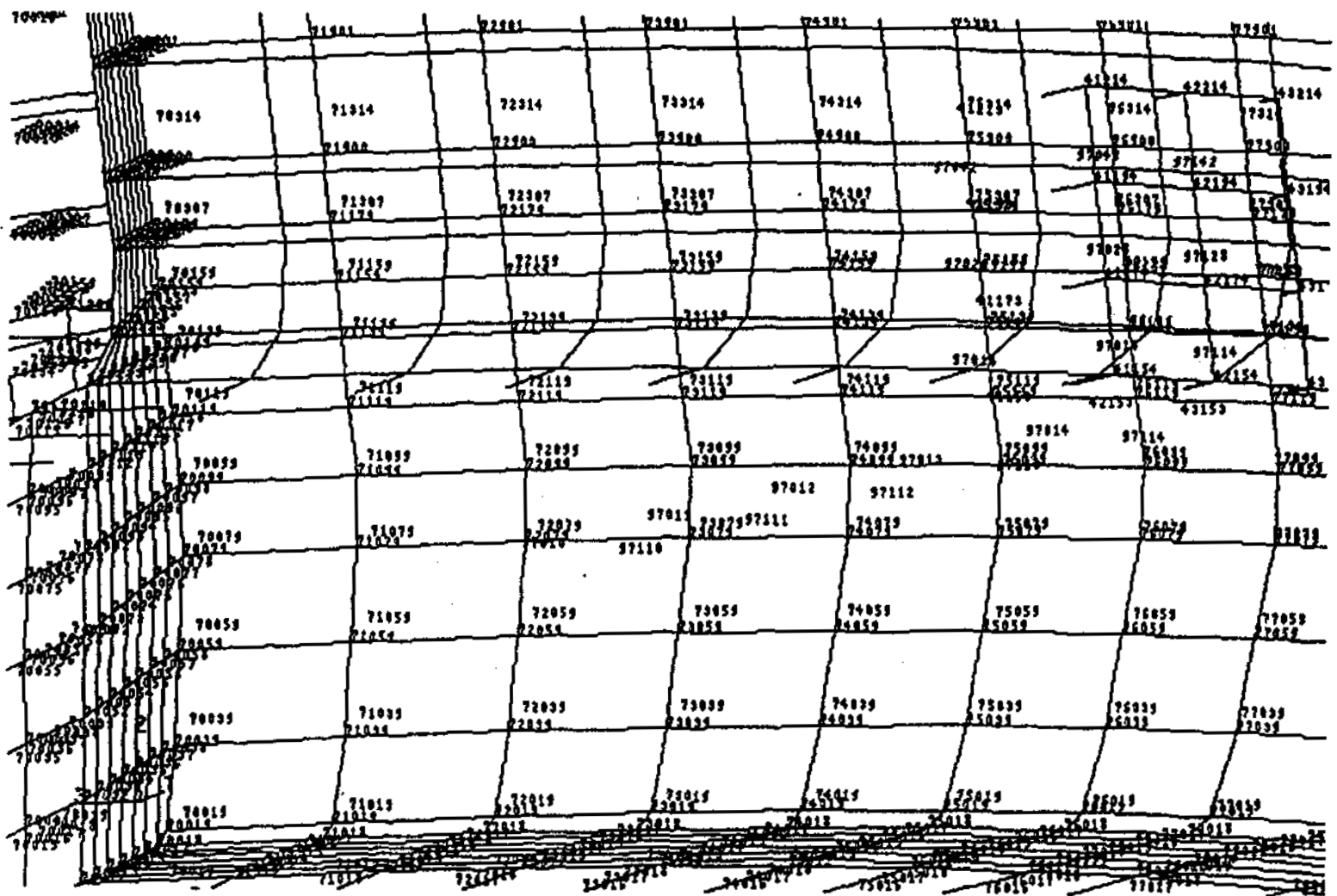

Node and Element Plot near Impact Area 


\section{CHECK LOWER WELD}

The table values are the results at the center of the elements. The strain contour plots Mrestetrpolated at the surface. Following calculations are based on the stress and strain plot at node 72179.

AT TIME $=0.021$ SECOND NOTE: maximum maximum principal stress from table

$$
\begin{array}{ll}
\text { minimum principal stress } & \sigma_{1}:=-20000 \\
\text { intermediate principal stress } & \sigma_{2}:=400 \\
\text { maximum principal stress } & \sigma_{3}:=16000 \\
\text { equivalent plastic strain } & \varepsilon_{\mathrm{eq}}:=0.0175
\end{array}
$$

than the mises stress is

$$
\text { Mises }:=\frac{1}{\sqrt{2}} \cdot\left[\left(\sigma_{1}-\sigma_{2}\right)^{2}+\left(\sigma_{2}-\sigma_{3}\right)^{2}+\left(\sigma_{3}-\sigma_{1}\right)^{2}\right]^{\frac{1}{2}} \quad \text { Mises }=3.127 \cdot 10^{4}
$$

Triaxiality Factor is

$$
\mathrm{TF}:=\frac{\left(\sigma_{1}+\sigma_{2}+\sigma_{3}\right)}{\text { Mises }} \quad \mathrm{TF}=-0.115
$$

Total elongation for stainiess steel $304 \mathrm{~L}$ is

$$
e_{t}:=0.214
$$

effective failure strain is

$$
\begin{array}{r}
e_{f}:=i f\left[T>0,\left(e_{t} \cdot 2^{1-T F}\right), 2 \cdot e_{t}\right] \\
e_{f}=0.428>\varepsilon_{e q} O . K .
\end{array}
$$




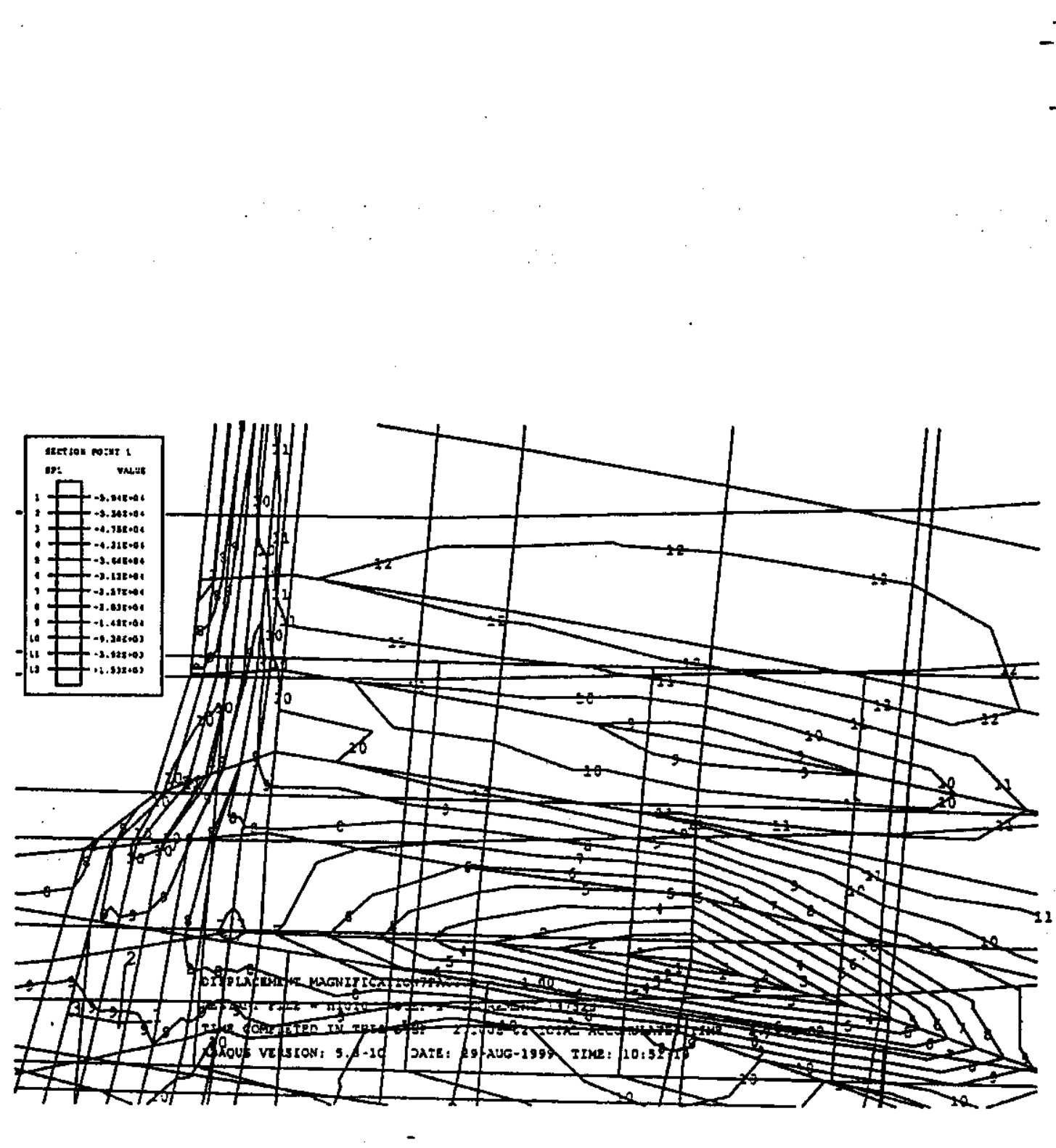

Minimum Principal Stress on node 72179 at 0.021 Second 


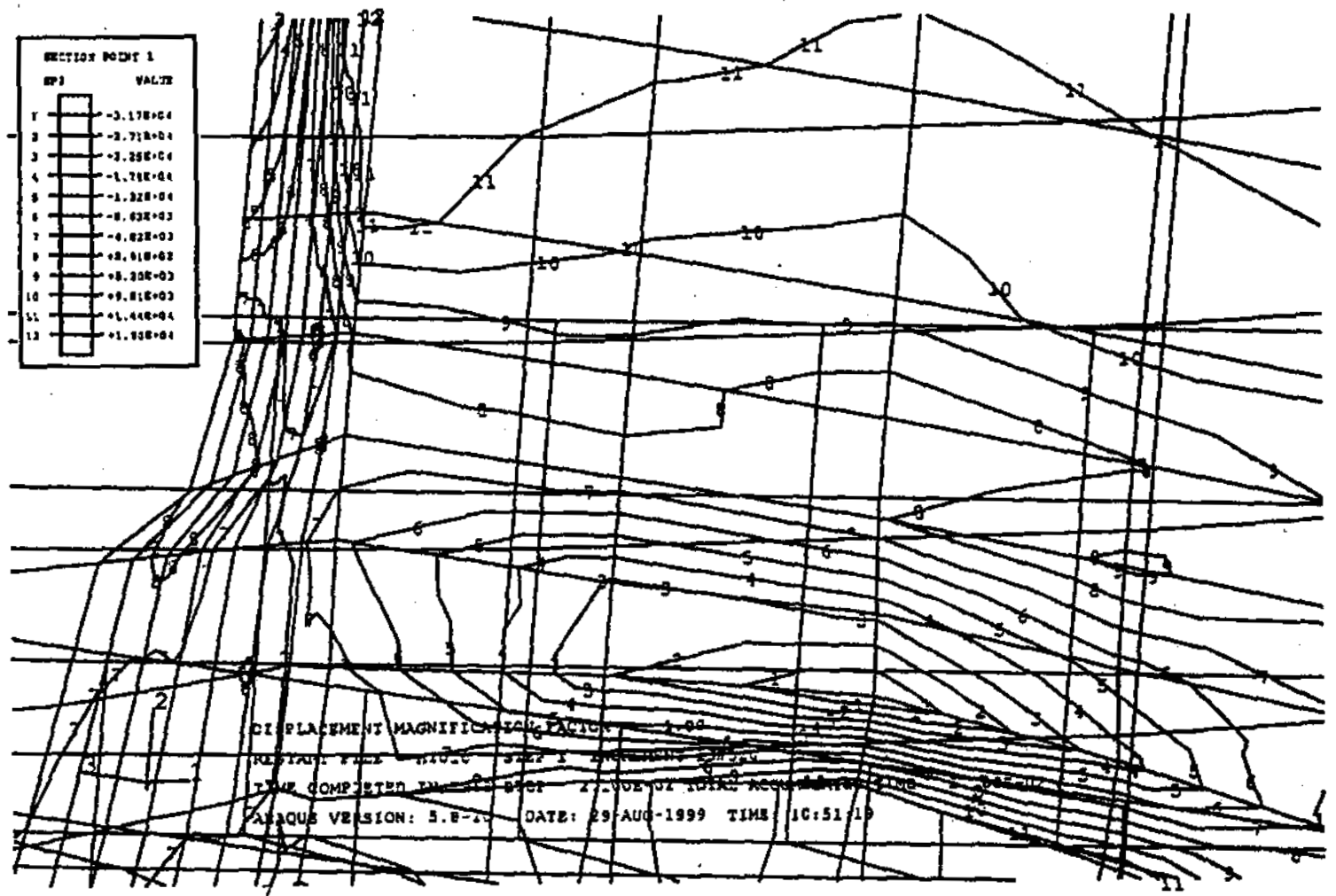

Intermediate Principal Stress on node 72179 at 0.021 Second 


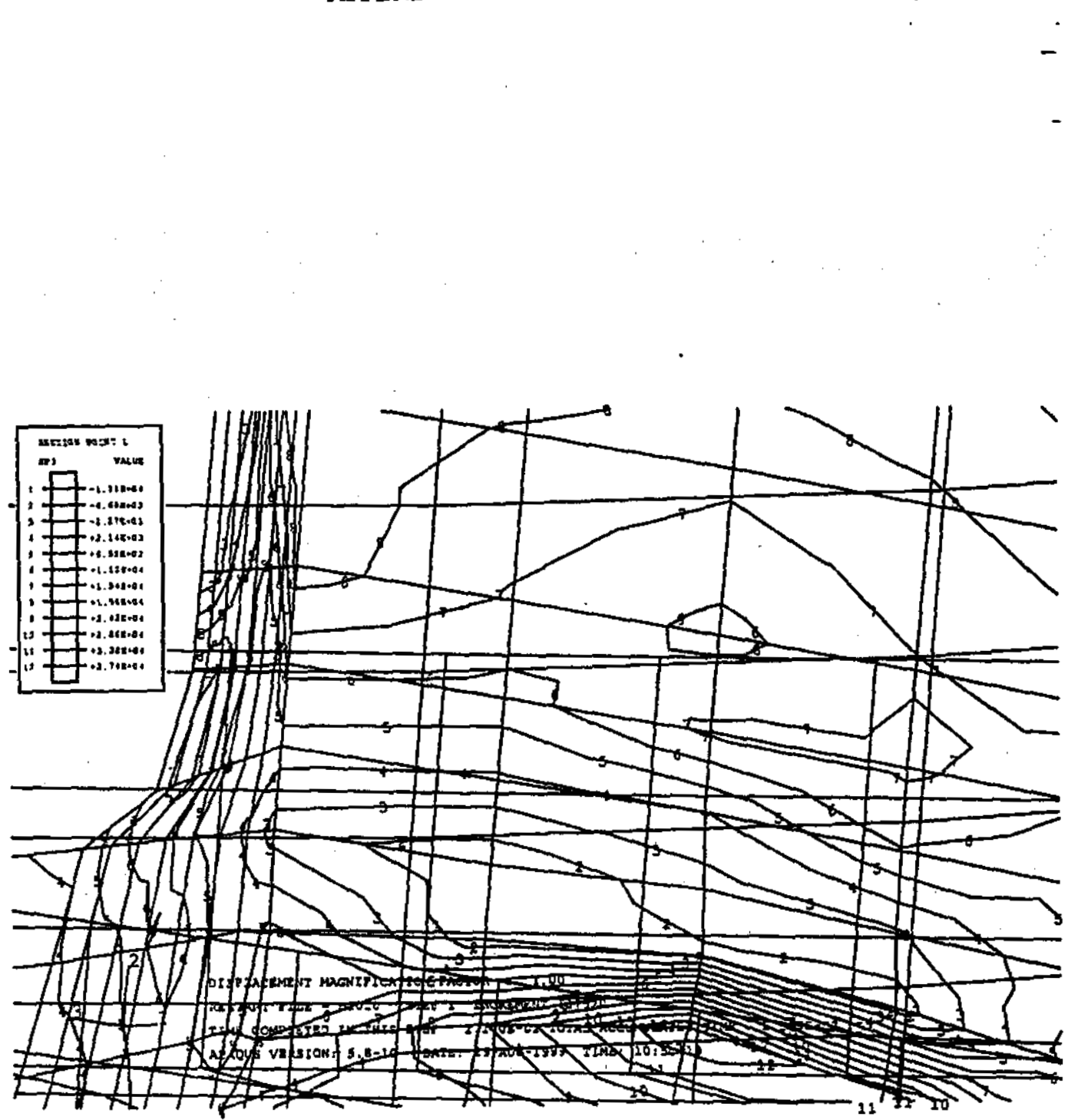

Maximum Principal Stress on node 72179 at 0.02175 Second 


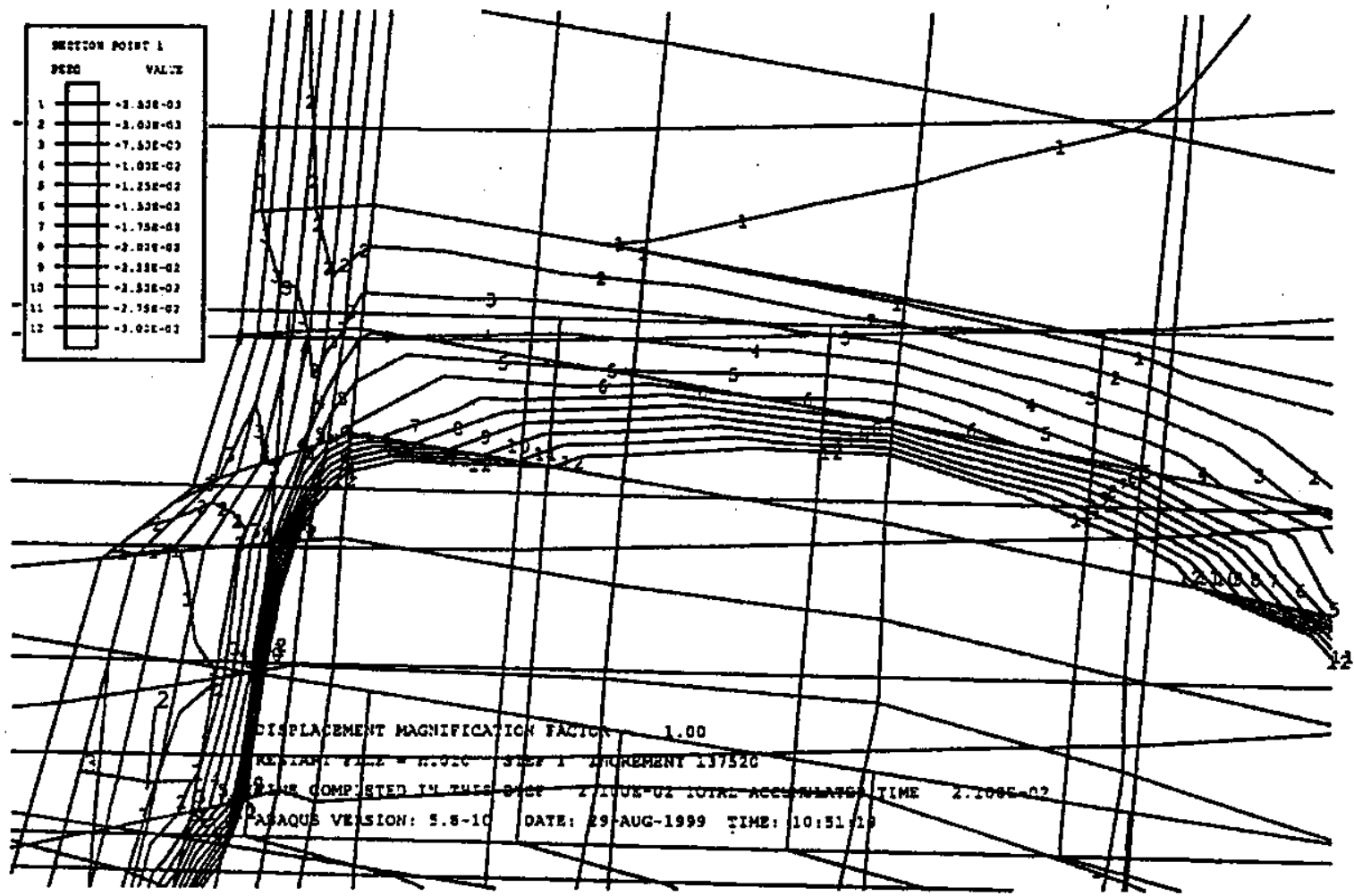

Equivalent Plastic Strain on node 72179 at 0.02 Second 
AT TIME $=0.02175$ SECOND NOTE: near maximum triaxial factor

$\begin{array}{ll}\text { minimum principal stress } & \sigma_{1}:=-9500 \\ \text { intermediate principal stress } & \sigma_{2}:=5400 \\ \text { maximum principal stress } & \sigma_{3}:=22000 \\ \text { equivalent plastic strain } & \varepsilon_{\text {eq }}:=0.02\end{array}$

than the mises stress is

$$
\text { Mises }:=\frac{1}{\sqrt{2}} \cdot\left[\left(\sigma_{1} \quad \sigma_{2}\right)^{2}+\left(\sigma_{2}-\sigma_{3}\right)^{2}+\left(\sigma_{3}-\sigma_{1}\right)^{2}\right]^{\frac{1}{2}} \quad \text { Mises }=2.72910^{4}
$$

Triaxiality Factor is

$$
\mathrm{TF}:=\frac{\left(\sigma_{1}+\sigma_{2}+\sigma_{3}\right)}{\text { Mises }} \quad \mathrm{TF}=0.656
$$

effective failure strain is

$$
\begin{array}{r}
e_{f}:=i f\left[T>0,\left(e_{t} \cdot 2^{1-T F}\right), 2 \cdot e_{t}\right] \quad>\varepsilon_{e q} O . K . \\
e_{f}=0.272>
\end{array}
$$




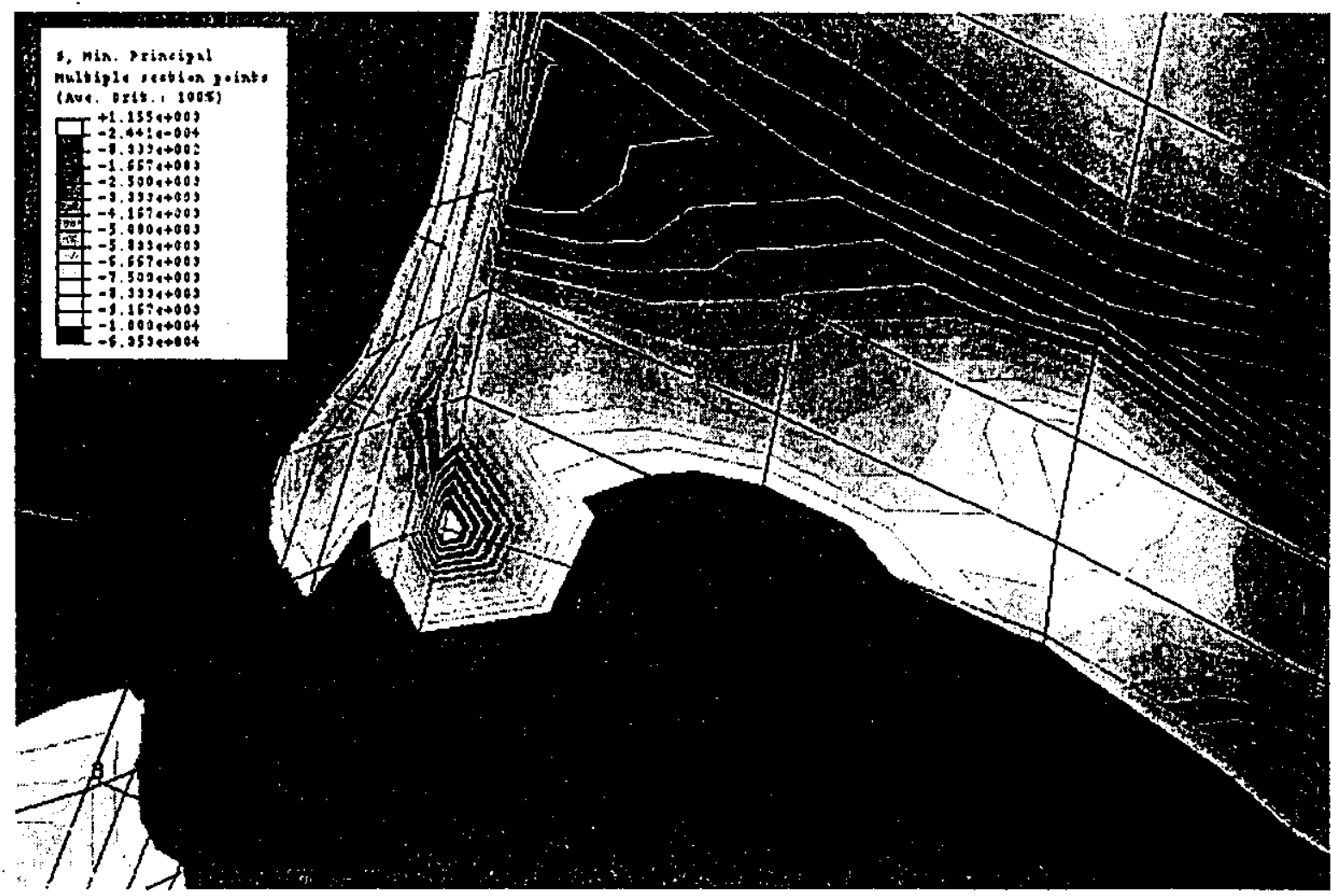

Minimum Principal Stress on node 72179 at 0.02175 Second 


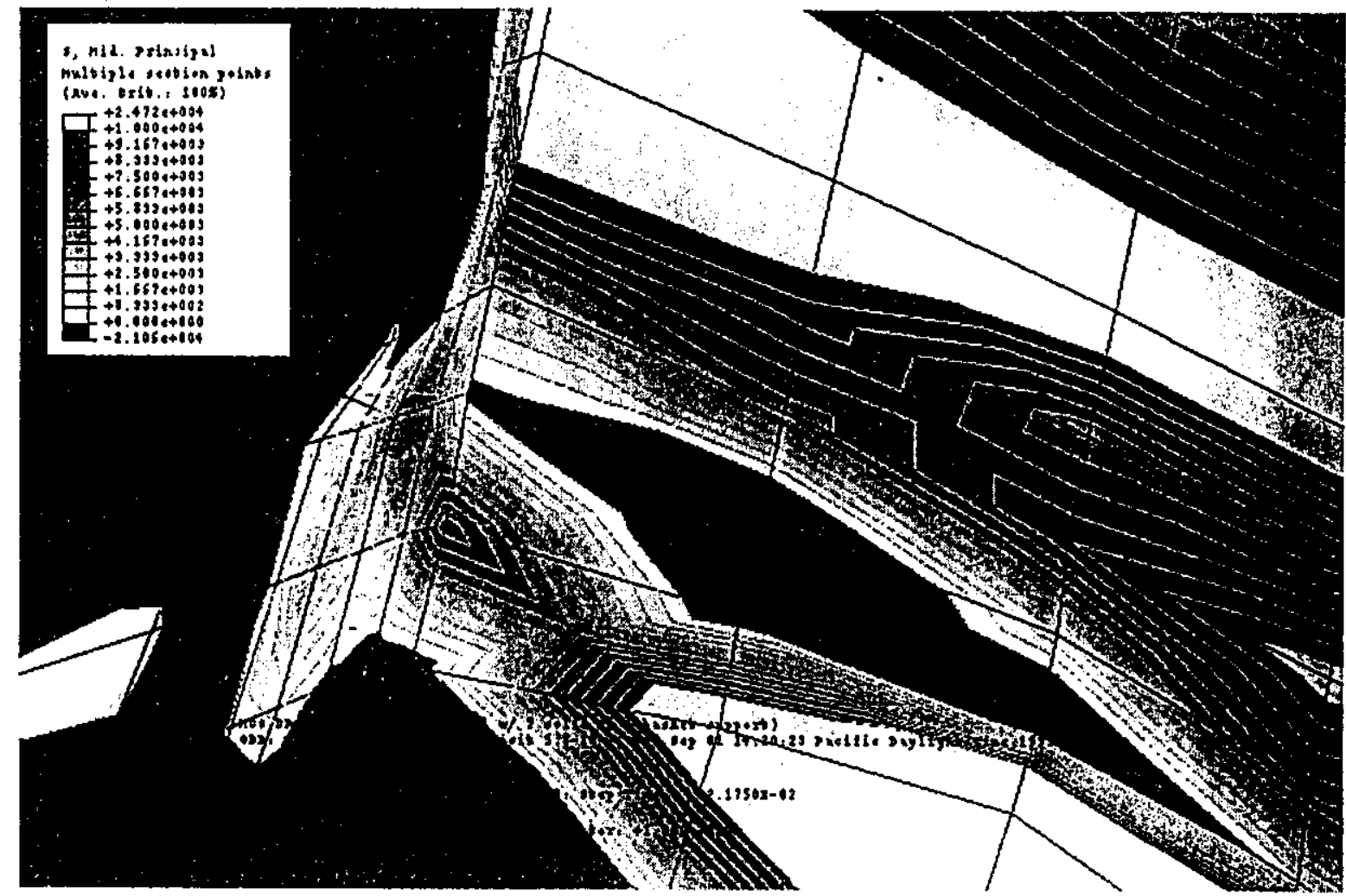

Intermediate Principal Stress on node 72179 at 0.02175 Second 


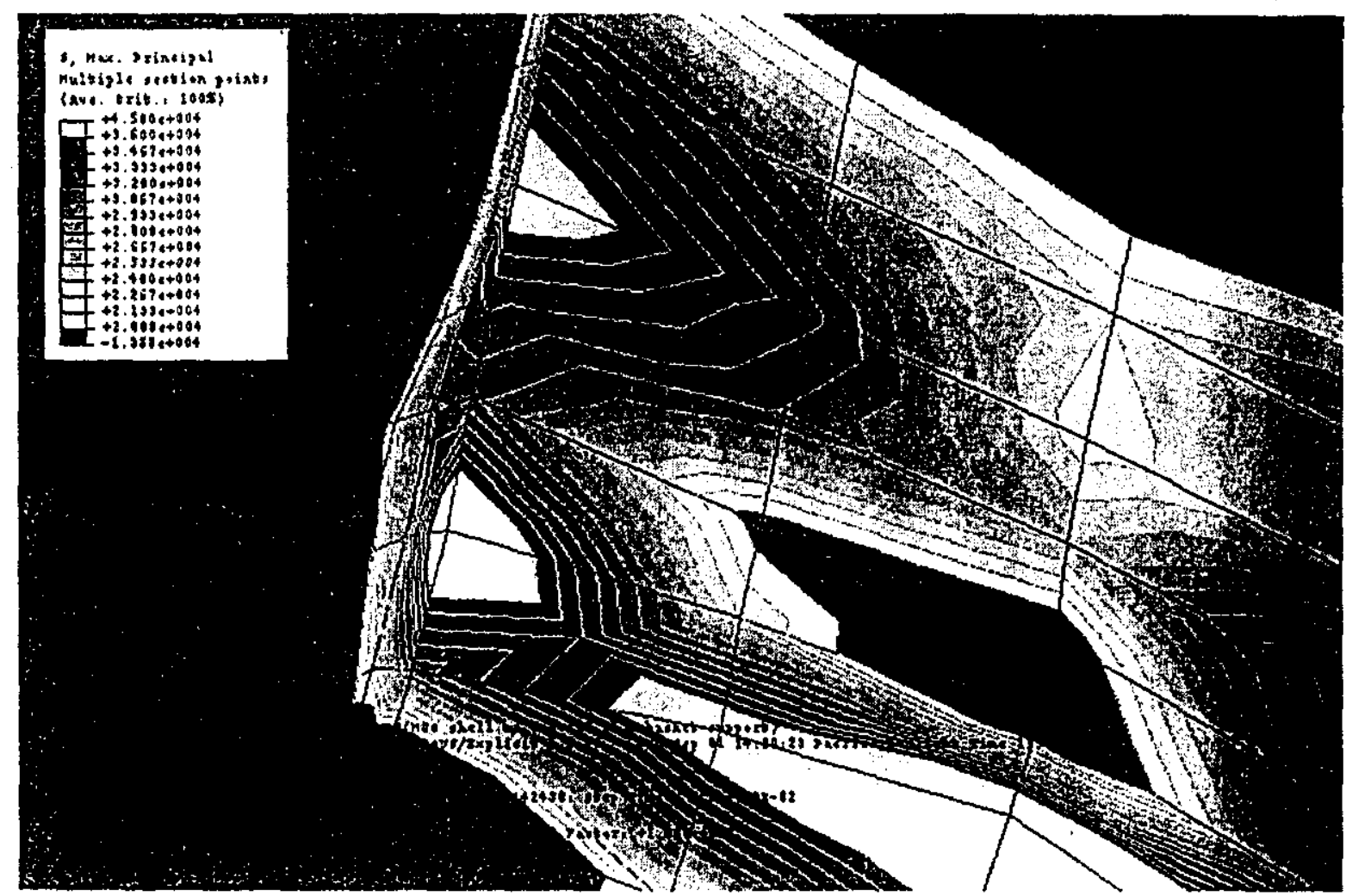

Maximum Principal Stress on node 72179 at 0.02175 Second 


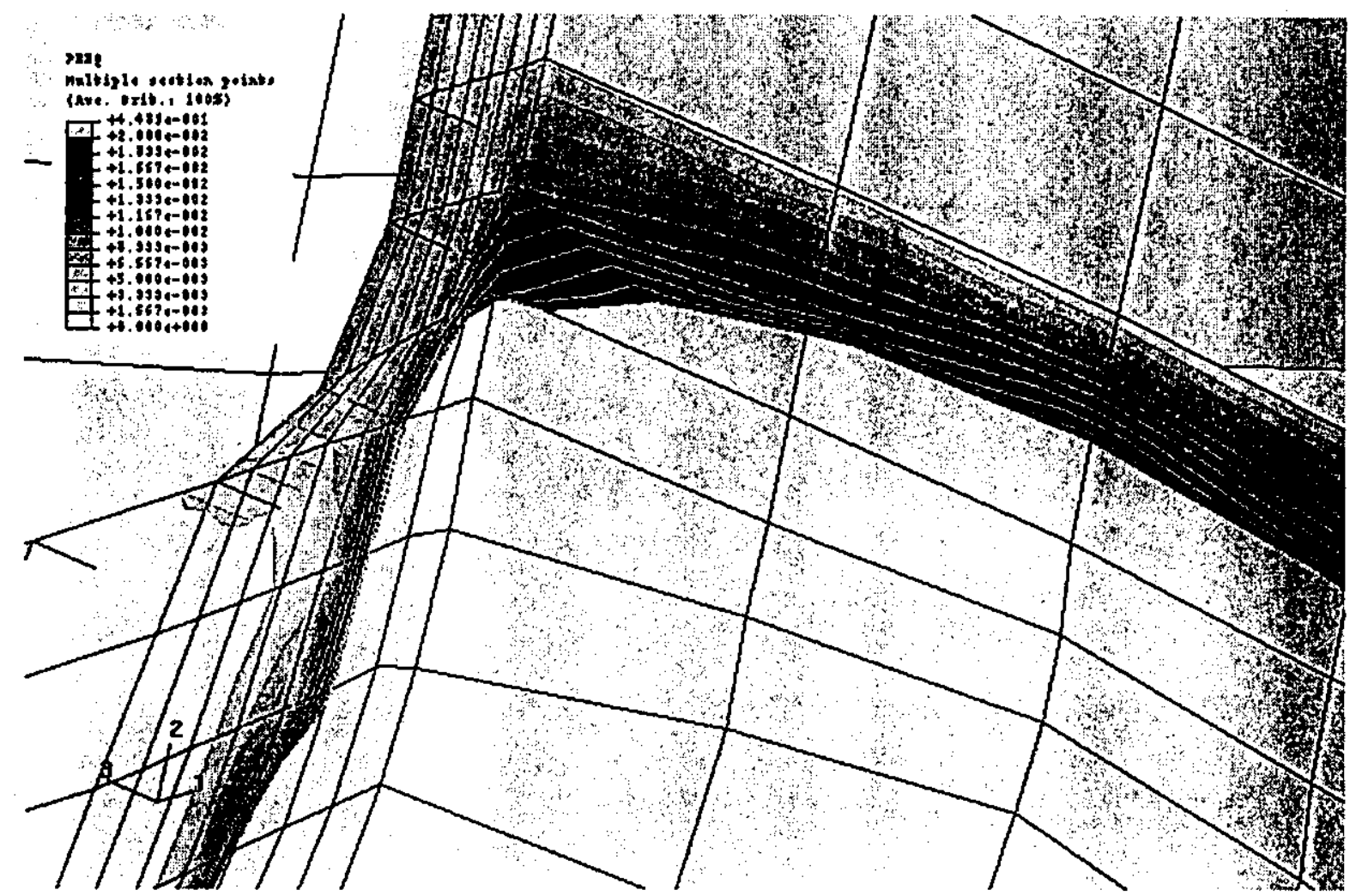

Equivalent Plastic Stress on node 72179 at 0.02175 Second 


\section{B.2 CHECK MCO BOTTOM}

ELEMENT 70019 (located at MCO bottom maximum strain area)

\begin{tabular}{|c|c|c|c|c|c|c|c|c|c|}
\hline $\begin{array}{c}\text { time } \\
\text { (second) }\end{array}$ & $\begin{array}{c}\text { minimum } \\
\text { principal } \\
\text { stress } \\
\text { (psi) }\end{array}$ & $\begin{array}{c}\text { intermed. } \\
\text { principal } \\
\text { stress } \\
\text { (psi) }\end{array}$ & $\begin{array}{c}\text { maximum } \\
\text { principal } \\
\text { stress } \\
\text { (psi) }\end{array}$ & $\begin{array}{l}\text { minimum } \\
\text { prinicipal } \\
\text { plastic } \\
\text { strain }\end{array}$ & $\begin{array}{c}\text { intermed. } \\
\text { principal } \\
\text { plastic } \\
\text { strain }\end{array}$ & $\begin{array}{c}\text { maximum } \\
\text { principal } \\
\text { plastic } \\
\text { strain }\end{array}$ & $\begin{array}{c}\text { triaxiality } \\
\text { factor } \\
\text { (TF) }\end{array}$ & $\begin{array}{c}\text { Mises } \\
\text { stress } \\
\text { (psi) }\end{array}$ & $\begin{array}{c}\text { equivalent } \\
\text { plastic } \\
\text { strain }\end{array}$ \\
\hline 0.0008 & -179210 & -124550 & -69634 & -0.1448 & 0.0012 & 0.1436 & -3.9348 & 94896 & 0.1665 \\
\hline 0.0015 & -192760 & -129700 & -67042 & -0.2091 & 0.0018 & 0.2073 & -3.5775 & 108875 & 0.2404 \\
\hline 0.0023 & -206460 & -134520 & -62126 & -0.2861 & 0.0014 & 0.2847 & -3.2249 & 124997 & 0.3296 \\
\hline 0.0030 & -211240 & -135840 & -62855 & -0.3142 & 0.0016 & 0.3126 & -3.1899 & 128511 & 0.3619 \\
\hline 0.0038 & -183340 & -121980 & -49669 & -0.3308 & 0.0018 & 0.3290 & -3.0631 & 115892 & 0.3809 \\
\hline 0.0045 & -118230 & -91761 & -26585 & -0.3308 & 0.0018 & 0.3290 & -2.8959 & 81692 & 0.3809 \\
\hline 0.0053 & -97067 & -78911 & -19176 & -0.3308 & 0.0018 & 0.3290 & -2.7647 & 70587 & 0.3809 \\
\hline 0.0060 & -104790 & -85078 & -25733 & -0.3308 & 0.0018 & 0.3290 & -3.0249 & 71276 & 0.3809 \\
\hline 0.0068 & -133200 & -100830 & -37161 & -0.3308 & 0.0018 & 0.3290 & -3.2044 & 84632 & 0.3809 \\
\hline 0.0075 & -162260 & -115330 & -47240 & -0.3308 & 0.0018 & 0.3290 & -3.2428 & 100171 & 0.3809 \\
\hline 0.0083 & -124870 & -97508 & -33537 & -0.3308 & 0.0018 & 0.3290 & -3.1522 & 81187 & 0.3809 \\
\hline 0.0090 & -81260 & -73948 & -15979 & -0.3308 & 0.0018 & 0.3290 & -2.7633 & 61949 & 0.3809 \\
\hline 0.0098 & -65744 & -54969 & -7096 & -0.3308 & 0.0018 & 0.3290 & -2.3637 & 54072 & 0.3809 \\
\hline 0.0105 & -54531 & -33510 & -86 & -0.3308 & 0.0018 & 0.3290 & -1.8531 & 47557 & 0.3809 \\
\hline 0.0113 & -49601 & -22341 & 2844 & -0.3308 & 0.0018 & 0.3290 & -1.5210 & 45431 & 0.3809 \\
\hline 0.0120 & -57787 & -37133 & -2965 & -0.3308 & 0.0018 & 0.3290 & -2.0412 & 47956 & 0.3809 \\
\hline 0.0128 & -64941 & -51592 & -8088 & -0.3308 & 0.0018 & 0.3290 & -2.4202 & 51493 & 0.3809 \\
\hline 0.0135 & -154570 & -113450 & -46452 & -0.3308 & 0.0018 & 0.3290 & -3.3269 & 94523 & 0.3809 \\
\hline 0.0143 & -112710 & -96877 & -43459 & -0.3310 & 0.0018 & 0.3292 & -4.0263 & 62848 & 0.3812 \\
\hline 0.0150 & -62543 & -21574 & -4666 & -0.3310 & 0.0018 & 0.3292 & -1.7224 & 51547 & 0.3812 \\
\hline 0.0158 & -59030 & -11461 & 8886 & -0.3310 & 0.0018 & 0.3292 & -1.0204 & 60371 & 0.3812 \\
\hline 0.0165 & -49230 & -7998 & 27905 & -0.3310 & 0.0018 & 0.3292 & -0.4386 & 66854 & 0.3812 \\
\hline 0.0173 & -41876 & -9322 & 29111 & -0.3310 & 0.0018 & 0.3292 & -0.3589 & 61547 & 0.3812 \\
\hline 0.0180 & -50712 & -10719 & 24812 & -0.3310 & 0.0018 & 0.3292 & -0.5595 & 65444 & 0.3812 \\
\hline 0.0188 & -79223 & -38824 & -10472 & -0.3310 & 0.0018 & 0.3292 & -2.1476 & 59844 & 0.3812 \\
\hline 0.0195 & -81066 & -30487 & -7435 & -0.3310 & 0.0018 & 0.3292 & -1.8240 & 65235 & 0.3812 \\
\hline 0.0203 & -78094 & -17704 & -2898 & -0.3310 & 0.0018 & 0.3292 & -1.4305 & 68995 & 0.3812 \\
\hline 0.0210 & -69833 & -19316 & -6858 & -0.3310 & 0.0018 & 0.3292 & -1.6621 & 57763 & 0.3812 \\
\hline 0.0218 & -64766 & -21103 & -6776 & -0.3310 & 0.0018 & 0.3292 & -1.7708 & 52319 & 0.3812 \\
\hline 0.0225 & -64810 & -20060 & -5768 & -0.3310 & 0.0018 & 0.3292 & -1.6989 & 53352 & 0.3812 \\
\hline 0.0233 & -83435 & -34240 & -12015 & -0.3310 & 0.0018 & 0.3292 & -2.0487 & 63304 & 0.3812 \\
\hline 0.0240 & -74936 & -16608 & -1759 & -0.3310 & 0.0018 & 0.3292 & -1.3926 & 66998 & 0.3812 \\
\hline 0.0248 & -81402 & -33337 & -9693 & -0.3310 & 0.0018 & 0.3292 & -1.9660 & 63291 & 0.3812 \\
\hline 0.0255 & -77050 & -30684 & -7337 & -0.3310 & 0.0018 & 0.3292 & -1.8723 & 61461 & 0.3812 \\
\hline 0.0263 & -74068 & -30800 & -8495 & -0.3310 & 0.0018 & 0.3292 & -1.9631 & 57747 & 0.3812 \\
\hline 0.0270 & -70087 & -27219 & -7756 & -0.3310 & 0.0018 & 0.3292 & -1.9021 & 55234 & 0.3812 \\
\hline 0.0278 & -69973 & -27192 & -6981 & -0.3310 & 0.0018 & 0.3292 & -1.8695 & 55708 & 0.3812 \\
\hline Max. & -41876 & -7998 & 29111 & -0.14480 & 0.00178 & 0.32920 & -0.3589 & 128511 & 0.3812 \\
\hline Min. & -211240 & -135840 & -69634 & -0.33100 & 0.00120 & 0.14360 & -4.0263 & 45431 & 0.1665 \\
\hline
\end{tabular}




\section{CHECK MCO BOTTOM}

Following calculations are based on the stress and strain plot at node 70019.

AT TIME $=0.0052501$ SECOND

minimum principal stress

intermediate principal stress

maximum principal stress

equivalent plastic strain
NOTE: near maximum triaxial factor

$$
\sigma_{1}:=-107900
$$$$
\sigma_{2}:=-78910
$$$$
\sigma_{3}:=-20300
$$

$\varepsilon_{\text {eq }}:=0.3966$

than the mises stress is

$$
\text { Mises }:=\frac{1}{\sqrt{2}} \cdot\left[\left(\sigma_{1}-\sigma_{2}\right)^{2}+\left(\sigma_{2}-\sigma_{3}\right)^{2}+\left(\sigma_{3}-\sigma_{1}\right)^{2}\right]^{\frac{1}{2}} \quad \text { Mises }=7.73 \cdot 10^{4}
$$

Triaxiality Factor is

$$
\mathrm{TF}:=\frac{\left(\sigma_{1}+\sigma_{2}+\sigma_{3}\right)}{\text { Mises }} \quad-\quad T \mathrm{~F}=-2.679
$$

Total elongation for stainless steel $304 \mathrm{~L}$ is

$$
e_{t}:=0.40
$$

effective failure strain is

$$
\begin{aligned}
\left.e_{f}:=i f T F>0,\left(e_{t} \cdot 2^{1-T F}\right), 2 \cdot e_{t}\right] & \\
e_{f}=0.8 & >\varepsilon_{e q} O . K .
\end{aligned}
$$




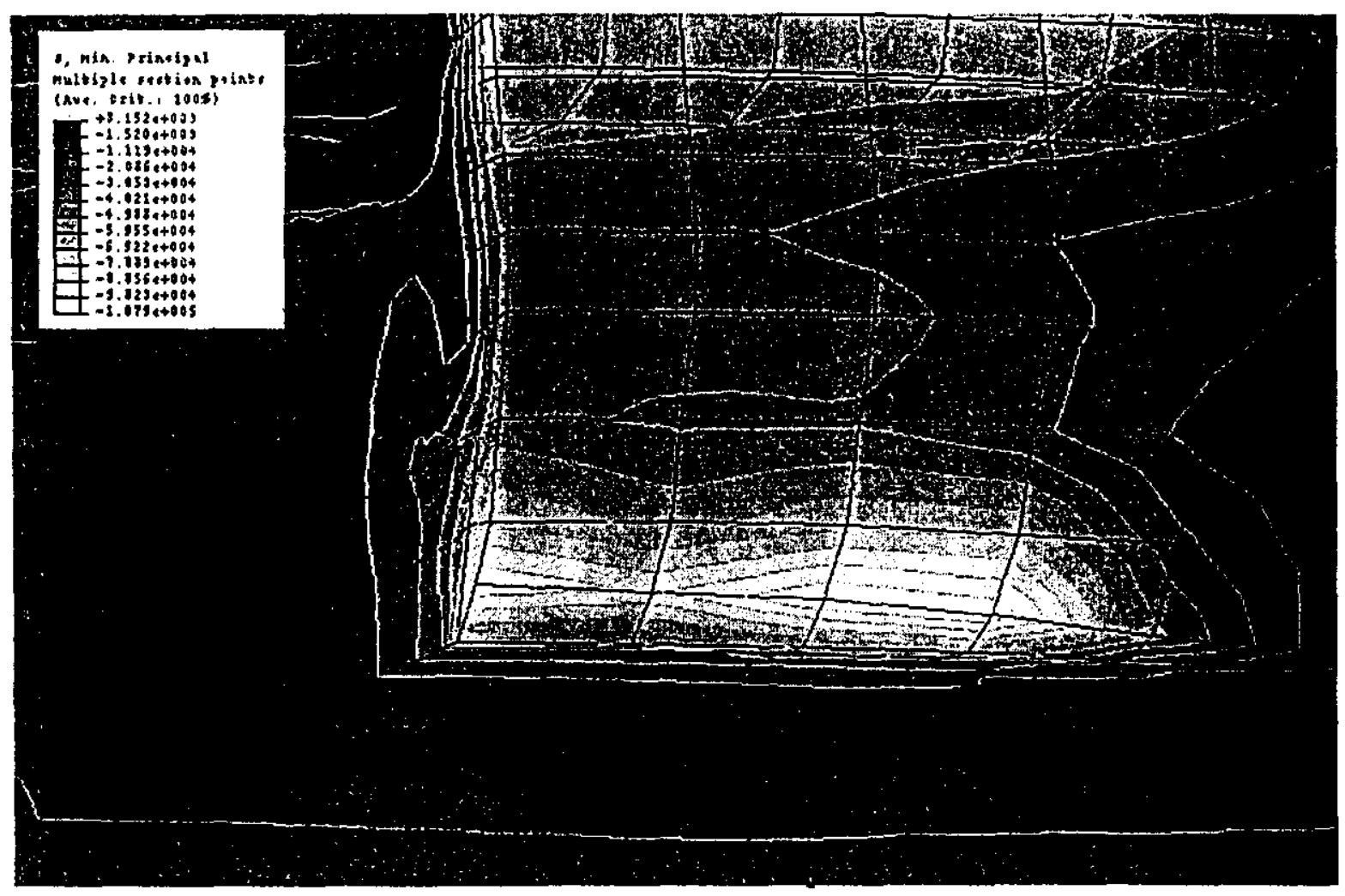

Minimum Principal Stress on node 70019 at 0.0052501 Second 


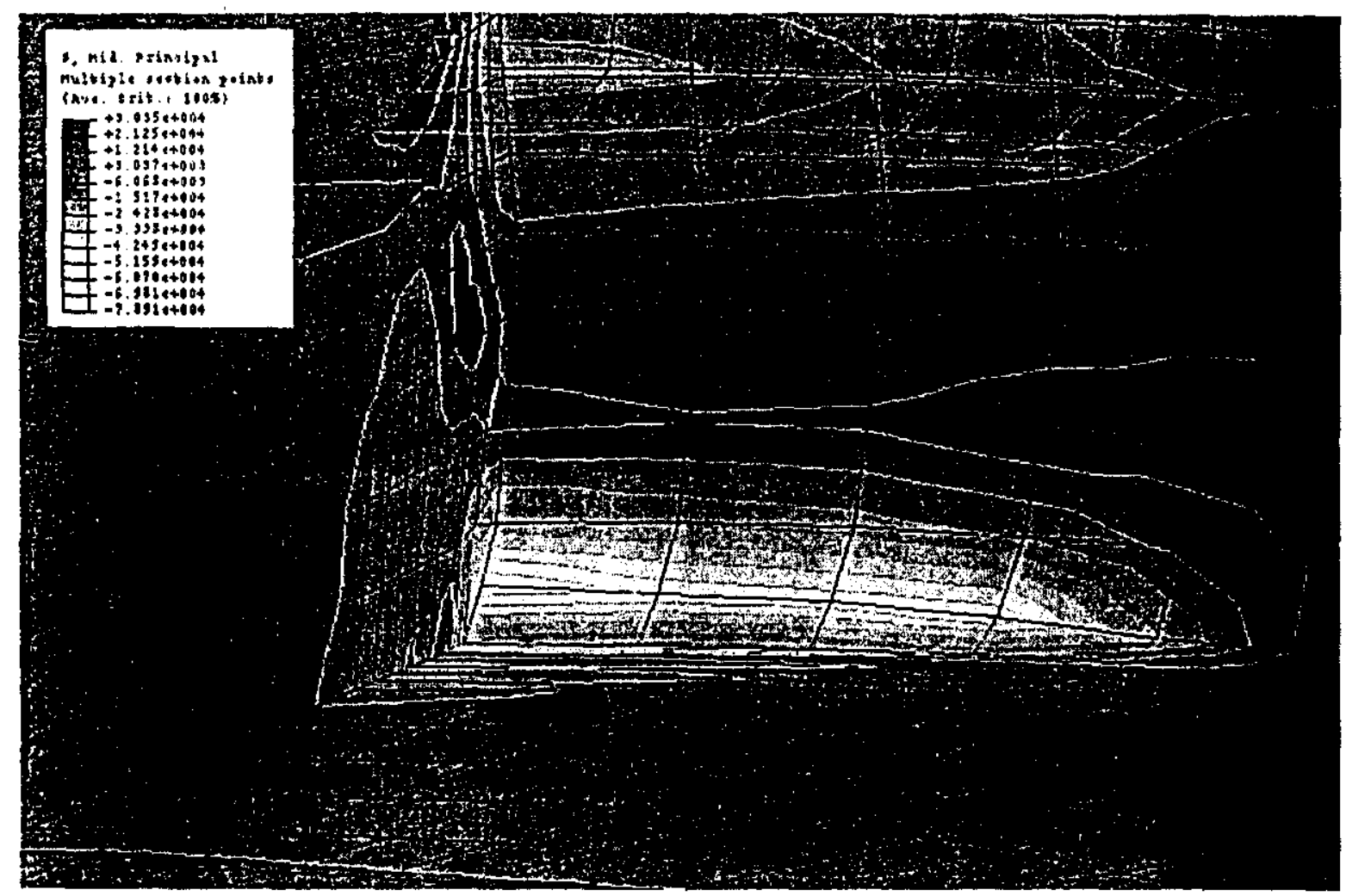

Intermediate Principal Stress on node 70019 at 0.0052501 Second 


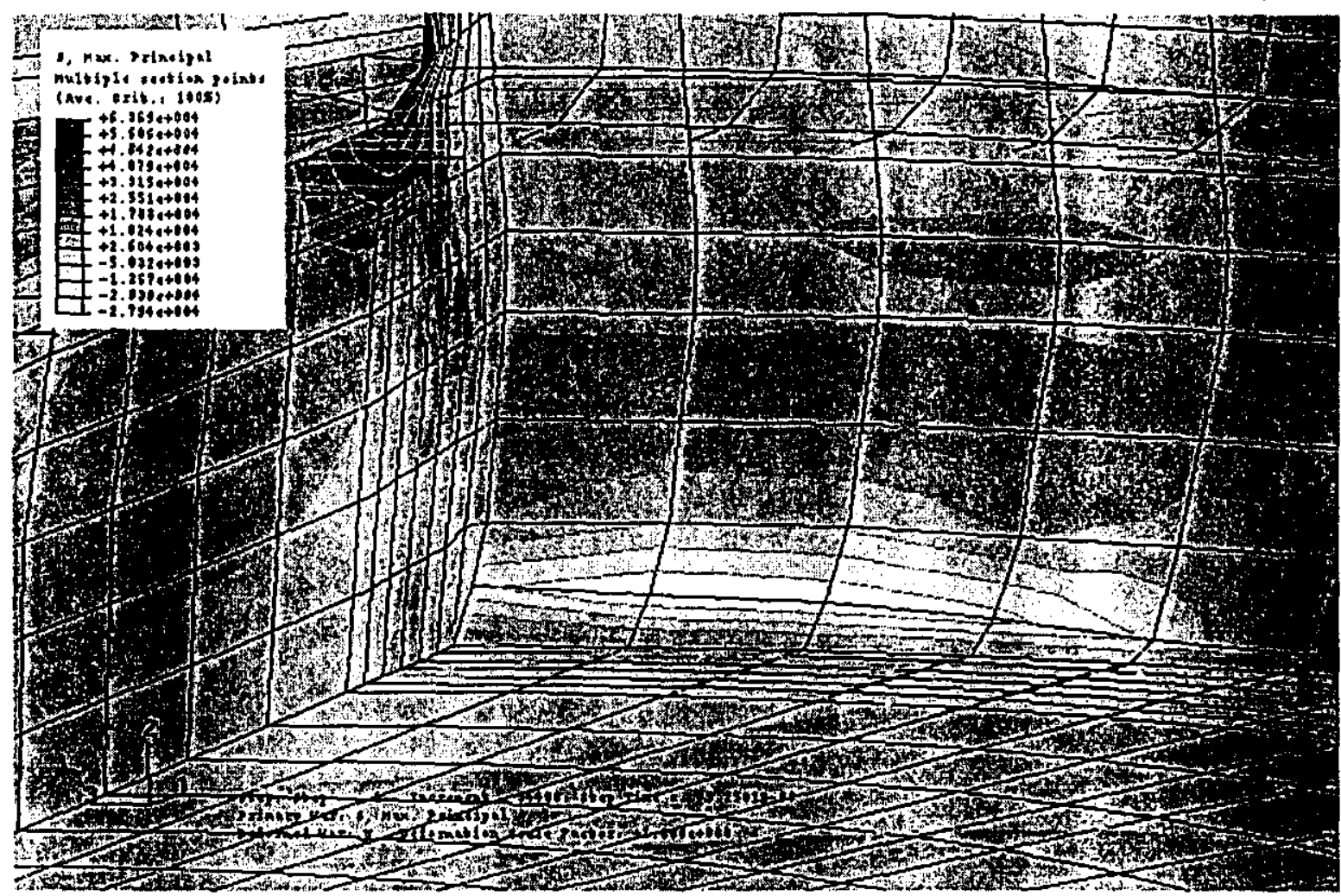

Maximum Principal Stress on node 70019 at 0.0052501 Second 


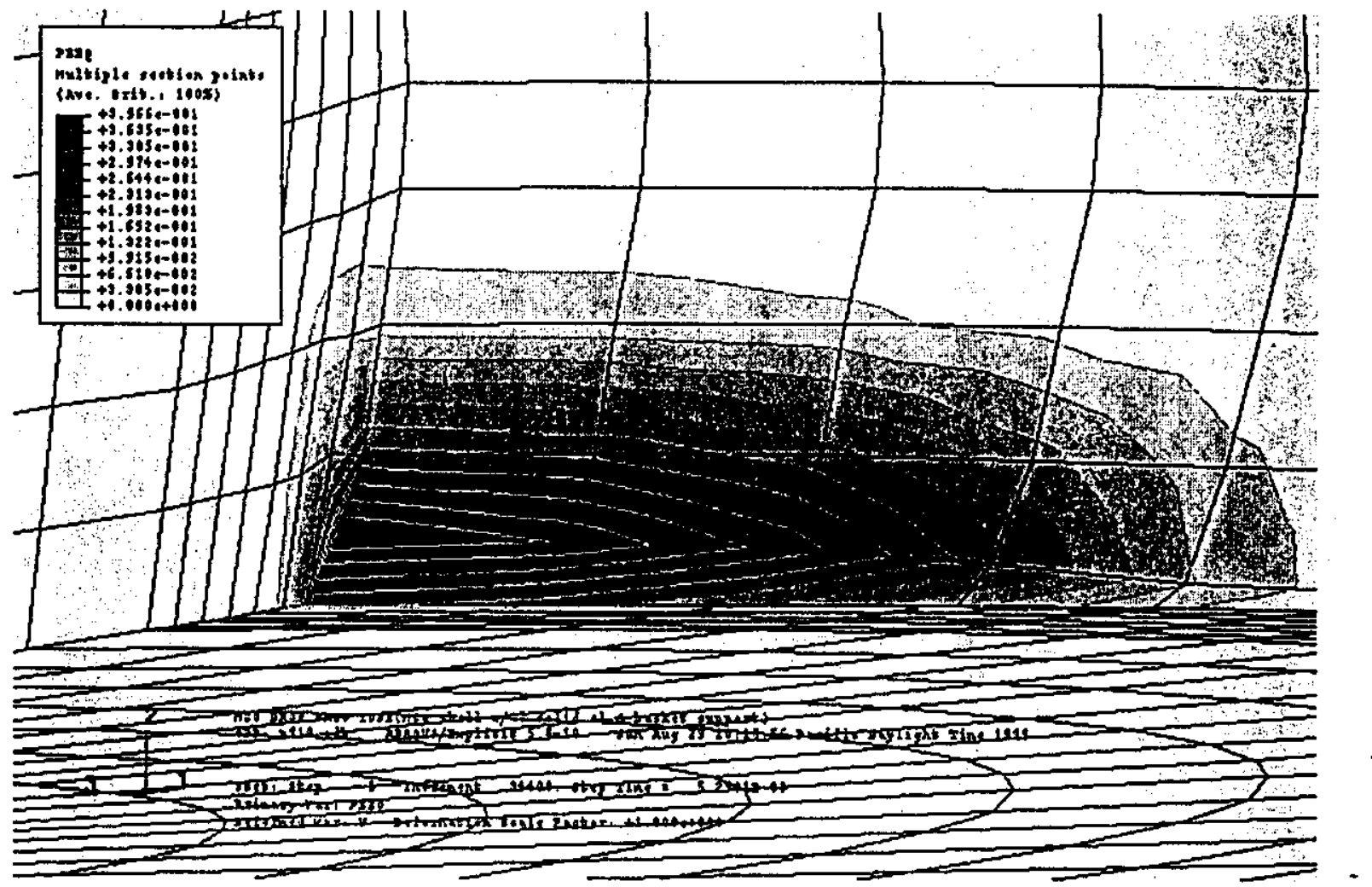

Equivalent Plastic Strain on node 70019 at 0.0052501 Second 


\section{APPENDIX - C COMPUTER INPUT FILES}




\title{
APPENDIX C
}

\section{ABAQUS INPUT FILE}

\author{
SECTION ONE
}

\section{MCO DROP ON STANDARD STORAGE TUBE}

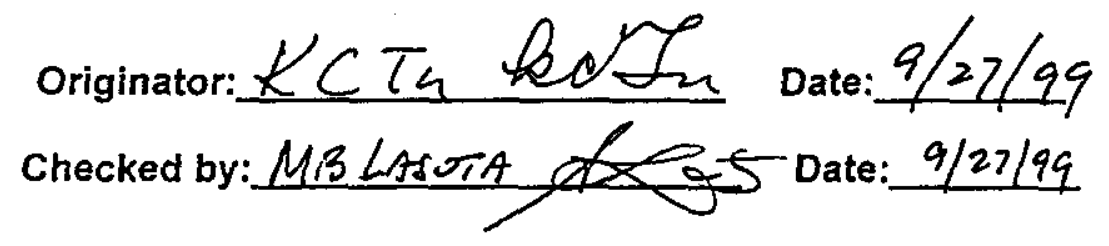


** file "nio_10.inp"

*HEADING

MCO DROP ONTO TUBECMCO shell w/ 7 solid el \&

basket support)

*INCLUDE, INPUT =mco7.txt

*INCLUDE, INPUT=b\$K1a4 . txt

*SYSTEM

\#INCLUDE, . INPUT $=s t d s t d 2 . t \times t$

*SYSTEM

$-1,22.75$

"NODE, NSET $=R$ RO 1

$95001,-17.5,55,0$

$95003,-17.5,114.15,0$

$95005,-13.625,128,91,0$

$95007,-13.625,160 ., 0$

*NODE, NSET $=R G D 2$

$95011,17.5,55,0$

$95013,17.5,114.15,0$

$95015,13.625,128.91,0$

$95017,13.625,160 ., 0$

\SYSTEM

,

*NÓDE, NSET $=$ RGO3

$95031,15.25,-34.5,0$

$95041,15.25,-3,0$

$95051,16.00,-2.25,0$

$95061,23.625,-2.25,0$

$95071,23.625,6,0$

- NCOPY, CHANGE NUMBER=1, OLD SET $=R G O 3, S H I F T, N E W$ SE $T=R$ GD3, $\mathrm{mul}$ i i pl $\mathrm{e}=6$

, 0 ,

$0,0,0,0,1,0,3.44$

* $N$ COPY, CHANGE NUMBER $=1$, OLO SET $=R G O 2, S H I F T, N E W$ SET=RGD2

0 ,

$0,0,0,0,1,0,3.75$

* NCOPY, CHANGE NUMBER $=1$, OLD SET=RGD 1, SHIFT, NEW SET $=R G D 1$

.0 ,

$0,0,0,0,1,0,-15$.

"node

$95020,-12.625,100$. ,

$95099,23.625,-10,0$

* el ement , type $=$ R304, el set $=$ rod1

$95001,95001,95002,95004,95003$

$95002,95003,95004,95006,95005$

$95003,95005,95006,95008,95007$

*et ement, type $=R 304$, elset $=$ rgd2

$95004,95011,95012,95014,95013$

$95005,95013,95014,95016,95015$

$95006,95015,95016,95018,95017$

*el ement , type=R304, el set $=r g d 3$

95007, 95031, 95032, 95042, 95041

*el gen, el set $=$ rgd3

$95007,4,10,1,5,1,4$

**

*ELSET, ELSET $=S S T A$

FLANG, TUBES, TUBEP

*ELSET, ELSET $=T T T$

MCO, EBSK, SSTA

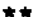

* SOLIO SECTION, ELSET=FLANG, MATERIAL =SA36

*SOLID SECTION, ELSET=TUBES, MATERIAL=SA36

*SHELL SECTION, ELSET=TUBEP, MATERIAL $\approx S A 36$

0.5

*rigid body, elset $=r g d 1$, ref node $=95020$
1.31

* rigid body, elset=rgd?, ref node $=95020$

0.001

*rigid body, elset=rgd3, ref node $=95099$

0.001

*MATERIAL, NAME=SS304

*DENSITY

.000735

*ELASTIC

$28 . E+06, .27$

*PLASTIC

36961,0

$38390,0.02$

$40405,0.05$

$41771,0.08$

$45369,0.18$

$51002,0.37$

$127236,0.466$

MATERIAL, NAME=\$A36

*DENSITY

.0007339

*ELASTIC

29.5E6, 0.30

*PLASTIC

36088,0

$38590,0.0197$

$60421,0.0904$

$75291,0.1486$

**

*BOUNDARY

95020, encastre

95099 , encastre

* initial CONDitions, TYPE=VELOCITY

$\mathrm{MCO}, 2,-264$

BSK, 2, -264

*RESTART, WRITE, NUMBER INTERVAL $=40$

*STEP

*OYNAMIC, EXPLICIT

, 3.E-2

**

* SURFACE DEFINITION, NAME=FTOF

FLGO, 54

FLGB, S1

TUBO, 54

* SURFACE DEFINITION, NAME=DECK

rgd3, SNEG

*CONTACT PAIR, INTERACT ION=FO

FTOF, DECK

* SURFACE INTERACTION, NaMe=Fo

* FRICTION

0.3

**

"SURFACE DEFINITION, NAME=FTIF

FLGL, S6

TUB1, 56

*SURFACE DEFINITION, NAME=MCOBF

$M C O B F, S 4$

$M C O B 8,51$

*CONTACT PAIR, INTERACTION=FM

MCOBF, FTIF

"SURFACE INTERACTION, NAME=FM

-FRICTION

0.3

$* *$

\#SURFACE OEFINITION, NAME=rgdIf rgdl, SPOS

*SURFACE DEFINITION, NAME=MCOTL 
APPENDIX C SECTION ONE INPUT FILE N1010.inp

MCOTL, SPOS

ॠCONTACT PAIR, INTERACTION=FMTL rgd1 $f$, MCOTL

*SURFACE INTERACTION, NAME=FMTL *Friction

0.3

**

" SURFACE DEFINITION, NAME=rgd2f rgd2, SNEG

*SURFACE DEFINITION, NAME=MCOTR MCOTR, SPOS

"CONTACT PAIR, INTERACTION=FMTR rod2f, MCOTR

*SURFACE INTERACTION, NAME=FMTR

\#FRICTION

0.3

**

"SURFACE DEFINITION, NAME=bskb1 bskb1, s1

bske1,s1

bskb1, s4

*SURFACE DEFINITION, NAME=bskb2

bskb2,s1

bskc2,s1

bskb2, 54

ॠSURFACE DEFINITION, NAME=bskb3

bskb3, s1

bskc3, s1

bskb3, 54

* SURFACE DEFINITION, NAME=bSkb4

bSkb4, 51

bskc4, s1

bskb4, S4

*SURFACE DEFINITION, NAME=bskbS

bskb5, $s 1$

bske5, s1

bskb5, 54

-SURFACE DEFINITION，NAME=bskb6

bskb6, $s 1$

bske6, s1

bskb6, 54

*CONTACT NOOE SET, NAME=bspb

bspb

* SURFACE DEFINITION, NAME=mCOSi

meobt, $\$ 2$

meos $i, s 6$

*CONTACT PAIR, INTERACTION=BSmCO

bspb, mCos $i$

"surface INTERACTION, NAME=BSmCo

\#FRICTION

0.3

ॠCONTACT NODE SET, NAME=bspt

bspt

*CONTACT PAIR, INTERACTION=BSKOI

bSPT, BSKB 1

"SURFACE INTERACTION, NAME=BSKO1

-FRICTION

0.3

* SURFACE deFINITION, NaMemmotb

meot, $\mathbf{s} 1$

*elset, el set=mcopi, generate

$70205,70240,1$

$71205,71240,1$

$72205,72240,1$

$73205,73240,1$

$74205,74240,1$

$75205,75240,1$

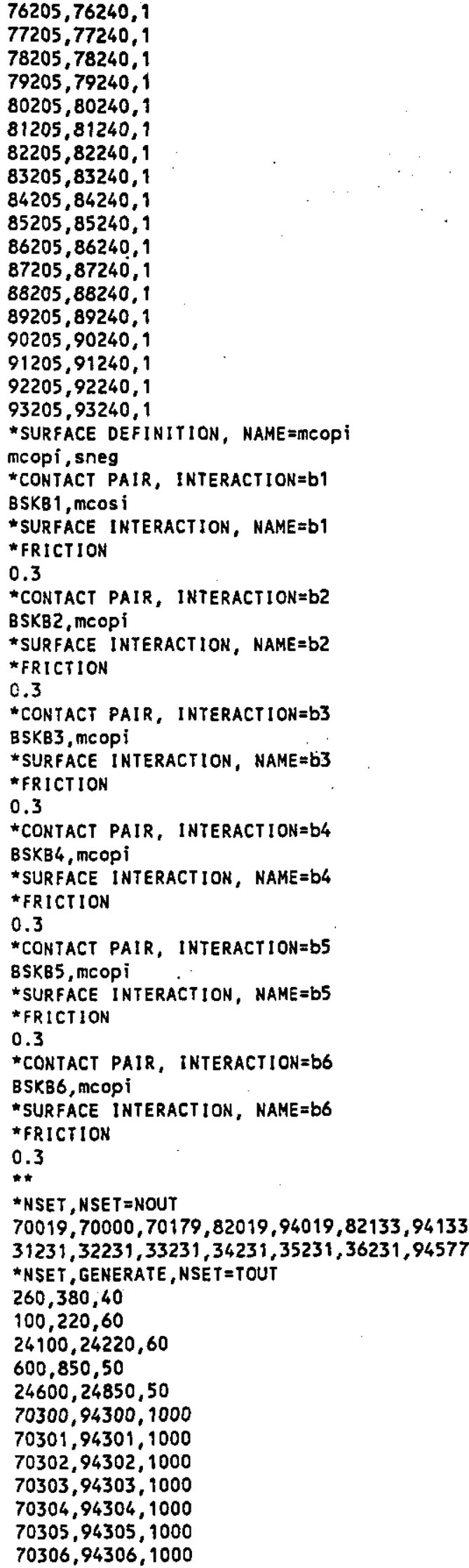


APPENDIXC SECTION ONE INPUT FILE N1010.inp

SNF-5204, Rev. 0/CSB-S-0073

$70307,94307,1000$

$70308,94308,1000$

$70309,94309,1000$

*OUTPUT, HISTORY, TIME INTERVAL=1.E-4

*NOOE OUTPUT, NSET=NOUT

$U, V, A$

NODE OUTPUT, NSET=TOUT

U

*NODE OUTPUT, NSET=P\&LR

$$
\text { RF }
$$

inset, nset=rgon

95020,95099

* NODE OUTPUT, NSET=rgdn

RF

WELSET, ELSET $=E O U T$

70301,70304,70307,70019

*ELEMENT OUTPUT, ELSET =EOUT

S, SP, PE, MI SES, PEEQ

*ENERGY output

ALLKE

-elset, elset=st

flang, tubes, tubep

*energy output, elset =s t

allie, allpd

*output, field, number interval $=40$

- element outout

$S, S P, M I S E S, P E, P E E Q, E, E P$.

-node output

$u, v, r f$

־MON I TOR, NODE $=70019$, DOF $=2$

*END STEP

* end of file 


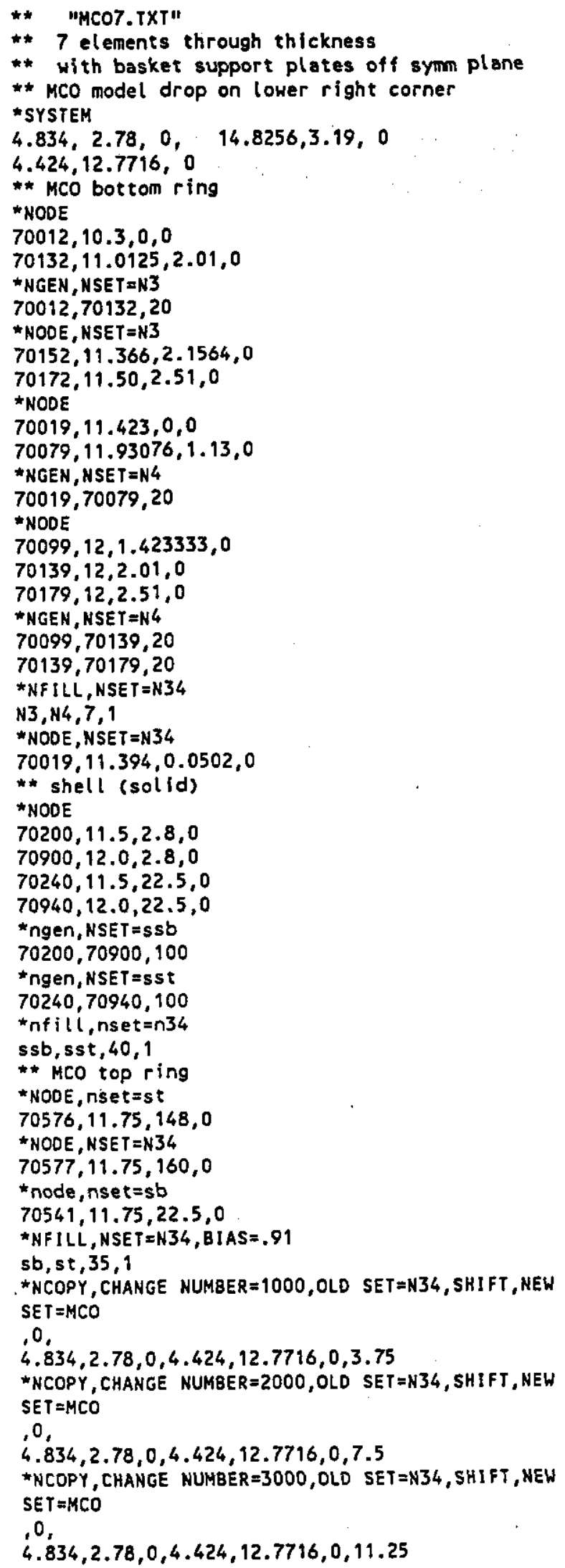

*NCOPY, CHANGE NUMBER $=4000,0 L D$ SET $=N 34, S H \overline{I F T}, \mathrm{NEW}$ SET $=M C O$

0 ,

$4.834,2.78,0,4.424,12.7716,0,15$.

*NCOPY, CHANGE NUMBER $=5000,0 L 0$ SET $=N 34$, SHIFT, NEW SET $=$ MCO

0 ,

$4.834,2.78,0,4.424,12.7716,0,18.75$

*NCOPY, CHANGE NUMBER $=6000,0 L D$ SET $=N 34$, SHIFT, NEW SET $=M C O$

0 ,

$4.834,2.78,0,4.424,12.7716,0,22.5$

$N$ COPY, CHANGE NUMBER $=7000$, OLD SET $=N 34$, SHIFT, NEW $S E T=M C O$

0 ,

$4.834,2.78,0,4.424,12.7716,0,26.25$

*NCOPY, CHANGE NUMBER $=8000$, OLD SET $=N 34$, SHIFT, NEW SE $T=M C O$

0 ,

$4.834,2.78,0,4.424,12.7716,0,30$.

${ }^{*}$ NCOPY, CHANGE NUMBER $=9000$, OLD SET $=N 34$, SHIFT, NEW SET $=M C O$

0 ,

$4.834,2.78,0,4.424,12.7796,0,36$.

*NCOPY, CHANGE NUMBER $=10000$, OLD SET $=N 34$, SHIFT, NEW SET $=M C O$

0 ,

$4.834,2.78,0,4.424,12.7716,0,42$.

*NCOPY, CHANGE NUMBER $=11000$, OLD SET $=N 34$, SHIFT, NEW SET $=M C O$

.0 ,

$4.834,2.78,0,4.424,12.7716,0,48$.

*NCOPY, CHANGE NUMBER $=12000$, OLD SET $=N 34$, SHIFT, NEW SET $=M C O$

0 ,

$4.834,2.78,0,4.424,12.7716,0,54$.

*NCOPY, CHANGE NUMBER $=13000$, OLD SET $=N 34, S H I F T, N E W$ SET $T=M C O$

0 ,

$4.834,2.78,0,4.424,12.7716,0,60$.

NCOPY, CHANGE NUMBER $=14000$, OLD SET $=N 34$, SHIFT, NEW $S E T=M C O$

0 ,

$4.834,2.78,0,4.424,12.7716,0,67.5$

*NCOPY, CHANGE NUMBER $=15000$, OLD SET $=N 34$, SHIFT, NEW SET $=M C O$

, 0 ,

$4.834,2.78,0,4.424,12.7716,0,75$.

$\star N C O P Y$, CHANGE NUMBER $=16000$, OLD SET $=N 34$, SHIFT, NEW SET $=M C O$

0 ,

$4.834,2.78,0,4.424,12.7716,0,82.5$

*NCOPY, CHANGE NUMBER $=17000$, OLD SET $=N 34$, SHIFT, NEW SET $=M C O$

0 ,

$4.834,2.78,0,4.424,12.7716,0,90$.

$\star N C O P Y$, CHANGE NUMBER $=18000$, OLD SET $=N 34$, SHIFT, NEW SET $=M C O$

0 ,

$4.834,2.78,0,4.424,12.7716,0,100$.

$N$ COPY, CHANGE NUMBER $=19000$, OLO SET $=N 34$, SHIFT, NEW SET $=M C O$

0 ,

$4.834,2.78,0,4.424,12.7716,0,110$.

* $C O P Y$, CHANGE NUMBER $=20000$, OLO SET $=N 34, S H I F T, N E W$ $S E T=M C O$

0 , 
$4.834,2.78,0,4.424,12.7716,0,120$. *NCOPY, CHANGE NUMBER $=21000$, OLD SET $=N 34$, SHIFT, NEW SET T $=M C O$

0 , $4.834,2.78,0,4.424,12.7716,0,135$ *NCOPY, CHANGE NUMBER $=22000$, OLD SET $=N 34$, SHIFT, NEW SET $=M C O$

0 .

$4.834,2.78,0,4.424,12.7716,0,150$

NCOPY, CHANGE NUMBER $=23000,020$ SET $=N 34$, SHIFT, NEW SET $=M C O$

0 ,

$4.834,2.78,0,4.424,12.7716,0,165$

"NCOPY, CHANGE NUMBER 24000, OLD SET $=N 34, S H I F T$, NEW SE T $=M C O$

0 ,

$4.834,2.78,0,4.424,12.7716,0,180$

ॠNOOE

$70000,1.25,0,0$

$70060,1.25,1.13,0$

ॠNGEN, NSET $=$ N 1

$70000,70060,20$

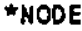

$70120,2.13,2.01,0$

*NGEN, NSET $=$ N1

$70060,70120,20$

*NCOPY, CHANGE NUMBER $=1000,0 L D$ SET $=N 1$, SHIFT, NEW

SET $=$ N 1, MULT I PLE $=24$

, 0 ,

$4.834,2.78,0,4.424,12.7716,0,7.5$

*NSET, NSET $=$ N2, GENERATE

$70012,94012,1000$

$70032,94032,9000$

$70052,94052,1000$

$70072,94072,1000$

$70092,94092,1000$

$70112,94112,1000$

$70132,94132,1000$

*NFILL, NSE T $=N 12, B$ IAS $=1.01$

N1, N2,12, 1

-ELEMENT, TYPE $=$ C308R, ELSET $=M C O B$

$70001,70000,70001,71001,71000,70020,70021,71021,7$

1020

*ELGEN, ELSET $=M C O B$

$70001,19,1,1,6,20,20,24,1000,1000$

$70113,2,20,20$

$70133,7,1,1,2,20,20,24,1000,1000$

*ELEMENT, TYPE $=$ C3D8R, ELSET $=$ MCOPS

$70301,70172,70173,71173,71172,70200,70300,71300,7$

1200

$70302,70173,70174,71174,71173,70300,70400,71400,7$

1300

$70303,70174,70175,71175,71174,70400,70500,71500,7$

1400

$70304,70175,70176,71176,71175,70500,70600,71600,7$

1500

$70305,70176,70177,71177,71176,70600,70700,71700,7$

1600

$70306,70177,70178,71178,71177,70700,70800,71800,7$

1700

$70307,70178,70179,71179,71178,70800,70900,71900,7$

1800

$70308,70200,70300,71300,71200,70201,70301,71301,7$

1201

ॠELGEN, ELSET $=$ MCOPS

$70301,24,1000,1000$

$70302,24,1000,1000$
$70303,24,1000,1000$

$70304,24,1000,1000$

$70305,24,1000,1000$

$70306,24,1000,1000$

$70307,24,1000,1000$

$70308,7,100,1,40,1,7,24,1000,1000$

tmpc

beam, 70541,70240

beam, 71541,71240

beam, 72541,72240

beam, 73541,73240

beam, 74541,74240

beam, 75541,75240

beam, 76541,76240

beam, 77541,77240

beam, 78541,78240

beam, 79541,79240

beam, 80541,80240

beam, 81541,81240

beam, 82541,82240

beam, 83541,83240

beam, 84541,84240

beam, 85541,85240

beam, 86541,86240

beam, 87541,87240

beam, 88541,88240

beam, 89541,89240

beam, 90541,90240

beam, 91541,91240

beam, 92541,92240

beam, 93541,93240

beam, 94541,94240

beam, 70541,70240

beam, 71541,71340

beam, 72541,72340

beam, 73541,73340

beam, 74541,74340

beam, 75541,75340

beam, 76541,76340

beam, 77541,77340

beam, 78541,78340

beam, 79541,79340

beam, 80541,80340

beam, 81541,81340

beam, 82541,82340

beam, 83541,83340

beam, 84541,84340

beam, 85541,85340

beam, 86541,86340

beam, 87541,87340

beam, 88541,88340

beam, 89541,89340

beam, 90541,90340

beam, 91541,91340

beam, 92541,92340

beam, 93541,93340

beam, 94541,94340

beam, 70541,70440

beam, 71541,71440

beam, 72541,72440

beam, 73541,73440

beam, 74541,74440

beam, 75541, 75440

beam, 76541,76440

beam, 77541,77440

beam, 78541,78440

bean, 79541,79440 
APPENDIXC SECTION ONE INPUT FILE MCO7.tXt

beam, 80541,80440 beam, 81541,81440 beam, 82541,82440 beam, 83541,83440 beam, 84541,84440 beam, 85541,85440 beam, 86541,86440 beam, 87541,87440 beam, 88541,88440 beam, 89541,89440 beam, 90541,90440 beam, 91541,91440 beam, 92541,92440 beam, 93541,93440 beam, 94541,94440 beam, 70541,70540 beam, 71541,71540 beam, 72541,72540 beam, 73541,73540 beam, 74541,74540 beam, 75541,75540 beam, 76541,76540 beam, 77541,77540 beam, 78541,78540 beam, 79541,79540 beam, 80541,80540 beam, 81541,81540 beam, 82541,82540 beam, 83541,83540 beam, 84541,84540 beam, 85541,85540 beam, 86541,86540 beam, 87541,87540 beam, 88541,88540 beam, 89541,89540 beam, 90541,90540 beam, 91541,91540 beam, 92541,92540 beam, 93541,93540 beam, 94541,94540 beam, 70541,70640 beam, 71549,71640 beam, 72541,72640 beam, 73541,73640 beam, 74541,74640 beam, 75541,75640 beam, 76541,76640 beam, 77541,77640 beam, 78541,78640 beam, 79541,79640 beam, 80541,80640 beam, 81541,81640 beam, 82541,82640 beam, 83541,83640 beam, 84541,84640 beam, 85541,85640 beam, 86541,86640 beam, 87541,87640 beam, 88541,88640 beam, 89541,89640 beam, 90541,90640 beam, 91541,91640 beam, 92541,92640 beam, 93541,93640 beam, 94541,94640 beam, 70541,70740 beam, 71541,71740 beam, 72541,72740

beam, 73541,73740

beam, 74541,74740

bean, 75541,75740

beam, 76541,76740

beam, 77541,77740

beam, 78541,78740

beam, 79541,79740

beam, 80541,80740

beam, 81541,81740

beam, 82541,82740

beam, 83549,83740

beam, 84541,84740

beam, 85541,85740

beam, 86541,86740

beam, 87541,87740

beam, 88541,88740

beam, 89541,89740

beam, 90541,90740

beam, 91541,91740

beam, 92541,92740

beam, 93541,93740

beam, 94541,94740

beam, 70541,70840

beam, 71541,71840

beam, 72541,72840

beam, 73541,73840

beam, 74541,74840

beam, 75541,75840

beam, 76541,76840

beam, 77541,77840

beam, 78541,78840

beam, 79541,79840

beam, 80541,80840

beam, 81541,81840

beam, 82541,82840

beam, 83541,83840

beam, 84541,84840

beam, 85541,85840

beam, 86541,86840

beam, 87541,87840

beam, 88541,88840

beam, 89541,89840

beam, 90541,90840

beam, 91541,91840

beam, 92541,92840

beam, 93541,93840

beam, 94541,94840

beam, 70541,70940

beam, 71541,71940

beam, 72541,72940

beam, 73541,73940

beam, 74541,74940

beam, 75541,75940

beam, 76541,76940

beam, 77541,77940

beam, 78541,78940

beam, 79541,79940

beam, 80541,80940

beam, 81541,81940

beam, 82549,82940

beam, 83541,83940

beam, 84541,84940

beam, 85541,85940

bean, 86541,86940

beam, 87541,87940

beam, 88541,88940 
beam, 89541,89940

beam, 90541,90940

beam, 91541,91940

beam, 92541,92940

beam, 93541,93940

beam, 94541,94940

*ELEMENT, TYPE $=54 R S, E L S E T=M C O P L$

$70205,70540,71540,71541,70541$

*ELGEN, ELSET $=$ MCOPL

$70205,36,1,1,24,1000,1000$

** MCO bottom center

* NODE

$60000,-1.08,0,0$

$66000,-.7637,0,-.7637$

*NGEN, NSET $=$ L 1

$60000,66000,1000$

ॠNODE

$60012,1.08,0,0$

$66012, .7637,0,-.7637$

$\star$ NGEN, NSET $=$ L2

$60012,66012,1000$

ॠNODE

$60006,0,0,0$

$66006,0,0,-1.08$

*NGEN, NSET $=$ L3

$60006,66006,1000$

-NFILL, NSET $=$ L12

$L 1, L 3,6,1$

$\mathrm{L} 3, \mathrm{~L} 2,6,1$

* NCOPY, CHANGE NUMBER $=60$, OLO SET $=L 12$, SHIFT, NEW

$S E T=L 13$

$-0.0262,0.8796,0$

*NFILL, NSET $=L 14$

$L 12, L 13,3,20$

$\star$ ELEMENT, TYPE $=C 308 R, E L S E T=M C O B$

$60101,60000,60001,61001,61000,60020,60021,61021,6$ 1020

*ELGEN, ELSET $=M C O B$

$60101,12,1,1,6,1000,12,3,20,72$

\#ELEMENT, TYPE $=C 308 R, E L S E T=E B 1$

$60001,60012,70000,71000,61012,60032,70020,71020,6$

1032

*ELGEN, ELSET $=E B 2$

$60001,6,1000,1,3,20,6$

ॠELEMENT, TYPE $=C 3 D 8 R$, ELSET $=E B 3$

$60019,66012,76000,77000,66011,66032,76020,77020,6$

6031

$60020,66011,77000,78000,66010,66031,77020,78020,6$

6030

$60021,66010,78000,79000,66009,66030,78020,79020,6$

6029 .

$60022,66009,79000,80000,66008,66029,79020,80020,6$ 6028

$60023,66008,80000,81000,66007,66028,80020,81020,6$ 6027

$60024,66007,81000,82000,66006,66027,81020,82020,6$ 6026

$60025,66006,82000,83000,66005,66026,82020,83020,6$

6025

$60026,66005,83000,84000,66004,66025,83020,84020,6$

6024

$60027,66004,84000,85000,66003,66024,84020,85020,6$ 6023

$60028,66003,85000,86000,66002,66023,85020,86020,6$ 6022
$60029,66002,86000,87000,66001,66022,86020,87020,6$ 6021

$60030,66001,87000,88000,66000,66021,87020,-88020,6$ 6020

$60031,66000,88000,89000,65000,66020,88020,89020,6$ 5020

$60032,65000,89000,90000,64000,65020,89020,90020,6$ 4020

$60033,64000,90000,91000,63000,64020,90020,91020,6$ 3020

$60034,63000,91000,92000,62000,63020,91020,92020,6$ 2020

$60035,62000,92000,93000,61000,62020,92020,93020,6$ 1020

$60036,61000,93000,94000,60000,61020,93020,94020,6$ 0020

„ELCOPY,ELEMENT SHIFT $=18$, OLO SET $=E B 3$, SHIFT

NODES $=20$, NEW SET $=E B 4$

*ELCOPY, ELEMENT SHIFT=18, OLD SET=EB4,SHIFT

NODE $S=20$, NEW SET $=E B 5$

*ELSET, ELSET $=$ MCOB

$E B 2, E B 3, E B 4, E B 5$

* MCO top center

^NODE

$50000,-8 ., 148,0$

$56000,-1 ., 148,-8.5$

*NGEN, NSET $=T 1$

$50000,56000,1000$

*NOOE

$50012,10.8,148,0$

$56012,9.1,148,-3.77$

*NGEN, NSET $=T 2$

$50012,56012,1000$

\#NODE

$50006,5.8,148,0$

$56006,5.8,148,-7.97$

*NGEN, NSET $=$ Y 3

$50006,56006,1000$

$\star N F I L L, N S E T=T 12$

$T 1, T 3,6,1$

$T 3, T 2,6,1$

* NCOPY, CHANGE NUMBER $=20,0 L D$ SET $=T 12$, SHIFT, NEW

$S E T=T 13$

$-0.4920,11.9899,0$

-ELEMENT TYPE $=$ C3DBR , ELSE $T=M C O T$

$60601,50000,50001,51001,51000,50020,50021,51021,5$ 1020

ॠELGEN , ELSET T=MCOT

$60601,12,1,1,6,1000,12$

*ELEMENT, TYPE $=$ C3O8R, ELSET $=E 811$

$50001,50012,70576,71576,51012,50032,70577,71577,5$

1032

*ELGEN, ELSET T=EB11

$50001,6,1000,1$

"ELEMENT, TYPE =C3D8R, ELSET $=E B 12$

$50007,56012,76576,77576,56011,56032,76577,77577,5$ 6031

$50008,56011,77576,78576,56010,56031,77577,78577,5$ 6030

$50009,56010,78576,79576,56009,56030,78577,79577,5$ 6029

$50010,56009,79576,80576,56008,56029,79577,80577,5$ 6028

$50011,56008,80576,81576,56007,56028,80577,81577,5$ 6027 
$50012,56007,81576,82576,56006,56027,81577,82577,5$ 6026

$50013,56006,82576,83576,56005,56026,82577,83577,5$ 6025

$50014,56005,83576,84576,56004,56025,83577,84577,5$ 6024

$50015,56004,84576,85576,56003,56024,84577,85577,5$ 6023

$50016,56003,85576,86576,56002,56023,85577,86577,5$ 6022

$50017,56002,86576,87576,56001,56022,86577,87577,5$ 6021

$50018,56001,87576,88576,56000,56021,87577,88577,5$ 6020

$50019,56000,88576,89576,55000,56020,88577,89577,5$

\section{0}

$50020,55000,89576,90576,54000,55020,89577,90577,5$

$50021,54000,90576,91576,53000,54020,90577,91577,5$ 3020

$50022,53000,91576,92576,52000,53020,91577,92577,5$

2020

$50023,52000,92576,93576,51000,52020,92577,93577,5$

\section{0}

$50024,51000,93576,94576,50000,51020,93577,94577,5$

0020

*ELSET , ELSET $=$ MCOT

EB11, EB12

$\star \star$

*ELSET, ELSET T=MCO8B, GENERATE

$70019,82019,1000$

$70018,82018,1000$

$70017,82017,1000$

$70016,82016,1000$

$70015,82015,9000$

$70014,82014,1000$

ॠELSET, ELSET IMCOBF, GENERATE

$70019,82019,1000$

$70039,82039,1000$

$70059,82059,1000$

$70079,82079,1000$

$70099,82099,1000$

$70119,82119,1000$

$70139,82139,1000$

*ELSEF, ELSET = MCOTR

70239

*ELSET , ELSET $=$ MCOTL

93239

•ELSET, ELSET $=$ MCOSF, GENERATE

70202,70215, 1

$71202,71215,1$

$72202,72215,1$

$73202,73215,1$

$74202,74215,1$

$75202,75215,1$

$76202,76215,1$

$77202,77215,1$

$78202,78215,1$

$79202,79215,1$

** add basket support plates

node

$40140,1.25,2.01,0$

$40200,1.25,3.25,0$

$40154,11.01,2.01,0$

$40214,11.01,3.25,0$

*ngen, nset =bsp1

$40140,40200,20$ *ngen, nset $=$ bsp2

40154,40214,20

"NCOPY, CHANGE NUMBER $=1000,0 L D$ SET=bSPI, SHTFT, NEW SET =bSP3

0 .

*NCOPY, CHANGE NUMBER $=2000,0 L D$ SET $=b S p 1, S H 1 F T, N E H$ SE $T=$ bsp3

0 ,

$4.834,2.78,0,4.424,12.7716,0,30$

*NCOPY, CHANGG NUMBER $=3000$, OLD SET=bSPI, SHIFT, NEW SET $=$ bSP3

0 ,

$4.834,2.78,0,4.424,12.7716,0,60$

*NCOPY, CHANGE NUMBER $=4000$, OLD SETEbSP1, SHIFT, NEW SET $=$ bSP3

0 ,

$4.834,2.78,0,4.424,12.7716,0,60$

*NCOPY, CHANGE NUMBER $=5000,0 L D$ SET=bSP1, SHIFT, NEW SET $T=b s p 3$

0 ,

$4.834,2.78,0,4.424,12.7716,0,90$

* $N$ COPY, CHANGE NUMBER $=6000,0 L D$ SET $=b S P 1$, SHIFT, NEW SET $=$ bsp3

.0 ,

$4.834,2.78,0,4.424,12.7716,0,120$

*NCOPY, CHANGE NUMBER $=7000$, OLD SET=bSP1, SH IFT, NEW SET $=$ bsp3

, 0 ,

$4.834,2.78,0,4.424,12.7716,0,120$

$N C O P Y$, CHANGE NUMBER $=8000$, OLD SET=bSP1, SHIFT, NEW SET $=$ bsp3

0 ,

$4.834,2.78,0,4.424,12.7716,0,150$

*NCOPY, CHANGE NUMBER $=9000$, OLD SET $=b S P 1$, SHIFT, NEW SET $=$ bSP3

0 ,

$4.834,2.78,0,4.424,12.7716,0,180$

NCOPY, CHANGE NUMBER $=1000,0$ LD SET $=b S P 2$, SHIFT, NEW SET $=$ bsp4

, 0 ,

$4.834,2.78,0,4.424,12.7716,0,26.7458$

* NCOPY, CHANGE NUMBER $=2000,0 L D$ SET $=b S P 2$, SHIFT, NEW SET $T=b S p 4$

0 ,

4.834,2.78,0,4.424,12.7716,0,30

*NCOPY, CHANGE NUMBER $=3000$, OLD SET=bSP2, SH1FT, NEW SE T $=$ bSP4

0 ,

$4.834,2.78,0,4.424,12.7796,0,33.2542$

*NCOPY, CHANGE NUMBER $=4000$, OLD SET=bSP2, SHIFT, NEW SET $=$ bsp4

0 ,

$4.834,2.78,0,4.424,12.7716,0,86.7458$

* $N O P Y$, CHANGE NUMBER $=5000$, OLO SET $=6 s P 2$, SHIFT, NEW SET $=$ bsp4

0 ,

$4.834,2.78,0,4.424,12.7716,0,90$

* NCOPY, CHANGE NUMBER $=6000$, OLD SET $=b S P 2, S H I F T, N E W$ SE T $=$ bSP4

0 ,

$4.834,2.78,0,4.424,12.7716,0,93.2542$

*NCOPY, CHANGE NUMBER $=7000$, OLD SET=bSP2, SHIFT, NEW SET $T=$ bsp4

0 ,

$4.834,2.78,0,4.424,12.7716,0,146.7458$ 
\#COPY, CHANGE NUMBER $=8000,0 L D$ SET=bSP2, SHIFT, NEW SET $=\mathrm{bSP} 4$

0 ,

$4.834,2.78,0,4.424,12.7716,0,150$

*NCOPY, CHANGE NUMBER $=9000$, OLD SET $=b S P 2$, SH I FT, NEW SET $=b S P 4$

0 ,

$4.834,2.78,0,4.424,12.7716,0,153.2542$

\#nset, nsetrobsp 3

bsp1

*nset, nset $=$ bsp4

bsp2

*nf $i l l$, nset $=m c o$

bsp3, bsp4, 14, 1

*ELEMENT, TYPE $=$ C308R, ELSET $T=b S P$

$97001,41140,41141,42141,42140,41160,41161,42161,4$

2160

$97101,42140,42141,43141,43140,42160,42161,43161,4$

3160

*ELGEN, ELSET $=$ bSP

$97001,14,1,1,3,20,14,3,3000,200$

$97101,14,1,1,3,20,14,3,3000,200$

mpe

link, 43140,44140

link, 43160,44160

link, 43180,44180

link, 43200,44200

link, 46140,47140

link, 46160,47160

link, 46180,47180

link, 46200,47200

*ELSET, ELSET T=MCOSL

MCOT, MCOB

* SOLID SECTION, ELSET=MCOSL, MATERIAL=\$\$304

* SOL IO SECTION, ELSET=MCOPS, MATERIAL $=\$ S 304$

*SHELL SECTION, ELSET=MCOPL, MATERIAL=\$S304

0.5

* SOLID SECTION, ELSET=bSP, MATERIAL=\$S304

*nset, nset $=b s p b$, generate

$40140,40154,1$

$41140,41154,1$

$42140,42154,1$

$43140,43154,1$

$44140,44154,1$

$45140,45154,1$

$46140,46154,1$

$47140,47154,1$

$48140,48154,1$

$49140,49154,1$

*nset, nset $=b s p t$, generate

$40200,40214,1$

$41200,41214,1$

$42200,42214,1$

$43200,43214,9$

$44200,44214,1$

$45200,45214,1$

$46200,46214,1$

$47200,47214, ?$

$48200,48214,1$

$49200,49214,1$

*NSET, NSET $=$ MCO

N34, SB, ST, N12,L14,T12,T13

bspt, bspb

"ELSET, ELSET=MCO

MCOPL, MCOSL, meops, bSP

*elset, elsetrmcobt, generate

$70101,93101,1000$
$70102,93102,1000$

$70103,93103,1000$

$70104,93104,1000$

$70105,93105,1000$

$70106,93106,1000$

$70107,93107,1000$

$70108,93108,1000$

$70109,93109,1000$

$70110,93110,1000$

$70111,93111,1000$

$70112,93112,1000$

*elset, el set=mcosi , gener ate

$70133,93133,1000$

$70153,93153,1000$

$70301,93301,1000$

$70308,93308,1000$

$70315,93315,1000$

$70322,93322,1000$

$70329,93329,1000$

$70336,93336,1000$

*NSET, NSET $=$ MCOSY, GENERATE

$70000,70999,1$

$94000,94999,1$

$50000,50999,1$

$60000,60999,1$

$79140,79200,20$

*BOUNDARY

MCOSY, ZSYMM

$* *$ end of file 


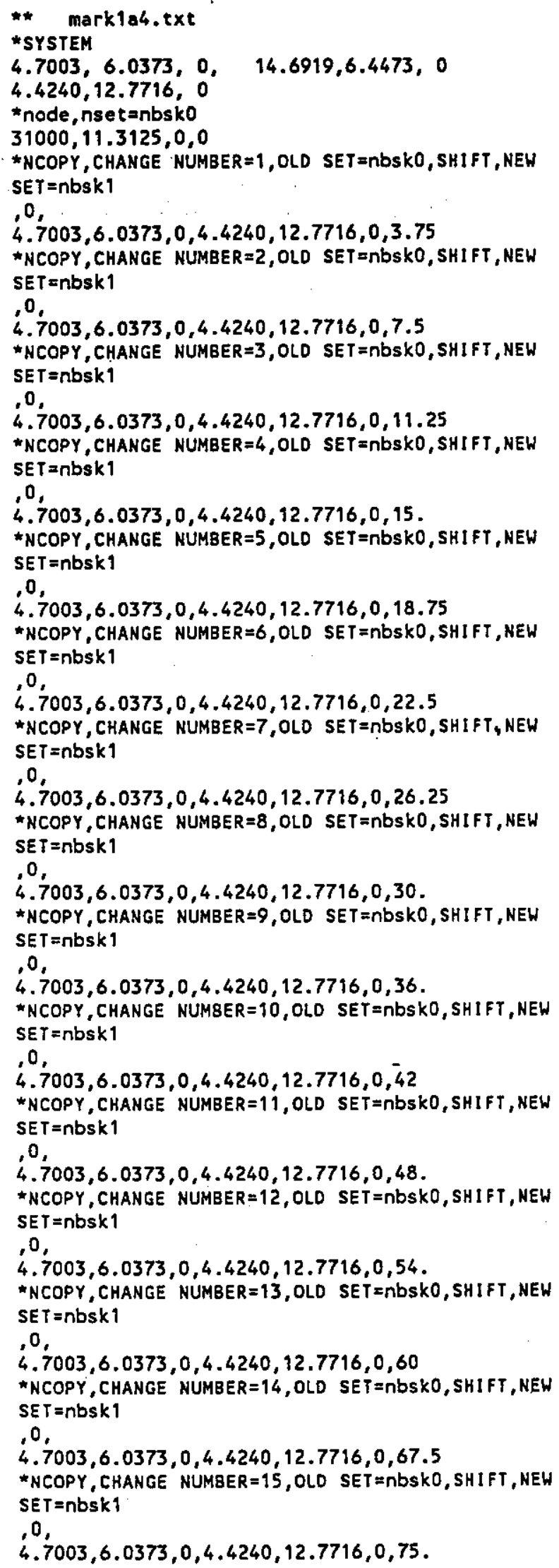

-NCOPY, CKANGE NUMBER = 16, OLD SET=nbskO, SH IFT, NEW SET =nbsK 1

0 ,

$4.7003,6.0373,0,4.4240,12.7716,0,82.5$

*NCOPY, CHANGE NUMBER=17, OLO SET=nbsKO, SHIFT, NEW SET $=$ nbsk 1

0 ,

$4.7003,6.0373,0,4.4240,12.7716,0,90$.

"NCOPY, CHAKGE NUMBER=18, OLO SET=nbSkO, SHIFT, NEW SET $T=n b S K 1$

0 ,

$4.7003,6.0373,0,4.4240,12.77916,0,100$.

\#NCOPY, CHANGE NUMBER=19, OLD SET=nbskO, SHIFT, NEW SET $=$ nbSk1

0 ,

$4.7003,6.0373,0,4.4240,12.7716,0,110$.

${ }^{\text {NCOPY }}$, CHANGE NUMBER $=20,0 L D$ SET=nbsKO, SH I FT, NEW SET $=$ nbsk 1

0 ,

$4.7003,6.0373,0,4.4240,12.7716,0,120$.

*NCOPY, CHANGE NUMBER $=21$, OLD SET=nbSKO, SHIFT, NEW SET $=n b s k 1$

0 ,

$4.7003,6.0373,0,4.4240,12.7716,0,135$

* NCOPY, CHANGE NUMBER=22, OLD SET=nbskO, SHIFT, NEW SET $=$ nbsk 1

0 ,

$4.7003,6.0373,0,4.4240,12.7716,0,150$.

* NCOPY, CHANGE NUMBER $=23$, OLD SET=nbSKO, SH IFT, NEW SET $=$ nbsk1

0 ,

$4.7003,6.0373,0,4.4240,12.7716,0,165$.

${ }^{*}$ NCOPY, CHANGE NUMBER $=24$, OLD SET=nbSKO, SHIFT, NEW SET $=n$ bs K 1

0 ,

$4.7003,6.0373,0,4.4240,12.7716,0,180$.

*nset, nset $=$ nbsk 1

nbsko

*node

$31037,-8,0,0$

$31115,-1 ., 0,-8.5$

*ngen, nset =bskt 1

$31037,31115,13$

*node

$31025,10.6,0,0$

$31103,9 ., 0,-3.76$

*ngen, nsetrbskt2

$31025,31103,13$

*node

$31031,0,0,0$

$31109,5.7,0,-7.9$

*ngen, nset $=$ bskt3

$31031,31109,13$

*nfill, nset=nbsk i

bskt2, bskt3,6,1

bskt3, bskt1,6,1

* NCOPY, CHANGE NUMBER $=200$, OLD

SET =nbsK I, SHI FT, NEW SET=nbSK1

$-0.041,0.9992$

*node, nset $=b s k p 0$

$31410,11.3125,8,0$

$31411,11.3125,16,0$

$31412,11.3125,23.166,0$

*NCOPY, CHANGE NUMBER $=10$, OLD SET $=6 S k P O$, SHIFT, NEW SET $T=$ nbskp, mul $t$ iple $e=3$

0 , 
$4.7003,6.0373,0,4.4240,12.7716,0,60$.

node, nset $=$ nbskp

$31400,8,0$

$31401,16,0$

$31402, .23 .166,0$

*nset, nset=nbsk 1

nbskp, bskpo

*NCOPY, CHANGE NUMBER $=1000$, OLD SET $=\pi b S k i$, SHIFT, NEW SE T $=$ nbsk

$-0.9499 .23 .1465$

*NCOPY, CHANGE NUMBER $=2000,0 L D$ SET=nbSK1, SHIFT, NEW SET $=$ nbsk

$-1.8998,46.2930$

\#COPY, CHANGE NUMBER $=3000$, OLD SET $=n b S K 1$, SHIFT, NEW SE $T=$ nbsK

$-2.8497,69.4396$

* $N$ COPY, CHANGE NUMBER $=4000,0 L 0$ SET=nbsK1, SHIFT, NEW SET $=$ nbSK

$-3.7996,92.5861$

*NCOPY, CHANGE NUMBER $=5000$, OLD SET=nbsK 1, SHIFT, NEW SET $=$ nbsk

$-4.7495,115.7326$

*nset, nsetrabk

nbsk, nbsk 1

\#ELEMENT T TYPE=C3D8R, ELSE T =bSKO

$31001,31025,31000,31001,31038,31225,31200,31201,3$ 1238

$31002,31038,31001,31002,31051,31238,31201,31202,3$ 1251

$31003,31051,31002,31003,31064,31251,31202,31203,3$ 1264

$31004,31064,31003,31004,31077,31264,31203,31204,3$ 1277

$31005,31077,31004,31005,31090,31277,31204,31205,3$ 1290

$31006,31090,31005,31006,31103,31290,31205,31206,3$ 1303

$31007,31103,31006,31007,31104,31303,31206,31207,3$ 1304

$31019,31115,31018,31019,31102,31315,31218,31212,3$ 1302

$31020,31102,31019,31020,31089,31302,31219,31220,3$ 1289

$31021,31089,31020,31021,31076,31289,31220,31221,3$

1276

$31022,31076,31021,31022,31063,31276,31221,31222,3$ 1263

$31023,31063,31022,31023,31050,31263,31222,31223,3$ 1250

$31024,31050,31023,31024,31037,31250,31223,31224,3$ 1237

$31025,31026,31025,31038,31039,31226,31225,31238,3$ 1239

*ELGEN, ELSET $=b S k O$

$31007,12,1,1$

$31025,12,1,1,6,13,12$

*ELcopy, element shif $t=1000$, old set $=b s k 0$, shift nodes $=1000$, new SET $=$ bsk

*ELcopy, element shif $t=2000$, old set $=b s \times 0$, shift nodes $=2000$, new SET $=$ bsk

¿EL copy, el ement shif $t=3000$, old set $=b s k 0$, shift nodes $=3000$, new SET $=b s k$
*ELcopy, element shift $=4000,01 d$ set=bsk0, shift nodes $=4000$, new SET $=$ bsk

"ELcopy, element shift $=5000$, old set $=b s k 0$, shift nodes $=5000$, new SET $=$ bsk

*ELEMENT, TYPE =B31, ELSET $T=$ pos tc

$31101,31031,31231$

$31102,31231,31400$

$31103,31400,31401$

*ELEMENT, TYPE $=B 31$, ELSET $=$ pos th

$31111,31000,31200$

$31912,31200,31410$

$31113,31410,3141.1$

\#ELEMENT, TYPE $=B 31, E L S E T=$ pos $t f$

$31121,31013,31213$

$31122,31213,31420$

$31123,31420,31421$

$31131,31020,31220$

$31132,31220,31430$

$31133,31430,31431$

*ELEMENT , TYPE $=B 31$, ELSET $=$ pos th

$31141,31024,31224$

$31142,31224,31440$

$31143,31440,31441$

-ELGEN, ELSET $=$ pos Tc

$31101,6,1000,1000$

$31102,6,1000,1000$

$31103,2,1,1,6,1000,1000$

$\star E L G E N, E L S E T=p O s$ th

$31111,6,1000,1000$

$31112,6,1000,1000$

$31113,2,1,1,6,1000,1000$

$31141,6,1000,1000$

$31142,6,1000,1000$

$31143,2,1,1,6,1000,1000$

ॠELGEN, ELSET $=$ post $f$

$31121,6,1000,1000$

$31122,6,1000,1000$

$31123,2,1,1,6,1000,1000$

$31131,6,1000,1000$

$31132,6,1000,1000$

$31133,2,1,1,6,1000,1000$

*elset, el set $=$ bsk

bsko

*elset, elset =ebsk

posth, postf, postc, bsk

*SOLIO SECTION, ELSET=bSK, MATERIAL=bsK

*BEAM SECTION, ELSET=postc, MATERIAL=bskp, SECTION=arbitrary

$4,1.906,0,1.348,1.348,2.4375$

$0,1.906,2.4375$

$-1.348,-1.348,2.4375$

$-1.906,0,2.4375$

*BEAM SECTION, ELSET=post $f$, MATERIAL=bskp, SECTION= trapezoid

$3.114,1.45,1.23,0$

"BEAM SECTION, ELSET=posth, MATERIAL=bskp,

SECTION= trapezoid

$1.557,1.45,0.615,0$

-MATER IAL, NAME=bsk

*DENSITY

.01556

$\star E L A S T I C$

$28 . E+06, .27$

*PLASTIC

30032. 0.0

$100701,0.293$

$101459 ., 0.300$ 
APPENDIXC SECTION ONE INPUT FILE Bsk1a4.txt

$102201 ., 0.307$

*MATER IAL, NAME=bskp

*OENSITY

.000735

*ELASTIC

28.E+06, . 27

-PLASTIC

$30032 ., 0.0$

$100701,0.293$

$101451 ., 0.300$

$102201 ., 0.307$

*mpc

link, 32031,31402

link, 32000,31412

link, 32013,31422

link, 32020,31432

link, 32024,31442

link, 33031,32402

link, 33000,32412

link, 33013,32422

link, 33020,32432

link, 33024,32442

link, 34031,33402

link, 34000,33412

link, 34013, 33422

link, 34020, 33432

l ink, 34024,33442

link, 35031, 34402

link, 35000,34412

link, 35013,34422

link, 35020,34432

link, 35024, 34442

link, 36031,35402

link, 36000, 35412

link, 36013,35422

link, 36020,35432

tink, 36024, 35442

*el set, el set =bskb1, generate 31001,31024, 1

*elset, elset=bskb2, generate $32001,32024,1$

*el set, el set=bskb3, generate $33001,33024,1$

"elset, elset=bskb4, generate $34001,34024,1$

"elset, elset=bskb5, generate $35001,35024,1$

"elset, elset =bskb6, generate $36001,36024,1$

*elset, el set=bskc1, generate 31025,31096, 1

*elset, elset=bskc2, generate 32025, 32096, 1

*elset, el set=bskc3, generate 33025, 33096, 1

*elset, el set =bskc4, generate $34025,34096,9$

"elset, elset=bskc5, generate 35025, 35096, 1

*elset, el set=bske6, generate $36025,36096,1$

*nset, nset $=8 S K S Y$, generate

$31000,36000,1000$

$31024,36024,1000$

$31025,31037,1$

$31225,31237,1$

$32025,32037,1$
SNFF-5204, Rev. 0/CSB-S-0073

$32225,32237,1$ $33025,33037,1$ $33225,33237,1$ $34025,34037,1$ $34225,34237,1$ $35025,35037,1$ $35225,35237,9$ $36025,36037,1$ $36225,36237,1$ $31400,36400,1000$ $31401,36401,1000$ $31402,36402,1000$ $31410,36410,1000$ $31411,36411,1000$ $31412,36412,1000$ $31440,36440,1000$ $31441,36441,1000$ $31442,36442,1000$ *BOUNDARY

BSKSY, 2SYMM ** end of file 


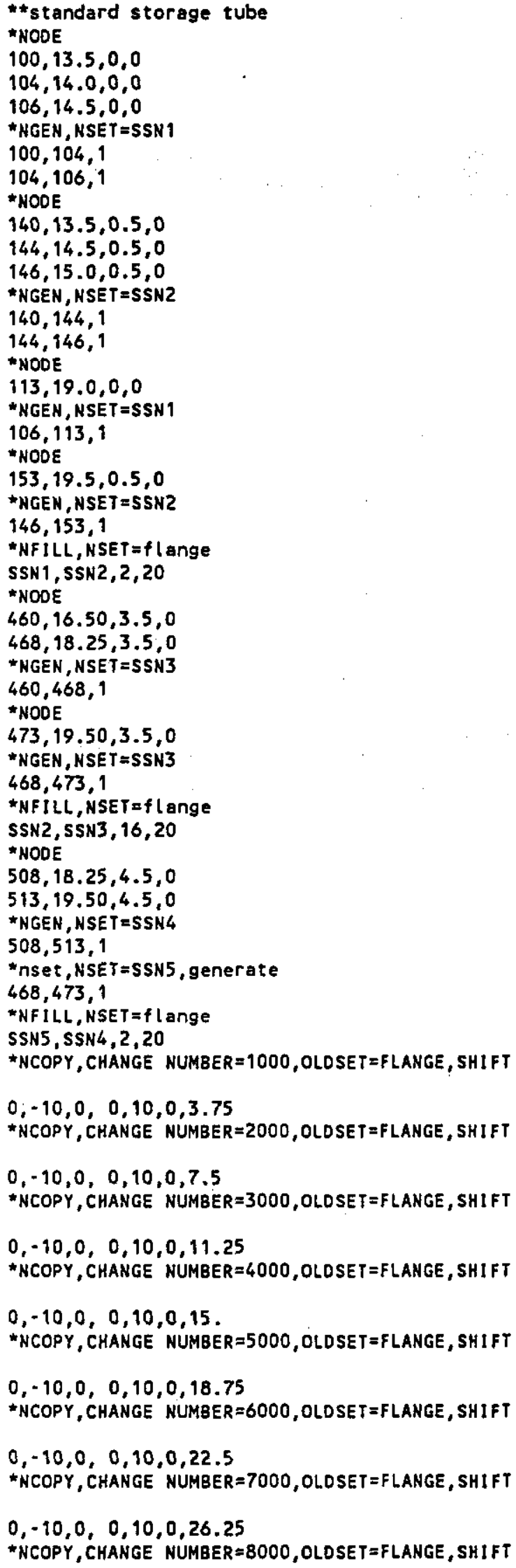

$0,-10,0,0,10,0,30$

$*$ NCOPY, CHANGE NUMBER $=9000$, OLDSET $=F L A N G E$, SHIFT

$0,-10,0,0,10,0,36$

*NCOPY, CHANGE NUMBER $=10000$, OLDSET =FLANGE , SHIF T

$0,-10,0,0,10,0,42$ :

*NCOPY, CHANGE NUMBER $=11000$, OLDSET $=F L$ LANGE, SH IF $T$

$0,-10,0,0,10,0,48$.

*NCOPY, CHANGE NUMBER $=12000$, OLDSET $=F$ LANGE, SH IF

$0,-10,0,0,10,0,54$.

* NCOPY, CHANGE NUMBER $=13000,0 L O S E T=F L A N G E, S H I F T$

$0,-10,0,0,10,0,60$

* NCOPY, CHANGE NUMBER $=14000,0 L O S E T=F L A N G E$, SHIFT

$0,-10,0,0,10,0,67.5$

* NCOPY, CHANGE NUMBER $=15000,0 L D S E T=F L A N G E, S H I F T$

$0,-10,0,0,10,0,75$.

*NCOPY, CHANGE NUMBER $=16000,0 L D S E T=F L A N G E$, SHIFT

$0,-10,0,0,10,0,82.5$

* NCOPY, CHANGE NUMBER $=17000,0 L D S E T=F L A N G E, S H I F T$

$0,-10,0,0,10,0,90$.

* $N$ COPY, CHANGE NUMBER $=18000,0 L D S E T=F L A N G E, S H I F T$

$0,-10,0,0,10,0,100$

${ }^{*}$ NCOPY, CHANGE NUMBER $=19000,0 L D S E T=F L A N G E$, SHIFT

$0,-10,0,0,10,0,110$.

* NCOPY, CHANGE NUMBER $=20000$, OLDSE $T=F L A N G E$, SHIFT

$0,-10,0,0,10,0,120$

$*$ NCOPY, CHANGE NUMBER $=21000$, OLOSET $=$ FLANGE, SHIFT

$0,-10,0,0,10,0,135$.

$*$ NCOPY, CHANGE NUMBER $=22000,0 L D S E T=F L A N G E, S H I F T$

$0,-10,0,0,10,0,150$.

"NCOPY, CHANGE NUMBER $=23000$, OLOSE $T=F L A N G E, S H ! F T$

$0,-10,0,0,10,0,165$.

"NCOPY, CHANGE NUMBER $=24000,0 L D S E T=F L A N G E$, SHIFT

$0,-10,0,0,10,0,180$

*ELEMENT, TYPE $=$ C308R, ELSET $=$ FLANG

$1,100,101,1101,1100,120,121,1121,1120$

-ELGEN, ELSET = FLANG

$1,18,20,1,13,1,18,24,1000,1000$

*ELEMENT, TYPE $=C 308 R$, ELSET $=$ FLANG $235,468,469,1469,1468,488,489,1489,1488$

*ELGEN, ELSET = FLANG

$235,2,20,1,5,1,2,24,1000,1000$

**

\#NODE

$600,13.5,-26.25$

$604,14.0,-26.25$

*NGEN, NSET = SSS ?

$600,604,1$

*NODE

$660,13.5,-20.25$

$664,14.0,-20.25$ 


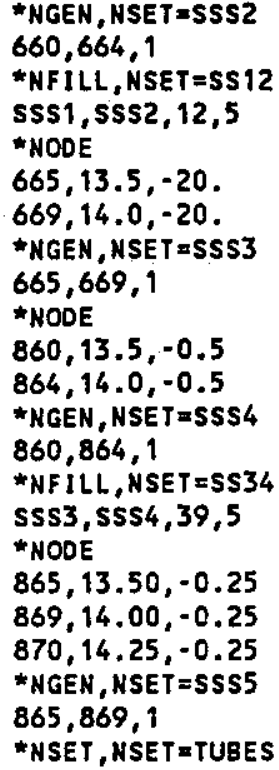

SS12, SS34, SSS5,870

* NCOPY, CHANGE NUMBER $=1000,0 L D S E T=T U B E S, S H I F T$

$0,-10,0,0,10,0,3.75$

NCOPY, CHANGE NUMBER $=2000$, OLDSET $=$ TUBES, SHIFT

$0,-10,0,0,10,0,7.5$

*NCOPY, CHANGE NUMBER $=3000$, OLDSET $=$ TUBES, SHIFT

$0,-10,0,0,10,0,11.25$

* NCOPY, CHANGE NUMBER $=4000$, OLDSET $=T U 8 E S, S H I F T$

$0,-10,0,0,10,0,15$

* NCOPY, CHANGE NUMBER $=5000$, OLDSET $=$ TUBES, SHIFT

$0,-10,0,0,10,0,18.75$

* NCOPY, CHANGE NUMBER $=6000$, OLOSET=TUBES, SHIFT

$0,-10,0,0,10,0,22.5$

ॠCOPY, CHANGE NUMBER $=7000$, OLDSET $=$ TUBES, SHIFT

$0,-10,0,0,10,0,26.25$

* $N$ COPY, CHANGE NUMBER $=8000$, OLDSET $=$ TUBES , SHI FT

$0,-10,0,0,10,0,30$

$*$ NCOPY, CHANGE NUMBER $=9000$, OLDSET $=$ TUBES, SHIFT

$0,-10,0,0,10,0,36$.

${ }^{*}$ NCOPY, CHANGE NUMBER $=10000$, OLDSET $=$ TUBES, SH I FT

$0,-10,0,0,10,0,42$

$*$ NCOPY, CHANGE NUMBER $=11000$, OLDSET $=$ TUBES, SHIFT

$0,-10,0,0,10,0,48$.

${ }^{*}$ NCOPY, CHANGE NUMBER $=12000$, OLDSET $=T$ TUBES, SHIFT

$0,-10,0,0,10,0,54$

NCOPY, CHANGE NUMBER $=13000$, OLDSET $=$ TUBES, SHIFT

$0,-10,0,0,10,0,60$.

* NCOPY, CHANGE NUMBER $=14000$, OLDSET $=$ TUBES, SHIFT

$0,-10,0,0,10,0,67.5$

$\checkmark$ NCOPY, CHANGE NUMBER $=15000$, OLDSET $=$ TUBES, SHIFT
$0,-10,0,0,10,0,75$

*NCOPY, CHANGE NUMBER $=16000,0 L D S E T=T U B E S, S H I F T$

$0,-10,0,0,10,0,82.5$

${ }^{*}$ NCOPY, $C H A N G E$ NUMBER $=17000$, OLOSET $=$ TUBES, SHIFT

$0,-10,0,0,10,0,90$.

* NCOPY, CHANGE NUHBER $=18000,0$ DSET $=$ TUBES, SH IFT

$0,-10,0,0,10,0,100$.

*NCOPY, CHANGE NUMBER $=19000,0$ LDSET $=$ TUBES, SHIFT

$0,-90,0,0,10,0,110$.

*NCOPY, CHANGE NUMBER $=20000$, OLDSET $=$ TUBES, SHIFT

$0,-10,0,0,10,0,120$.

*NCOPY, CHANGE NUMBER $=21000$, OLDSET $T=$ TUBES, SHIFT

$0,-10,0,0,10,0,135$.

*NCOPY, CHANGE NUMBER $=22000$, OLDSET $=$ TUBES, SHIFT

$0,-10,0,0,10,0,150$.

$*$ NCOPY, CHANGE NUMBER $=23000$, OLDSET $=$ TUBES, SH I FT

$0,-10,0,0,10,0,165$.

*NCOPY, CHANGE NUMBER $=24000$, OLDSET $=$ TUBES, SH IFT

$0,-10,0,0,10,0,180$.

*ELEMENT, TYPE $=$ C3OBR, ELSET T TUBES

$301,600,601,1601,1600,605,606,1606,1605$

*ELGEN, ELSET = TUBES

$301,53,5,1,4,9,53,24,1000,1000$

•ELEMENT , TYPE $=$ C308R, ELSET $=$ TUBES

$550,865,866,1866,1865,100,101,1101,1100$

*ELGEN, ELSET $=$ TUBES

$550,5,1,1,24,1000,1000$

*ELEMENT , TYPE $=$ C3D6, ELSET $=$ TUBES

$556,869,870,864,1869,1870,1864$

*ELGEN, ELSET $=$ TUBES

$556,24,1000,1000$

*ELEMENT, TYPE $=$ C306, ELSET $=$ TUBES

$557,105,106,870,1105,1106,1870$

*ELGEN, ELSET $=$ TUBES

$557,24,1000,1000$

*NOOE, NSET $=$ SSP 1

$900,13.75,-475,0$

*NODE, NSET $=$ SSP2

$997,13.75,-27,0$

*NFILL, B!AS $=1.03$, NSET $=$ TUBEP

SSP1, SSP 2, 97, 1

$N$ COPY, CHANGE NUMBER $=1000$, OLDSET $T=T$ TUEEP, SHIFT

$0,-10,0,0,10,0,3.75$

*COPY, CHANGE NUMBER $=2000$, OLDSET $=$ TUBEP, SHIFT

$0,-10,0,0,10,0,7.5$

${ }^{*}$ NCOPY, CHANGE NUMBER $=3000,0$ LDSET $=$ TUBEP, SHIF T

$0,-10,0,0,10,0,11.25$

*NCOPY, CHANGE NUMBER $=4000,0$ LDSET $=$ TUBEP, SHIFT

$0, \cdot 10,0,0,10,0,15$.

* NCOPY, CHANGE NUMBER $=5000$, OLDSET $=$ TUBEP, SHIFT

$0,-10,0,0,10,0,18.75$ 
*NCOPY, CHANGE NUMBER $=6000$, OLDSET $=$ YUBEP, SHI FT

$0,-10,0,0,10,0,22.5$

* NCOPY, CHANGE NUMBER $=7000$, OLDSET $=$ TUBEP, SHIFT

$0,-10,0,0,10,0,26.25$

* $\mathrm{NCOPY}, \mathrm{CHANGE}$ NUMBER $=8000$, OLOSET $=$ TUBEP, SHIFT

$0,-10,0,0,10,0,30$.

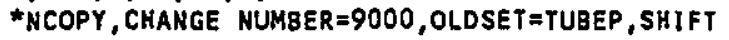

$0,-10,0,0,10,0,36$.

$\because$ NCOPY, CHANGE NUMBER $=10000$, OLDSET $=$ TUBEP, SHIFT

$0,-10,0,0,10,0,42$.

* COPY, CHANGE NUMBER $=11000$, OLDSET $=$ TUBEP, SHIFT

$0,-10,0,0,10,0,48$.

NCOPY, CHANGE NUMBER $=12000$, OLDSET $=$ TUBEP, SHIFT

$0,-10,0,0,10,0,54$.

"NCOPY, CHANGE NUMBER $=13000$, OLDSET $=$ TUBEP, SHIFT

$0,-10,0,0,10,0,60$.

- $\mathrm{NCOPY}$, CHANGE NUMBER $=14000$, OLDSET $=$ TUBEP , SHIF T

$0,-10,0,0,10,0,67.5$

*NCOPY, CHANGE NUMBER $=15000$, OLOSET=TUBEP, SHIFT

$0,-10,0,0,10,0,75$.

*NCOPY, CHANGE NUMBER $=16000$, OLOSET $=$ TUBEP, SHIFT

$0,-10,0,0,10,0,82.5$

* NCOPY, CHANGE NUMBER $=17000$, OLDSET $=$ TUBEP, SH IFT

$0,-10,0,0,10,0,90$.

* NCOPY, CHANGE NUMBER $=18000$, OLOSET $=$ TUBEP, SHIFT

$0,-10,0,0,10,0,100$.

* NCOPY, CHANGE NUMBER $=19000$, OLDSET $=$ TUBEP, SHIFT

$0,-10,0,0,10,0,110$.

${ }^{*}$ COPY, CHANGE NUMBER $=20000$, OLDSET $=$ TUBEP, SHIFT

$0,-10,0,0,10,0,120$

* NCOPY, CHANGE NUMBER $=21000$, OLOSET $=$ TUBEP, SHIFT

$0,-10,0,0,10,0,135$.

* NCOPY, CHANGE NUMBER $=22000$, OLDSET $=$ TUBEP, SHIFT

$0,-10,0,0,10,0,150$.

* $\mathrm{COPY}$, CHANGE NUMBER $=23000$, OLDSET $=$ TUBEP, SHIFT

$0,-10,0,0,10,0,165$.

* $\mathrm{NCOPY}$, CHANGE NUMBER $=24000$, OLDSE $T=$ TUBEP, SHJFT

$0,-10,0,0,10,0,180$.

ELEMENT, TYPE $=\$ 4 R S, \varepsilon L S E T=T U B E P$

$600,900,1900,1901,901$

*ELGEN, ELSET $=$ TUBEP

$600,97,1,1,24,1000,1000$

ELEMENT, TYPE $=S 4 R S, E L S E T=$ TU8EP

$698,997,1997,1602,602$

*ELGEN, ELSET = TUBEP

$698,24,1000,1000$

*ELEMENT, TYPE $=\$ 4 R S, E L S E T=T U B E P$

$699,602,1602,1607,607$

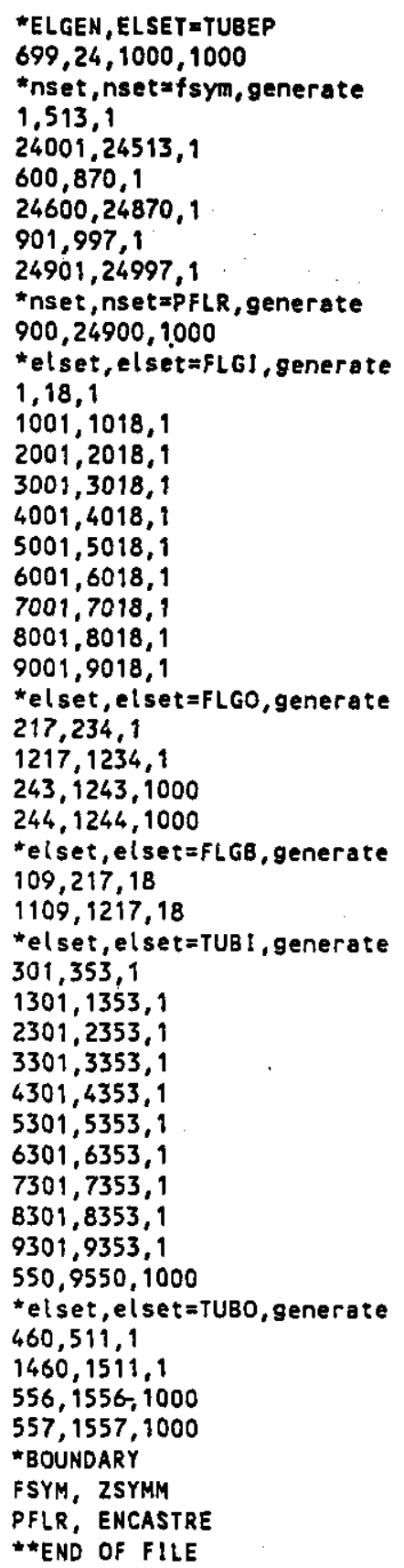




\section{APPENDIX C}

\section{ABAQUS INPUT FILE}

SECTION TWO

MCO DROP ON SERVICE STATION

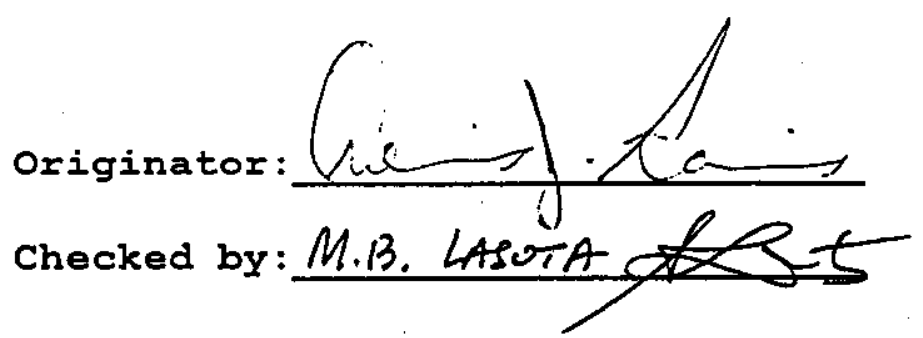

Date: $9 / 2>/ 99$

Date: $9 / 27 / 99$ 
*SURFACE DEFINITION, NAME=rgdif rgd1, SPOS

*SURFACE DEFINITION, NAME=MCOTL MCOTL, SPOS

-CONTACT PAIR, INTERACTION=FMTL rgdif MCOTL

"SURFACE. INTERACTION, NAME=FMTL -FRICTION

0.3

"SURFACE DEFINITION, naMe=rgd2f rgd2, SNEG

* SURFACE DEFINITION, MAME=MCOTR MCOTR, SPOS

"CONTACT PAIR, INTERACTION=FMTR rgd2f, MCOTR

* SURFACE INTERACTION, NAME=FMTR *FRICTION

0.3

* SURFACE DEFINITION, NAME=bskb1 bskb1,s1

bske1,s1

bskb1, 44

-SURFACE DEFINITION, NAME=bSKb2

bskb2,s1

bskc2, 11

bskb2, $\$ 4$

*SURFACE DEFINITION, NAME=bskb3

bskb3,s1

bske3, s1

bskb3, $\$ 4$

*SURFACE DEFINITION, NAME=bskb4

bskb4, $\$ 1$

bske4, $\$ 1$

bskb4, $\$ 4$

*SURFACE DEFINITION, NAME=bskb5

bskb5,si

bske5, s1

bskb5, \$4

* SURface definition, Name=bskbo

bskb6, $\$ 1$

bskc6, s1

bskb6, s4

*CONTACT NODE SET, NAME=bspb

bspb

*SURFACE DEFINITION, NAME=ncos $i$

mcobt, 52

mcosi, s6

* CONTACt PAIR, INTERACTION=BSmCo

bspb, mcos $i$

*SURFACE INTERACTION, NAME=8SmCo

*FRICTION

0.3

״CONTACT NODE SET, NAME=bspt

bspt

*CONTACT PAIR, INTERACT ION=BSKO1 bSPT, BSKB1

* SURFACE INTERACTION, NAME=BSKOI

* FRICTION

0.3

*SURFACE DEFINITION, NAME=mcotb mCOT, $\mathbf{S} 1$

"SURFACE DEFINITION, NAME=mCOPi

mCODl, sneg

*CONTACT PAIR, INTERACTION=b1

BSKB 1, mCOPi

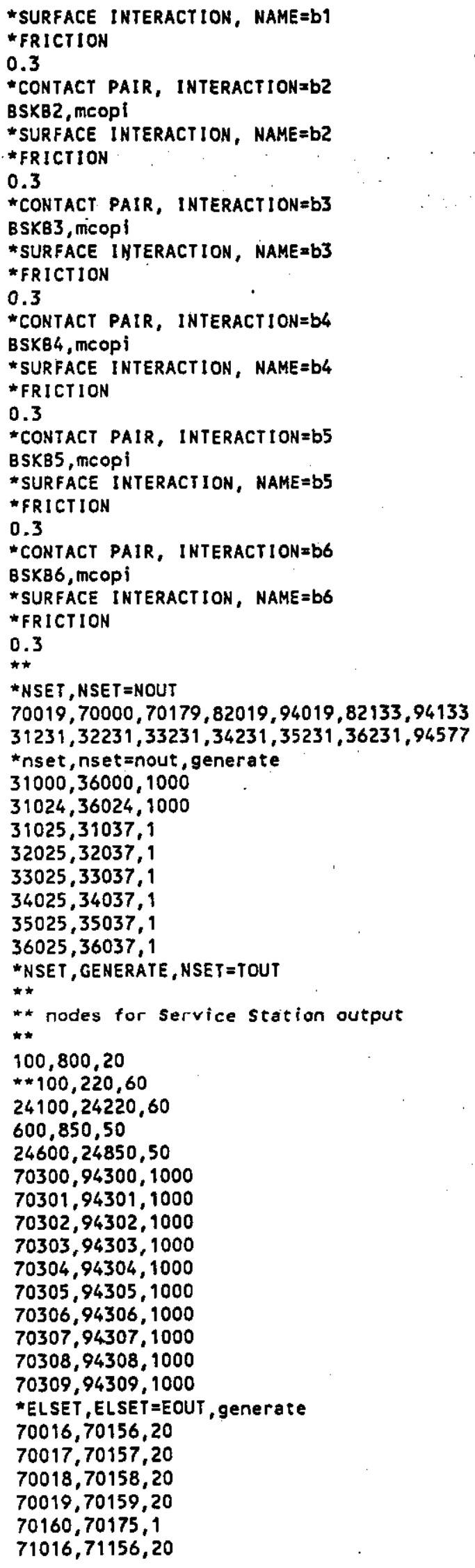


$71017,71157,20$

$71018,71158,20$

$71019,71159,20$

$71160,71175,1$

$72016,72156,20$

$72017,72157,20$

$72018,72158,20$

$72019,72159,20$

$72160,72175,1$

$73016,73156,20$

$73017,73157,20$

$73018,73158,20$

$73019,73159,20$

$73160,73175,1$

-OUTPUT, HISTORY, TIME INTERVAL=1.E-4

-NODE OUTPUT, NSET=NOUT

$U, V, A$

ॠNODE OUTPUT, NSET =TOUT

*NODE OUTPUT, NSET=FLY

RF

\#NODE OUTPUT, NSET =FLXYZ

RF

*NODE OUTPUT, NSET=CAXYZ

RF

\#nset, nset $=$ rgodn

95020

*NOOE OUTPUT, NSET=rgdn

RF

"ENERGY output

ALLKE

*etset, elset =st

hatch, cask, guide

*energy output, elset=st

allie, al lpd

-ELEMENT

OUTPUT, ELSET $=E O U T$, pos it $i$ on=nodes, variable=prese

lect

*output, field, number interval $=40$

*element output

S, SP, MISES, PE, PEEQ , E, EP

"node output

$u, v, r f$

«MONITOR, NODE $=70019, D O F=2$

*END STEP

** end of tile 
* markia3.txt

*SYSTEM

$3.5355,-3.7513,0$

$3.3392,2.9958,0$

$13.5312,-3.4604,0$

*node, nset=nbsk0

$31000,11.3125,0,0$

* NCOPY, CHANGE NUMBER $=1$, OLO SET=nbSKO, SHIFT, NEH SETInbSk1

0 ,

$3.5355,-3.7513,0,3.3392,2.9958,0,3.75$

* NCOPY, CHANGE NUMBER=2, OLD SET =nbSKO, SHIFT, NEW SET TnbsK 1

0 ,

$3.5355,-3.7513,0,3.3392,2.9958,0,7.5$

*NCOPY, CHANGE NUMBER $=3,0 L O$ SET $=n b S K O, S H I F T, N E W$ SET $=$ nbsK 1

0 ,

$3.5355,-3.7513,0,3.3392,2.9958,0,11.25$

\COPY, CHANGE NUMBER $=4$, OLD SET $=$ nbSKO, SHIFT, NEW SE T =nbsK 1

0 ,

$3.5355,-3.7513,0,3.3392,2.9958,0,15$.

- NCOPY, CHANGE NUMBER $=5,0 L D$ SET $=n b s k O, S H I F T, N E W$ SET $=$ nbsk 1

0 ,

$3.5355,-3.7513,0,3.3392,2.9958,0,20.0$

-NCOPY, CHANGE NUMBER $=6,0 L O$ SET $=$ nbSKO, SHIFT, NEW SET =nbsk 1

0 ,

$3.5355,-3.7513,0,3.3392,2.9958,0,25.0$

* NCOPY, CHANGE NUMBER $=7$, OLD SET $=n b S K 0, S H I F T$, NEW

SET =nbSK 1

, O.

$3.5355,-3.7513,0,3.3392,2.9958,0,30.0$

* $N$ COPY, CHANGE NUMBER $=8$, OLO SET $=n b S K O, S H I F T, N E W$ SET $=$ nbSk 1

0 ,

$3.5355,-3.7513,0,3.3392,2.9958,0,37.5$

*NCOPY, CHANGE NUMBER=9, OLO SET=nbskO, SHIFT, NEW. SET =nbsK 1

0 ,

$3.5355,-3.7513,0,3.3392,2.9958,0,45.0$

*NCOPY, CHANGE NUMBER $=10$, OLD SET=nbSKO, SHIFT, NEW SET=nbsk1

.0 .

$3.5355,-3.7513,0,3.3392,2.9958,0,60.0$

* NCOPY, CHANGE NUMBER $=11$, OLD SET=nbSKO, SHIFT, NEW SET =nbSK 1

0 ,

$3.5355,-3.7513,0,3.3392,2.9958,0,75.0$

-NCOPY, CHANGE NUMBER $=12$, OLD SET=nbSKO, SHIFT, NEH SET $=$ nbsk 1

0 ,

$3.5355,-3.7513,0,3.3392,2.9958,0,90.0$

*NCOPY, CHANGE NUMBER $=13$, OLD SET $=$ nOSKO, SHIFT, NEW SET =nbSK 1

0 ,

$3.5355,-3.7513,0,3.3392,2.9958,0,105.0$

* NCOPY, CHANGE NUMBER $=14$, OLD SET=nbSkO, SHIFT, NEW SET $=$ nbsk 1

0 ,

$3.5355,-3.7513,0,3.3392,2.9958,0,120.0$

*NCOPY, CHANGE NUMBER $=15$, OLD SET $=n b S K O$, SHIFT, NEW SET $=$ nbsK 1

0 ,

$3.5355,-3.7513,0,3.3392,2.9958,0,135.0$
*NCOPY, CHANGE NUMBER $=16$, OLD SET $=$ nbskO, SHIFT, NEH SET $=$ nbsk 1

0 ,

$3.5355,-3.7513,0,3.3392,2.9958,0,142.5$

*NCOPY, CHANGE NUMBER=17, OLD SET=nbSKO, SHIFT, NEW SET $=$ nbsK 1

0 ,

$3.5355,-3.7513,0,3.3392,2.9958,0,150.0$

$* N C O P Y, C H A N G E$ NUMBER $=18$, OLD SET =nbskO, SHIFT, NEW SET=nbsK 1

.0 ,

$3.5355,-3.7513,0,3.3392,2.9958,0,155.0$

*NCOPY, CHANGE NUMBER $=19$, OLD SET =nbSKO, SHIFT, NEW SET=nbsK 1

0 ,

$3.5355,-3.7513,0,3.3392,2.9958,0,160.0$

*NCOPY, CHANGE NUMBER $=20$, OLO SET $=$ NOSKO, SHIFT, NEW SETIInbSK1

0 ,

$3.5355,-3.7513,0,3.3392,2.9958,0,165.0$

${ }^{*}$ NCOPY, CHANGE NUMBER $=21$, OLD SET $=$ nbskO, SHIFT, NEW SET $=$ nbsk1

0 ,

$3.5355,-3.7513,0,3.3392,2.9958,0,168.75$

* NCOPY, CHANGE NUMBER $=22$, OLD SET=nbSKO, SHIFT, NEW SET $=$ nbsk 1

0 ,

$3.5355,-3.7513,0,3.3392,2.9958,0,172.5$

*NCOPY, CHANGE NUMBER $=23$, OLD SET $=$ nbSKO, SHIFT, NEW SE T =nbsK 1

0 ,

$3.5355,-3.7513,0,3.3392,2.9958,0,176.25$

* NCOPY, CHANGE NUMBER $=24$, OLD SET $=$ nbSKO, SHIFT, NEW SET $=$ nbSK 1

0 ,

$3.5355,-3.7513,0,3.3392,2.9958,0,180$.

*nset, nset =nbsk

nbsko

node

$31037,-10.3,0,0$

$31115,-8.9,0,-5.1$

*ngen, nset =bskt 1

$31037,31115,13$

*node

$31025,10.3,0,0$

$31103,8.9,0,-5.1$

*ngen, nset $=$ bskt 2

$31025,31103,13$

*node

$31031,0,0,0$

$31109,0,0,-10.3$

*ngen, nset $=$ bskt 3

$31031,31109,13$

*nfili, nset=nbsk 1

bskt2, bskt3, 6, 1

bskt3, bskt 1, 6, 1

* NCOPY, CHANGE NUMBER $=200$, OLD SET=nbSK1, SHIFT, NEW SET $=$ nbsK1

$-0.0291,0.9996$

\#node, nset $=b s k p 0$

$31410,11.3125,7,0$

$31411,11.3125,13,0$

$31412,11.3125,19,0$

* NCOPY, CHANGE NUMBER $=10$, OLD SET=bSKPO, SHIFT, NEW SET =nbskp, mul t iple $=3$

0 , 
$3.5355,-3.7513,0,3.3392,2.9958,0,60$.

*node, nset =nbskp

$31400, .7 ; 0$

$31401, .13,0$

$31402, .19,0$

*nset, nsetrnbsk?

nbskp, bskpo

"NCOPY, CHANGE NUM8ER $=1000$, OLD SET=nbsk1, SHIFY, NEW SE $\mathrm{r}=\mathrm{nbsk}$

$-0.6738,23.1562$

-NCOPY, CHANGE NUMBER=2000, OLD SET=nbsk1, SHIFT, NEW SET T=nbsk

$-1.3476,46.3124$

*HCOPY, CHANGE NUMBER $=3000$, OLD SET=nbsk1, SHIFT, NEW SET $\mathrm{InbSK}$

$-2.0213,69.4686$

*NCOPY, CHANGE NUMBER $=4000$, OLO SET=nOSk 1, SHIFT, NEW SET $=$ nbsk

$-2.6951,92.6248$

-NCOPY, CHANGE NUMBER $=5000$, OLD SET $=$ nbSk1, SHIFT, NEW SET $=$ nbSK

$-3.3689,115.7810$

\#nset, nset =bsk

nbsk, nbsk1

*ELEMENT, TYPE $=C 308 R, E L S E T=b S K O$

$31001,31025,31000,31001,31038,31225,31200,31201,3$ 1238

$31002,31038,31001,31002,31051,31238,31201,31202,3$

1251

$31003,31051,31002,31003,31064,31251,31202,31203,3$

1264

$31004,31064,31003,31004,31077,31264,31203,31204,3$ 1277

$31005,31077,31004,31005,31090,31277,31204,31205,3$ 1290

$31006,31090,31005,31006,31103,31290,31205,31206,3$ 1303

$31007,31103,31006,31007,31104,31303,31206,31207,3$ 1304

$31019,31115,31018,31019,31102,31315,31218,31219,3$ 1302

$31020,31102,31019,31020,31089,31302,31219,31220,3$ 1289

$31021,31089,31020,31021,31076,31289,31220,31221,3$ 1276

$31022,31076,31021,31022,31063,31276,31221,31222,3$

1263

$31023,31063,31022,31023,31050,31263,31222,31223,3$ 1250

$31024,31050,31023,31024,31037,31250,31223,31224,3$

1237

$31025,31026,31025,31038,31039,31226,31225,31238,3$

1239

*ELGEN, ELSET=bSkO

$31007,12,1,1$

$31025,12,1,1,6,13,12$

"Elcopy, element shift=1000, old set=bsk0, shift nodes $=1000$, new SET $=$ bsk

*ELcopy, element shift $=2000$, old set $=b s k 0$, shift nodes $=2000$, new SET $=b s k$

"Elcopy, element shift $=3000$, old set $=b s k 0$, shift nodes $=3000$, new SET $=$ bsk
"El copy, element shift $=4000,0$ dd set=bsk0, shift nodes $=4000$, new SET $=$ bsk

¿ELcopy, element shift $=5000$, old set=bsko, shift nodes $=5000$, new SET $=$ bsk

${ }^{*}$ el set, el set $=b s k$

bsko

*ELEMENT, TYPE =B31, ELSET $=$ pos TC

$31101,31031,31231$

$31102,31231,31400$

$31103,31400,31401$

$31105,31402,32031$

"ELEMENT, TYPE $=831$, ELSET $=$ pos th

$31111,31000,31200$

$31112,31200,31410$

$31113,31410,31411$

$31115,31412,32000$

*ELEMENT, TYPE $=B 31$, ELSET $\approx$ pos $t f$

$31121,31010,31210$

$31122,31210,31420$

$31123,31420,31421$

$31125,31422,32010$

$31131,31014,31214$

$31132,31214,31430$

$31133,31430,31431$

$31135,31432,32014$

ॠELEMENT, TYPE $=B 31$, ELSET $=$ pos th

$31141,31024,31224$

$31142,31224,31440$

$31143,31440,31441$

$31145,31442,32024$

*ELGEN, ELSET $=$ pOS TC

$31101,6,1000,1000$

$31102,6,1000,1000$

$31103,2,1,1,6,1000,1000$

$31105,5,1000,1000$

*ELGEN, ELSET = pos th

$31111,6,1000,1000$

$31112,6,1000,1000$

$31113,2,1,1,6,1000,1000$

$31115,5,1000,1000$

$31141,6,1000,1000$

$31142,6,1000,1000$

$31143,2,1,1,6,1000,1000$

$31145,5,1000,1000$

*ELGEN, ELSET $=$ pos $t f$

$31121,6,1000,1000$

$31122,6,1000,1000$

$31123,2,1,1,6,1000,1000$

$31125,5,1000,1000$

$31131,6,1000,1000$

$31132,6,1000,1000$

$31133,2,1,1,6,1000,1000$

$31135,5,1000,1000$

*elset, elset=ebsk

posth, postf, postc

*SOLID SECTION, ELSET=bSK, MATERIAL=bsk

*8EAM SECTION, ELSET=pOstc, MATERIAL=bskp, SECTION=PIPE

$3.125,2.4375$

"BEAM SECIION, ELSET=postf, MATERIAL=bskp,

SECTION= trapezoid

$3.114,1.45,1.23,0$

*BEAM SECTION, ELSET=posth, MATERIAL=bskp, SECTION= trapezoid

i.557, 1.45,0.615,0

*MATER IAL, NAME =bsk

*OENSITY 
APPENDIXC SECTION TWO INPUT FILE Bsk1as.txt

.01472

*ELASTIC

28.E+06,.27

ॠPLASTIC

30032.0 .0

$100701 . .0 .293$

$101451 ., 0.300$

102201.0 .307

"MATER IAL , NAME =bskp

-OENSITY

.000735

*ELASTIC

28.E+06, .27

-PLASTIC

30032.,0.0

$100701 ., 0.293$

$101451 . .0 .300$

$102201 ., 0.307$

*elset, elset=bskb? , generate

31001,31024, 1

-elset, elsetrbskb2, generate $32001,32024,1$

*el set, el set =bskb3, generate

$33001,33024.1$

*elset, elset =bskb4, generate

$34001,34024,1$

*elset, elset=bskb5, generate

$35001,35024,1$

*elset, el set =bskb6, generate $36001,36024,1$

*el set, el set=bskc1, generate 31025,31096, 1

*elset, el set=bskc2, generate 32025,32096, 1

*elset, elset=bskc3, generate 33025, 33096, 1

*elset, elset=bskc4, generate 34025, 34096, 1

* el set, elset=bskc5, generate 35025, 35096, I

*el set, el set=bskc6, generate

$36025,36096,1$

*nset, nset $=B S X S Y$, generate

$31000,36000,1000$

$31024,36024,1000$

$31025,31037,1$

$31225,31237,1$

$32025,32037,1$

$32225,32237,1$

$33025,33037,1$

$33225,33237,1$

$34025,34037,9$

$34225,34237,9$

$35025,35037,1$

$35225,35237,1$

$36025,36037,1$

$36225,36237,1$

$31400,36400,1000$

$31401,36401,1000$

$31402,36402,1000$

$31410,36410,1000$

$31411,36411,1000$

$31412,36412,1000$

$31440,36440,1000$

$31441,36441,1000$

$31442,36442,1000$

- BOUNDARY
BSKSY, ZSYMM

* end of file
SNF-5204, Rev. 0/CSB-S-0073 


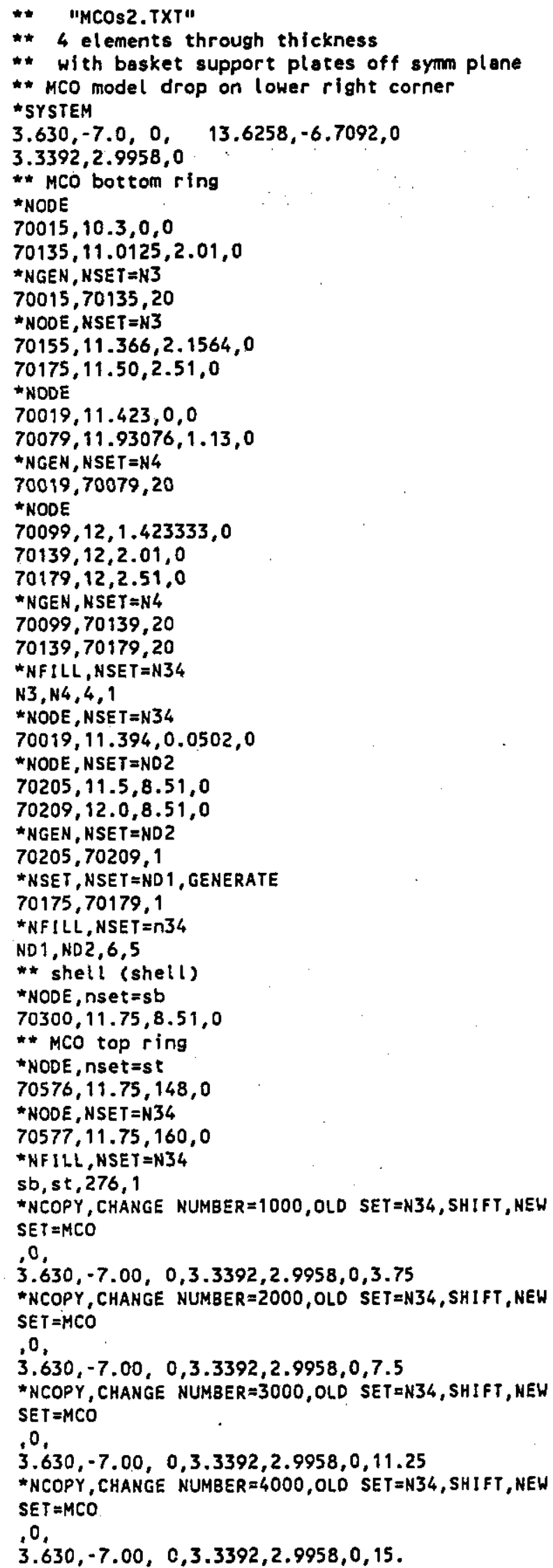

*NCOPY, CHANGE NUMBER $=5000,0 L 0$ SET $=N 34$, SHIFT, NEH SET $=M C O$

0 ,

$3.630,-7.00,0,3.3392,2.9958,0,20.0$

*NCOPY, CHANGE NUMBER $=6000,010$ SET $=N 34, S H I F T, N E H$ $S E T=M C O$

0 ,

$3.630,-7.00,0,3.3392,2.9958,0,25.0$

*NCOPY, CHANGE NUMBER $=7000,0 L O$ SET $=N 34$, SHIFT, NEW SET $=M C O$

0 ,

$3.630,-7.00^{\circ}, 0,3.3392,2.9958,0,30.0$

NCOPY, CHANGE NUMBER $=8000,0 L D$ SET $=N 34$, SHIFT, NEH SET $=M C O$

0 ,

$3.630,-7.00,0,3.3392,2.9958,0,37.5$

NCOPY, CHANGE NUMBER $=9000,010$ SET $=N 34, S H I F T, N E W$ SET $=M C O$

0 ,

$3.630,-7.00,0,3.3392,2.9958,0,45.0$

*NCOPY, CHANGE NUMBER $=10000,0 L D$ SET $=N 34$, SHIFT, NEW SET $=M C O$

0 ,

$3.630,-7.00,0,3.3392,2.9958,0,60.0$

* $N$ COPY, CHANGE NUMBER $=19000$, OLD SET $=N 34$, SHIFT, NEW SET $=M C O$

0 ,

$3.630,-7.00,0,3.3392,2.9958,0,75.0$

* NCOPY, CHANGE NUMBER $=12000,0 L D$ SET $=N 34$, SHIFT, NEW SET $=M C O$

0 ,

$3.630,-7.00,0,3.3392,2.9958,0,90.0$

* $N$ COPY, CHANGE NUMBER $=13000$, OLD SET $=N 34$, SHIET, NEW SET $=M C O$

0 ,

$3.630,-7.00,0,3.3392,2.9958,0,105.0$

*NCOPY, CHANGE NUMBER $=14000,0 L D$ SET $=N 34$, SHIFT, NEW SET $=M C O$

0 ,

$3.630,-7.00,0,3.3392,2.9958,0,120.0$

* NCOPY, CHANGE NUMBER $=15000,0 L O$ SET $=N 34$, SHIFT, NEW SET $T=M C O$

, 0 ,

$3.630,-7.00,0,3.3392,2.9958,0,135.0$

- $\quad$ NCOPY, CHANGE NUMBER $=16000$, OLD SET $=N 34$, SHIFT, NEW SET $=$ MCO

.0 ,

$3.630,-7.00,0,3.3392,2.9958,0.142 .5$

*NCOPY, CHANGE NUMBER $=17000,0 L 0$ SET $=N 34$, SHIFT, NEW SET $=$ HCO

0 ,

$3.630,-7.00,0,3.3392,2.9958,0,150.0$

NCOPY, CHANGE NUMBER $=18000$, OLD SET $=N 34, S H I F T$, NEW SET $=$ MCO

.0 ,

$3.630,-7.00,0,3.3392,2.9958,0,155.0$

* NCOPY, CHANGE NUMBER $=19000$, OLD SET $=N 34$, SHIFT, NEW SET $=M C O$

, 0 ,

$3.630,-7.00,0,3.3392,2.9958,0,160.0$

$\star$ NCOPY, CHANGE NUMBER $=20000$, OLD SET $=N 34$, SHIFT, NEW $S E T=M C O$

, 0 ,

$3.630,-7.00,0,3.3392,2.9958,0,165.0$

$\star N C O P Y, C H A N G E$ NUMBER $=21000,0 L D$ SET $=N 34, S H I F T, N E W$ SET $T=M C O$

0 , 
APPENDIX C SECTION TWO

INPUT FILE Mcos2.txt
$3.630,-7.00,0,3.3392,2.9958,0,168.75$ "NCOPY, CHANGE NUMBER $=22000$, OLD $S E T=N 34, S H I F T, N E W$ $S E T=M C O$

, 0 .

$3.630,-7.00,0,3.3392,2.9958,0,172.5$

-NCOPY, CHANGE NUMBER $=23000$, OLD SET $=N 34$, SHIFT, NEW SET $=M C O$

0 ,

$3.630,-7.00,0,3.3392,2.9958,0,176.25$

* NCOPY, CHANGE NUMBER $=24000,0 L D$ SET $=N 34$, SHIFT, NEW SET $=M C O$

, 0 ,

$3.630,-7.00,0,3.3392,2.9958,0,180$

NOOOE

$70000,1.25,0,0$

$70060,1.25,1.13,0$

\#GEN, NSET $=$ N 1

$70000,70060,20$

ॠNODE

$70120,2.13,2.01,0$

*NGEN, NSET $=$ N 1

$70060,70120,20$

* NCOPY, CHANGE NUMBER $=1000$, OLD SET $=N 1$, SH!FT, NEW $S E T=N 1, M U L T I P L E=24$

, 0 ,

$3.630,-7.00,0,3.3392,2.9958,0,7.5$

*NSET, NSET $=$ N2, GENERATE

$70015,94015,1000$

$70035,94035,1000$

$70055,94055,1000$

$70075,94075,1000$

$70095,94095,1000$

$70115,94115,1000$

$70135,94135,1000$

*NFILL, NSET $=$ N $12, B I A S=1.01$

N1,N2, 15, 1

-ELEMENT, TYPE $=C 308 R, E L S E T=M C O B$

$70001,70000,70001,71001,71000,70020,70021,71021,7$ 1020

$70160,70175,70176,71176,71175,70180,70181,71181,7$ 1180

\ELGEN, ELSET $=$ MCOB

$70001,19,1,1,6,20,20,24,1000,1000$

$70116,2,20,20$

$70136,4,1,1,2,20,20,24,1000,1000$

$70160,4,1,1,6,5,4,24,1000,1000$

*mpe

beam, 70300,70205

beam, 71300,71205

beam, 72300,72205

beam, 73300,73205

beam, 74300,74205

beam, 75300,75205

beam, 76300,76205

beam, 77300,77205

beam, 78300,78205

beam, 79300,79205

beam, 80300,80205

beam, 81300,81205

beam, 82300,82205

beam, 83300,83205

beam, 84300,84205

beam, 85300,85205

beam, 86300,86205

beam, 87300,87205

beam, 88300,88205

beam, 89300,89205
SNF-5204, Rev. 0/CSB-S-0073

beam, 90300,90205

beam, 91300,91205

beam, 92300,92205

beam, 93300,93205

beam, 94300,94205

beam, 70300,70206

beam, 71300,71206

beam, 72300,72206

beam, 73300,73206

beam, 74300,74206

beam, 75300,75206

beam, 76300,76206

beam, 77300,77206

bean, 78300,78206

beam, 79300,79206

beam, 80300,80206

beam, 81300,81206

beam, 82300,82206

beam, 83300,83206

beam, 84300,84206

beam, 85300,85206

beam, 86300,86206

beam, 87300,87206

beam, 88300,88206

beam, 89300,89206

beam, 90300,90206

beam, 91300,91206

beam, 92300,92206

beam, 93300,93206

beam, 94300,94206

pin, 70300,70207

pin, 71300,71207

pin, 72300,72207

pin, 73300, 73207

pin, 74300,74207

pin, 75300,75207

pin, 76300,76207

pin, 77300,77207

pin, 78300,78207

pin, 79300,79207

pin, 80300,80207

pin, 81300,81207

pin, 82300,82207

pin, 83300,83207

pin, 84300,84207

pin, 85300,85207

pin, 86300,86207

pin, 87300,87207

pin, 88300,88207

pin, 89300,89207

pin, 90300,90207

pin, 91300,91207

pin, 92300,92207

pin, 93300,93207

pin, 94300,94207

beam, 70300,70208

beam, 71300,71208

bean, 72300,72208

beam, 73300,73208

beam, 74300,74208

beam, 75300,75208

beam, 76300,76208

beam, 77300,77208

beam, 78300,78208

bean, 79300,79208

bean, 80300,80208

beam, 81300,81208 
beam, 82300,82208

beam, 83300,83208

beam, 84300,84208

beam, 85300,85208

beam, 86300,86208

beam, 87300,87208

beam, 88300,88208

beam, 89300,89208

beam, 90300,90208

beam, 91300,91208

beam, 92300,92208

beam, 93300,93208

beam, 94300,94208

beam, 70300,70209

beam, 71300,71209

beam, 72300,72209

beam, 73300,73209

beam, 74300,74209

beam, 75300,75209

beam, 76300,76209

beam, 77300,77209

beam, 78300,78209

beam, 79300,79209

beam, 80300,80209

beam, 81300,81209

beam, 82300,82209

beam, 83300,83209

beam, 84300,84209

beam, 85300,85209

bean, 86300,86209

beam, 87300,87209

beam, 88300,88209

beam, 89300,89209

beam, 90300,90209

beam, 91300,91209

beam, 92300,92209

beam, 93300,93209

beam, 94300,94209

•ELEMENT, TYPE $=S 4 R S, E L S E T=M C O P L$

$70300,70300,71300,71301,70301$

"ELGEN, ELSET $=$ MCOPL

$70300,277,1,1,24,1000,1000$

** MCO bottom center

ॠNODE

$60000,-1.08,0,0$

$66000,-.7637,0,-.7637$

*NGEN, NSET $=$ L i

$60000,66000,1000$

*NODE

$60012,1.08,0,0$

$66012, .7637,0,-.7637$

NGEN, NSET $=$ L2

$60012,66012,1000$

\#OOE

$60006,0,0,0$

$66006,0,0,-1.08$

*NGEN, NSET $=$ L3

$60006,66006,1000$

$\star N F I L L, N S E T=L 12$

$L 1, L 3,6,1$

$L 3, L 2,6,1$

* NCOPY, CHANGE NUMBER $=60$, OLD $S E T=L 12, S H I F T, N E W$ SET $=L 13$

$-0.0256,0.8796,0$

*NF ILL, NSET $=\mathrm{L}, 14$

$L 12, L 13,3,20$
*ELEMENT, TYPE = C3DBR, ELSET $=$ MCOB

$60101,60000,60001,61001,61000,60020,60021,61021,6$ 1020

ॠELGEN, ELSET $=$ MCOB

$60101,12,1,1,6,1000,12,3,20,72$

"ELEMENT, TYPE $=$ C3O8R, ELSET $=E 81$

$60001,60012,70000,71000,61012,60032,70020,71020,6$ 1032

ॠELGEN, EL SET =EB2

$60001,6,1000,1,3,20,6$

*ELEMENT, TYPE $=$ C3D $8 R, E L S E T=E B 3$

$60019,66012,76000,77000,66011,66032,76020,77020,6$ 6031

$60020,66011,77000,78000,66010,66031,77020,78020,6$ 6030

$60021,66010,78000,79000,66009,66030,78020,79020,6$ 6029

$60022,66009,79000,80000,66008,66029,79020,80020,6$ 6028

$60023,66008,80000,81000,66007,66028,80020,81020,6$ 6027

$60024,66007,81000,82000,66006,66027,81020,82020,6$ 6026

$60025,66006,82000,83000,66005,66026,82020,83020,6$ 6025

$60026,66005,83000,84000,66004,66025,83020,84020,6$ 6024

$60027,66004,84000,85000,66003,66024,84020,85020,6$ 6023

$60028,66003,85000,86000,66002,66023,85020,86020,6$ 6022

$60029,66002,86000,87000,66001,66022,86020,87020,6$ 6021

$60030,66001,87000,88000,66000,66021,87020,88020,6$ 6020

$60031,66000,88000,89000,65000,66020,88020,89020,6$ 5020

$60032,65000,89000,90000,64000,65020,89020,90020,6$ 4020

$60033,64000,90000,91000,63000,64020,90020,91020,6$ 3020

$60034,63000,91000,92000,62000,63020,91020,92020,6$ 2020

$60035,62000,92000,93000,61000,62020,92020,93020,6$ 1020

$60036,61000,93000,94000,60000,61020,93020,94020,6$ 0020

*ELCOPY, ELEMENT SHIFT $=18$, OLD SET $=E B 3$, SHIFT NODES $=20$, NEW SET $=E B 4$

*ELCOPY, ELEMENT SHIFT $=18$, OLD SET $=E B 4, S H I F T$ NODES $=20, N E W$ SET $=E B 5$

*ELSET, ELSET $=$ MCOB

$E B 2, E B 3, E B 4, E B 5$

$\star$ MCO top center

*NODE

$50000,-10.8,148,0$

$56000,-9.3,148,-5.4$

* NGEN, NSET T $=T 1$

$50000,56000,1000$

ॠNODE

$50012,10.8,148,0$

$56012,9.3,148,-5.4$

*NGEN, NSET $=T 2$

$50012,56012,1000$

*NODE

$50006,0,148,0$

$56006,0,148,-10.8$ 


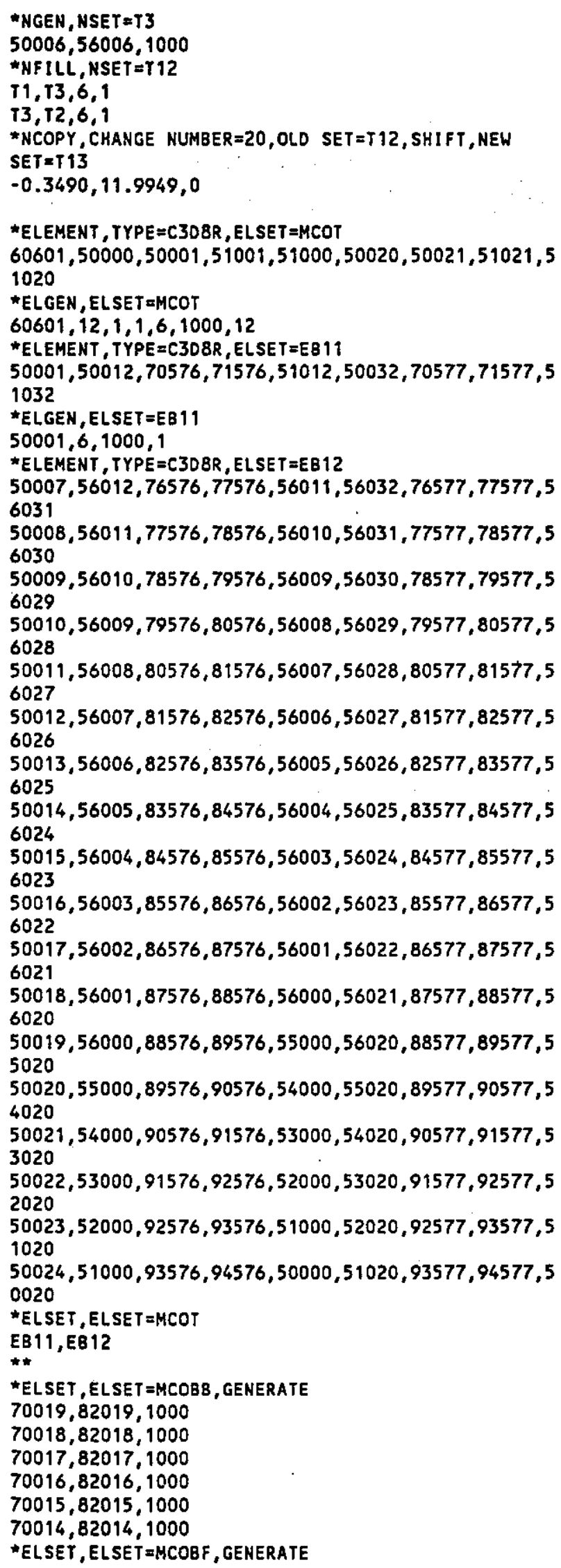

$70019,82019,1000$

$70039,82039,1000$

$70059,82059,1000$

$70079,82079,1000$

$70099,82099,1000$

$70119,82119,1000$

$70139,82139,1000$

*ELSET, ELSET=MCOTR

70576

*ELSET, ELSET =MCOTL

93576

***ELSET , ELSET =MCOSF , GENERATE

$* * 70202,70215,1$

$\star * 71202,71215,1$

**72202,72215, 1

**73202,73215, 1

$\star \star 74202,74215,1$

**75202,75215, 1

$\star * 76202,76215,1$

$* * 77202,77215,1$

**78202,78215, 1

$\star * 79202,79215,1$

** add basket support plates

*node

$40140,0.5,2.01,0$

$40200,0.5,3.25,0$

$40154,11.00,2.01,0$

$40214,11.00,3.25,0$

*ngen, nset $=$ bsp1

$40140,40200,20$

*ngen, nset $=$ bsp2

40154,40214,20

* NCOPY, CHANGE NUMBER $=1000,0 L 0$ SET $=$ bSP 1, SHIFT, NEW SE $T=b s p 3$

0 ,

$3.630,-7.00,0,3.3392,2.9958,0,0$

*NCOPY, CHANGE NUMBER $=2000,0 L O$ SET=bSP1, SHIFT, NEW SET $=b S P 3$

0 ,

$3.630,-7.00,0,3,3392,2.9958,0,30$

* NCOPY, CHANGE NUMBER $=3000,060$ SET=bSP?, SHIFT, NEW SET $=b s p 3$

0 .

$3.630,-7.00,0,3.3392,2.9958,0,60$

*NCOPY, CHANGE NUMBER $=4000,0 L D$ SET=bSP1, SHIFT, NEW SET $=$ bsp3

0 ,

$3.630,-7.00,0,3.3392,2.9958,0,60$

* NCOPY, CHANGE NUMBER $=5000,0 L D$ SET=bSP1, SHIFT, NEW SET $=$ bSP3

0 ,

$3.630,-7.00,0,3.3392,2.9958,0,90$

*NCOPY, CHANGE NUMBER $=6000,0 L D$ SET $=b S P 1$, SHIFT, NEW SET $T=$ bsp 3

0 ,

$3.630,-7.00,0,3.3392,2.9958,0,120$

*NCOPY, CHANGE NUMBER $=7000,0 L D$ SET $=b S P 1$, SHIFT, NEW SET $=$ bsp3

0 ,

$3.630,-7.00,0,3.3392,2.9958,0,120$

${ }^{\star} N C O P Y$, CHANGE HUMBER $=8000,0 L D$ SET $=b S P 1$, SHIFT, NEW SET $=$ bs P3

0 ,

$3.630,-7.00,0,3.3392,2.9958,0,150$

* NCOPY, CHANGE NUMBER $=9000,0 L 0$ SET $=6 S P 1$, SHIFT, NEW SET $T=b s p 3$

0 , 
$3.630,-7.00,0,3.3392,2.9958,0,180$ *NCOPY, CHANGE NUMBER $=1000,0 L D$ SET $=b S P 2$, SHIFT, NEW SET =bSp4

0 ,

$3.630,-7.00,0,3.3392,2.9958,0,28.69805$

"NCOPY, CHANGE NUMBER $=2000,0 L D$ SET=bSP2, SHIFT, NEN SE T $=$ bsp4

0 ,

$3.630,-7.00,0,3.3392,2.9958,0,30$

* NCOPY, CHANGE NUMBER $=3000,0 L 0$ SET=bSP2, SHIFT, NEW SET $=b s p 4$

0 ,

$3.630,-7.00,0,3.3392,2.9958,0,31.30195$

*NCOPY, CHANGE NUMBER $=4000,0 L 0$ SET=bSP2, SHIFT, NEW SET $=$ bsp4

, 0 ,

$3.630,-7.00,0,3.3392,2.9958,0,88.69805$

*NCOPY, CHANGE NUMBER $=5000,0 L D$ SET $=b S P 2, S H ! F T, N E W$ SET $=$ bSP 4

0 ,

$3.630,-7.00,0,3.3392,2.9958,0,90$

-NCOPY, CHANGE NUMBER $=6000,0 L D$ SET=bSP2, SHIFT, NEW SET $=$ bsp4

, 0 ,

$3.630,-7.00,0,3.3392,2.9958,0,91.30195$

*NCOPY, CHANGE NUMBER $=7000,0 L D$ SET $=b S P 2, S H I F T, N E W$ SET $=$ bSP4

0 ;

$3.630,-7.00,0,3.3392,2.9958,0,148.69805$

* NCOPY, CHANGE NUMBER $=8000,0 L D$ SET $=b S P 2$, SHIFT, NEW SE T=bsp4

0 ,

$3.630,-7.00,0,3.3392,2.9958,0,150$

*NCOPY, CHANGE NUMBER $=9000,0 \mathrm{LD}$ SET=bSP2, SHIFT, NEW SET $=$ bsp4

0 ,

$3.630,-7.00,0,3.3392,2.9958,0,151.30195$

*nset, nset $=b s p 3$

bsp1

*nset, nse $t=b s p 4$

bsp2

*nfill, nset $=$ mco

bsp3, bsp4, 14, 1

•ELEMENT, TYPE $=$ C3D8R, ELSET T=bSP

$97001,41140,41141,42141,42140,41160,41161,42161,4$

2160

$97101,42140,42141,43141,43140,42160,42161,43161,4$

3160

*ELGEN, ELSET $=b S P$

$97001,14,1,1,3,20,14,3,3000,200$

$97101,14,1,1,3,20,14,3,3000,200$

mpe

link, 43140,44140

link, 43160,44160

link, 43180,44180

link, 43200,44200

link, 46140,47140

link, 46160,47160

link, 46180,47180

l ink, 46200,47200

*ELSET, ELSET=MCOSL

MCOT, MCOB

*SOLID SECTION, ELSET=MCOSL, MATERIAL=\$5304

"SHELL SECTION, ELSET=MCOPL, MATERIAL=\$S304

0.5

"SOLID SECTION, ELSET=bSP, MATERIAL=SS304

*nset, nset=bspb, generate
$41140,41154,1$

$42140,42154,1$

$43140,43154,1$

$44140,44154,1$

$45140,45154,1$

$46140,46154,1$

$47140,47154,1$

$48140,48154,1$

$49140,49154,1$

"nset , nset=bspt , generate

$41200,41214,1$

$42200,42214^{\circ}, 1$

$43200,43214,1$

$44200,44214,1$

$45200,45214,1$

$46200,46214,1$

$47200,47214,1$

$48200,48214,1$

$49200,49214,1$

* NSE T, NSET $=$ MCO

N34, SB, ST, N12, L14, T12, T13

bspt, bspb

*ELSET, ELSETIMCO

MCOPL, MCOSL, bSP

*elset, elset=mcobt, generate

$70101,93101,1000$

$70102,93102,1000$

$70103,93103,1000$

$70104,93104,1000$

$70105,93105,1000$

$70106,93106,1000$

$70107,93107,1000$

$70108,93108,1000$

$70109,93109,1000$

$70110,93110,1000$

$70111,93111,1000$

$70112,93112,1000$

$70113,93113,1000$

$70114,93114,1000$

$70115,93115,1000$

*elset, elset=meosi , generate

$70136,93136,1000$

$70156,93156,1000$

$70160,93160,1000$

$70164,93164,1000$

$70168,93168,1000$

$70172,93172,1000$

$70176,93176,1000$

$70180,93180,1000$

* NSET, NSET = MCOSY, GENERATE

$70000,70999,1$

$94000,94999,1$

$50000,50999,1$

$60000,60999,1$

$79140,79200,20$

*BOUNDARY

MCOSY, 2SYMM

** end of file 


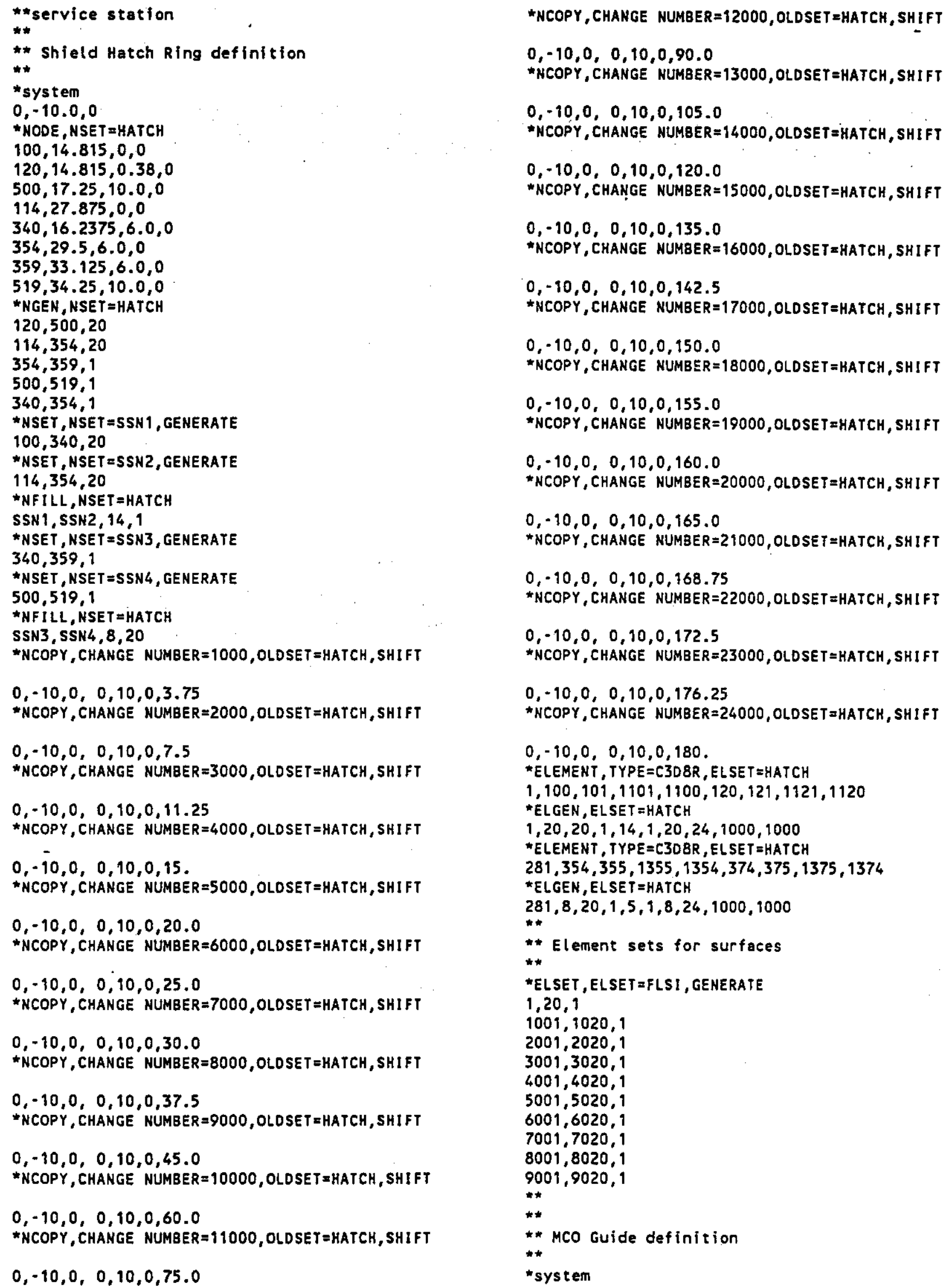


$0,-18.81,0$

*NODE

$520,14.905,0,0$

$533,20.75,0,0$

$534,14.905, .5,0$

$547,20.75, .5,0$

$548,13.315,1.0,0$

$549,14.11,1.0,0$

$550,14.905,1.0,0$

$563,20.75,1.0,0$

$564,13.315,1.25,0$

$579,20.75,1.25,0$

$772,15.125,8.0,0.0$

$787,20.75,8.0,0$

WNGEN

$520,533,1$

$534,547,1$

$550,563,1$

-NGEN, NSET $=$ SSNS

$564,579,1$

*NGEN, NSET $=$ SSN6

$772,787,1$

*NF ILL

SSN5, SSN6, 13, 16

\#*

** Adjust node coordinates to correct element angles

**

ॠNODE

$565,14.11,1.25,0$

*NGEN

$565,579,1$

*NSET, NSET = GUIDE, GENERATE

$520,787,1$

*NCOPY, CHANGE NUMBER $=1000$, OLDSET $=$ GUIDE, SHIFT

$0,-10,0,0,10,0,3.75$

*NCOPY, CHANGE NUMBER $=2000$, OLDSET $=$ GUIDE, SHIFT

$0,-10,0,0,10,0,7.5$

$\star N C O P Y, C H A N G E$ NUMBER $=3000$, OLDSET $=$ GUIDE, SHIFT

$0,-10,0,0,10,0,11.25$

*NCOPY, CHANGE NUMBER $=4000$, OLDSET $=$ GUIDE, SHIFT

$0,-10,0,0,10,0,15$.

*NCOPY, CHANGE NUMBER $=5000$, OLDSET $=$ GUIDE, SHIFT

$0,-10,0,0,10,0,20.0$

*NCOPY, CHANGE NUMBER $=6000$, OLDSET $=$ GUIOE, SHIFT

$0,-10,0,0,10,0,25.0$

* $\mathrm{NCOPY}$, CHANGE NUMBER $=7000$, OLDSET $=$ GUIDE, SHI FT

$0,-10,0,0,10,0,30.0$

$\star N C O P Y$, CHANGE NUMBER $=8000$, OLDSET $=$ GUIDE, SHIF T

$0,-10,0,0,10,0,37,5$

*NCOPY, CHANGE NUMBER $=9000$, OLDSET $=$ GUIDE, SHIFT

$0,-10,0,0,10,0,45.0$

* NCOPY, CHANGE NUMBER $=10000$, OLOSET $T=$ GUIDE, SHIF T

$0,-10,0,0,10,0,60.0$

$N$ COPY, CHANGE NUMBER $=11000$, OLDSET $=$ GUTDE, SHIFT

$0,-10,0,0,10,0,75.0$
\#NCOPY, CHANGE NUMBER $\{2000$, OLDSET $=$ GUIDE, SHIFT

$0,-10,0,0,10,0,90.0$

*NCOPY, CHANGE NUMBER $=13000$, OLDSET $=$ GUIDE, SHIFT

$0,-10,0,0,10,0,105.0$

"NCOPY, CHANGE NUMBER $=14000$, OLDSET $=$ GUIDE, SHIFT

$0,-10,0,0,10,0,120.0$

${ }^{*}$ NCOPY, CHANGE NUMBER $=15000$, OLDSET $=$ GUIDE, SHIFT

$0,-10,0,0,10,0,135.0$

*NCOPY, CHANGE NUMBER $=16000$, OLDSET=GUIDE, SHIFT

$0,-10,0,0,10,0,142.5$

-NCOPY, CHANGE NUMBER $=17000$, OLDSET $=$ GUIDE, SHIFT

$0,-10,0,0,10,0,150.0$

-NCOPY, CHANGE NUMBER $=18000$, OLDSET $=$ GUIDE, SHIFT

$0,-10,0,0,10,0,155.0$

*NCOPY, CHANGE NUMBER $=19000$, OLDSET $=$ GUIDE, SHIFT

$0,-10,0,0,10,0,160.0$

*NCOPY, CHANGE NUMBER $=20000$, OLDSET $=$ GUIDE, SHIFT

$0,-10,0,0,10,0,165.0$

* $N$ COPY, CHANGE NUMBER $=21000$, OLDSET $=$ GUIDE, SHIFT

$0,-10,0,0,10,0,168,75$

* NCOPY, CHANGE NUMBER $=22000$, OLDSET $=$ GUIDE, SHIFT

$0,-10,0,0,10,0,172.5$

* NCOPY, CHANGE NUMBER $=23000$, OLDSET $=$ GUIOE, SHIFT

$0,-10,0,0,10,0,176.25$

* NCOPY, CHANGE NUMBER $=24000$, OLDSET $=$ GUIDE, SHIFT

$0,-10,0,0,10,0,180$

-ELEMENT, TYPE $=$ C3DBR, ELSET $=$ GUIDE

$584,520,521,1521,1520,534,535,1535,1534$

-ELGEN, ELSET = GUIDE

$584,13,1,1,24,1000,1000$

ॠELEMENT, TYPE $=$ C3D8R, ELSET $=$ GUIDE

$598,534,535,1535,1534,550,551,1551,1550$

*ELGEN, ELSET $=$ GUIDE

$598,13,1,1,24,1000,1000$

ॠELEMENT, TYPE $=C 308 R, E L S E T=G U 1 D E$

$612,548,549,1549,1548,564,565,1565,1564$

ॠELGEN, ELSET = GUIDE

$612,15,1,1,14,16,16,24,1000,1000$

* Element sets for surfaces

-

-ELSET, ELSET =GSI, GENERATE

$612,820,16$

$1612,1820,16$

$2612,2820,16$

$3612,3820,16$

$4612,4820,16$

$5612,5820,16$

$6612,6820,16$

$7612,7820,16$

$8612,8820,16$

$9612,9820,16$

*ELSET, ELSET $=$ GS81

612,613 
APPENDIX C SECTION TWO INPUT FILE Service.txt

1612,1613

2612,2613

3612,3613

4612,4613

5612,5613

6612,6613

7612,7613

8612,8613

9612,9613

10612,10613

11612,11613

12612,12613

13612,13613

14612,14613

15612,15613

16612,16613

17612,17613

18612,18613

19612,19613

20612,20613

21612,21613

22612,22613

23612,23613

24612,24613

*ELSET, ELSET $=$ GS82

598,584

1598,1584

2598,2584

3598,3584

4598,4584

5598,5584

6598,6584

7598,7584

8598,8584

9598,9584

10598,10584

11598,11584

12598,12584

13598,13584

14598,14584

15598,15584

16598,16584

17598,17584

18598,18584

19598,19584

20598,20584

21598,21584

22598,22584

23598,23584

24598,24584

*ELSET, ELSET = GSB3, GENERATE

$584,597,1$

$1584,1597,1$

$2584,2597,1$

$3584,3597,1$

$4584,4597,1$

$5584,5597,1$

$6584,6597,1$

$7584,7597,1$

$8584,8597,1$

$9584,9597,1$

10584, 10597, 1

$11584,11597,1$

$12584,12597,1$

$13584,13597,1$

$14584,14597,1$

$15584,15597,1$
SNF-5204, Rev. 0/CSB-S-0073

$16584,16597,9$

$17584,17597,1$

$18584,18597,1$

$19584,19597,1$

20584, 20597, 1

$21584,21597,1$

22584,22597, 1

$23584,23597,1$

$24584,24597,1$

"SYSTEM

$0,-17.31,0$.

**

* Cask Definition

$\star *$

* NODE

$820,12.125,-6.87,0$

$824,12.125,-10.87,0$

-NGEN, NSET = CASK

$820,824,1$

*NODE

$825,12.75,-.5,0$

$831,12.75,-6.4281,0$

$835,12.595,-11.2023,0$

$837,12.95,-13.0,0$

*NGEN, NSET =CASK

$825,831,1$

$831,835,1$

$835,837,1$

* NODE

$840,13.75,-.5,0$

$852,13.75,-13.0,0$

*NGEN, NSET=CASK

$840,852,1$

-NODE, NSE T $=$ CASK

$855,14.88,-.5,0$

$856,14.88,-1.5,0$

$867,14.88,-13.0,0$

*NGEN, NSE T = CASK

$856,867,1$

*NODE

$871,15.9,-1.5,0$

$882,15.9,-13.0,0$

* NGEN, NSE T = CASK

$871,882,1$

*NODE

$886,16.905,-1.5,0$

$897,16.905,-13.0,0$

*NGEN, NSET $=$ CASK

$886,897,1$

*NODE

$901,17.905,-1.5,0$

$912,17.905,-13.0,0$

*NGEN, NSET =CASK

$901,912,1$

"NODE

$916,18.905,-1.5,0$

$927,18.905,-93.0,0$

*NGEN, NSET =CASK

$916,927,1$

* NODE

$931,19.905,-1.5,0$

$942,19.905,-13.0,0$

*NGEN, NSET $=$ CASK

$931,942,1$

** Adjust nodes for bevel at top of cask

*NOOE, NSET $=$ CASK

$825,13.25,-.5,0$ 
$826,12.9833,-1.5,0$

$827,12.75,-2.375,0$

*NCOPY, CHANGE NUMBER $=1000,0$ LDSET $=$ CASK, SHIFT

$0,+10,0,0,10,0,3.75$

-NCOPY, CHANGE NUMBER $=2000$, OLDSET $=$ CASK, SHIFT

$0,-10,0,0,10,0,7.5$

-NCOPY, CHANGE NUMBER $=3000,0 L D S E T=C A S K$, SHIFT

$0,-10,0,0,10,0,11.25$

*NCOPY, CHANGE NUMBER $=4000,0$ LDSET $=$ CASK, SHIFT

$0,-10,0,0,10,0,15$

NCOPY, CHANGE NUMBER $=5000$, OLDSE $T=C A S K$, SHIF

$0,-10,0,0,10,0,20.0$

NCOPY, CHANGE NUMBER $=6000,0 L D S E T=C A S K, S H I F T$

$0,-10,0,0,10,0,25.0$

*NCOPY, CHANGE NUMBER $=7000$, OLDSET $=$ CASK, SHIFT

$0,-10,0,0,10,0,30.0$

*NCOPY, CHANGE NUMBER $=8000,0 L D S E T=C A S K$, SHI $F$

$0,-10,0,0,10,0,37.5$

-NCOPY, CHANGE NUMBER $=9000$, OLDSET $=$ CASK, SHIF T

$0,-10,0,0,10,0,45.0$

NCOPY, CHANGE NUMBER $=10000$, OLDSET $=$ CASK, SHIFT

$0,-10,0,0,10,0,60.0$

* NCOPY, CHANGE NUMBER $=11000$, OLDSET $T=C A S K$, SHIFT

$0,-10,0,0,10,0,75.0$

$\star$ NCOPY, CHANGE NUMBER $=12000$, OLDSET $=$ CASK, SH $\} \mathrm{FT}$

$0,-10,0,0,10,0,90,0$

*NCOPY, CHANGE NUMBER $=13000$, OLDSET $T=$ CASK, SHIFT

$0,-10,0,0,10,0,105.0$

* $N$ COPY, CHANGE NUMBER $=14000$, OLOSET $=$ CASK, SHIFT

$0,-10,0,0,10,0,120.0$

* NCOPY, CHANGE NUMBER $=15000$, OLDSE T=CASK, SH IFT

$0,-10,0,0,10,0,135.0$

*NCOPY, CHANGE NUMBER $=16000$, OLOSET $=$ CASK, SH!F T

$0,-10,0,0,10,0,142.5$

NCOPY, CHANGE NUMBER $=17000$, OLOSET $=$ CASK, SHIFT

$0,-10,0,0,10,0,150.0$

*NCOPY, CHANGE NUMBER $=18000$, OLDSET $=$ CASK, SHIFT

$0,-10,0,0,10,0,155.0$

*NCOPY, CHANGE NUMBER $=19000,0 L D S E T=C A S K$, SHIFT

$0,-10,0,0,10,0,160.0$

* NCOPY, CHANGE NUMBER $=20000$, OLDSET $=$ CASK, SHIF T

$0,-10,0,0,10,0,165.0$

* COPY, CHANGE NUMBER $=21000$, OLOSET $=$ CASK, SHIFT

$0,-10,0,0,10,0,168.75$

* $N$ COPY, CHANGE NUMBER $=22000$, OLDSET $=$ CASK, SHIFT
$0,-10,0,0,10,0,172.5$

* NCOPY, CHANGE NUMBER $=23000$, OLDSET $=$ CASK, SHIFT

$0,-10,0,0,10,0,176.25$

$*$ NCOPY, CHANGE NUMBER $=24000$, OLOSET $=$ CASK, SHIFT

$0,-10,0,0,10,0,180$

$*$ *

ॠELEMENT , TYPE $=C 308 R, E L S E T=C A S K$

$501,821,832,1832,1821,820,831,1831,1820$

*ELGEN, ELSET = CASK

$501,4,1,1,24,1000,1000$

ॠELEMENT, TYPE $=C 3 D 8 R$, EL SE $T=$ CASK

$505,826,841,1841,1826,825,840,1840,1825$

ॠELGEN, ELSET = CASK

$505,12,1,1,2,15,12,24,1000,1000$

*ELEMENT, TYPE $=C 3 D 8 R$, ELSE $T=C A S K$

$529,857,872,1872,1857,856,871,1871,1856$

^ELGEN, ELSET $=$ CASK

$529,11,1,1,5,15,11,24,1000,1000$

เ*

* Element set for surface

$*$

*ELSET, ELSET =CAI1 , GENERATE

$505,510,1$

$501,504,1$

$515,516,1$

$1505,1510,1$

$1501,1504,9$

$1515,1516,1$

$2505,2510,1$

$2501,2504,1$

$2515,2516,1$

$3505,3510,1$

$3501,3504,1$

$3515,3516,1$

$4505,4510,1$

$4501,4504,1$

$4515,4516,1$

$5505,5510,1$

$5501,5504,1$

$5515,5516,1$

$6505,6510,1$

$6501,6504,1$

$6515,6516,1$

$7505,7510,1$

$7501,7504,1$

$7515,7516,1$

$8505,8510,1$

$8501,8504,1$

$8515,8516,1$

$9505,9510,1$

$9501,9504,1$

$9515,9516,1$

*ELSET, ELSET T CAI 2

501

1501

2501

3501

4501

5501

6501

7501

8501

9501

ॠLSET, ELSET =CA I 3 
APPENOIX C SECTION TWO INPUT FILE Service.txt

504

1504

2504

3504

4504

5504

6504

7504

8504

9504

*ELSET, ELSET = CAT 1

505,517

1505,1517

2505,2517

3505,3517

4505,4517

5505,5517

6505,6517

7505,7517

8505,8517

9505,9517

10505,10517

11505,11517

12505,12517

13505,13517

14505,14517

15505,15517

16505,16517

17505,17517

18505,18517

19505,19517

20505,20517

21505,21517

22505,22517

23505,23517

24505,24517

${ }^{\star} E L S E T, E L S E T=C A T 2$

517

1517

2517

3517

4517

5517

6517

7517

8517

9517

10517

11517

12517

13517

14517

15517

16517

17517

18517

19517

20517

21517

22517

23517

24517

"ELSET, ELSET =CAT3, GENERATE

$529,573,11$

$1529,1573,11$

$2529,2573,11$

$3529,3573,11$
SNF-5204, Rev. 0/CSB-S-0073

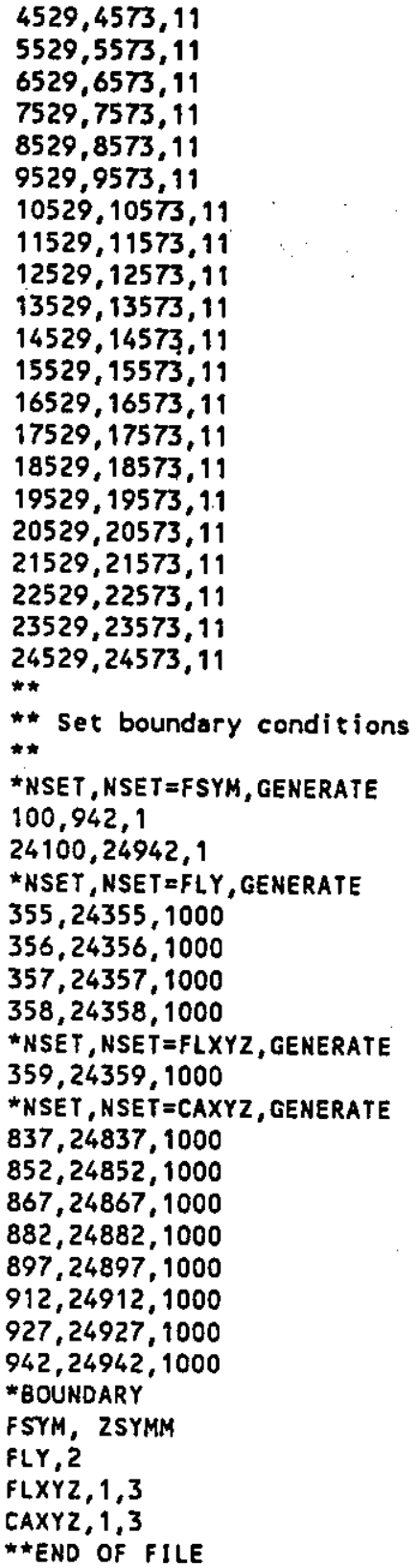


APPENDIX D

PEER REVIEW COMMENT RECORD

AND FDNW TRANSMITTAL RECORD 


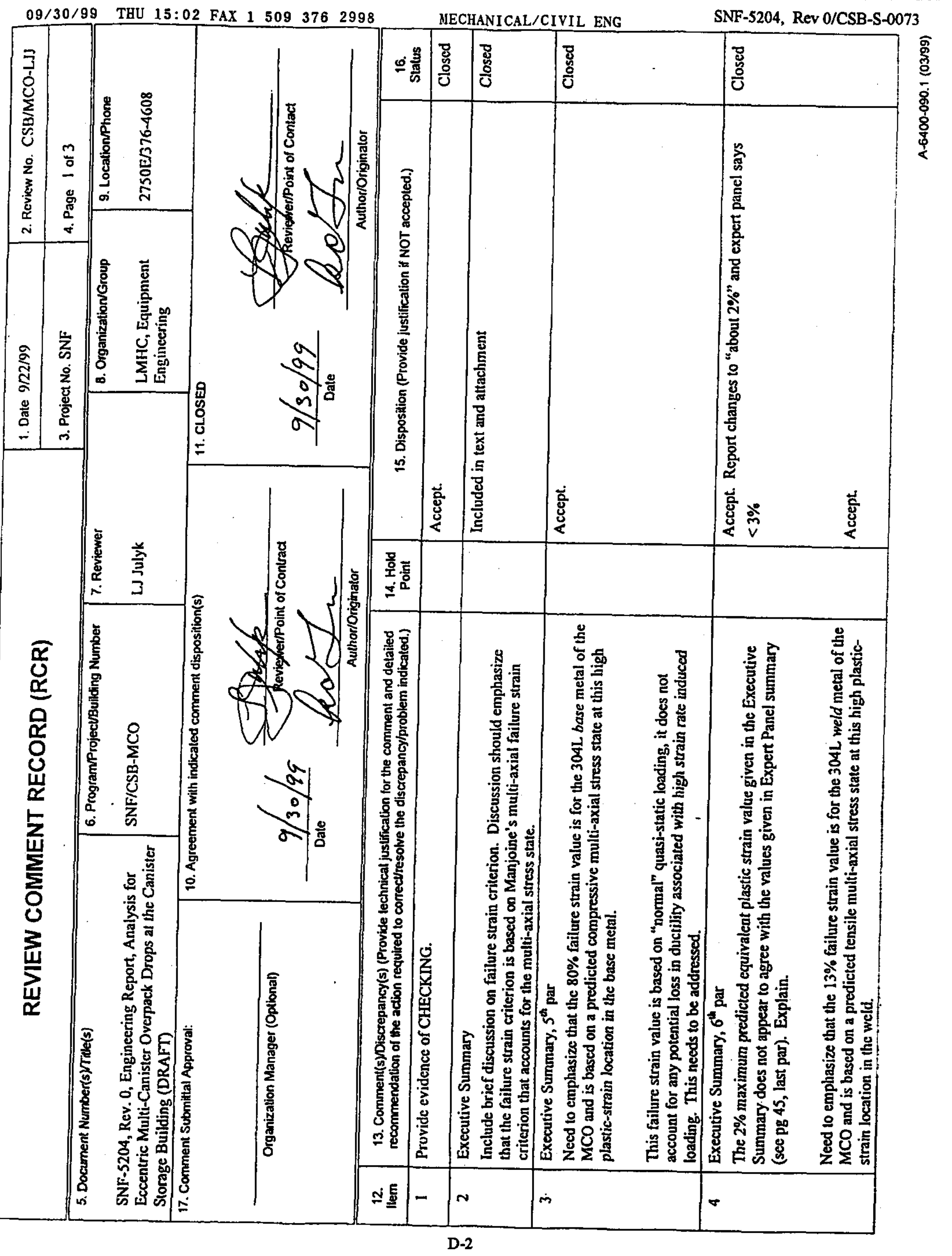




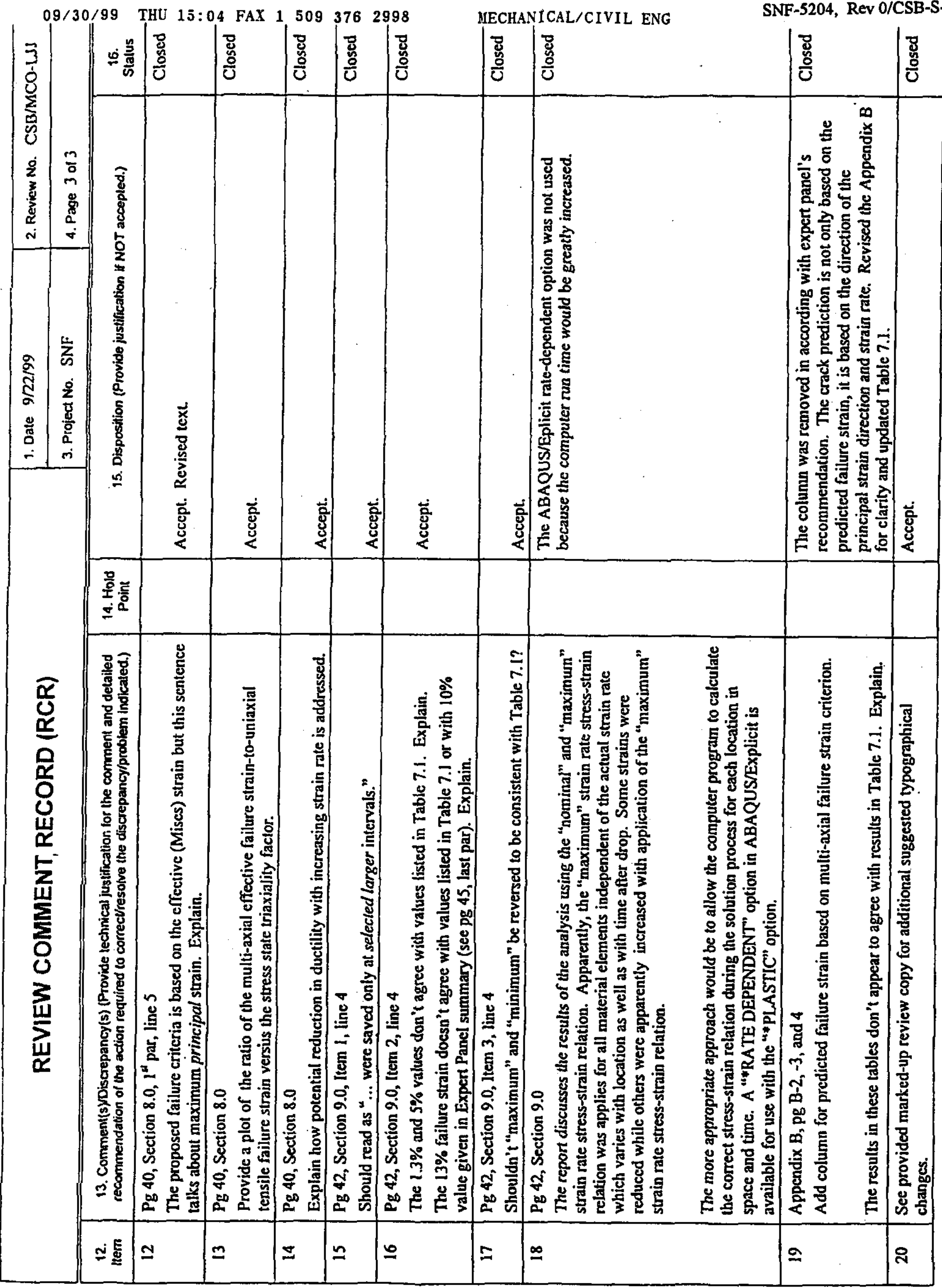


KEYWORD DESIGNEE TO INDICATE DISTRIBUTION OF CORRESPONDENCE \& ATTACHMENTS IF REQUIRED

$A=$ ACTIONEE

KW = KEYWORD DESIGNEEJORIGINATOR
DATE: $10 / 5 / 99$

LOG NUMBER:FOP-1050

FILE LOCATION: $102.5 E$

TRANSMITTAL TO: DE \& S

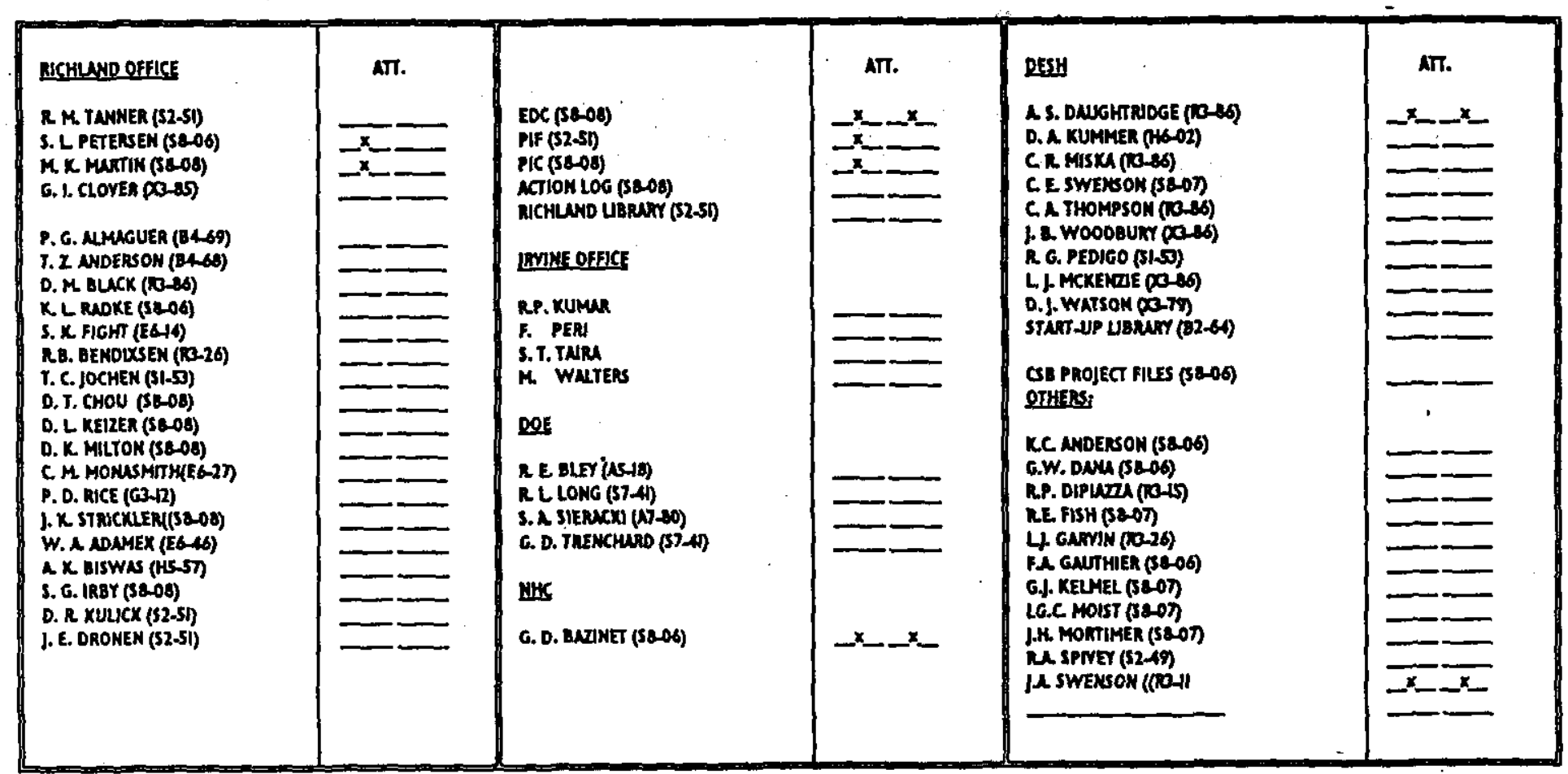

ACTION ASSIGNMENT/COMMENTS

DATE REQUIRED:

DESCRIPTION:

$-$

\section{TITLEIDESCRIPTION}

ANALYSIS FOR EXCENTRIC MULTI-CANISTER OVERPACK DROPS AT THE CANISTER STORAGE

BUILDING

\section{KEYWORDS}

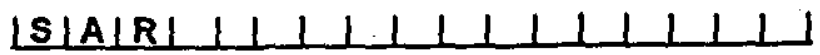

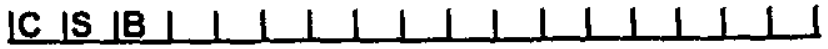

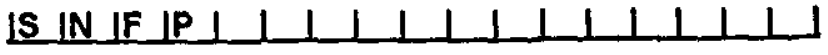

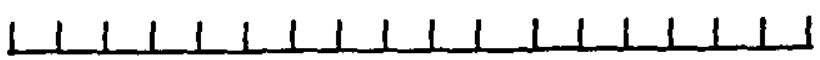

